\title{
A continuous psychosis phenotype: from description to prediction
}

Citation for published version (APA):

Hanssen, M. S. S. (2004). A continuous psychosis phenotype: from description to prediction. [Doctoral Thesis, Maastricht University]. Datawyse / Universitaire Pers Maastricht.

https://doi.org/10.26481/dis.20040528mh

Document status and date:

Published: 01/01/2004

DOI:

10.26481/dis.20040528mh

Document Version:

Publisher's PDF, also known as Version of record

\section{Please check the document version of this publication:}

- A submitted manuscript is the version of the article upon submission and before peer-review. There can be important differences between the submitted version and the official published version of record.

People interested in the research are advised to contact the author for the final version of the publication, or visit the DOI to the publisher's website.

- The final author version and the galley proof are versions of the publication after peer review.

- The final published version features the final layout of the paper including the volume, issue and page numbers.

Link to publication

\footnotetext{
General rights rights.

- You may freely distribute the URL identifying the publication in the public portal. please follow below link for the End User Agreement:

www.umlib.nl/taverne-license

Take down policy

If you believe that this document breaches copyright please contact us at:

repository@maastrichtuniversity.nl

providing details and we will investigate your claim.
}

Copyright and moral rights for the publications made accessible in the public portal are retained by the authors and/or other copyright owners and it is a condition of accessing publications that users recognise and abide by the legal requirements associated with these

- Users may download and print one copy of any publication from the public portal for the purpose of private study or research.

- You may not further distribute the material or use it for any profit-making activity or commercial gain

If the publication is distributed under the terms of Article $25 \mathrm{fa}$ of the Dutch Copyright Act, indicated by the "Taverne" license above, 
A CONTINUOUS PSYCHOSIS PHENOTYPE: FROM DESCRIPTION TO PREDICTION 
ISEN $90-5278-410-8$

Lay-out: Johan Past wa | Manon Hanssen

Cover design: Ruth Donners

Production: Datawyse ! Universiatire Pers Maastricht

\section{M.S.S. Hunssen}

All rights reserved. No part of this thesis may be reproduced or transmitied in any form or by any means, clectronic on mechanical, including photocopying, recording or any information storage or retrieval system, withoun permission in writing from the anther, or, when appropriate, from the publishers of the publications. 


\title{
A CONTINUOUS PSYCHOSIS PHENOTYPE: FROM DESCRIPTION TO PREDICTION
}

\author{
PROEFSCHRIFT
}

ther verkrijging van de graad van doctor

and de Universiteit Maastricht,

op gezag van de Rector Magnificus,

Profi. mr. G.P.M.F. Mols,

volgens het besluit van het College van Decanen,

in thet openbaar te verdedigen

op wrijdag 28 mei 2004 om 12.00 uur

door

Manon Sophie Severine Hanssen

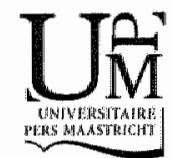




\section{Promotor}

Prof. dr.J.J. van Os

\section{Copromotores}

Dr. R.V. Bijl (Wetenschappelijk Onderzoek-en Documentatiecentrum (WODC) van het Ministerie van Justitie, Den Hagy)

Dr. Ph.A.E.G. Delespaul

\section{Beoordelingscommissile}

Prof, dr. F.R.J. Verhey (voorzitter)

Prof. dr. D.H. Linszen (Universiteit van Amsterdam)

Prof. dr. H.L.G.J. Merckelbach

Prof. dr. R. Vlietinck

Dr. M.G. Vollema (Meerkanten GGZ Flevo-Veluwe)

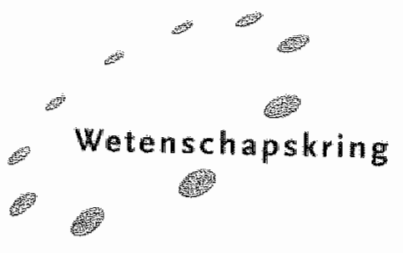

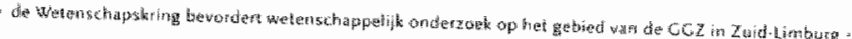




\section{Contents}

1. Introduction

2. Strauss (1969) revisited: a psychosis continum in the general population?

3. Evidence that three dimensions of psychosis have a distribution in the general population

4. How psychotic are individuals with non-psychotic disorders?

5. Evidence for family-specific variation of subclinical psychosis dimensions in the general population

6. Self-reported psychotic experiences in the general population: a valid screening tool for DSM-III-R psychotic disorders?

7. Outcome of self-reported psychotic experiences in the general population: a prospective study

8. The role of distress in delusion formation

9. Epilogue

Summary

Samenvatting

Dankwoord

Curriculum vitae 



\section{CHAPTER 1}

\section{Introduction}


8 CHAPTER I 
The title of this thesis, A conimuous psychosis phenotype from descriphon to prediction, reflects the main theme that is developed in its pages.

First, in any psychological research it is essential to have a testable and valid working model of the outcome under study, in this case the psychosis phenotype. Whereas phenotype is the manifestation of a characteristic that is visible to the eye, genotype is the underlying genetic constellation of a subject, which interacts with the ever-changing environment to yield the expression of the subject's phenotype (Sham 1998). The clinical features of psychosis include positive symptoms (i.e., symptoms that are present and are not part of the nomal range of variation, such as delusions and hallucinations); negative symptoms (i.e., features that are nomally present but are absent in the diseased state, such as flat affect, apathy, social isolation); disorganisation in speech and behaviour; affective symptoms (such as depression and mania) and catatonia (i.e., extreme and uncomfortable bodily postures, stereotypical movements, etc.) (Gelder, Gath et al. 1996). A continuing challenge to psychosis research is the heterogeneity of the clinical features, and one way to reduce this heterogeneity is to construct dimensions of related symptoms on which patients may have quantitatively varying scores. Another, arguably less effective (van Os, Fahy et al. 1996; van Os, Gilvarry et al. 1999) way to reduce heterogeneity is to compose groups of patients that form qualitatively distinct diagnostic categories (Andreasen, Nopoulos et al. 1999).

The notion of quantitatively varying symptom dimensions implies that symptoms and the disorders they are part of are not all-or-nothing phenomena, but are quantitative phenotypes that can be placed on a continuum (Johns and van Os 2001). A concept that is intrinsic to the notion of a psychosis continum is that of schizotypy. Schizotypy is defined as observable personality traits or as attenuated psychotic symptoms that are expressed as a result of an underlying genetic vulnerability to psychotic disorder (Claridge and Beech 1995).

If there is a true continum of psychosis, and its expression is transmitted within families, for example under the influence of genetic factors, one would expect familial clustering at lower levels of the psychosis continum, similar to the familial aggregation of clinical psychotic disorders such as schizophrenia (van Os, Marcelis et al. 1997; Cardno, Sham et al. 2001; Cardno, Rijsdijk et al. 2002). Family and twin studies examine the rolle of genetic factors indirectly by treating genes as a latent variable. Heritability estimates can be calculated based on the pattem of familial aggregation of observable traits (Neale and Cardon 1992).

Subjects can be placed on the psychosis continum according to parameters like severity and frequency, and can go through transitions along the continum from one position to another. These shifts along the continumm take on special significance in the realm of research into the early prediction of psychosis (Yung, McGorry et al. 1996). Typically, early prediction studies (Yung, Phillips et al. 1.998; Haefner, Loeffler et al. 
1999; MeCorry, McKenzie et al. 2000) have attempted to identify sensitive and specific predictors of the transition from subtle, non-clinical expression of psychosis to fullblown disorder. The well-known problem of false-positive and false-negative misclassification is fuelling ethical debates on diagnostic labelling and pre-psychotic interventions with low-dose antipsychotics (McGorry, Yung et al. 2001).

Given the fact that transitions across the psychosis continuum have been demonstrated to occur, the question arises which factors drive these transitions. According to the cognitive model of psychosis (Garety, Kuipers et al. 2001) unusual perceptual experiences may lead to delusions and, ultimately, to a full-blown psychotic disorder under the influence of distress, attributions of externality and cognitions of power imbalance with regard to the unusual experiences (Fowler 2000 ). Such models provide a rationale for the use of cognitive behavioural techniques to prevent an individual from developing full-blown psychotic symptoms (Kingdon and Turkington 1994; Morrison. Bentall et al. 2002).

This thesis describes empirical models of the continuous psychosis phenotype, from the description in symptom dimensions to the feasibility of early prediction of psychosis. The theme of this thesis is elaborated further in the remainder of the introduction below. In addition, guided by the literature, it develops the study objectives and presents an outline of the various chapters reporting empirical data.

\section{The heterogeneous psychosis phenotype}

The climical heterogeneity of psychosis is a widely recognised problem in the search for the most valid psychosis phenotype. Two models have been presented to account for the problematic definition of the psychosis phenotype: the categorical subtypes model and the dimensional model (Andreasen, Nopoulos at al. 1999).

The categorical subtypes model divides various clinical features of psychosis into discrete subcategories. Examples are the Bleulerian/Kraepelinian subtypes (i.e. hebephrenic, catatonic, paranoid and simple schizophrenia) (Gelder, Gath et al. 1996; Kraepelin and Bleuler 1996), Crows Type VType II (Crow 1980), and Andreasen's positive/mixed/negative subtypes (Andreasen and Olsen 1982). Although the categorical subtypes model boosted schizophrenia research in the 1980s, the allocation of subjects to subcategories does not correspond to the overlapping clinical presentation of psychotic symptoms (Andreasen. Nopoulos et al. 1999).

This has led researchers to suggest that a dimensional approach may be more valid. Acconding to this model, the symptoms are grouped together in symptom dimensions (Andreasta, Nopoulos et al. 1999). This dimensional approach to psychosis has initiated research in a number of symptom dimensions of psychosis. Findings by liddle (1987) 
demonstrated three factors, viz., psychomotor poverty, disotganisation and reality distortion, which were not mutually exchsive. This means that the factors may be present in one individual, due to three separate pathological mechanisms within a single disease process, unlike the non-overlapping positive-mixed-negative subtypes proposed by Andreasen (1982). The three-dimensional model of positive, negative and disorganisational symptoms has become widely accepted (Liddle 1987; Andreasen, Nopoulos et al. 1999; Vollema and Hoijtink 2000). This parsimonious model, however, has been described as too simple (Peralta and Cuesta 2001), in that it overlooks relevant factors in the phenomenology of psychosis, such as affective factors (Hirsch 1991; Taylor 1992; van der Does, Limszen et al. 1993; van Os, Verdoux et all. 1999). Recently, evidence was found for the existence of eight dimensions of psychosis, namely psychosis, disorganisation, negative, mania, depression, excitement, catatonia and lack of insight (Peralta and Cuesta 2001).

\section{The continuum of psychosis: phenomenology}

The dimensional view is closely linked to the notion of continuity of symptoms. The first to suggest that variations in personality in the general population correspond to expressions of psychosis was Kretschmer in 1925 (Kretschmer 1951; Claridge 1997; Crow 1998). Four decades later, Strauss (1969) corroborated the continum hypothesis by describing continua in function regarding hallucinations and delusions in patients (Strauss 1969).

Two continuum views prevail in contemporary psychosis research (Claridge and Beech 1995). The first model is quasi-dimensional and states that schizophreniaspectrum disorders lie on a continum of increasing severity. More specifically, this model confines the continum concept to a disease process, ranging from schizotypal. schizoid and paranoid personality disorder to psychosis, or from affective disorder to psychosis (Claridge 1997). The finding that schizophrenia and affective disorder coaggregate within families supports the quasi-dimensional view (Taylor 1992; Cardno, Rijsdijk et al. 2002). Additional evidence has been provided by the finding of a high prevalence and risk of schizophrenia-spectrum disorders in relatives of patients with schizophrenia (Kety, Rosenthal et al. 1971; Kendler and Gardner 1997). The second continuum model is fully dimensional and incorporates the quasi-dimensional view (Claridge 1997). The continuum from normal variations in symptoms or personality to clinical psychotic disorders is often defined using psychotic-like experiences, attenuated psychotic symptoms (Peters, Joseph et al. 1999; Poulton, Caspi et al. 2000; Stefanis, Hanssen et al. 2002; Verdoux and van Os 2002), schizotypy (Rado 1953; Meeh1 1962), psychosis proneness (Chapman, Edell et al. 1980) and psychoticism (Eysenck 1992). 
Evidence for the fully-dimensional model has come from several general population studies (Eaton, Romanoski et al. 1991; Kendler, Gallagher et al. 1996; van Os, Hanssen et al. 2000), which demonstrated that psychotic experiences in the general population are more prevalent than the rare DSM-IV diagnosis of schizophrenia. For example, the Eastern Baltimore Mental Health Survey found prevallences of delusions and hallucinations in the general population of $10 \%$ and $5 \%$, respectively, based on the Diagnostic Interview Schedule (DIS), a self-report interview administered by lay interviewers (Eaton, Romanoski et al. 1991). Moreover, schizotypy studies have demonstrated the existence of contimuity from schizotypy to clinical psychosis. These studies suggest that the deconstruction of schizotypy into factors is comparable to the tri-factor structure found in clinical psychosis, and that schizotypy expresses a genetic vulnerability to clinical psychosis (Kendler, Lieberman et al. 1989; Chapman, Chapman et al. 1994; Claridge 1997; Venables and Rector 2000; Vollema and Hoijtink 2000). Measures of schizotypy, on the other hand, do not contain all concepts found in schizophrenia (Venables and Rector 2000). Nevertheless, another important argument for continuity is the finding that schizotypy correlates with biological, psychophysiological, cognitive and neuropsychological markers also found in schizophrenia (Vollema and van den Bosch 1995).

\section{Factor structure of schizotypy and psychotic symptom dimensions}

Inspired by the factor studies on the psychosis construct (Liddle 1987), researchers also want to disentangle the factor structure of schizotypy. A large, population-based twin study by Kendler and Hewitt (1992), using self-report measures of schizotypy resulted in three factors, namely positive trait schizotypy (i.e., perceptual aberration and magical. ideation), nonconformity (i.e., psychoticism, nonconformity and physical anhedonia) and social schizotypy (i.e., paranoid ideation and social anhedonia). However, Eysenck and Barrett (1993) re-analysed the data provided by Kendler and Hewitt (1992) and drew different conclusions. Their findings yielded a three-factor model including neuroticism, extraversion and psychoticism, factors that are in accordance with Eysenck's dimensional view of psychoticism. According to Eysenck, psychoticism is a measurable trait in the general population, expressing a risk of psychosis (Eysenck and Barrett 1993). On the other hand, Vollema and van den Bosch (1995) concluded on the basis of their overview of nine factor-analytical studies that three, and possibly four factors emerge from the data: positive schizotypy, negative schizotypy, nonconformity and social anxiety/cognitive disorganisation. They selected studies using self-report schizotypy scales in the general population or anong students, except for one clinical study, and most importantly, they inchuded Eysenck's measures (Vollema and van den Bosch 1995). Recently, Venables and Rector (2000) conducted a confirmatory factor analysis on self-reported schizotypy in students. The results yielded three factors, 
namelly positive schizotypy including disorganisation, negative schizotypy and social impaiment. However, this three-factor solution did not include disorganisation as a separate factor (Venables and Rector 2000). Vollema and Hoijtink (2000) proposed the implementation of generalised multidimensional Rasch models (GMRMs) to study the factor structure of schizotypy in dichotomous questionnaire responses among psychiatric inpatients and outpatients. Their model with the best fit included positive schizotypy, disorganisation and negative schizotypy (Vollena and Hoijtink 2000). Loughland and Williams (1997) also found evidence for a three-factor structure of schizotypy in undergraduate students, namely unusual experiences, cognitive disorganisation and introvertive anhedonia. They drew a parallel with the threedimensional model reported by Liddle (1987) in clinicall psychosis (Loughland and Williams 1997). Despite their relatively normal sample of students, Lougland and Williams (1997) detected disorganisation as one of the schizotypy factors in contrast to Venables and Rector (2000).

In conclusion, many studies have yielded positive, negative and disorganisation factors of schizotypy (Vollema and van den Bosch 1995; Loughland and Williams 1997; Vollema and Hoijtink 2000), although some other, less consistent, dimensions like nonconformity, psychoticism etc., have also been reported (Kendler and Hewitt 1992; Eysenck and Barrett 1993; Vollema and van den Bosch 1995; Venables and Rector 2000). It has been noted that the dimensions of schizotypy resemble those identified in schizophrenia, suggesting phenomenological continuity between the clinical and non-clinical constructs (Vollema and van det Bosch 1995; Gruzelier 1996; Vollema and Hoijtink 2000).

\section{Longitudinal continuity of schizotypy and attenuated psychoric symptoms}

Schizotaxia is a concept proposed by Meehl and defined as a genetically based meurointegrative disturbance that always leads to schizotypy. In some cases, schizotaxia may, in interaction with the environment, develop into schizophrenia (Meenl 1962). Following Meehl (Meeh』1962), schizotypy researchers have regarded schizotypy or psychosis proneness as vulnerability marker for schizophrenia, reflecting the underlying genetic liability to develop psychosis (Claridge 1997). Evidence has been generated from several lines of research. A follow-up study among college students showed that a high score on perceptual aberration, magical ideation on both predicted the onset of psychotic disorders a decade later. It was especially the subjects with a high score on both magical ideation and social anhedonia who were at increased risk of developing psychosis (Chapman, Chapman et al. 1994). In addition, Kwapil (1998) concluded that an extremely high score on social anhedonia in college students was a specific predictor of the future presence of schizophrenia-spectrum disorders (Kwapil 1998). Vollema et al. (2002) reported that the score on the positive dimension of a 
schizotypy questiomaure administered to relatives of patients with psychotic disorders corresponded to their genetic risk of psychosis (Vollema, Sitskoorn et al. 2002). Attenuated psychotic symptoms also constitute evidence of a diathesis for clinical psychosis. A 15-year follow-up study indicated that self-reported psychotic symptoms in children predicted the onset of schizophreniform disorders (Poulton, Caspi et al. 2000). Cardno et al. (2001) investigated affected twins to establish whether the genes inducing a symptom dimension only modify the expression of the phenotype or whether these genes also induce an increased risk of psychosis. They found that the disorganised, negative, manic and general psychotic dimensions showed familial aggregation, indicating a genetic effect. However, only the disorgamised dimension significantly predicted the genetic risk of psychoses (Cardno, Shan et al. 2001). Thus, the enigma has become even more complex as a result of evidence that suggests different genetic effects of familial symptom dimensions on the risk of psychosis.

\section{Familial clustering of schizophrenia and schizotypy}

The vulnerability-stress model of schizophrenia (Zubin and Spring 1977) is widely used as a paradigm in studying and explaining the aetiology of schizophrenia. It describes an individual's diathesis for schizophrenia that may surface in interaction with environmental stressors. This is a form of genotype-environment interaction (van $O \mathrm{~s}$ and Marcelis 1998). Genotype-environment correlation implies that certain genotypes are more likely to occur in certain enviromments, lowering the threshold of disease expression (Neale and Cardon 1992). It is not only the genotype which determines the observable phenotype in wivo, but the environment also affects the characteristics of the phenotype. Hence, schizophrenia is currently seen as a multifactorial disease, possibly caused by multiple genes (Tsuang, Stone et al. 1999).

The discussion regarding the heterogeneous phenomenology of psychosis also has implications for the aetiological heterogeneity and homogeneity hypotheses of psychosis. Although some authors have advocated the homogeneity hypothesis (Cardno and Farmer 1995; Crow 1995), implying the existence of one single gene (viz. the $X-Y$ homologous gene) predisposing to cerebral asymmetry and psychosis, most evidence points to aetiological heterogeneity (Tsuang and Faraone 1995).

The family and win designs are usefull tools for genetic research on psychosis. The objective of family studies is to find familial aggregation of certain characteristics, as familial clustering is generally thought to represent the effect of shared genes, at least in the case of psychosis. It is known that multifactorial polygenic diseases, like psychosis, aggregate within families (Kendler and Gardner 1997), but that they do not segregate in 
families like Mendelian diseases with probabilities of $25 \%$ and $50 \%$, respectively, for recessive and dominant characteristics (Gottesman and Erlenmeyer-Kimling 2001).

As regards the familial clustering of clinical psychosis, Kendler and Gardner (1997) compared three family studies of schizophrenia and concluded that schizophrenia clusters in families and shows some overlap in familial factors with schizotypal personality disorder and non-affective psychotic disorders. They suggested, however, that the evidence for overlap in familial factors for schizophrenia and affective disorder is insubstantial (Kendler and Gardner 1997). By comparing the frequency of mental disorders in the biological and adoptive families of adopted subjects, Kety et al. (1971) found that biological relatives of adoptees diagnosed with schizophrenia had a significantly greater prevalence of schizophrenia-related disorders than the adoptive families (Kety, Rosenthal et al. 1971 ).

Given the substantial level of familial clustering of psychotic disorders, researchers have investigated to what degree the dimensions of the subclinical psychosis phenotype are transmitted independently. For example, Wickham et al (2001) found evidence for familial clustering of psychomotor poverty, manic symptom dimensions and, to a lesser extent, disorganisation in families multiply affected with schizophrenia (Wicklham, Walsh et al. 2001). Vollema et al. (2002) reported that the score on the positive dimension of a schizotypy questionnaire administered to relatives of patients with psychotic disorders corresponded to their genetic risk of psychosis.

The issue of familial clustering of the multi-dimensional, non-clinical manifestation of psychosis has been much less extensively studied in family samples from the general population, compared to general population twin samples. Kendler and Hewitt (1992) studied twins from the general population and concluded that the variance in most selfreport schizotypy scales, except for perceptual aberration, involved substantial genetic contributions (Kendler and Hewitt 1992). In addition, Meyer and Hautzinger (2001) reported familial aggregation of the scores of the hypomanic personality scale (a vuinerability marker for affective disorders), as well as the scores of the social anhedonia and impulsive nonconformity scales, in families from the general population (Meyer and Hautzinger 2001).

Results of studies comparing the ability of self-report instruments and the clinical interview method to detect familial clustering of schizotypy have been ambiguous. Kendller et al. (1996) found that only self-reported social anhedonia differed significantly between relatives of patients with schizophrenia and control subjects. However, contrary to the findings obtained with the self-report scales, results for the interview assessments in the same sample yielded evidence of higher levels of negative schizotypy, social dysfunction and odd behaviour in the relatives (Kendler, Thacker et al. 1996). 
Taken together, there is evidence for both phenomenological and longitudinal continuity between schizotypy and schizophrenia, as well as for familial clustering of schizotypy and schizophrenia. However, the question whether schizotypy and schizophrenia share familial actiological factors still needs to be elucidated. Recently, Fanous and colleagues (2001) demonstrated that interview-based positive and negative symptoms in schizophrenia predicted their equivalent schizotypal symptoms in nonpsychotic relatives. This finding indicates that schizotypy and schizophrenia lie on an aetiological contimum (Fanous, Gardner et al. 2001).

\section{Early prediction and prevention of psychosis}

Sub-threshold psychotic symptoms may lie on a continuum ranging from normal mental states to psychosis (Strauss 1969; MoGorry 2000). This description of the phenomenology of psychosis is highly relevant to the field of earty prediction and prevention in psychosis. The position a subject occupies on the psychosis continuum expresses his or her degree of psychosis proneness. Individuals may move along the continum, from normal states to the onset of psychotic symptoms with a high risk of transition to psychosis. Intervening in this prodromal phase may be beneficial to the outcome of the high-risk subject. In turn, patients with psychotic disorders also move along the continuum, in that they go through periods in which their psychotic symptoms are in remission. Again, monitoring symptoms or signs in patients can be used to prevent a relapse.

During the last decade, early prediction and prevention research in psychosis has been evolving from the search for efficient indicators of future psychosis onset (Yung. MoGorry et: al. 1996; Yung, Phillips et al. 1998; McGorry, Mckenzie et al. 2000; Miller, Lawrie et al. 2002), via a discussion of the ethical concerns of early intervention in the pre-psychotic phase (Yung and McGorry 1997; McGorry, Yung et al. 2001), to the implementation of randomised controlled trials (RCT's) to provide evidence-based treatment for the early stages of psychosis development (McGorry, Yung et al. 2002; Montison, Bentall et al. 2002).

\section{Is early prediction of psychosis possible?}

Studies have shown that young adults scoring high on schizotypy measures are at increased risk of developing psychotic disorders (Chapman, Chapman et al. 1994; Kwapil 1998). In addition, Poulton et al. (2000) presented evidence from their 15-year follow-up study that 11-year-olds with self-reported psychotic symptoms had a high specific risk of developing schizophreniform disonders (Poulton, Caspi et al. 2000). Early prediction research attempts to define specific and sensitive predictors of 
impending psychosis, in order to intervene as early as possible in the disease process to prevent harm and social dysfunction. Both sociodemographic and psychopathological wariables, that is, gender, marital status, sub-threshold psychotic symptoms, family history of psychotic disorders, social dysfunction, early negative and depressive symptoms, schizotaxia etc., have been described as risk factors for psychotic disorder (Falloon 1992; Tien and Eaton 1992; Häfner, Maurer et al. 1998; Yung, Phillips et al. 1998; Haefner, Loeffler et al. 1999; Tsuang, Stone et al. 2000).

Bebbington and Nayani (1995) have developed an interview that measures attenuated psychotic symptoms and that can be applied by lay interviewers to screen for psychosis. They found that the positive predictive value (PPV, i.e., the proportion of subjects with a positive result on the test who are correctly identified by the test) of their instrument was extremely high, namely over $90 \%$. However, they pointed out that the PPV is prevalence-dependent and that they had used a selected sample with a higher prevalence of psychosis than found in the general population (Bebbington and Nayani 1995).

Yung et al. (1996), working within the scope of the Personal Assistance and Crisis Evaluation (PACE) Clinic, formulated criteria for three high-risk groups for impending psychosis, namely the attenuated psychotic symptoms group, the Brief Limited Intermittent Psychotic Symptoms (BLIPS) group and the trait plus state risk factors group (Yung, MoGorry et al. 1996). They concluded that implementing the high-risk criteria enabled them to identify high-risk subjects with a transition rate of $40 \%$ within 6 months (Y'ung, Phillips et al. 1998). Critics have pointed out the problem that five subjects became psychotic within one month after inclusion (Morrison, Bental et al. 2002). On the other hand, Yung et al. (1998) emphasised that they were confident that these five subjects had not been psychotic at inclusion and had been willing to disclose their problems to the examiner. Recently, Morrison et al. (2002) using Yung's criteria, reported a transition rate of $22 \%(5 / 23)$ measured between 6 and 12 months after inclusion, so lower than in the study by Yung et al (1998). However, the transition rates in both studies were comparable if the five subjects in the study by Yung et al (1998) who made the transition to psychosis in the first month were excluded. Moreover, Klosterkötter et al. (2001) reported that almost $50 \%$ of their high-risk subjects made a transition to schizophrenia (Klosterkötter, Hellmich et al. 2001).

Thus, the early prediction studies have so far been very confident about their ability to accurately predict the onset of psychosis in their high-risk groups, with a low risk of labelling false-positives. However, it has to be kept in mind that these studies assessed the efficiency of their predictors in highly selected samples with a high baseline prevalence of psychosis. This inevitably leads to a higher specificity and lower sensitivity of the risk factors (Bebbington and Nayani 1995; van Os, Takei et al. 1997). Less effort has so far been invested into early prediction research in the general 
population. An example is the study by Davidson et al. (1999), which showed that deficits in social functioning, organisational ability and intellectual functioning were good predictors of the future development of schizophrenia in healthy male subjects (Davidson, Reichenberg et al. 1999). The problem of using attenuated psychotic symptoms in the general population as predictors of future psychosis onset is that these psychotic-like symptoms are much more prevalent than the clinical disorder (Eaton, Romanoski et al. 1991; Kendler, Gallagher et al. 1996; van Os, Hanssen et al. 2000y, resulting in a large risk of false-positives. As current early prevention studies are implementing psychological and biological interventions in the prodromal phase of psychosis (McGorry, Yung et al. 2002, Morrison, Bentall et al. 2002), there is a need for more epidemiological studies assessing the sensitivity, specificity and post-test probability of attenuated psychotic symptoms in the general population.

In conclusion, the allocation of people to a high-risk group for impending psychosis is an evidence-based strategy. Nevertheless, these findings alone do not pave the way for the safe implementation of early prevention strategies. In addition, the findings of the early prevention studies should be taken into account, as should ethical concerns regarding false-positives.

\section{Is the time right for early prevention in psychosis?}

This subsection first considers the three types of prevention in psychosis, namely primary, secondary and tertiary prevention. Them, the most important early psychosis prevention projects worldwide and the encountered ethical problems are addressed.

The goal of primary prevention in psychosis is to prevent the transition of a subject in the prodromal phase to full-blown psychosis. In other words, primary prewention tries to decrease the incidence of psychosis. The aim of secondary prevention is to detect the occurrence of the first psychotic episode as early as possible, in order to keep the Duration of Untreated Psychosis (DUP) low, as a decrease in DUP may lead to a decrease in the prevalence of psychosis. Tertiary prevention is the implementation of an effective maintenance treatment and/or rehabilitative treatment over a long period after the start of the psychotic disorder. It also involves relapse prevention (McGorry 2000 ; Larsen, Fris et al. 2001 ).

Since the distinction between primary and secondary prevention in early psychosis is not always clear-cut, the detection and treament of prodromal symptoms with or without distress and disability is often called indicated prevention (Yung. Phillips et al. 1998; McGorry 2000; Larsen, Friis et al. 2001).

The ultimate goal of indicated prevention in psychosis is to give an individual with psychotic-like symptoms the opportunity to function as adequately as possible in late adolescence and early adulthood, in the sense of completing an education, starting a job and forming meaningtul interpersonal relationships (MoGorry, Edwards et al. 1996; 
Yung, McGorry et al. 1996). These building blocks of life may prewent a transition to frank psychosis or, in the case of transition, may lead to a better prognosis. Additionally, early detection could also result in the identification of individuals who have already developed a psychotic disorder. These individuals thus come to the attention of mental health services earlier, minimising the duration of untreated psychosis (DUP) and possibly leading to a better outcome. Larsen et al. (2001) concluded in their review that studies on outcome and DUP had not settled the problem, but shortening the DUP might be a promising tool. In addition, Linszen and colleagues (2001) reported that early intervention in young adults with a shor DUP was effective in the short term, but not after a five year follow-up.

It is not the intention of the present introduction to cover all contemporary early psychosis prevention projects worldwide. Brielly, the most important of these are the PACE clinic in Melboume, Australia (Yung, McGorry et al. 1996; Yung, Phillips at al. 1998; McGorry, Yung et al. 2002), the Hillside Recognition and Prevention (RAP) programme in New York, United States of America (Comblatt 2002), the Farly Detection and Intervention Evaluation (EDIE) trial in Manchester, United Kingdom (Morrison, Bentall et al. 2002), and the Prevention through Risk Identification, Management, and Education (PRIME) Research Clnic in New Haven, United States of America (Rosen, Woods et al. 2002). These projects have demonstrated that it is possible to set up mental health services for young people at high risk of full-blown psychosis, to monitor them, and to implement early prevention strategies. Monitoring the transition rates of their subjects allows early prevention researchers to assess the specificity and sensitivity of their prodromal psychosis markers in order to find better predictors. The main early prevention strategies applied are individual and family counselling, psychoeducation, psychological treatments including cognitive behavioural treatment, and prescription of psychotropic drugs including antidepressants, anxiolitics and low-dose neuroleptics. An ethical problem all these projects encounter is the rate of false-positives. It has been suggested that informing persons that they are at high risk of developing a psychotic disorder would inevitably push these persons across the threshold due to distress, and that the high-risk subjects could experience stigmatisation. Furthermore, it has been questioned whether neuroleptics with known side effects should be prescribed to prodromal subjects (McGlashan and Johamessen 1996; Yung and McGorry 1997; McGlashan 1998; Gottesman and Erlemmeyer-Kimling 2001).

The research group of McGorry and colleagues proposed to combine several risk factors to increase the specificity of the prodromal labelling in order to reduce the falsepositives rate (Yung and McGorry 1997). They also added an additional selection criterion in the form of the help-seeking behaviour of subjects. They stated that only subjects displaying help-seeking behaviour were eligible to enter their early prevention services, the PACE clinic (McGorry, Yung et al. 2002). As these young help-seeking 
persons experience problems in their lives, the PACE clinic focuses on the problems that are put forward by the young person itself. McGorry and colleagues concluded that this is an efficient and no-harm strategy towards high-risk subjects.

To sum up, the early prevention projects worldwide have successfully established their place in mental health care, are searching for more sensitive and specific predictors and have started to implement early prevention strategies. However, the early prevention strategies are based on efficient treatments for florid psychotic disorders. Litte is known regarding the efficacy of these treatments in subjects at incipient risk of psychosis. Below, I describe the field of the RCTs in indicated prevention of psychosis.

\section{The current state of knowledge from randomised controlled trials}

McGorry and colleagues in Australia were the first to report results of a randomised controlled trial in 59 subjects at high risk of impending psychosis (McGorry, Yung et al. 2002). The subjects were randomised to a "needs-based" intervention group (control group) or to a low-dose risperidone and cognitive behavioural therapy (CBT) group (experimental group). The transition rate after 6 months was significantly lower in the experimental group than the control group $(10 \%$ versus $36 \%)$, suggesting that administration of low-dose neuroleptics and CBT decreases the risk of transition to psychosis in high-risk subjects. The number needed to treat was four (NNT $=1:(0.36-$ $0.1)=3.9$ ). In other words, four patients had to be treated to prevent one subject from making the transition to full-blown psychosis over a monitoring period of six months. This RCT had several limitations. First of all, the design was not entirely double-blind. Second, the relative therapeutic contributions by CBT and risperidone were unknown. Finally, subjects in the experimental group attended more therapy sessions. Nevertheless, this RCT was executed to the best available standards, considering that this was the first RCT on intervention in the prodromal phase of psychosis. Therefore, this design can serve as a starting point for implementing effective treatment in the prodromal phase. In addition, this study can be rightly regarded as a pioneering attempt, showing the way for future RCTs. At the time of writing of the present thesis, no other RCTs on indicated prevention of psychosis had been published, though several were underway.

\section{Cognitive model of psychosis}

As evidence points to the existence of transitions on the psychosis continuum, it is essential to understand the factors that influence these transitions. Not all possible interacting psychological, biological and social factors in the pathway to full-blown 
psychosis can be addressed in this introduction, which focuses instead on the role of cognitive appraisal of unusual experiences.

The cognitive model of psychosis (Garety, Kuipers et al. 2001) states that appraisals of anomalous perceptual experiences, in other words the personal and emotional significance of unusual experiences, and the confusion between internal and extemal events are important factors in the onset and maintenance of psychosis (Fowler 2000 ). This is reminiscent of the hypothesis originally stated by Maher $(1974,1988,2003)$, that the formation of delusions is, to put it simply, the search for the meaning of unusual experiences (Maher 1974; Maher 1988; Maher 2003). An example of the significance of appraisal processes is provided by the sudy by Peters et al. (1999). This study demonstrated that the scores obtained on the Peters et al. Delusion Inventory (PDI) (Peters, Joseph et al. 1999) by subjects from the general population and by inparients with psychotic disorders showed considerably overlap. Patients, however, reported a higher degree of conviction, preoccupation and distress than the subjects from the generall population.

Bentall et al. (2001) focused particularly on the formation of paranoid delusions. They stated that subjects with low self-esteem and an extemal attributing coping mechanism are highly liable to develop paranoid delusions (Bentall, Corcoran et al. 2001). They also emphasised the role of fear of rejection and criticism (Morrison, Bentall et al. 2002). Hemsley (1993) incorporated in his cognitive theory a biological mechanism operating in the hippocampus and related brain structures, and suggested that this dysfunctional biological mechanism would result in an inability to integrate the moment-by-moment sensory input with stored memory, predisposing to delusional thinking (Hemsley 1993; Hemsley 1994).

The cognitive biases (i.e., 'a jumping to conclusions' style of thinking) as well as emotional biases (i.e., hypervigilance for threatening triggers, liability to make external attributions for threat) interact with each other (Fowler 2000). Both the cognitive and the emotional reactions to hearing voices are crucial for the persistence of such voices. Voice hearers who ascribe malevolence or dominance to their voices are more often distressed and in need of treatment than voice hearers who hear pleasant voices and can set limits on their voices (Escher, Romme et al. 2002). Birchwood (1997, 2000) takes the idea of the perceived dominance of voices a step further by suggesting that subjects who hear voices also take into account their own social ranking amongst significant others when they evaluate the power and omnipotence of their" voices (Birchwood and Chadwick 1997; Birchwood, Meaden et al. 2000).

The importance of cognitive appraisal of unusual experiences as a mediating factor on the pathway to full-blown psychosis has a clinical implication, in that the findings regarding the cognitive model of psychosis provide an incentive to apply cognitive 
behavoural techniques in psychosis (Kingdon and Turkington 1994) and the prepsychotic phases (McGorry, Yung et al. 2002; Morison, Bentall et al. 2002).

\section{Outline and objectives of the studies}

The objective of the studies discussed in this thesis was (i) to examine the hypothesis of the continuous psychosis phenotype, (ii) to study familial clustering of dimensions of psychotic experiences in the general population and (iii) to formally examine the epidemiological parameters underlying early prediction in psychosis, allowing us to formulate the implications of high-risk subject identification and treatment strategies.

\section{The search for a psychos is continum in the general population}

First, we hypothesised that schizophrenia-spectrum disorders and psychotic symptoms exist as continua in nature rather than being qualitatively different entities (Johns and van Os 2001). Chapter 2 addresses this conceptual problem on the basis of a large representative general population study: the Netherlands Mental Health Survey and Incidence Study (NEMESIS) (Bijl, Ravelli et al. 1998; Bijl, van Zessen et al. 1998). Additionally, psychotic symptoms and their associations with known risk factors were studied in an attempt to lend aetiological validity to the concept of a psychosis continum. The instrument used in NEMESIS is the Composite International Diagnostic Interview (CIDI), which yields DSM-III-R diagnoses.

\section{Dimensions of psychotic experiences in the generat population}

Chopter 3 introduces the Community Assessment of Psychic Experiences (CAPE), self-report questionnaire based on the PDI. The CAPE has been used in the Athens Study of Psychosis Proneness and Incidence of Schizophrenia (ASPIS) to study the positive, negative and depressive dimensions of psychosis in a representative general poptilation sample of young men. The aims of the study were to find evidence for correlated but independent positive and negative dimensions in the general population and for the independent existence of a depressive dimension in addition to positive and negative symptoms in psychosis.

\section{How psychotic are individuals with non-psychotic disarders?}

We wished to extrapolate results on the continuity of psychotic experiences to the issue of continuity between psychotic and non-psychotic disorders. The objective of the Continum of Mental Disorders Study (COMED Study), described in chapter 4, was to compare the dimensions of psychosis across different patient groups in a community mental health service (CMHS) and non-patients in the general population. In addition, 
the CAPE distress score, relating to the experience of psychosis, was compared between the patient groups and the general population.

Family-specific variation of subclinical psychosis dimensions in the general population Chopter 5 examines the familial aggregation of subclinical psychotic experiences in the general population, guided by previous results in this area. This chapter reports on a family study in the general population, the COMED Study. We hypothesised that the psychosis dimensions of the CAPE and the schizotypy scales from the Structured Interview for Schizotypy-Revised (SIS-R) would show aggregation within families. Furthermore, we examined whether the self-report questionnaire CAPE, including a depressive dimension, and the Structured Interview for Schizotypy-Revised differed in their ability to detect familial clustering of subclinical psychosis dimensions in a general population sample.

Self-reported pychotic experiences: a screening tool for psychosis?

Chapter 6 discusses the value of self-reported psychotic experiences in the general population as a screening instrument for psychotic disorder, as examined in NEMESIS (Bijl, Ravelli et al. 1998; Bijl, van Zessen et al. 1998). The predictive values of several categories of self-reported psychotic experiences for the concurrent presence of DSMIII-R psychotic disorders were calculated.

Outcome of self-reported psychotic experiences in the general population: a prospective study

Extending the findings of the diagnostic value of psychotic experiences prospectively, the stability of self-reported psychotic experiences was studied in NEMESIS. Chapter 7 discusses the 2-year outcome of psychotic experiences and the feasibility of carly prediction in the general population.

\section{The role of distress in delusion formation}

The study using the CAPE (chapter 4) showed that patients with psychotic experiences were more distressed than subjects in the general population with psychotic experiences. Additionally, the NEMESIS study showed that psychotic experiences involving distress were a better predictor of the concurrent and future presence of a psychotic disorder than experiences without distress. These findings are in line with contemporary cognitive theories on psychosis, which state that distress is an important determinant in the development of a need for care in the context of psychosis. Thus, chapter $\&$ examines the role of distress in delusion formation in a prospective design using NEMESIS data. 
Finally, chopter 9 summarises and discusses the findings of the studies, and presents implications for future research and clinical practice.

Overall, therefore, this thesis had three objectives:

1. To examine and validate the notion of a continum of psychosis in the general population and in patients receiving outpatient care.

2. To study the familial aggregation of subclinical psychosis dimensions in families sampled from the general population.

3. To study the predictive validity of psychotic-like experiences in terms of their ability to predict clinical need and to formulate the clinical implications of the findings. 


\section{References}

Andreasen, N. C., Nopoulos, P., OLeary, D. S.. Miller, D. D. Wassink, T. and Finm, M. (1999), Defining the phenotype of schizophrenia: cognitive dystnetria and its neural mechanisms. Biological Psychudry $46(7):$ 908-920.

Andreasen, N. C. and Olsen, S. (1982). Negative v positive schizophrenia. Definition and validation. Archnes of General Psychiatry $39(7): 789-794$.

Bebbington, P. and Nayani, T. (1995). The Psychosis Screening Questionnaire Mnternarowal Mownal of Methods in Psychiatic Research 5 : 11-19.

Bentall, R. P... Corcoran, R., Howard, R., Blackwood, N. and Kindernaan, P. (2001). Persecutory delusions: a review and theoretical integration. Clinical Psycholagy Review 21(8): 1143-1192.

Bijl, R. V., Ravelli, A. and wan Zessen, G. (1998). Prevalence of psychiniric disorder in the general population: results of The Netherlands Mentat Health Survey and Incidence Stady (NEMESIS). Sockot Psychiary and Psychiartic Epidemiology 33(12):587-595.

Bijl, R. V., wan Zessen, G., Ravelli, A., de Rijk, C. and Langendoen, Y. (1998), 'The Netherlands Mental Health Survey and Incidence Sudy (NEMESIS): objectives and design. Social Psychiatry and Psychiatic Epidemiology $33(12)$ : $581-586$.

Birchwood, M. and Chadwick, P. (1997), The omnipotence of voices: testing the validity of a cognitive model. Fsychologreal Medicine 27(6): 1345-1353.

Birchwood, M., Meaden, A., Trower, P... Gilbert, P. and Plaistow, 1. (2000). The power and ommipotence of voices: subordination and entrapment by voices and significant others. Psychologicol Medicine 30(2): $337-344$.

Cardno, A. G. and Farmer, A. E. (1995). The case for or against heterogencity in the etiology of schizophrenia. The genetic evidence. Schizophrenia Research /7(2): 153-159.

Cardno, A. G., Rijsdijk, F. V., Sham, P. C., Murray, R. M. and McGutinn, P. (2002). A twin study of genetic relationships between psychotic symptoms. American Jounat of Psychatry 159(4): 539-545.

Cardno, A. G., Sham, P. C., Murray, R. M. and McGuffin, P. (2001). Twin study of symptom dimerasions in psychoses. British Joumal of Psychatry $779: 39-45$

Chapman, L. J., Chapman, J. P., Kwapil, T. R., Eckblad, M. and Zinser, M. C. (1994). Putatively psychosisprone subjects 10 years later. Jound of Abnornal Psychology $103(2): 171-183$.

Chapnuan, L. J., Edell, W. S. and Chapman. J. P. (1980). Physical anhedonis, percepiual aberration, and psychosis proneness. Schizophrewia Bulletin 6(4): 639-653.

Claridge. G. (1997). Schizotypy. Implications for IIlmess and Meallh. Ox ford, Oxllord University Press.

Claridge, G. and Beech. T. (1995). Fully and quasi-dinuensional constructions of schizotypy. In: Schizofypot Personalivy A. Raine, "T" Lencz and S. A. Mednick (Eds.). New York, Cambridge Universiyy Press.

Comblatt, B. A. (2002). The New York high risk project to the Hillside recognition and prevention (RAP) program. Americap Journal of Medical Genetics /44(8): 956-966.

Crow, T. J. (1980). Molecular pathology of schizophrenia: more than one disease process? British Medicat Jound $280(6207): 66-68$.

Crow. T. J. (1995). A continuum of psychosis, one human gene, and not much else - the case for homogeneity. Schizophrenia Research I7(2): 135-145.

Crow, T. J. (1998). From Kraepelin to Kretschmer leawened by Sehneider. The tritnsition from caltegories bl psychosis to dimensions of variation intrinsic to Homo sapiens. Archives of General Paychiatry 55 : 502 . 504. 
Davidson, M., Reichenberg, A., Rabinowitz, W., Wrer, M. Kaplan, Z, and Mark, M. (1999). Behavioral and

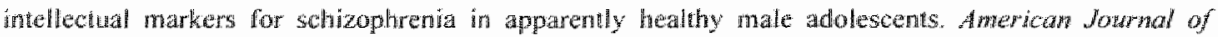

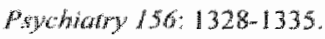

Eaton, W. W., Romanoski, A., Anthony, . C. and Nestadt, G. (1991). Screning for psychosis in the general population whth a self-report interview. The Journal of Nerwoss and Menot Disease 179(11): 689-693.

Escher, S., Romne. M., Buiks, A., Delespaui, P. and Var Os, 1. (2002). Independent course of childhood

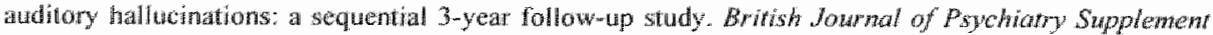
$181(43): \$ 10.518$

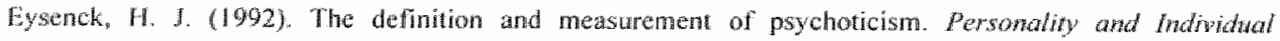
Differences $/ 3(7): 757-785$

Eysencik., H. J. and Bartet, P. (1993). The nature of schizotypy. Psycholagicar Repords 73:59-63.

Falloon, I. R. (1992). Early imtervention for first episodes of schizophronia a preliminary exploration. Psychiory $55(1): 4-15$.

Panous, A., Gardner, C., Walsh, D. and Kendier, K. S. (2001). Relationship between positive and negative symptonis of schizophrenia and sethizolypal symptoms in nonpsychotic rebatives. Arehres of Generat Psychiolyy 5\%: 669-673.

Fowler. D. (2000). Psychological formulation of early episodes of pspchosis: a cogmitive model. In: Early

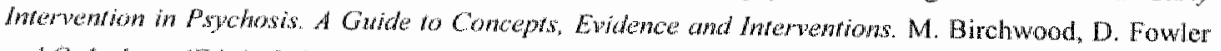
and C. Jackson (Eds.). Chichester, foln Whey \& Sons. LTD: 101-127.

Ratety, P. A. Kaipers, E., Fowler, D., Freman. D. and Bebbington, P. E. (2001). A cognitive model of the positive symptorus of psychosis. Psychological Medrone 3I(2): 189-195.

Gelder, M., Gath, D. Mayou, R, and Cowen, P. (1996). Oxford Texbook of Psychowy. New York, Oxtord University Press lnc.

Gottesman. I. and Erlenmeyer-Kinnling, 1.. (2001). family ant twin strategites as a head start in defining prodromes and endophenotypes for hypothetical early-interventions in schizophrenia. Schizophrewa Raserah $51(1): 93-102$.

Gruzelier, J. H. (1996). The factorial structure of schizotypy: Pant I. Affinities with syndromes of schizophrenia. Schrophenia Bulkefin 22(4): 6111-620.

Haether, J. Loefler, W., Maurer, K., Hambrech, M. and an der Heiden, W. (1999). Depression, negative symptoms, social stagnation and social decline in the early course of schizophrenta. Acto Psychotrica Scomatianuica $100(2): 105-118$

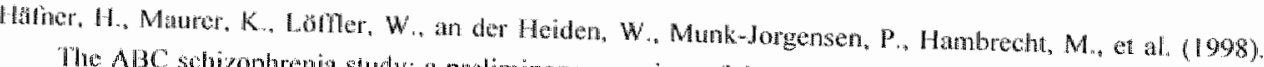

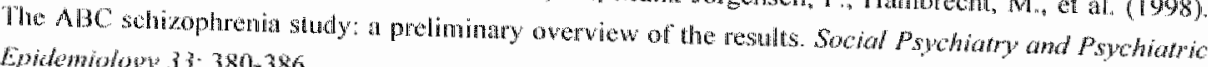

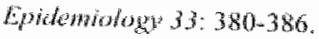

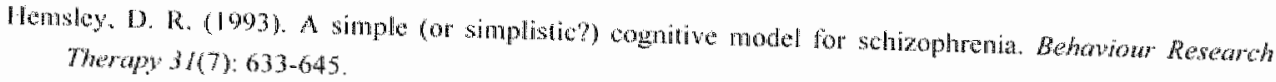

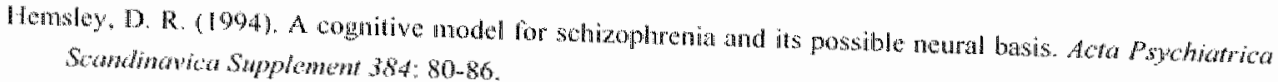

Hitsch, S. R. (1991). Atective symptoms in schizophenta, basic prodromal and residuat, implications for a

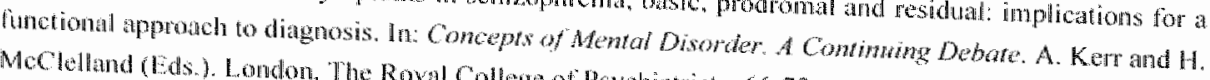

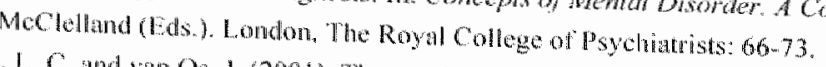

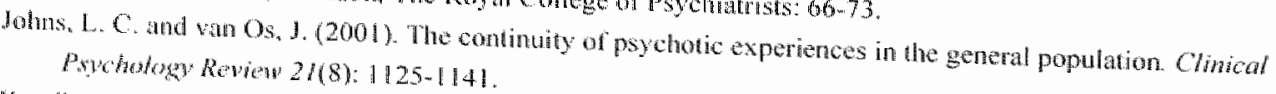

Kendler, K. S. Gallagher, T. J. Abelson. J. M. and Kessler, R. C. (1996). Lilctime prevalence, demographic

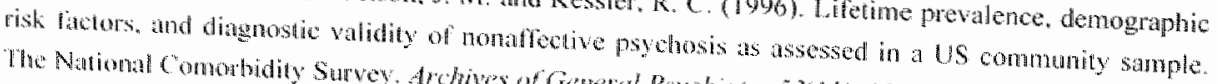

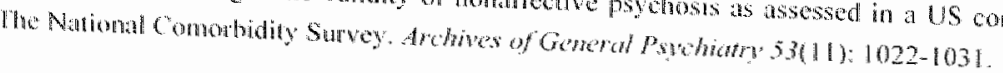




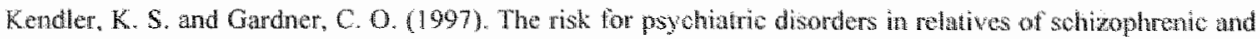

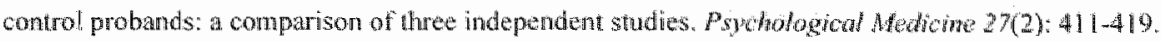

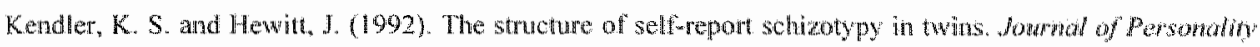
Disordexs $6(1): 1-17$.

Kendler, K. S., Lieberman, J. A. and Walsh, D. (1989). The Struchured Interview for Sehizotypy (SIS): a preliminary report. Schizophrenia Bulferin $1.3(4): 599-57$.

Kendler, K. S., Thacker, L. and Walsh, D. (1996). Self-repont metsures of schizotypy as indices of lamilial

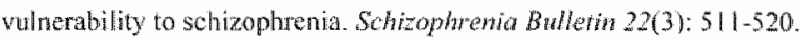

Kety, S. S., Rowenthal, D. Wender, P. H. and Schulsinger. F. (1971). Mental illness in the biological and

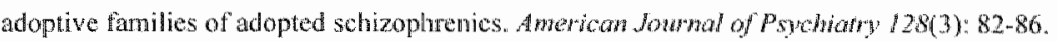

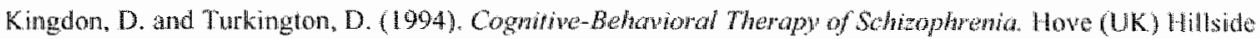
(USA), Lawrence Erbaum Associates.

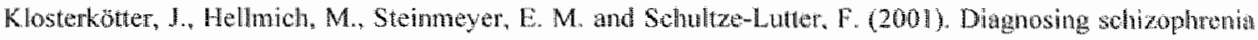
in the initial prodromal plase. Archives of General Prychiary 58 : 158-164.

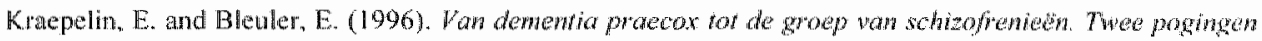

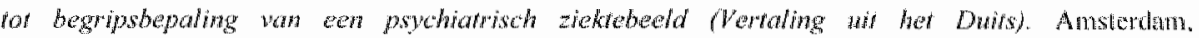
Candide/ Wredo Veldt BV.

Kretschner, E. (1951). Körperban wh Charakner. Berlin, Gottingen, Heidelberg, Springer-Vartag.

Kwapil, T. R. (1998). Sochal anhedonia as a predictor of the development of schizophenta-spectrum disorders. Joumal of Abnomal Psychology 107(4): 558-565.

Larsen, T. K., Fris, S., Haahr, U., Joa, 1., Johannessen, J. O., Melle, 1., a al. (2001). Garly detection and intervention in tirst-episode schizophrenia: a critical review. Acta Psychiarica Scandinawica $103(5)$ : $323-334$

Liddle, P. F. (1987). The symptoms of chronic schizophrenia: A ne-examination of the positive-negative dichotomy. British Jownal of Psychiany 151: 145-151.

Loughand, C. M. and Williams, L. M. (1997). A cluster analytic study of schizotypal trait dimensions. Personality and Indiwidual Differences $23(5): 877-883$.

Maher, B. A. (1974). Delwsional thinking and perceptual disolder. Jownal of Individua Psychology $30: 98$. 113.

Maher, B. A. (1988). Anomalous experience and delusional thinking the logic of explanations. In: Dolusionel Behefs. T. F. Olinanms and B. A. Maher (Eds.). New York. Wiley: 15-33.

Maher, B. A. (2003). Psychopathology and delusions: reflections on methods and modets. In: Panciplex of Experimenta" Pschopahology. M. F. Henzenwegen and J. M. Hooley (Lds.). Wastungton, DC. American Psychological Association: 9-28.

McGiashan, T, H. (1998). Eaty detection and intervention of sobizophrenia rationale and rescarch. B*insw Sourmal of Psychatry Supptement 172(33): 3-6.

MeGlashan, T. H. and Johannessen, I. O. (1996). Early detection and incrvention with schizophenia: rationale. Schizophewion Buhetin 22(2):201-222.

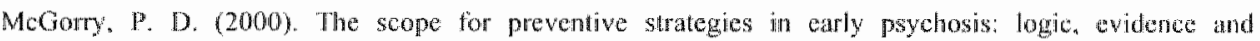

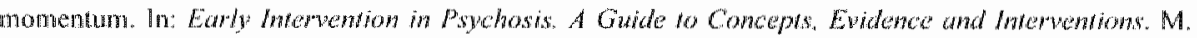
Bitchwood, D. Fowler and C. Jackson (Eds.). Chichester, John Wiley \& Sons, L.TD, 3-27.

MeGory, P. D., Edwards, J. Mihalopoulos. C., Harrigan, S. M. and Jackson, IV. I. (1996). EPPIC: an evolving system of early detection and optimal management, Schizophromia Bulletin 22(2), $305-326$.

McGorry, P. D. Makenzie, D., Jackon, H. J., Waddell, and Cury, C (2000) Can we improve the diagnostic efficiency and predictive power of prodranal sympoms for schizophenia? schizophenia Research $42(2): 91-100$ 
MoGory, P. D. Yung, A, and Phillips, L. (2001). Ethics and early intervention in psychosis: keeping up the pace and staying in step. Schizophenia Research $5 /(1): 17.29$.

McGorry, P. D., Yung, A. R. Phillips, L. J., Yuen, H. P., Francey, S., Cosgrave, E. M., et al. (2002). Randomized controlled triat of interventions designed to reduce the risk of progression to first-episode paychosis in a chinical sample with subthreshoid symptoms. Archives of Generaf Psychiady 59(10): 921 928.

Meha, P. E. (1962). Schizotaxia, schizolypy, setvizophrenia. The Americam Psychologist 17: 827-838.

Meyer, T. D. and Hatizinger. M. (2001). Hypomanic personality, social anhedonia and impulsive moneonformity: cvidence for familial aggregation? Jownot of Personothy Disonders $15(4): 281-299$.

Miller, P., Lawric, S. M., Byme, M., Cosway. R. and Johnstone, E. C. (2002). Self-rated schizotypal cognitionis, psychotic symptoms and the orset of schizophrenia in young people at high risk of schizophrenia. Acta Psychiatrica Scandinawiea 105: $341-345$.

Morrison, A. P., Bentall, R. P., French, P., Walford, L., Kilcommons, A. Knight, A., et al. (2002). Randomised controlled trial of early detection and cognitive therapy for preventing transition to psychosis in high-risk individ:als. Study design and interim analysis of transition rate and psychologicall risk factors. British Jutrwal of Psychiary Supplement 43: \$78-84.

Neale, M. C. and Cardon, I. R. (1992). Mexhodology for Genetic Studies of Twins and Families. Dordrechl/Boston/London, Kluwer Academic Pubishers.

Peralta, V. and Cuesta, M. J. (2001). How many and which are the psychopathological dimensions in schizophrenia? lssues influencing their ascertainment. Schizophenia Research 49(3): 269-285.

Peters, E. R., Joseph. S. A. and Garety. P. A. (1999). Measurement of defusional dideation in the nomal poppulation: Introducing the PDI (Peters et al. Delusions In wentory). Schizophrenia Bulietin 25(3): 553576 .

Potulton, R., Caspi. A., Moffit, T". E., Camon, M., Murray, R. and Harrington, H. (2000). Children's selfreponted psychotic symptoms and adult schizophreniform disorder: a 15 -year longitudinal study.

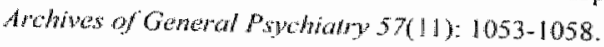

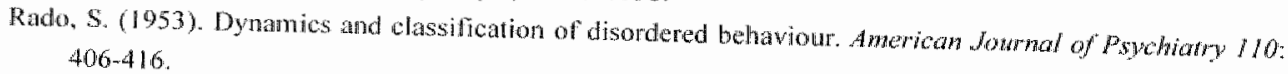

Rosen, J. L., Woods, S. W. Miller, T. J. and MeGlashan, T. H. (2002). Prospective observations of emerging psychosis. The Journat of Nernons and Menul Disease 190: 133-141.

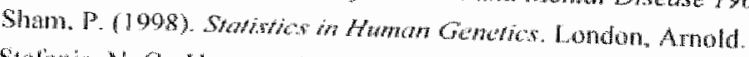

Sterinis, N. C. Manssen, M. Smirnis. N. K., Avramopoutos, D. A. Evdokimidis, I. K., Stefanis, C. N. et al.

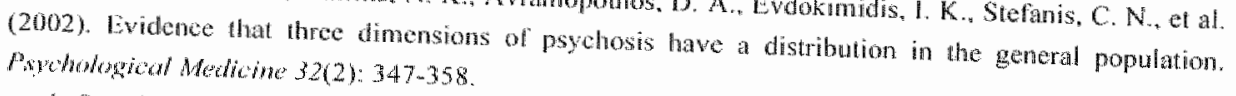

Sirauss. I. S. (1969). Hallucinations and delusions as points on continua funcrion. Rating scale evidence,

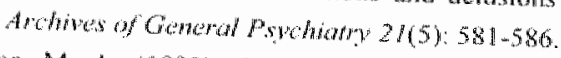

Taylor. M. A. (1992). Are schizophrenia and aftective disorder related? A selective literature review.

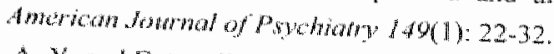

Tien, A. Y. alnd Earon, W. W. (1992). Psychopathologic precursors and sociodomographic risk factors for the schizophenia syndrome. Archives of General Pspchiobry 45: 37.46.

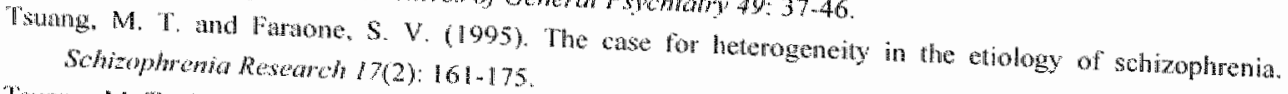

Tsuang. M. T. Stone. W. S. and Furane. S. V. (1999). Schizophrenia: A review of genetic studies. Harvard
Rewicw of Psychotry 7: 185-207.

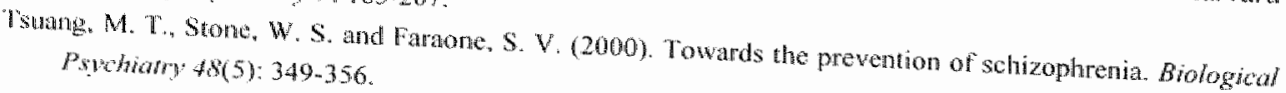




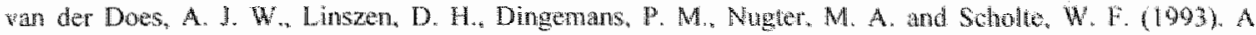

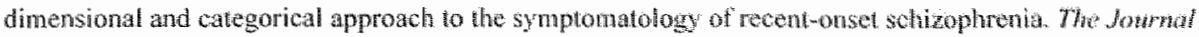
of Nervous and Menthi Disease 19: 744749.

wan Os, J., Falny, T. A., Jones, P. Harvey, I. Sham, P. Lewis, S., ef al. (1996). Psychopathologion syndromes

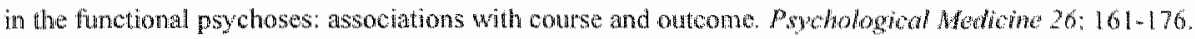

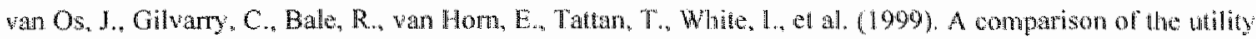

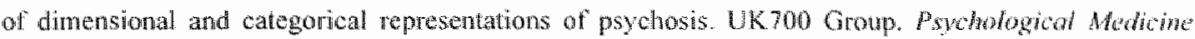
$29(3): 595-606$

sun Os, J., Harssen, M., Bill, R. V. and Ravelli, A. (2000). Sirwuss (1969) revisited: a psychosis contumum in. the general population? Schrophronia Research $45(1-2): 11-20$.

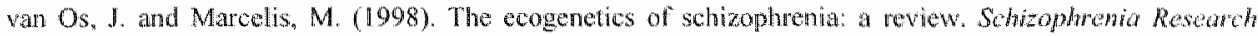
$32(2): 127-135$

van Os, J. Marcelis, M., Sham, P., Jones, P., Gilvary, K. and Muray, R. (1997). Psychopathological syndromes and familial morbid risk of psychosis. British Jownat of Pachativ $170: 241-246$.

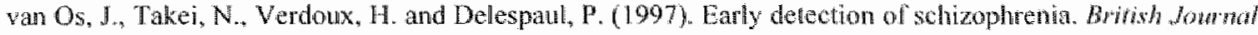
of Psychiatry 170:579.

van Os, J., Vardoux, H. Bijl, R. and Rwelli, A. (1999), Psychosis as a continum of vatuation in dimensions

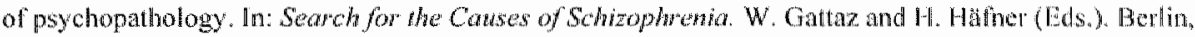
Springer: $59-80$.

Venables, P. H. and Rector, N. A. (2000). The content and structure of schizotypy. atudy using conlinatory Cactor zualysis. Schizophenia Bulletim 2606): 587-602.

Verdoux, H. and van Os, 1. (2002). Psychotic symptoms in non-chinical populatons and the comtinum of psychosis. Schizophrenia Research 54(1-2); $59-65$.

Vollema, M. G. and Hoijtink, H. (2000). The multidimensionality of self-report sehizotypy in asychintric population. an andysis using maltidimensional Rasch models. Sohizophenia Bwherin $26(3): 565-575$.

Kollema, M. G., Sitskoorn, M. M. Appels. M. C. and Kath, R. S. (2002). Does the Sohizotypal Personality Questionnaire reflect the biological-genetic valnerability to schizophrenia? Schrophrema Reseaweh $54(1-2): 39-45$.

Vollema, M. G. and wan den Bosch, R. I. (1995). The multidimensionality of schizotypy. Sohzophrenia Buflem 211): $19-31$.

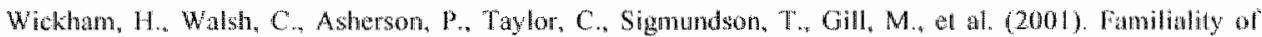

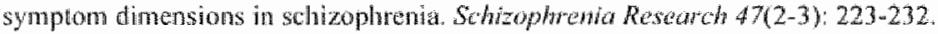

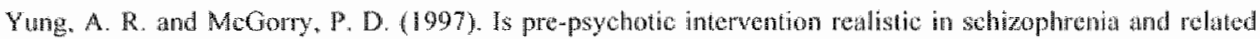

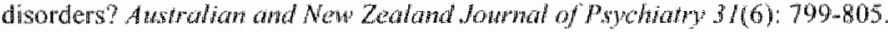

Yung. A. R., MoGorry, P, D. McFarlane, C. A., Jackson, H. J, Patton, G. C. and Rakkar, A. (1996\%,

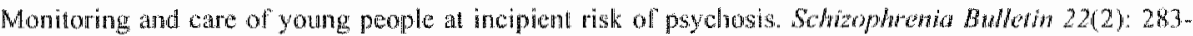
303.

Yung, A. R2, Philips, L. J., MeGorry, P. D., McFarlane, C. A., Francey, S., Harrigan, S., cil al. (1998). Prediction of psychosis. A step towands indicated prevention of schizophrenat Brish fowthat of Poychiatry Supplement $172(33): 14-20$.

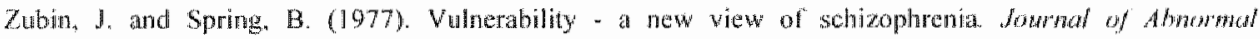
psychology so(2): $103-126$ 



\section{CHAPTER 2}

\section{Strauss (1969) revisited: a psychosis continuum in the general population?}

Jim van os $^{!}$

Manon Hanssen'

Rob V. Bijl $\left.\right|^{2}$

Anneloes Ravelli ${ }^{2}$

'Department of Psychiatry and Neuropsychology, South Limburg Mental Health Research and Teaching Network, EURON, Maastricht University, Mastricht, The Netherlands

2 The Netherlands Institute of Mental Health and Addiction (Trimbos Institute), Utrecht, The Netherlands 
$32 \mid$ CHAPTER 2 


\title{
Strauss (1969) revisited: a psychosis continuum in the general population?
}

\author{
$J_{\text {im van Os }}{ }^{\text {a }}{ }^{*}$, Manon Hanssen ${ }^{\text {a }}$, Rob V. Bijl ${ }^{b}$, Anneloes Ravelli ${ }^{b}$

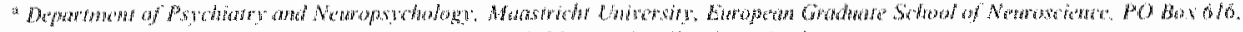

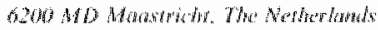

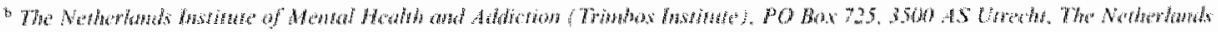

\begin{abstract}
Alustraet

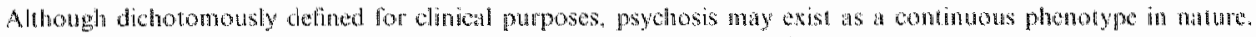

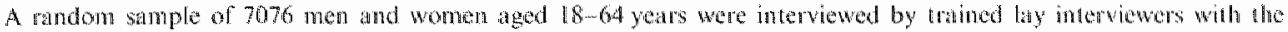

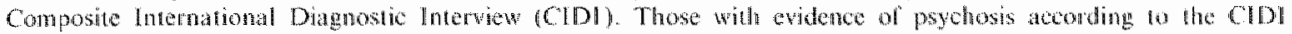
were additionaly internewed by psychiatists. For the 77 ClDI cone psychosis lioms, we compared a psychiatrists

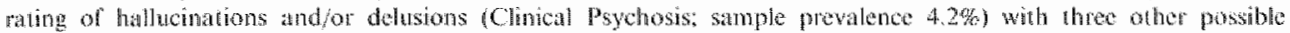

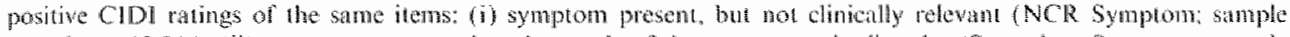

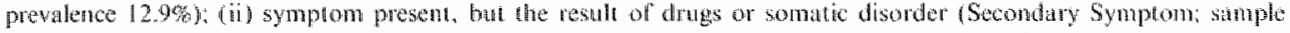
prewatence $0.6 \%$; lene $40 \%$ ). Of the 1237 individuals with any ype of positive pychosis rating (sample prewalace $17.5 \%$ ). only 26

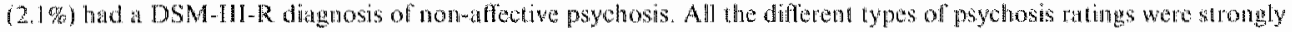

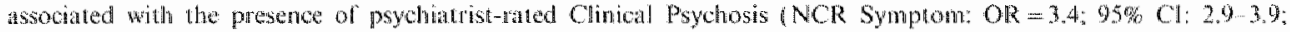

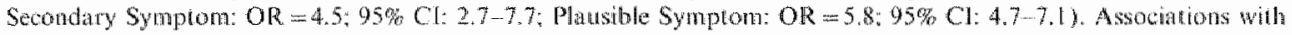
lower age, single marital stalus, urban dwalling, lower level of edaction, lower quality of hle. depressive symptoms and blunting of aflect did not difter qualtatively as a finction of ype of raing of the psychotic symptom, we similar in individuals with and without any CIDl lifetime diagnosis, and closely resembled those previously reported for sctuzophrenia. Presence of any nating of thallucinations was strongly associated with any rating of delusions (OR

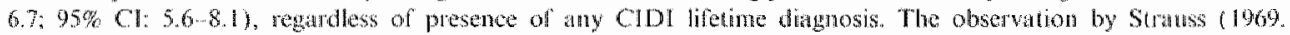

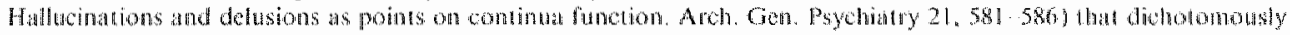

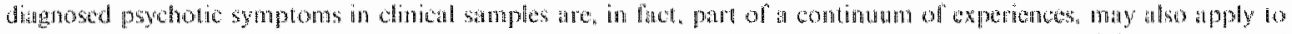

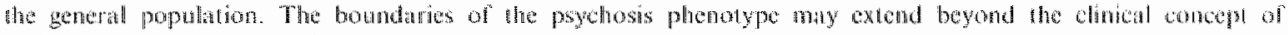
schizophrenia, 2000 Elsevier Science B.V. All righis rescrved.
\end{abstract}

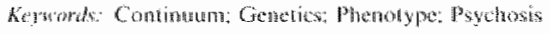

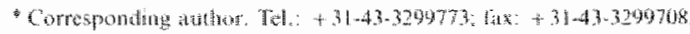

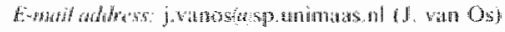




\section{Introduction}

A disorder caused by one gene that is $100 \%$ penetrant can arguably be considered as a dichotomous entity that is either present or absent, Although few would alrgue thatl this is the case for psychiatric phenotypes, clinicians mevertheless have to make at dichotomous decision to treat. However, what the clinician diagnoses as a case for treatment may only be a selected fraction of the tolal occurrence of the phenotype in question (Kendler and Gardner, 1998; Levy et al., 1994) A case in point is psychosis. Psychotic symptoms in clinical samples have been shown to be "points on continua of function" varying contmuously along dimensions of, for example, conviction, preoccupation and implausibility (Strauss, 1969). Furthernore, symptoms in chincal samples may hat we some degree of contimuity with psychosis-like or schizotypal experiences in the general population (Claridge, 1994; Coleman et all, 1996; Crow, 1993" Eysenck, 1952; Gnuzelier, 1996; Kretschmer, 1925; Mechl, 1962). Attrough, theoretically, a contintuous phenotype may be compatible with a single locus in the case of, for example, multiple atleles of varying effec or epigenetic modulation. the presence of multiple interacting genes of small effect on continuous dimensions is considered a plausible scenario in the case of schizophrenia (Cloninger, 1994). Identification of a continutrous phenotype maly therefore result in a productive seatrch for such gentes of small effect (Cardno et al., 1997: Plomin et a1., 1994; Van OS et al., 1997). Surveys of unselected general population samples have consistently shown that a latrge number of individuats report experiences that strongly resemble the symptoms of psychotic patients (Eaton et wl. 1904: Kendler et ill. 1996. Verdoux et al., 1998). However, whell striet criteria of clinical relevance and imparment are applicd only at faction of these individuals moet criteria for a clinical disorder swoh as schizophrenta (Kendler et al, 1996), the remainder not being considered as part of the phenotype. In a general population sample of 7076 individuals, we focused on any interviewbased experience resembling dinical symptoms of psychosis. We hypothesised that such experiences, in spite of not being labelled as true clinical symptoms, would nevertheless (i) show overlap with clinical symptoms in terms of psychopathology, risk factors and functional measures, and (ii) be prevatent in both 'cases' and "noncalses' of psychiatric disorder.

\section{Methods}

\subsection{Sample and procedures}

The Netherlands Mental Health Survey and Incidence Study (NEMESIS) is a prospective study with three measurement points over a period of 3 yeurs ( $\mathrm{Bijl}$ et al. $1998 \mathrm{a}, \mathrm{b}$ ). The current report is based on the baseline data. A raultistage, straiffied, random sampling procedure was used to first select 90 rmunicipalities, then a sample of private households, and finally a Dutch-speaking indiwidual aged 18-64 years within each houseJold. Individuals living in institutions were not eligible for interview. Because many patients with schizophrenia and other severe mental illness in the Netherlands are in long-term care in specialised institutions, rates of these disorders were relatively low (Bijl et al, 1998a, b). Selected households were sent an introductory letter by the Minister of Health, inviting them to participate. A total of 7076 individuals provided informed consent and were interviewed at baschine, representing a response rate of $64.2 \%$. Nearly $44 \%$ of nonresponders atgreed to fill in a postal questionnaire, including a General Health Questionnaire (Goldberg and Williams, 1988), and were found to hawe the same mean GHQ score (responders: 1.19 , non-responders: 1.16). Purtial non-response wats negligible because of the computer-assisted interviewing procedure. The sample was found to be representative of the Dutch population in tems of gender, marital status and level of urbanisation (Biil et al. 1998b), with the exception of an underrepresentation of individuals in the age group $18-24$ years. As this was a study of relative rather than absolute risk, no poststratuification weightings were applied to the data

\subsection{Instruments and dicagnoses}

Subjects were interviewed at home. The Composite International Diagnostic Interview 
(CIDY) wersion 1.1 (Robins et al., 1988: Smeets and Dingemans, 1993; World Health Organisation, 1990) was used, yielding DSM-IILR diagnoses. The CIDI was designed for trained interviewers who ate not clinicians. The data were collected by minety interviewers who were experienced in systeratic data collection, hawing received a 3 day raining course in recruiting and intervewing, forlowed by a 4 day course at the WHO-CIDI traning centre in Amsterdant Extensiva nonitoring and quality checks took plack throughoul the entire data-collection period (Bijl et th 1998b). The CIDI is used worldwide, and WHO field research has fomd high interrater reliability (Cottlet al. 1991; Wittchen al., 199.1), and high test-retest reliabitity (Semler et al., 1987: Wacker et al. 1990). In the present study, the following DSM-ULI-R diagnostic groupings were used: (i) anxiety disorder, (ii) dysthymia, (iii) majo: depression, (iw) bipolat disorder, (v) non-affective psychosis, (vi) esting disorder and (vii) alcohol and/or substance abuse and/or dependence. Individuals with any history of these CIDI-based DSM-III-R diagnoses will hereafter be referred to as cases, the remainden: as non-cases.

\subsection{Pisyohosin rangus}

Lifetine ratings from the 17 ClOH core psychosis sections on delusions ( 13 items) and hallucinations (font items) were used (items GI-G13, GI5, G16. 620, G21). These concern classic psychotic symptoms involving. for exmple, persecution, thought intorterence, auditory hallucinations and passivity phenomena. All these items can be ratod in six. wiys: (1) no symptom: (2) symptom present, but not climically relevant not bothered by in and not seeking help for it); (3) symptom result of ingestion of drugs: (4) symptom result of somatic disease; (5) true psychitric symptom; (6) symptom is not really a symptom because thene appears to be some piansible explanation for at Catogories 3 and 4 were joined together. The categories will be donoted hereaften: category 2: NCR Symptom (Not Curically Relevand); Category $3+4$ : Secondary Symptom, category 5: Chical Psychosis; ategory 6. Matsible Symptom. Beoduse psychotic symptomys are difficult to diagnose in at structured interview
(Anthony el a1. 1985; Cooptrand Collkcot, 1994: Helner ef a. 1985). clivical re-interviews were conducted ower the telephone by an sen registrar in psychiatry for all individuls who had at lowst one rating of Clinical Psychosis or Puasible Symptom, using questions from the Suructured Clinical Intervew for DSM-IIL-R (SCID), wh instrumen with proven retiabitily and validity in diagnosing sohizophrenial (Spitzer at al. 1992). CIDI psychosis matings of Clinical Psychosis of Plausible Symptoms were corroded on the basis of these clincal intervews, and the NEMESIS DSM. III-R diagnoses of schizophrenta and other nonaftective psychotic disorders are based on the data from these dirical re-interviews.

\subsection{Demegnaphic rist factors and chmical iremis assoriated with psychosis}

The following demographic vatiables that have previously been shown to be issociated. with schizophrenia (Jableasky, 1995; Kendler at al. 1996: Marcelis et al, 1998) were included: thge $(18-24,25-34,35-44,45-54,55-64$ years), sex, urbanicity of place of residence ffive levels acoording to the Dutch Central Burevu of Statistics; Central Bureau of Statistics, 1993 ), hevel of income (top $25 \%$, next $50 \%$, lowest $25 \%$ ), years of education ( 16 or more, $13-15,12,0$-11), unemployment, and single marial status fling alone versus other). In order to assess the functional significance of any symptoms, associations with total scores on the SF-36 quality of life schedule (Vin der Zed et all. 1993, Walte et al., 1994j were examined. In order to examine the multidimensonality (Kitamurat al., 1995; MoChory al al. 1998) of the ratings of positive psychotic symptoms, associatons whith depsese and negative symploms were Eximined, as well associtions with CID lifethime dagnoses. Depressive symptoms were CIDI items $\mathrm{E} 1$ (2 weeks of consiskent how mond) (prevalence $45.0 \%$ ) and 12 ( 2 years of predominanty low mood) (prevalenco 12.4\%). Negative symptomatology was apresented by item P3. hat anfoct (prevalemer 0.3\%). Associations willy CID lifetine diagnosis were assessed by companing individuals in a pathoula diagnostic category whin individuats whoul any CIDI lifetime disgnosis. In onder to 
watablist whether any association applied not only to those identifed as having a lifetme history of prychintric diserder, but also to the "healthy" population, we examined all associations for inter

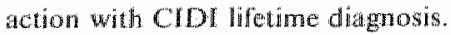

\subsection{Anabses}

Associations were expressed as odds ratios, using logistic regresion in STATA (StataCorp. 1999). Interactions wh CIDI diagnosis (any lifetime diagnogis versus no diagnosis) were assessed by likelihood ratio tests. For didgnostic interachons with demographic variables (48 tests). Aphe wase ser $1 \%$. Normally distributed quality of life scores were divided by their tertiles in onder to creale tiertile groups.

\section{Restills}

\subsection{Freguency of psychosis natwgs}

A total of 7075 individuals aged $18-64$ years (women: $53.3 \%$ ) had valid ratings on the 17 CIDI psychosis items. The pevalence of difenent lypes of ratings ranged from $8.7 \%$ and $6.2 \%$ for respecthely, delusions and hallucinations not consideted clinically retevant, to $0.3 \%$ for secondary delusions and secondary hallucinations (Table 1 ). The prewalence of "treme" psychiatrist-rated clinical delusions and hallucinations was $3.3 \%$ and $1.7 \%$, respectwely, the prevalewe of either delusions or hallucimation was $4.2 \%$. All types of ratings of delustons and holucinations were nuch more conmon, after adjustment for age and sex, in the 2910 individuals who had rewerted any type of CIDI diagnosis. Nearly a third of the cases $(27,6 \%)$ versus a tenth (10.4\%) of non-cases had had any type of positive symptom rating ladjusted $\mathrm{OR}=3.2 ; 95 \% \mathrm{CH}: 2.8-$ 3.7). The ratro of chically not relevant to alinically relevant delusions was around 2 in cases, and neally 6 in non-cases. Fror hallucinations these ratios were approximately 3 and 8 , respoctively (Table 1). Of the 1237 individuals with any type of positive psychosis mating, only $26(2.1 \%)$ had a diagnosis of non-affective psychosis.

\subsection{Associations between different types of positive raings}

NCR Symptoms, Secondary Symptoms and Plausible Symptoms were all wery strongly associ. ated, in a dose-response fashion (HIt, 1965), with the presence of Clinical Psychosis (Table 2). For example, the risk of Clinicn Psychosis was increased 4.6 times in the presence of one $\mathrm{NCR}$ Symptom, and increased 10.4 times in the preserce

Thithe

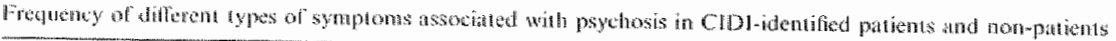

\begin{tabular}{|c|c|c|c|c|}
\hline \multirow[t]{2}{*}{ 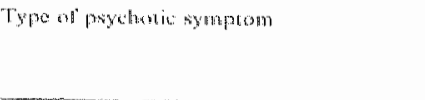 } & \multicolumn{3}{|c|}{ 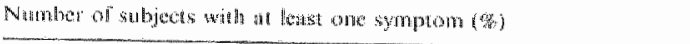 } & \multirow{2}{*}{ 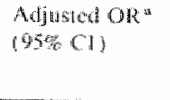 } \\
\hline & $M(1)=0.953$ & 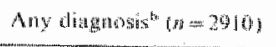 & 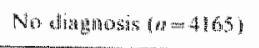 & \\
\hline 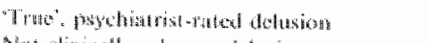 & $230(3, \ldots)$ & $188(6.5)$ & $42(1)\{\}$ & $6.6(4.7 \ldots 9.3)$ \\
\hline 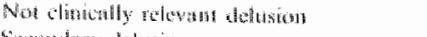 & A $14(\$ 2)$ & $374(12.9)$ & $240(5.8)$ & $2.4(2.0-2.8)$ \\
\hline 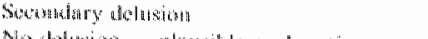 & $18(0,3)$ & $17(0.61)$ & 100 & $25.4(3,4.1915)$ \\
\hline 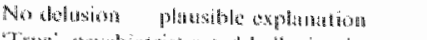 & $365(3.8)$ & $265(7.0)$ & $60(1)$ & $5(1,3,56,9)$ \\
\hline 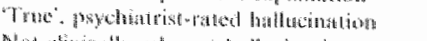 & $122(1.7)$ & $196(3.6)$ & 160.43 & $9.915 .516 .8 j$ \\
\hline 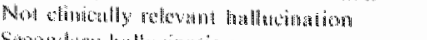 & $4,35(6.29)$ & $296(100,2)$ & $13 \times 3,30$ & $32\{2,-4,1)\}$ \\
\hline 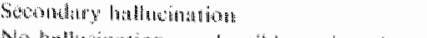 & $23(n, 3)$ & 1700.9 & 60.1 & $5011.9-1360$ \\
\hline 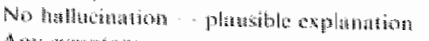 & $34(615)$ & 3211.4 & 2014 & $28,45,69.960$ \\
\hline Any syanpotant & $125 \% * 175 \%$ & $80727.6)$ & $4.50(104)$ & $3,2,2,3)-3\}$ \\
\hline
\end{tabular}

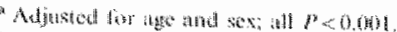

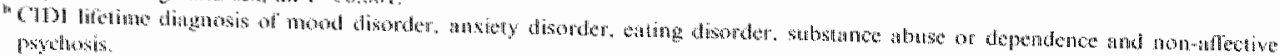

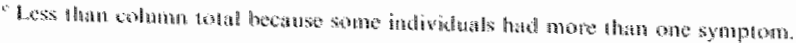


Table 2

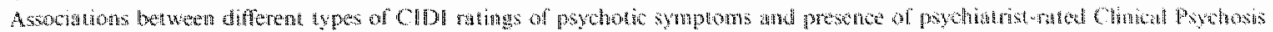

\begin{tabular}{|c|c|c|c|c|c|}
\hline \multirow{2}{*}{$\begin{array}{l}\text { Type of pspolymalic } \\
\text { sympon }\end{array}$} & \multicolumn{5}{|c|}{ 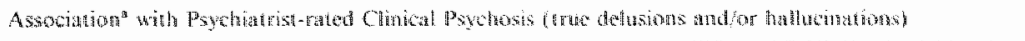 } \\
\hline & 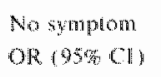 & $\begin{array}{l}\text { One symplom } \\
\text { OR (as } 9 \text { (a) }\end{array}$ & $\begin{array}{l}\text { Two or more symphoms } \\
\text { OR (95\% Cl) }\end{array}$ & 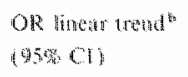 & 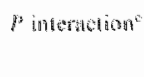 \\
\hline Noto cingally relevant & i & $46(3,4-6,2)$ & $10.4(7,6-14.4)$ & $3.4(2.9-3.9)$ & 0.02 \\
\hline Secontary & 1 & $9.1+4.0-20.63$ & $10.2\{2.6 \cdots 99,6\}$ & $4.5(2.7-7.7)$ & 13 \\
\hline Platuible" & 1 & 11.418 .16 .11 & $23.0(14.1 \cdots 34,4\}$ & $5.44 .7 \ldots 7.1)$ & $\pi 96$ \\
\hline
\end{tabular}

a All asseciations $p<0$, and

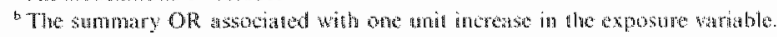

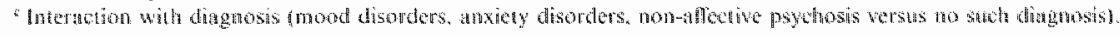

of two or more NCR Symptoms (Table 2). These associations were similar for cases and non-cases alike, with the exception of the association between NCR Symptoms and Clinical Psychosis. This association was stronger in, but not specific to, noncases $(\mathrm{OR}=4.1 ; 95 \%$ Cl: $2.9-5.8)$ in comparison to cases $(\mathrm{OR}=2.6,95 \% \mathrm{CI}: 2.2-3.0)$.

\subsection{Associations between different types of positive ratings and dentographic rish factars and clinical variables}

Associations between demographic and clinical variables on the one hand, and NCR Symptom, Secondary Symptom and Platisible Symplom on the other were adjusted, in addition to age and sex, for the presence of Clinical Psychosis. The pattern of adjusted associations betwen different types of psychosis ratings and demographic risk factors and clinical watiables was generally very similar for all groups (Table 3). Female sex younger age, higher level of urbanicity. lower income. lower level of education, unemployment, and single marital status were, with wery few exceptions, associated with each type of psychosis rating. All ratings were strongly associated with lower quality of life, and associations were of approximately equal strength for each type of psychosis ratting. Only one demographic varikble by diagnosis intelactions was significant at the pre-set alphat of $1 \%$.

Tuble 3

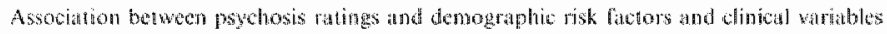

\begin{tabular}{|c|c|c|c|c|}
\hline \multirow[t]{2}{*}{ Exponare variables } & \multicolumn{4}{|c|}{ 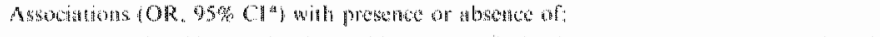 } \\
\hline & 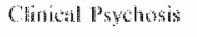 & NCR Symploin" & Secondary Sympleming & 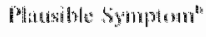 \\
\hline Formatio SaX & $1.3(1,\{-1\}$ & $1.10 .9 \cdot 1.2)$ & $0.7 \mid(1), 3 \%(1,4)$ & $1.9 .110401 .7 \%$ \\
\hline Wigher age (five lewels & 0.8600 .790 .95 & $0,80(0,810101)$ & $0.90(0.74-1.25)$ & 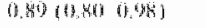 \\
\hline 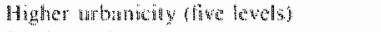 & $1.3,1.2-1.4\}$ & $1.2(1.1 .1 .24)$ & $1.5(1.110)$ & 1196.971 .21 \\
\hline Single mirtal staling & $1.8(1.42 .4)$ & $1.5(1.3 \cdots 1.8)$ & 2.011 .04 .4 .60 & $1,(1,4,2,4)$ \\
\hline Lower income (thee dewets) & $1.3(1.1 \cdots 1.6)$ & $1.1(1.001 \cdots 1.22)$ & $1.1(0.7 \cdots 18)$ & $1 . .111 .11 .5)$ \\
\hline 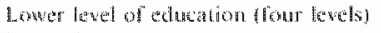 & $1.3(1.1-1.4)$ & $1.1(1,051.2)$ & $1.2(0.915)$ & $1.2111 .041 .3 \mathrm{hi}$ \\
\hline Whentiplyanent & $24(1.7,4)$ & $1.5(1.1 \ldots 1.9)$ & $25(1.1 \ldots 59)$ & $2.1+11.40)$ \\
\hline 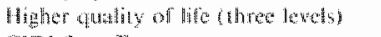 & $0.6100 .520 .72 \mathrm{y}$ & $0.77(0.71 \cdot 0.85)$ & 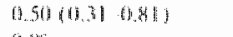 & $0.60468)(1), 78)$ \\
\hline ChDI Hitt at blect & 11.905 .1281 & $3.0\{1.273\}$ & 0.5 & $2.9(10.7 \cdot 10.2\}$ \\
\hline 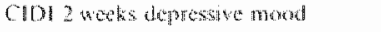 & $5,4(4,1,7,3)$ & $2.0(1.7-2.3)$ & $=81(1.8-81)$ & $3.5(2.746)$ \\
\hline CADA 2 years depertinge nood & $7,3,(5,7 \ldots 9,7)$ & $2.1(1.725)$ & $26(1,3) 5.4)$ & $4.6(3.26)$ \\
\hline
\end{tabular}

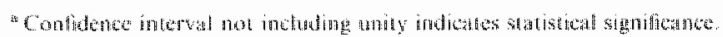

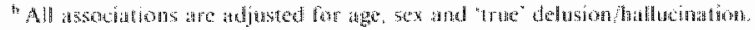

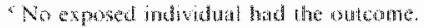


This interaction indicated that the effect of urbanisation on Plausible symptoms was stronger in individuals with any lifetime diagnosis.

Psychiatristrated Clinical Psychosis was strongly itssociated with flat affect and depressive mood, but so were, to a lesser exient, wher types of psychosis ratings. The presence of any rating of hallucinutions $(n=551,7.8 \%)$ was strongly predictive of atay type of dellusion $(n=931,13.2 \%)(\mathrm{OR}=$ $6.7 .95 \%$ Cl: $5.6 \% 8.1, P<0.001 \%$, both in individwals with any ClDI lifetime diagnosis $(O R=5.5$, $95 \% \mathrm{CI}: 4.4-6.9)$ and in indivduats without CIDI lifetime diagnosis $(\mathrm{OR}=4.3,95 \% \mathrm{Cl}: 2.9 \ldots .3)$.

All types of rallings were strongly associated with every possible CIDI lifetime diagnosils, after adjustment for Chnical Psychosis as described above and additional adjustmen for age and sex (Table 4). The only exception was a clifical diagnosis of non-affective psychosis.

\section{Discussion}

\subsection{A pychosis continum?}

We found that $4.2 \%$ of the general population had psychiatrist-rated evidence of delusions or hallucinations, and that $17.5 \%$ of the population $(n=1237)$ sample reported any experience resenbling the ctinical psychosis concept. Although only $2 \%$ of these 1237 individuals received a DSMIII-R diagnosis of non-affective psychosis, their experiences were continuous in terms of psychopathology, risk factors and functional measures with psychiatrisi-rated psychosis. This applied to individuals both with and without any formall diagnosis of psychiatric disorder. The findings: suggest that the psychosis phenotype as it exists in nature may be nearly 50 times $(17.5 \%$ divided by the schizophrenia prevalence of $0.4 \%$ ) more prevalent than the more narrow nedical concept. Our fundings are in agreement with the observation that self-rated psychosis-like or schizotypal experiences predict onset of psychotic illness and depression in college sudents (Chapman et al., 1994; K wapil et al. 1997), athd evidence of a substantial familial relationstip between interview-based clinicat and subelinical forms of psychosis (Kendler et al. 1993; Kendler and Walsh, 1995).

Although our definition of psychosis relied hedvily on positive symptoms, strong associations with affective and negative symptoms suggest this definition also tapped into other symptom domains that form part of clinical disorders such as schizo phrenia. For example, the association of psychiatrist-rated Clinical Psychosis with CIDI fat affect was very strong, as indicated by an $O R$ of 11.9 $(95 \% \mathrm{CI}: 5.1-28.1)$. The effect size of NCR for ClDI flat affect was also large at $3.0(95 \% \mathrm{CI}$ : $1.2-7.3)$. Althoug ${ }^{2} \mathrm{~h}$ suggesive, these findings do not constitute proof that the psychotic experiences that were measured in this study are really contimuous with the experiences encountered in the clinical disorder. Future general population studies

Title 4

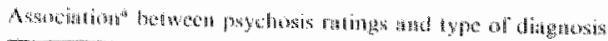

\begin{tabular}{|c|c|c|c|c|c|}
\hline D) Matamas & 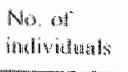 & $\begin{array}{l}\text { OR "Clinical } \\
\text { Psyolnosis }\end{array}$ & $\begin{array}{l}\mathrm{OR}^{*} \mathrm{NCR} \\
\text { Sytraptam }\end{array}$ & 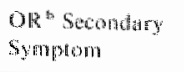 & 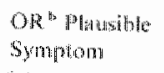 \\
\hline Ambely disuaters & $142 y$ & 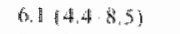 & $19: 1.6233$ & $6.8(2.3-17.4)$ & $4.12 .9-5.81$ \\
\hline 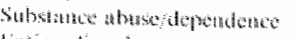 & $110 ?$ & $5.4(3.7-7.25)$ & $2.011 .6-2.48$ & $7.2(2.520 .3)$ & $30(20-45)$ \\
\hline hathy disordar & 56 & $256(126 \ldots 513)$ & $1.716 .9-x, 3)$ & $192(1.5-2424)$ & $47(1.8-120)$ \\
\hline Dysthysain & 448 & $(0.2(4)-9.5)$ & $\| 6 ! 2,2 ! H$ & $64+20.2400$ & $5.0(3.2-7.9)$ \\
\hline Majug depresinga & 1164 & $6.4(4,5,9,0)$ & $1.6(1,320)$ & $73(2.6-20.7)$ & $4.9(3.479)$ \\
\hline 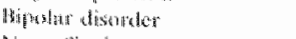 & 132 & $14.84(8.7252\}$ & $23(1,5 \cdots)$ & $7.8(1.347 .5)$ & $10.9(6,3 \cdots 189$ \\
\hline Norn-aflective psychowis & 26 & $x$ & $0.5+0,2-21)$ & 迹 & $2.1(0.6-3)$ \\
\hline
\end{tabular}

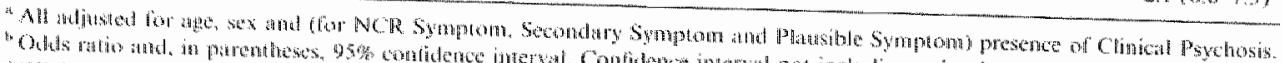

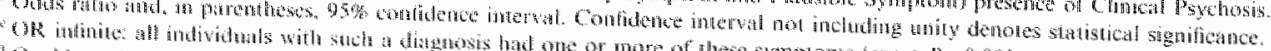

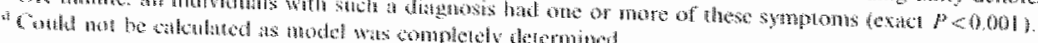


will need to include more specific measures of both negative and affective symptom dimensions, and more specific neasures of underlying cognitive, familial and developmental risk factors.

The fact that the ratings of Clinical Psychosis and Plausible Symptoms were checked and corrected by a psychatrist with the help of a clinical interview, albeit over the telephone, reduces the possibility that endorsement rates for these ratings reffect misinterpretation of CLDI psychosis probes on the part of respondents or misinterpretation of their answers on the part of lay interviewers. In some cases, howewer, ratings of Clinical Psychosis may have been wrongly labelled as NCR or Plausible Symptoms because of a particular response siyle of the respondent. Although such misclassitication may have occurred occasionally, its rate would have to be very high to fully explan the observed associations with demographic and other variables in Table 3. NCR Symptoms and Secondary Symptoms were not checked by clinicians, and are likely to contain some false positives. However, the fact that these ratings newertheless correlated strongly with psychiatrist-rated Clinical Psychosis suggests continuity with the elinicianbased concept. Furthermore, this type of misclassification camnot explain the fact that the pattern of associations between risk factors and all CIDI psychosis ratings was similar to that reported for schizophrenia, nor the fact that there were similar associations with other symptom dimensions. The strong association between psychiatrist-rated Clinical Psychosis and psychiatrist -rated fPlausible Symptom is in agreement with the findings reported by Strauss $(1969)$, who demonstrated What psychiatrists are frequently forced to score the presence of a delusion of hallucination as "uncertatin', because of the apparent presence of extemal realify factors. This author proposed that these experiences may nevertheless bo commuous with "true" psychotic phenomena. This study showed a similar influence of external reality factors in al general population sample. The strong assochation between Chinat Psychosis and Plausible Symptom is indicative of continuily between the two phenomena.

The rates of clinician-based delusions and halhucinations, $3.3 \%$ and $1.7 \%$ respectively, are substan- tally higher than the prevalence of non-affective psychosis. The fact that the prevalence of delusions and hallucinations is apparently substantially higher than the prevalence of non-affective psychosis is in agreement with the stiggestion that not all individuals with "trte" psychotic symptons ane patients (Claridge, 1997, Honge al a 1998). A formal DSM diagnosis requires marked social and/or professional dysfunction, while some individuals with psychotic symptoms do not have impairments, of only to a lesser degree (Honig et al. 1998). Although not severe enough to meet criteria for DSM disorder, some degree of dystumbtion for cach type of CIDl psychosis rating wats apparent, as evidenced by associntions with lower quality of life, unemployment, negative and depressive synptoms, regardless of presence of any psychiatric diagnosis. Experiences resembling DSMIII-R non-affective psychosis therefore do appear to have some impact on well-being and functioning, which suggesis they latuve some degres of dinical relevance as well.

Mechanisms of psychosis may be similar in healthy individuals and patients. For example, it is atractive to speculate that the association between delusions and hallucinations in both CIDI cases and non-cases can be attributed in part to cognitive activity whereby the individuat seeks to explain abnormal perceptual experiences (Maher, 1974,1988 )

\subsection{Lack of diagnastic specifority and symprom dimensyons}

Strong associations existed between all types of symptom ratings and all types of lifetime diagnow ses, with the exception of non-affective psychosis. Non-affective psychosis was associated only with a rating of Clinical Psychosis, and to in lesser extern with a vating of Plausible Symptoms, becaluse only individuals with these symptoms would have had clinical interviews with the psychiatrist. The findings indicate that the boundaries of the psychosis phenotype do not concur with traditional diagnostic labels. This lack of specificity of psychosis concurs with a recent population-based family study showing increased ates for schizophremia and schizophrenia-spectrum disonders for most 
classess of affective and non-affective illness (Kendler et al, 1998). Similarly, in the US National Comorbidity Survey, very strong associations were revealed berween non-atective psychosis and lifetime presence of all other DSM diagnostic categories (Kendler et at., 1996 ). Strong associations for all types of CIDI psychosis ratings: also existed with other psychiatric symptoms, such as depressive symptoms and negative symptoms. The broad psychosis phenotype may thus include variations in other symptoms, as indeed does the clinical disorder (Kitamura et al, 1995; McGorry et al, 1998; Van Os et al., 1999).

\subsection{Associations wh demographic risk factars}

Associations with lower educational achievemont, younger age, living alone and lower income were alpparent for all types of ClDI psychosis ratings. This suggests a developmental mechanism similar to that reported for schizophrenia (Jones et al.. 1994). Similarly, atssociations, with level of urbanicity suggest an effect of environmental risk factors as reported in schizophrenia (Lewis et al., 1992; Marcelis et al., 1998). Women more often displayed positive symptoms of psychosis. In an analysis of 1292 cases of schizophrenia from 10 cotwntries, Hambrecht ef al. (1992) similarly reported a higher prevalence of positive symptoms, such as fantastic and paranoid delusions, in women. Recent latent class analyses suggest that men are more likely to present with negative symptoms and women with positive symptoms, such ar perrecutory delusions (Castle et al. 1994: Goldstcin et at. 1990$)$.

\section{Conclusion}

In conclusion, the dat a suggest that the findings reported by Strauss $(196 \%)$, on continuity of psychatio phenomena in climical samples, also apply to the general population. Subclinical psychotic phenomena elicited by lay interviewers were continuous with clinical psychosis rated by psychiatrists. The data therefore suggest that the search for the determinats of the psychosis phenotype should be conducted along broatd dimensional lines, in addition to the more narrow focus on the clinical definition.

\section{References}

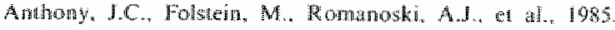

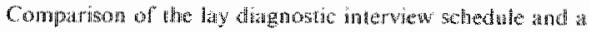

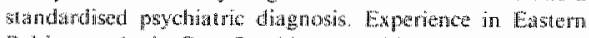

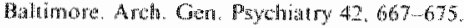

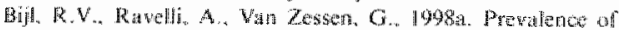

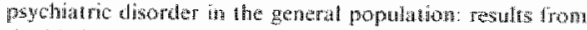

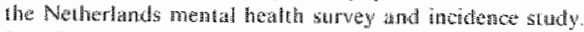
Sok Psychatry Psychatr. Fpideniol 33. $587-596$.

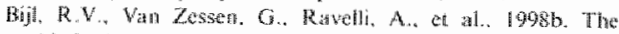

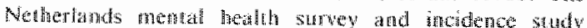

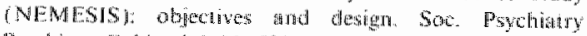

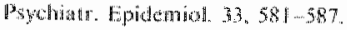

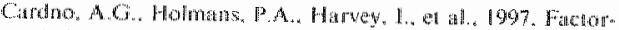

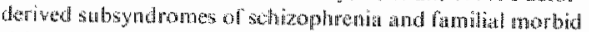
ristks, Sichizopler. Res. $23,231-238$.

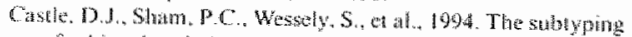

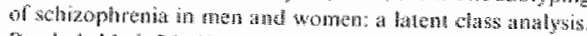
Psychot. Med, 24, 41-51.

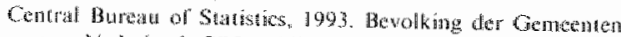

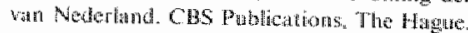

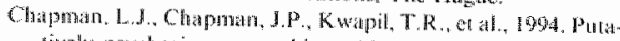

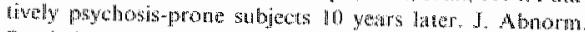
1sychol $103,171-183$

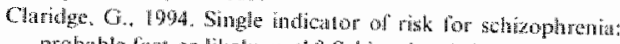

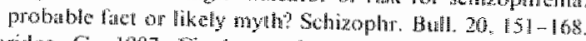

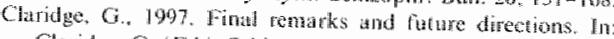

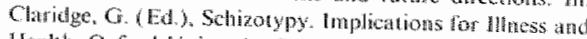

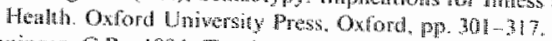

Clonatger. G.R. 1994. Turning point in the design of linkage

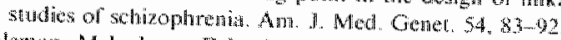

Cokm M.J., Lewy. D. I... Lenzenweger, MF

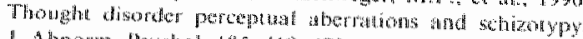

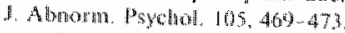

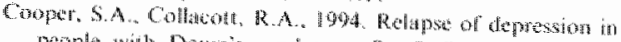

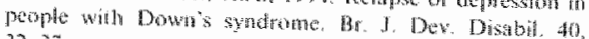
$32, \cdots, n$

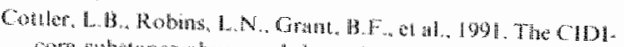

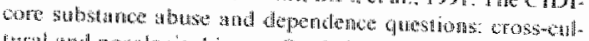
Luraf and nosological is

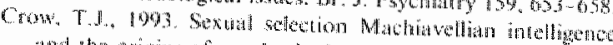

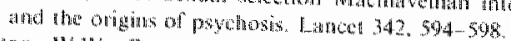

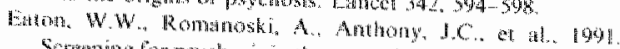

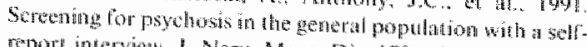

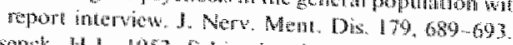

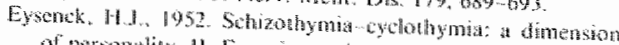

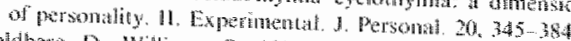

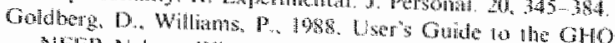

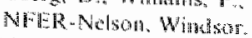

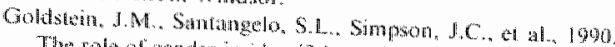

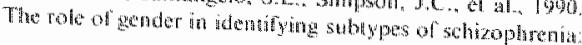


a fitem class anzlyic approach. Schizophr. Bull. 16. $263-275$

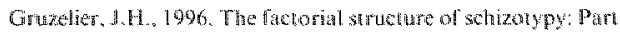

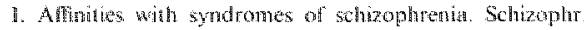
Bull. $22,611-620$

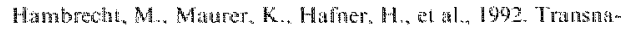

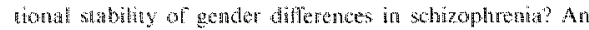
andlysis based on the Who stwdy on dateminans of out come of severe meantal disordess Eur. A,roh. Bsychisary Clin. Netrasci. 242.613.

Hetzor, J. E. Robins. L.N. McEvor, L.T. et st., 1985. A com-

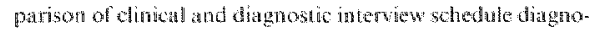

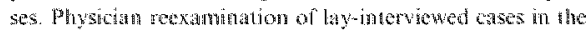
gapenexal population, Arch. Gen. Psychiatry 42, 657 666

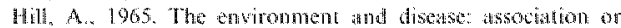
catusation? J. R. Soc. Med. 58, 295-300.

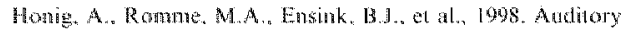
thalderinations a comparison between patiens ated non pationes. 1. Nerv, Mont. Dis. 185, 6446-651.

Jablenshy. A. 1995. Schizopluen a the epidemiological horizon. In: Hirsch, S. Weinberger, S. Reds.), Schizophanian. Blickwell Science. London.

Jones. P.. Rodgets. B. Murray, R . el al., 1944. Chilu development risk factors lor adult schizophenta in the British 1946 birth cohort. Inancet 344 . 1398 1402.

Kendler, K.S., Gallagher, "I.1., Abelswn. 1.M., et al., 1096. Liletime prevatlence. demographic risk fachors, and diagnostic

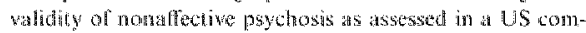
munily sample. The Nationth Comorbidity Surby. Areh. Gen. Psychiatery $53.1022 \ldots 1031$

Kendler, K.S., Gadner Jr. C.O., 19g8. Bowndaries of major deprescion: an evaluakion of DSM-TV eriteria. Am. J. Psychiatry $155,172 \ldots 177$.

Kendler, K.S., Karkowski, L.M. Watsh, D.., 1998. The strucLate of psychosis: laten chass a aalysis of probands from the Thoscontmon Family Sudy. Areh. Gen. Psychiary 55, $492-499$

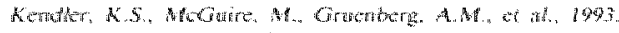
The Roseommon Family Sady. IIJ Schizophentit-redatod personility disordes in reinliwes. Arch. Gen. Psychiaty 50.7878 .78

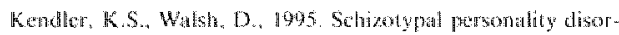

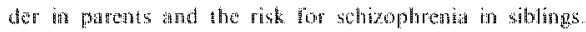

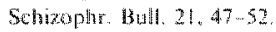

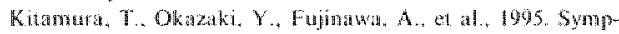

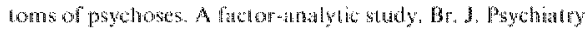
$166,236-440$

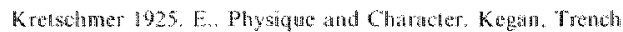
atal Trubner London. W.I.H. Spolt, Trans.

Kwapil. T. MR... Miller. M, B. Zinser. M.C. et al. 1997. Magical

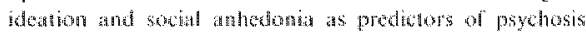
proneness: a partal replication. 1. Abnom. Psychol. 106. $441-495$.

Levy, D.L. Holzman. P.S. Manlliysse, S., et il, 1924. Eye racking and schizopheniat: a selective review. Schizophe Bull. $30,+7762$
Lewis, O., David, Andreasson. S., at ah, 1992. Schizom phrenta and cily life. Latacel 30.137 . 40

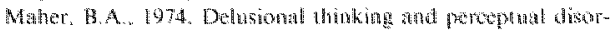
der. Indivat. Psychol. $30.98-11$ औ.

Maher. BA. 1988. Anomatom experience and delusional

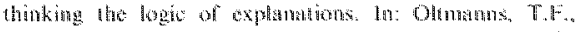

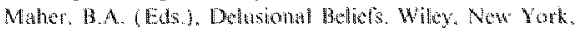
pp. $15,3.3$.

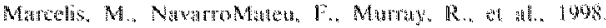
Urbanzation and pyehosis: a suty of 1942 1078 birth

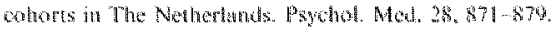

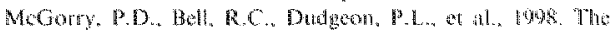
dimensional structure of lirst epsode psychosis: mo axplozatory linctar malysis. Pyelwol Med. 28, $935 \% 947$.

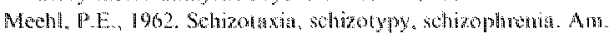

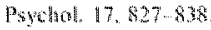

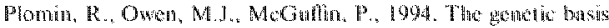
of complex thinm bethivions. Sciened 264, 1733-1739.

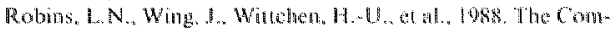
posite lnermationał Dingnosic Intervew. An epidemologi-

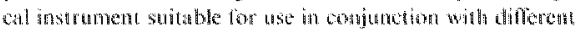

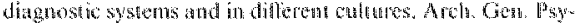
diatey $45,10691077$.

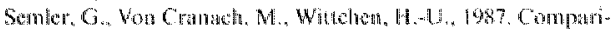
son between the Conposite haternational Dingetosic Inter view and the Present State Examination. World Hestill Organisallion, Geneva. Report to the WHOMDAMHA nask force on instument development.

Streers, R.M.W. Dingemsns, P.M.A.J. 1993, Compositio Internationat Diagnostic Interwiew (CDD) Vense 1.1. Worlat Heallh Organisation, Ansterdam/Getueva.

Spiczer, R.L. Willitms, I. B., Gibbon, M. an at.. 1982. "the Structured Clinich Laterview for DSM-III-R (SCD). 1: His-

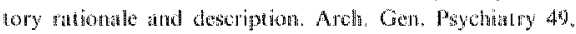
624-629.

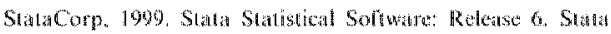
Corporntion, College Stintion, TX.

Statuss, J.S. 1969. Hatlucinations and delusions at poins on

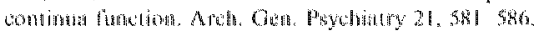

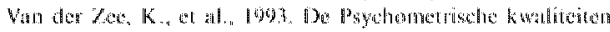

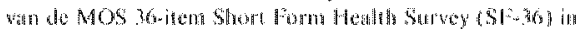

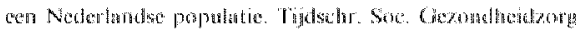
$71.183-191$

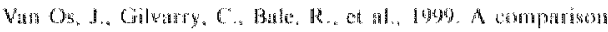

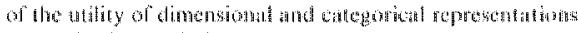

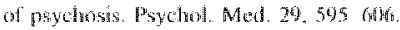

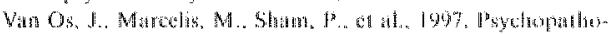

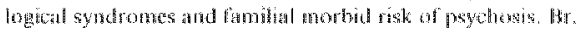
1. Paychistiry 170, 241 246.

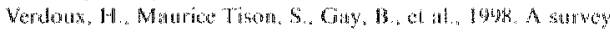

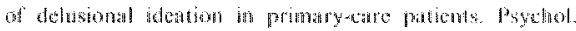
Mcd. 28, 12\%134.

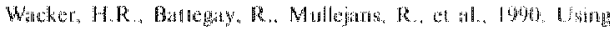

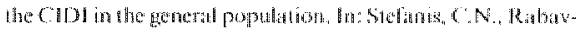

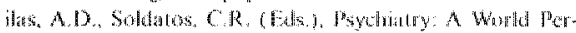

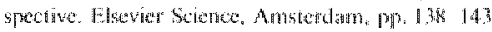

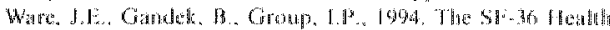




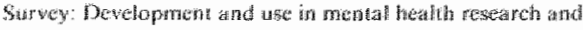

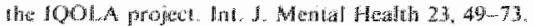

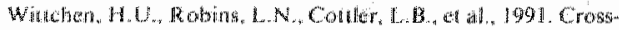

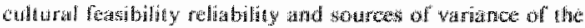

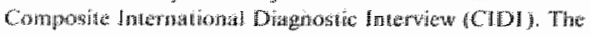

Multomute WHOADAMHA Fich Trials. Br. D. Psychiatry $139.645-653$.

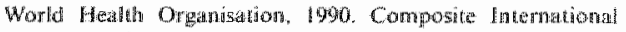
Diagnostic Interview (ClDI) Wersion 10 . World Heallh Organisation, Genced. 


\title{
CHAPTER 3
}

\section{Evidence that three dimensions of psychosis have a distribution in the general population}

\author{
N.C. Stefanis \\ M. Hanssen ${ }^{2}$ \\ N. K. Smimis \\ D. A. Avramopoulos" \\ I. K. Evdokimidis \\ C. N. Stefanis \\ H. Verdoux ${ }^{3}$ \\ J. $\operatorname{van} \mathrm{Os}^{2.44}$
}

1 University Mental Health Research Institute (UMHRD), Athens, Greece

2 Department of Psychiatry and Neuropsychology, South Limburg Mental Health Research and Teaching Network, EURON, Maastricht University, Maastricht, The Netherlands

3 Department of Psychiatry, University Victor Segalen and Hôpital Charles Perrens, Bordeaux, France

4 Division of Psychological Medicine, Institute of Psychiatry, London, United Kingdom 
44 CHAPTER 3 


\title{
Evidence that three dimensions of psychosis have a distribution in the general population
}

\author{
N.C.STEFANIS, M.HANSSEN, N.K.SMIRNIS, D.A.AWRAMOPOULOS \\ I. K. EVDOKIMLDIS, C.N.STEWANIS, H. VERDOUX, ANDJ. VANOS
}

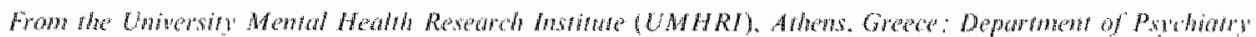

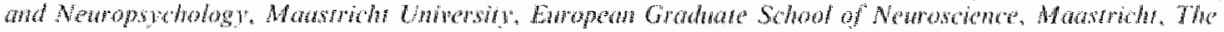

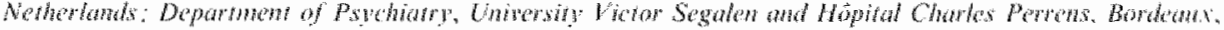

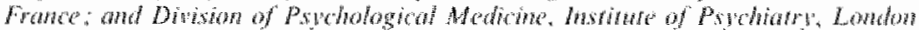

\begin{abstract}
Background. The aims of the study were: first to examine, using clinical symptoms of patienis as a template, whether the correlated but independent dimensions of posilive, negative and depressive symptoms that have been identifed in clinical psychosis, also have a distribution as non-elinical experiences in the general population; and second, to establish to what degree population variation in experience of positive and negative features of psychosis is actually independent of experience of depression.
\end{abstract}

Method. In a representative population sample of 932 young men, we measured experiences of positive, negative and depressive features of psychosis, using a 40 -item self-report instrument. Confirmatory factor analysis was used to compare the fit of hypothesized one-, two- and threefactor solutions.

Results. A three-factor model of separate depressive, positive and negative dimensions provided a better fit to the data than either a two-factor or unidimensional model. All three dimensions were correlated with each other, but also showed good discriminant validity in relation to established sales, confirming their relative independence.

Conclusion. The data suggest that the correlated dimensions of clinical psychosis also have a distribution in the general population, and that depressive symptoms may form an integtal patrl of psychosis-like experiences in the general population.

\section{INTRODUCTION}

A substantial body of research suggests that the symptoms of patients with psychotic disorder's show replicable patterns of correlation with each other. Multivariate analyses of psychotic reatures have consistently yielded clusters of positive, negative and disorganization symptoms, not only in patients with schizophrenia (Bilder et al 1985; Liddle. 1987; Peralta ef al. 1992, 1994; Grube ef al. 1998), but also in patients with schizoaffective and other psychotic disorders (Maziade el al. 1995; Peralta et at.

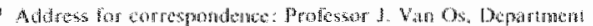

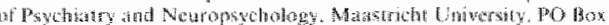

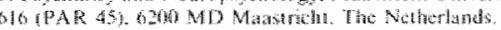

1997; Ratakonda at al. 1998). As aldective symptoms tended to be excladed from these first generation symptom-analytical studies even though they form an integral part of schizo. phrenia and other psychotic syndromes (Soni ${ }^{\text {at }}$ al. 1992; Sax el at. 1996), more recent andeavoum that were less biased by Kraepelinian concens of dichotomizing affective and non-affective syndromes, included depressive and manto symptoms. These investigations yirtded additional dimensions of depressive and manic/ excitement symptoms but less consistent evidence of a conceptual disorganization Factor (Kitamurat et al. 1995; Lindenmayer et al. $1995 a, b$; McGorry ed al 1998; Van Os at al. 1999a). 
Most studies used multwariate techniques where orihogonality was imposed on the factorial solutions, producing uncorrelated symp tom dimensions. However, zeromcotrelition of symptom dimensions strans reality for ckample, positive and negative symptoms tend to co-occur logether), and studies using statistical lechniques which allowed for correlation between factors did find that the various symptom dimensions covaried with each other (Peralla el al. 1994; Peralla \& Cuesta, 1998). The dimensional representation of the psychosis phenotype therefora suggests that psychosis is the simultaneous variation of up to five distinet, albeit correlated, symptom dimensions.

The dimensional representation facilitates the view that psychosis is a quantitative trait, the distribution of which may well extend into the general population. Just as there is evidence that suggests that the depression phenotype may exist as a continuous distribution of symptoms in the population (Anderson ef at. 1993; Whittington \& IHuppert, 1996; Kendler \& Gardner, 1996), the symptom dimensions of psychosis may similarly be measurable in the general population (Johns \& Van Os, 2001). Broadly, two approaches can be distinguished. The first approach is to measure in the general population the satne symptoms that are seen in patients with psychotic disorders. The implicit assumption of this approach is that experieneing "symptoms" of prychosis such as delusions and thatlucinations is not inevitably associated with presene of disorder. The latter may be dependent on symptom factors such ats intrusiveneas. frequency and co-morbidity of symptoms on the one hand, and personal and cultural factors such as coping illness behaviour, societal foleranes and the development of functional imparments on the other. Thus, ever though the prevalence or the clinatal disurder is low, the previtence of the symptoms can conceivably be much higher. The second approach is different, and assumes that in the subudisorder range Along the continumm. the expression of the trit is atlonuated and lakes on the form of "schizotypal" signs and symptoms. Sudies using various measures of schizotypy have proposed two or three factor solutions resembling thase of schizophrenia excluding affective symptoms. Thus, symptom factors resembling positive, negative and conceptual disorganization dimensions have been reported by several authors (Bemtall et al. 1989: Raine et al 1994; Venables \& Bailes, 1994; Williams, 1994: Vollema Van den Bosch, 1995; Claridge et at. 1996: Gruzelier. 1996). However, several questions remain to be answered. First, although measures of schizotypy are strongly associated with neuroticism and depression in crosssectional, longitudinal and family studies (Chapman ef af. 1980, 1994; Schulz et al. 1986: Allen el al 1987; Lenzenweger \& Loranger. 1989; Tien ef al 1992; Torgersen el al. 1993; Corruble et at. 1996: Kaney et at. 1997; Kwapil et at 1997; Hafner et al. 1999; Verdoux ef al. 1999), measures of affective sympioms have universally been excluded from schizotypy scales. It is thus not known whether variation in positive and negatiwe psychosis-like expertences are in fact an expression of depressive symptomatology, or co-vary with depression. Previous work suggesis that the expression of experience of positive symptoms of psychosis is dependent on the level of depression (Van Os et at. 1999 b). In the current study, therefore, experiences of depression were measured smultaneously with other dimensions. A second issue is that the schizotypy scalles do not always cover the type and range of experiences seen in clinical patients, making it difficult to compare patients with individuals in the general population. It has been shown, for example, that schizotypy scales measuring delusions tend to bo incomplete (Peters ef $a$. 1999). For the current study, a diferent approach was therefore adopted, based more on the measurenent of the psychotic symptoms themselves rather than the hypothesized attanuated experiences.

Peters and colleagues recently developed and validated as selfreport instrument to measure delusional ideation (scored dimensionally) in the general population (Peters ef al 1999). Contrary to scules measuring schizotypal signs and symptoms, the PDH measures are directly based on clinical dethsions as described in the Present State Examination, 9th Edifion, covering the range of delusional experiences (Wing et al. 1974) and scoring them dimensionally. The face validity of the iterns is ensured by keeping as close as possible to the form of questioning suggested by the PSE, but most questions are 
toned down by adding "ats if" to the questions (for esample: "Do you ever feel as, if electrical devices such as computers can influence the way you think?). The 21 -item version of the scale. with three additional itens on hallucinatory experiences, has been used in population-based research (Verdoux ef al. $1998 a$; Van Os ef al. 1999 b). The current study was designed to test the hypothesis that seweral distinct, but correlated dimensions of psychosis can be identified in the general population. To this end, items tapping into other symptom dimensions were added to the PDI, again using clinical symptoms seen in patients with psychotic disorders ats reference. As self-report measures were used in order to obtain a large enough population sample size for the multivariate analyses, no attempt was made in this study to measure dimensions of mania and conceptual disorganization, since these measures are much less likely to be reliably captured by self-report instruments in the general population (Rodgers \& Mann, 1986; Vollema, 1999). This study therefore focused on the three dimensions of positive, negative and depressive symptoms. Confirmatory lactor analysis (CFA) without imposing orthogonality was used to test statistically the tenability of the specified threefactor population dimensional model, in comparison with models of two dimensions or a single undifferentiated dimension. The twodimensional model used in this study was based on the hypothesis that what is measured by "negative symptoms' in the general population is in fact the expression of an underlying dimension of depression. Thus, the twodimensional model consists of a positive and a depressive factor. The exclusion of at single undiflerentiated psychopathology factor underlying seemingly different sympiom dimensions in the general population is particularly im. portant. For example, recent investigations of childhood psychopathology across very large population samples found that the existence of up to cight dimensions of child problem behaviour derived from exploratory factor analysis of the Child Behaviour Checklist (Achenbach et al. 19891 were not supported by cmpirical data using CFA. In fact, support was found for one undifferentiated factor explaining a large proportion of the co-variation of all symptoms
(Greenbaum \& Dedrick. 1998: Hantman ef ad. 1999).

\section{METHOD \\ The CAPE}

The basic ingtrument used was the PDI-21, with some modifications and additions. First, items on religious delusions were omitted becanse of concerns that it might confuse religious study subjects. Secondly, some items that subjects in previous investigations had reported to be anbiguous were omilud or rephrased (Verdoux ef at 1998 b). Thirdly. two items on auditory hallucinations were added. Finally, each item required ticking only two dimensional scales (compared with one dichotomous presence/ absence item and three dimensions of conviction, preoccupation and distress in the PDI): the first scale on the frequency of the experience on a four-point scale of "never", "sometines" "often" and "nearly always" to anoid "ticking the midde box" bias), the second scale on the degree of distress (" not clistressed" "a bit distressed". "quite distressed" and "very distressed"). The reduction to only two dimensions of rrequency and distress per symptom was introduced as previous research with the PDI-2l in a large general population sample (Verdoux et al. 1998 b) had shown that individuals in such at sample fail to consistently rate three different scales per symptom, so that in practice only the first presence/ absence scalle can be used in the allatlyses witli loss of dimensionut information. A totat of 18 items of posilive psyctootic symptoms was used.

Fourteen items on negative symptoms were added to the PDI. These items were derived, where possible (not all items are suibable lor selfrepott), from the SANS (Andreasen, 1989), and an instrument of subjectwe experience of negaiive symptoms, the SENS (Selten of at. 1998) The phrasing of the questions followed that of the PDI items, and was based on the descriplions and guestions in the SANS and the SENS. Examples of items are: "Do you ever feel that you have fow or no emolions at important events?" or: "Do you ever feel that you are lacking in motivation to do things?", or: "Do you ever feel that you are neglecting you appearance and personal hygiene?" and: "Do 
you ver feet that you have no interest to be with other people?".

As some of the items that are used to measure negative symplonts are also sensitive to depression, we whed to include a number of itoms on depression that do not overlap with the items on hegative symptoms. Previous work suggests that especially cognitive symptoms of depression (e.g. sadness, pessimism, hopelessness, foeling a failure, feeling guilty), discriminate betwen depression and negative symptoms (Kibel et al. 1993). A total of eight items on depression was thus included.

The instrument with the 18 positive symptom items, 14 negalive symptom itens and eight depressive symptom items will hereafter be referred to as the CAPE (Community Assessm ment of Psychic Experiences-see: http:// cape42. homestead.com/index html). It was translated from English into Greek by consensus of three Greek-speaking psychiatrists trained in English-speaking countries. It was backtranslated by an independent professional translator. Differences between the original and backtratnslated versions were resolved by the translator and back-iranslator, followed by a small pilot involving 15 subjects after which some additional small changes were made.

\section{Sample}

The ASPIS Athens Study of Psychosis Proneness and Incidence of Schizophrenia) is an investigation of schizotypy and psychosis dimensions in newly recruited air force conscripts undergoing basic training as part of their compulsory military service in Greece (Steftris et al. 2001 ). This sample was specifically chosen as there is consistent evidence that individuats at this age are most likely to display the clinical and sub-clinical experiences of psyctuosis. thus increasing the stutisticall power (Rust, 1988 : Claridge al al. 1996; Verdoux el al. 19986 ; Peters er at 1999: Van Os el al 2000). In eight separiate waves, 1944 subjects were examined. In order to werify the degree of collaboration with the self-report seales, three test questions were added to the total intervicw package, that read, for example as follows: "please answer this question by ticking box 4 ". The 1413 individuals $(73 \%)$ who had correctly ticked the boxes on all four guestions were incladed in the analyses. The CAPE was used in the last six waves of interviews, and reports meeting the fourquestion criterion were available for 1028 individualls. Due to partial non-response, individuals with non-missing responses on all 40 items were 932 for the frequency dimensions, and 876 for the distress dimensions.

\section{Analyses}

It is possible to test predictions of patterns of clustering of the experiences of psychosis using CFA. For hypothesis testing purposes, CFA is superior to exploratory factor analysis (EFA), which identifies possible factors that account for co-variation among items in a sample, but may only give a very rough idea of true underlying dimensions in the population (Bollen, 1989; Byme, 1989). In CFA, predicuions can be examined by relating the hypothesized symptom dimensions to empirical data in a factor analytical model. According to this model, the unobserved symptom dimensions are constructs, or latent variables, that cannot be studied directly. However, they may be studied indirectly through individual symptoms that can be considered as their indicators. The factor analytical model assumes that the latent variables account for the co-variation between the observed variables. The gap between observed symptoms and latent symptom dimensions can thus be bridged by analysis of the co-variance between the observed symptoms. This analysis makes it possible to ascertain the extent to which the hypothesized symptom clusters that are thought to be indicative of underlying latent dimensions are consistent with the covariance structure in the datia. The hypothesis of the current investigation was that a model of three distinct but correlated dimensions would be more consistent with the data than: ( $)$ a model of two dimensions where depressive symptoms are not distinct from negative symptoms, leaving two dimen. sions of negative/depressive versus positive symptoms: and (ii) a uni-dimensional model where positive, negative and depressive symptoms in the general population are not separable from each other and can thus be seen as indicators of the same undifferentiated psychopathology dimension.

CFA was carried out using MPLUS (Muthen \& Muthen, 1998). In CFA. three parameters are ofinterest. The first concerns the factor loadings. or the extent to which the observed symptoms 
are related to the latent dimensions. The second is the cowariance between the common factors. or the extent to which the latent dimensions are related to each other. The third regards the unique factors of the observed symptoms, or the degree to which the obserwed symptoms contain variance that is unrelated to the latent dimensions (measurement error). With these iluree parameters, an estimated covariance matrix of the observed symptoms can be constructed. The values of the three parameters, which are unknown, are estimated such that the estimated symptom covariance matrix is as close as possible to the observed symptom covariance matrix. If the estimated covariance matrix is close to the observed co-variance matrix, the model is said to fit the data well. The model fit is most commonly evaluated with the maximum likelihood method yielding a chi-square test statistic. The smaller the chi-square statistic, the more the estimated and observed covariance matrix are consistent with each other. "The chisquare test statistic of different models can be compared with each other, in order to establish which one provides the best fit. If the models that are being compared are not nested in each other (one. two or three-dimensional models of psychotic symptoms are not nested in each other) direct comparisons of the chi-squared goodness-of-fit index of the different models is not possible. A common procedure is then to modify the difference in chi-squared goodnessof-fit index of the models to take account of the number of free parameters in the model as an indicatitor of the degree of parsimony of the model. One popular index is the Akake information criterion $(A \| C)$, the model with the lowest AIC being considtered as the best compromise between goodness-of-fit and parsimony (Sham, 1998).

While indices derived from the chi-square statistic are useful for the comparison of the fit of several competing modets, it is not, ance the model that is most consistent with the datat has been selected, necessarily a good measure of how consistent this model actually is with the observed data, especially in large samples. This is because large samples lead to large chi-square values, which may result in false rejection of the model. In addition to the chi-square statistic, several other indices of goodness-of-fit can be used that are less biased by sample size. The
RMSEA root mean square error of approximation (RMSEA) allows for the description of discrepancy between the hypothesized model and the observed data, corrected for the size of the model. Ii therefore can more easily accommodate acceptance of the model that the sample size-sensitive fit of the chi-square statistic (Heck, 1998). An RMSEA value of 0.05 or less has been proposed as indicative of reasonable on between model and data (Browne \& Cudeck. 1993). In order to examine whether any results would be dependent on a small number of individuals with high values on alll dimensions who might really be cases of clinical psychosis, a sensitivity analysis was conducted excluding the individualls with the $25 \%$ highest scores on the SCL-90 Paranoia seale and the SCL-90 Psychosis subscale

\section{Validity analyses \\ Discriminam walidity}

In order tio assess whether the CAPE discriminates between dimensions of posivive, negative and depressive symptoms its purported, the following andlyses were conducted. First, we selected several established self-report scales measuring these dimensions. For depression we used the Depression scale of the Symptom Checklist-90 (SCL-90; (Donias et al. 1991)); for the posiltive symptoms we used i) the Perceptual Aberration Scale (PAS; (Chapman ef al. 1978), which is very strongly associated with the Magical ldeation Scale (Chapman \& Chapman, $1987)$ and ii) the SCL-90 Puranoia subscule (included becauge the PAS does not contain items on paranoid ideation); for negative symptoms we used the Social Isolation and filat Afreet subscales of the Scluzolypal Personality Questionaire $\left(\mathrm{SPQ}^{2} \mathrm{Q}\right.$; (Raind, 1991). All subjects ratod themselves using thesc scales in the same session during which they filled in the CAPE. Wo hypothesized that: (i) the CAPE depression dimension would show the strongest association with the SCL-90 Depression subscale; (ii) the CAPE negative symptom dimension would show the strongest association with the SPQ scales Social Isolation and Flat Affect: and (iii) the CAPE positive dimension would show the strongest association with the PAS and the SCL. 90 Paranoia subscale. In order to test these hypotheses, a multivariate regression procedure was carried ont in STATA version 6 (STATA, 
1999). Mufivariate regression differs from mulliple regression in that several dependent wariables (in this case: PAS, SCL-90 Paranoia subscale, $\mathrm{SPQ}$ scales and $\mathrm{SCL}-90$ Depression scale) are jointly regressed on the same independent variables (in this case: CAPE positive. negative and depressive dimension scores). The individual coefficients and standard errors produced in multivariate regression are identical to those that would be produced by multiple regressilon, but the difference is that multivariate regression allso estimates the between-equation co-variances, so that coefficients across equations can be tested. Thus, multivariate regression allowed us to directly test, for example, the null hypothesis that the coefficient of the regression of the PAS on the CAPE positive dimersion score did not differ from the coeficient of the regression of the PAS on the CAPE negative dimension score. In order to remove scale difference, CAPE positive, negative and depression scores were expressed as units standard deviation (standardized scores).

\section{Distress validity}

In order to establish the clinical validity of the positive, negative and depression dimensions of the CAPE, we tested for associations between the frequency and distress scates for each irem. We bypothesized that for each iten, higher reported lrequency of the experience would not be neutral, as evidenced by lange and significant correlations with measures of distress.

\section{RESULTS}

\section{Comparison of onem, fwo- and three-dimensional} models of psychopathology

The anatlyses suggestad that for the items of the CAPE, scored in terms of rrequency of occurrence, a three-factor model provided at better fit to the data than the other two models. The unidimensional model provided the poorest fit (Table 1). The RMSEA showed a similar pat. tern, the three-dimensional model giving the lowest RMSEA (0.045), which suggests that the model is reasonably close to the data. Given reports that non-bizarre and bizarre positive psychotic symptoms maty appear as separate factors in clinical samples (Cardno ef al. 1999; Van Os et al. 1997a), we tested a four-factor model with a separate dimension of bizarre, "first rauk" psychotic experiences (passivity experiences, thought insertion, thought broadcasting, thought withdrawal, thought echo, voices conversing with each other, electrical devices influencing the thoughts of the person). This model did not provide additional improvement of fit over the three-factor model $(\mathrm{AIC}=6582 \mathrm{I}, \mathrm{RMSEA}=0.045,95 \% \mathrm{CI} 0043$, 0.047) and could therefore be rejected on grounds of parsimony. The sensitiviy analysis with exclusion of the $25 \%$ bighest scorers on the SCL 90 Paranoia and Psychosis subscales revealed a similar pattern of results (one factor, $\mathrm{AlC}=33207, \mathrm{RMSEA}=0.055,95 \%$ CI 0.052 , 0.059 ; two factors, $\mathrm{AIC}=32583$, RMSEA $=$ $0.048,95 \%$ CI $0.045,0.051$; three factors. AIC $=32506, \quad$ RMSEA $=0.046,95 \%$ CI 0043 . $0049)$.

As expected, the dimensions co-varied with each other, with correlations between the three dimensions in the range of $0 \cdot 7$, indicating that variation in one dimension explains anround $50 \%$ of the variance in another (positivenegative correlation $r=0.67$; positivedepressive correlation, 0.72 ; negative-depressive correlation, $0-72$ ). In onder to examine whether the correlations between depression on the one hand, and experiences of positive and negative symptoms of psychosis on the other were simply the result of feelings of distress associated with

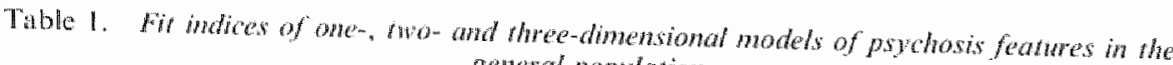
general popallation

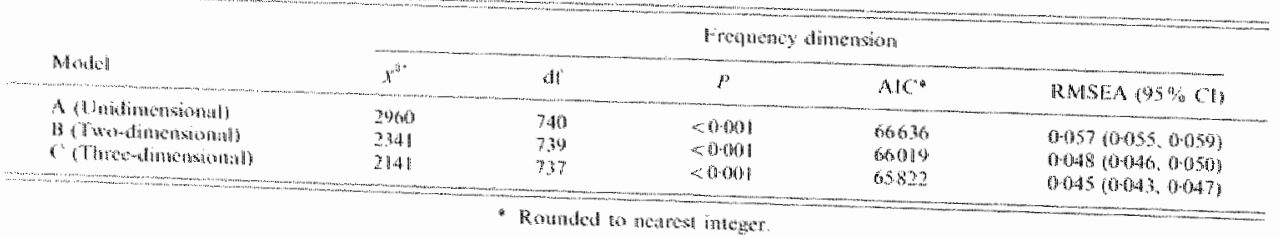




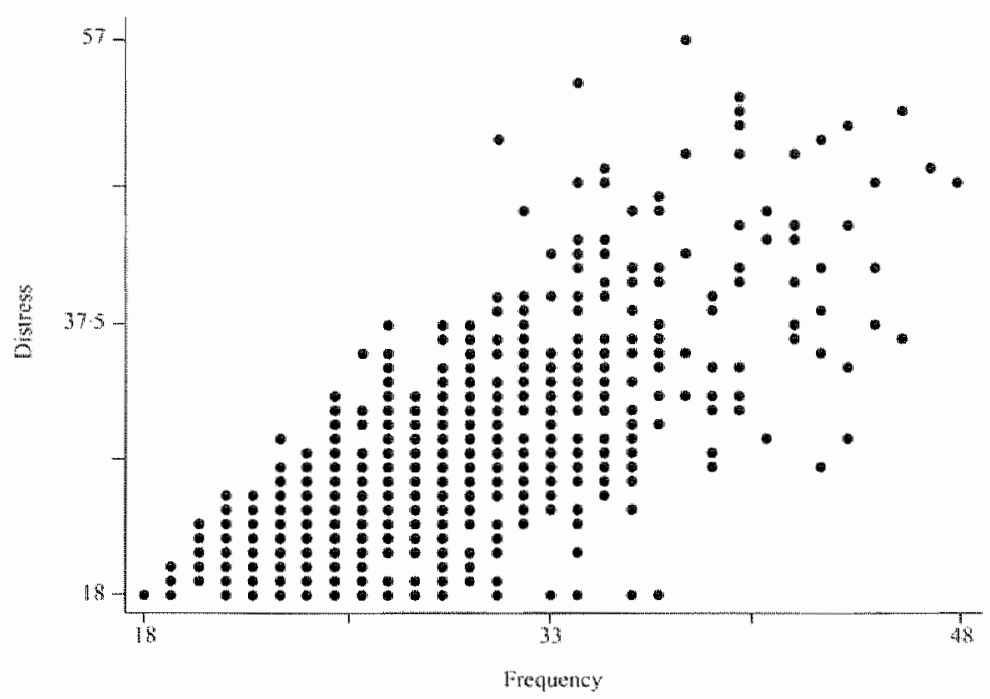

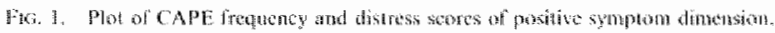

Table 2. Testing for differensial contributions of CAPE dimensions to measures of positiv (POS), negative (NEG) and depressive (DEP) symproms

\begin{tabular}{|c|c|c|c|c|c|}
\hline \multicolumn{2}{|c|}{ Vartrublales } & \multirow[b]{2}{*}{ Codilician ( $95 \%$ CD) } & \multicolumn{3}{|c|}{ 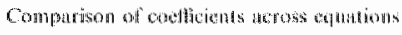 } \\
\hline Indtopenden & Cyapendent & & Syinploms & $f(4,804)$ & $y$ \\
\hline PAs & 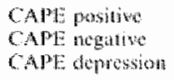 & 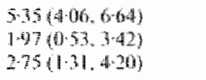 & $\begin{array}{l}\mathrm{POS}=\mathrm{NEC} \\
\mathrm{POS}=\mathrm{DEP}\end{array}$ & $\begin{array}{l}915 \\
545\end{array}$ & $\begin{array}{l}00126 \\
0020\end{array}$ \\
\hline SC1-90) Pinnamolat & $\begin{array}{l}\text { CAPE positive } \\
\text { CAME negative } \\
\text { CAle doprosioge }\end{array}$ & 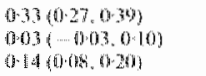 & $\begin{array}{l}\mathrm{POS}=\mathrm{NEC} \\
\mathrm{POS}=\mathrm{DEO}\end{array}$ & $\begin{array}{l}38.5 \\
1545\end{array}$ & 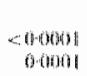 \\
\hline SE L Do Deprosion & 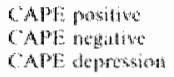 & 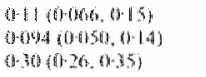 & 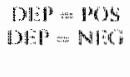 & $\begin{array}{l}3254 \\
23\end{array}$ & 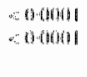 \\
\hline SPQ Sacial fonglaten & 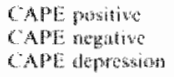 & 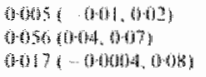 & 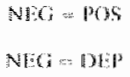 & 64 & $\begin{array}{l}0.6012 \\
0.012\end{array}$ \\
\hline 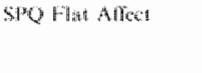 & 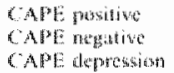 & 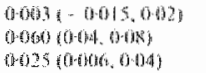 & $\begin{array}{l}\mathrm{NHA}=\mathrm{MOS} \\
\mathrm{NHO}=\mathrm{DF}\end{array}$ & $\begin{array}{l}146 x \\
402\end{array}$ & (1) 64045 \\
\hline
\end{tabular}

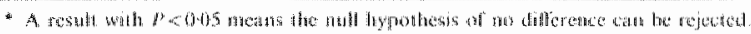

experiences of positive and negative symptoms. of psychosis, partial correlations were calculated. Thus, when distress associated with positive symptoms was held constant, the partial correlation between positive and depressive experiences was reduced but remained significant $(r=0.25, P<0.0000)$. Similarly, when distress associated with negative symptoms was held constant, the partial correlation between negatlive and depressive experiences was reduced but remained significant $(r=0.41 ; p<0.0001)$.

\section{Correlation between frequency and distress}

The mean Pearson correlation coefficien be* tween the dimensions of frequency and distress was $0.71(5, \mathrm{D} .=0.16$, range $0.27-0.94)$, and was 
of similar magnitude for the three hypothesized dimensions (depressive symptoms, 0.74 ; negative symptoms, 0.73 ; positive symptoms, 0.67). The lowest correlations were for the positive symptom items with a grandiose content: "Do you ever feetl as if you are destined to become someone very important?' $(r=0.27)$ and "Do you ever feel that you are a very special or unusual person?" $(r=0.32)$. Inspection of the graphical plots of measures of frequency and distress suggested a linear, dose-response pattern of association. An example is given for measures of frequency and distress of the prositive symptom dimension in Fig. 1 .

\section{Discriminani validity}

The associations between CAPE dimensions of posilive, negative and depressive experiences of psychosis and established scalles measuring these symptorns confirmed the hypothesized pattern. Thus, the CAPE positive symptom score displayed stronger associations with the PAS and the SCL-90 Paranoia subscale than the negative and depression scores; the CAPE negative symptoms score displatyed stronger associations with the SPQ negative symptom scales, and the CAPE depressive symptoms scone displayed stronger associations with the SCL-90 Depression scale (Table 2).

\section{DISCUSSION}

The two starting points of this investigation were: (i) to examine to what degree vartation in positive and negative dimensions of pyychosis is independent of experience of depression; (ii) to examine, using clinical symptoms of patients ats a template. whether the correlated but independent symptom dimensions of psychosis have at distribution in the general population. In a population sample of 932 young men in the age range most at risk of psychotic experiences. there was avilence for the existence of three independen yet correlated dimensions of experiences resembling the main symptom dimensions of psychotic illness that are encountered in dinical samples: depression, negalive symptoma and positive symptoms. These factors were not occasioned by a few individuals with very high levels of psychotic experiences and with possible psychotic disorder. Frequency of occurrence of the experiences was strongly associated with level of distress, whth the exception of experiences of grandiosity. The instrument used to simultaneously assess positive, negative and depressive experiences of psychosis showed discriminan validity with established scales, and again suggested relative independence of measures of depression in relation to experience of positive and negative features of psychosis.

The findings suggest that the symptoms of psychosis have a distribution in the general population, and that psychosis can be seen as a continuum of variation in several correlated symptom dimensions. Although the respondents were healthy subjects, the fact that frequency and distress were associated with each other in a linear, dose-response fashion, suggests that the frequency measures used are not entirely neutral clinically. Thus, it is possible that higher frequency of occurrence will facilitate help-seeking bellaviour, eventually resulting in patient status. (Johns \& Van OS, 2001).

The fact that dimensions of positive, negative and depressive experiences of psychosis were correlated, parallels the situation in clinical samples. However, the correlations of around 0.7 between the three dimensions are larger than those in CFA analyses in clinical samples, where reported correlations are in the order of $02-0.6$ (Peralta et al. 1994; Peralta \& Cuesta, 1998). A likely reason for this discrepancy is that expression of symptom dimensions in the general population is much more attenuated than in clinical samples, making it much more difficult to measure them sensitively and discriminate between them. Another possible explanation is that in clincal samples, high scores on one dimension may overshadow symptoms from another. For example, in patients with very high levels of negative symptoms, co-morbid positive psychotic symptoms may be less likely to be elicited, resulting in reduced corretations between symptom dimensions. Regardless of which explanation applies, however, confirmatory factor andysis in our sample suggested a threerather than a two- or unidinensional solution fitted the data best, and the discriminant validity of the three dimensions appeared satisfactory.

The data suggest that experience of depression accompanies experience of positive and negative features of psychosis, not only in chinical samples, but also in the general population. One 
explanation may be that the distress associated with positive and negalive experiences simply generates feelings of depression. Although our data showed that was in part the case, it is wnlikely to be the sole explanation, given that when distress was controlled for associations between depression and the other dimensions remained highly significant. Work in clinical samples suggests that affective and non-affective psychotic syndromes share at least some inportant aetiological factors, as indicated by studies that suggest overlap in familinl clustering of psychosis in individuals with affective and non-sffective psychotic disorders (Kendler et al. 1993), overlap in cognitive impaiment and high levels of neuroticism prior to the onset of depression and schizophrenia (Jones et al. 1994; Krabbendam er al. 2001, Van Os et al 1997 b, 2001), overlap in cerebral ventricle enlargement in schizophrenia and affective disorder (Elkis et al. 1995) and overlap of risk functions associated with life events, ethnic group, prenatal famine, urban birth and having a relative with depression (Bebbington er al. 1993; Maier et al. 1993; Van Os et al. 1996; Marcelis et al. 1998; Brown et at. 2000 ). Sharing of some areas of risk would be a plausible explanation of correlated symptom distributions, at leasi in clinical samples. It is attractive to speculate that the same shared risk factors that cause the co-occurrence of depressive and non-affective experiences of psy. chosis at the clinicall level, are also involwed in the co-occur rence of the subclimical experiences. This would in lact a mount to the view that there is continuity between correlated dimensions of psychosis at the clinical and the subclinical level. This hypothesis is supported by the fact that, at least as far as the experience of positive symptoms is concerned similar neuropsychological abnormalities and a similar patiem of demographic and risk factor associations is apparent for the clinical and subchimial manifestations (Rust, 1988; Lenzenweger et al. 1991: Lyons el al. 1991; Claridge et al. 1996: Voglmaier et al. 1997; Chen ex al. 1998; Verdoux et al. 1998 b; Peters et al. 1999; Van Os ed al. 2000). Tt is also supported by population and twin studies suggesting that depression exists in nature as a distribution of symptoms rather than a dichotomously defined disorder (Anderson et al. 1993; Whittington \& Huppert, 1996; Kendlet \& Gardner, 1998), with similar emerging evi- dence for positive symptoms of psychosis (Van Os ef al. 2001). While such an inferpretation of the data remains speculative, it may nevertheless. prove useful to further examine the experiences of psychosis atong these lines.

The results should be interpreted in the context of several limilations. First, only three dimensions of psychosis were considered suitable for inclusion in the self-report scale. Howewer. the positive and negative dimensions are considered the two most robust non-affective symptom domains, and depression is the most common affective sympton domain in psychosis. Nevertheless, it remains necessary to also collect interview data including items on the mania and disorganisation dimensions. Secondly. our findings are based on self-report data, which inevitably results in more misclassification and therefore yields less precise results, especially in the case of psychotic symptoms. Therefore, replication with interview data is necessary. Thirdly, of the origimal eligible individuals, nearly $30 \%$ was excluded because of probable non-collaboration. It is quite possible that, as a group, these excluded individuats were different from the included respondents on certain personality characteristics that are associated with experiences of psychosis. In as much as this is the case, caution should be exercised in generalizing the results to all populations of young men. Similarly, no women were included in the sample, so that the results are not necessarily applicable to this group. Fourthly. structural equation modelling sugugested that at three factor model prowided a better fit to the observed data than the other models, but this cannot be taken as proof of the existence of three dimensions in mature. Structural equation models are a test of an a priori hypothesized rellationship among variables; if these a prom assumptions atre incorrect, the model will allso be incorrect, no matter how close the resulding statistical fit. However, the thypothesis that experience of psychosis consists of villious dimensions as examed in this paper is widely accepted and has been subject to numerous empirical investigations. Fifthly, while the "ats if" approach to ask about delusionial idcation is considered suitable to assess psychotic experiences along a hypothesized continutm by some (Koehler 1979): Poters ef al. 1999), others use the "as if" experience as a qualitative cut-off 
in the assessment of delusions, the "as if" experience indicange that the ridea is not held with total convictor (sims, 1988 ). The choice of approath dopends on the purpose: in clinicul pratice a dichotomous tratment decision is necessary, in which case a qualitative cul-of point for delusional thimking may be mone appropriate, fin observational research in the general population, however, a continum apm proach may be more useful than wse of a qualitative cut-of point. Finally, we hawe used the umbrella term 'psychosis' to inchude both subalinicall experiences reported by individuals in the general poptation and chinical symptoms repoted by putients with psychotic disorders. The problem with this approach is that psychoputhological resemblance between patient and mon-patent samples does not per se constitute formal proof that clinical and subchinicat expariences form part of the same continum. However, evidence presented elsewhere suggests that, apart from poychopathological resem. blance, psychosis like experienees in the general population and psychotic symptoms in clinical samples also share risk factors, psychological mechanisms and epidemiological patterns of variation (Sharpley \& Peters, 1999; Johns \& Van Os, 2001; Van Os et at. 2001).

\section{REFERENCES}

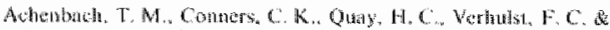

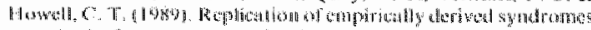

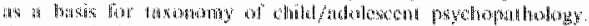

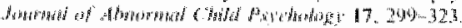

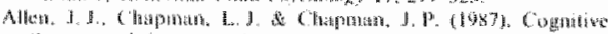

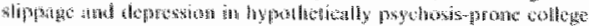

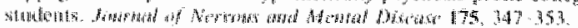

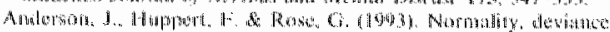

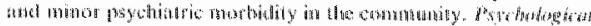

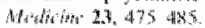

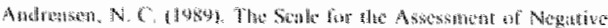

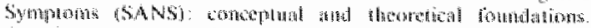

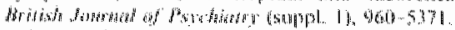

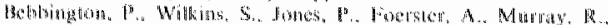

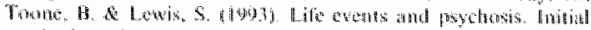

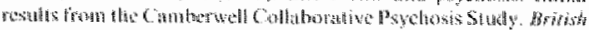

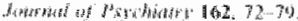

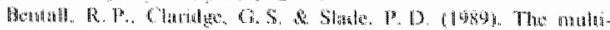

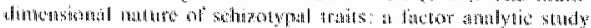

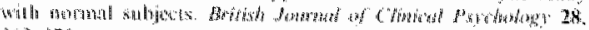
ind 175

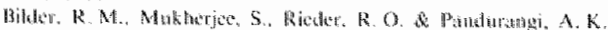

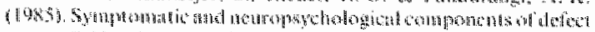

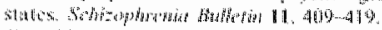

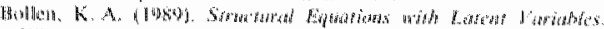

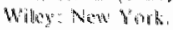

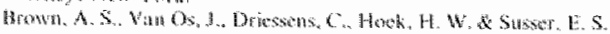

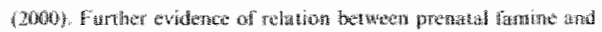

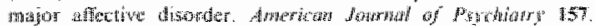
191-19s.

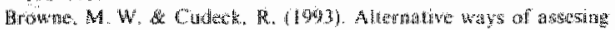

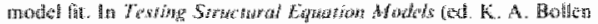

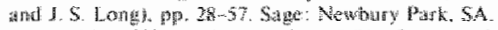

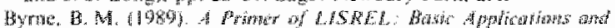

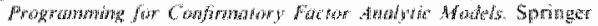
Vertag New of

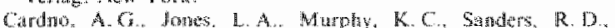

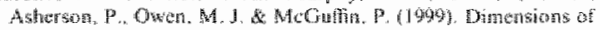

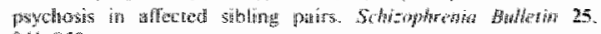
$841-850$.

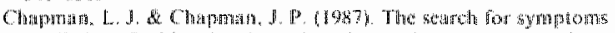

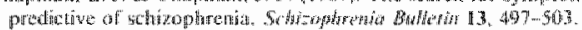

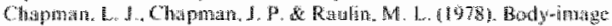

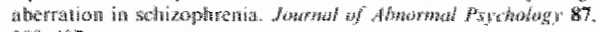
396.) -407

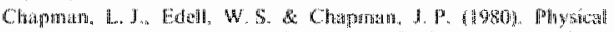

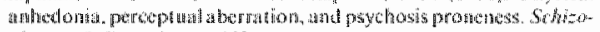

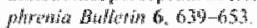

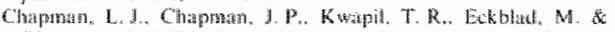

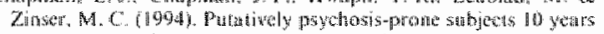

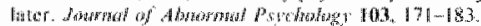

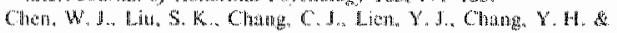

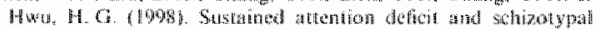

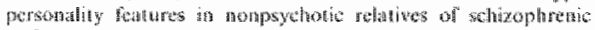

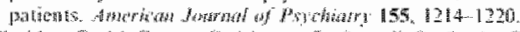

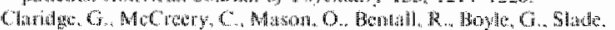

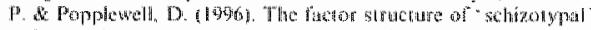

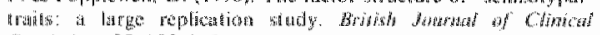

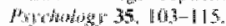

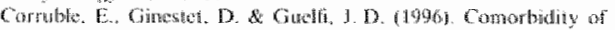

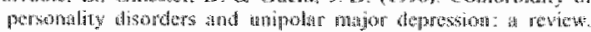

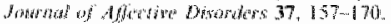

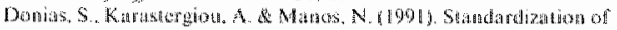

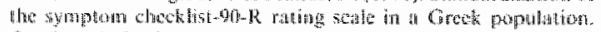

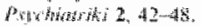

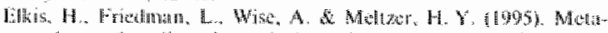

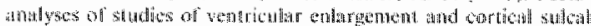

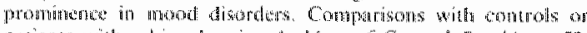

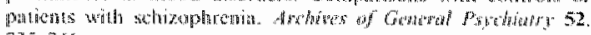
$7.5-746$.

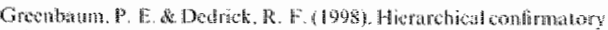

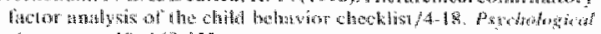
And

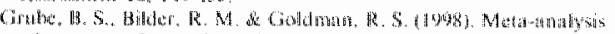

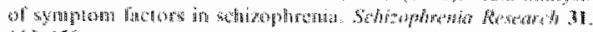
$11,4.120$

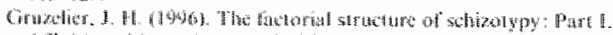

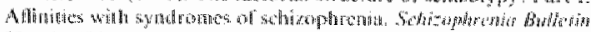
22,611020

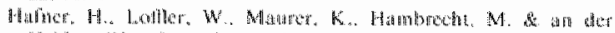

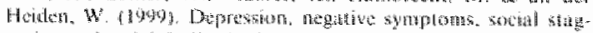

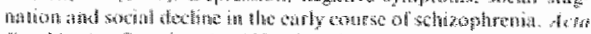

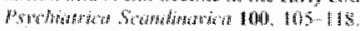

Hat?

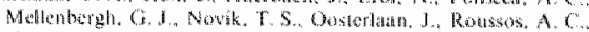

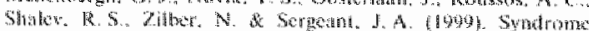

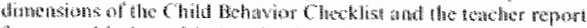

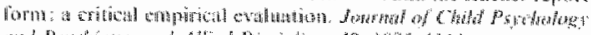

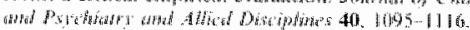

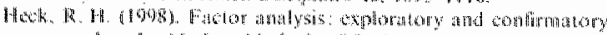

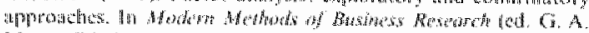

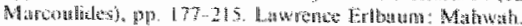

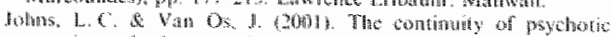

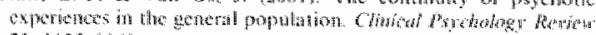
$21,1125,1141$

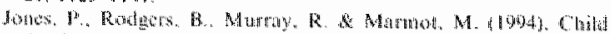

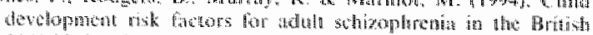
I. 


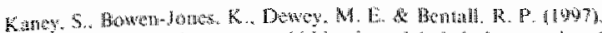

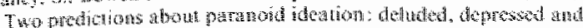

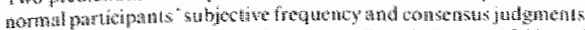

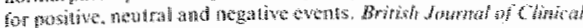

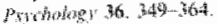

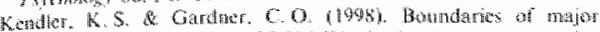
ferresion? Mhither 15\%, 17? 177

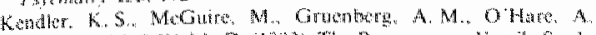

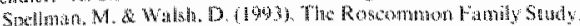

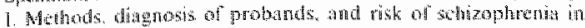

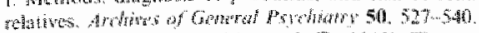

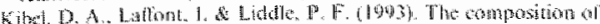

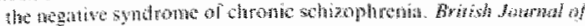
PGortate 162.744-750.

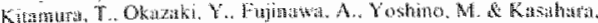

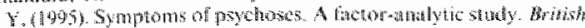

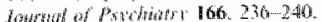

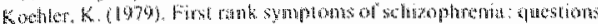

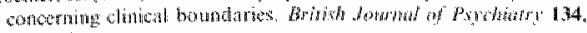
$236)-48$

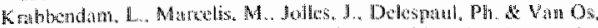

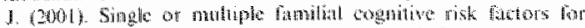

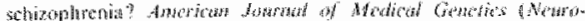

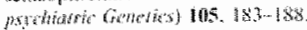

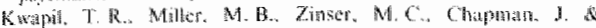

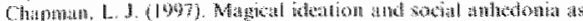

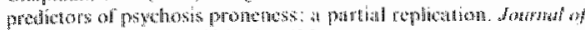

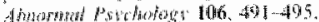

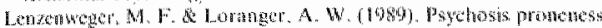

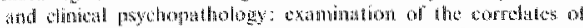

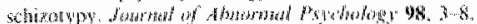

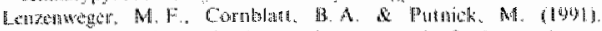

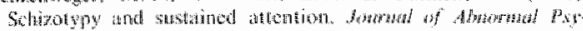

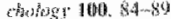

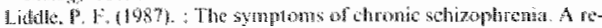

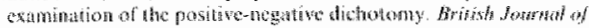
Prothorm 151. 145-151

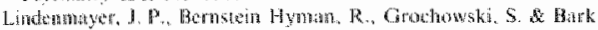

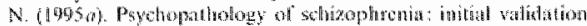

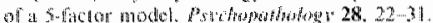

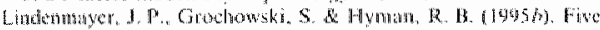

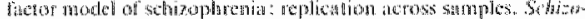

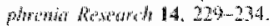

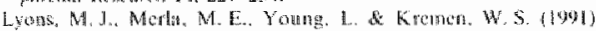

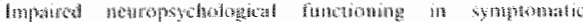

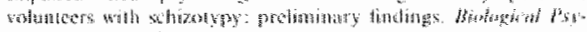

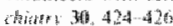

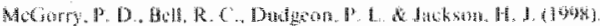

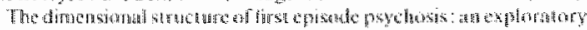

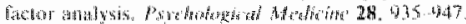

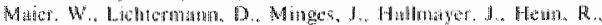

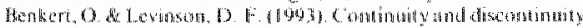

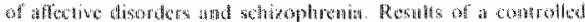

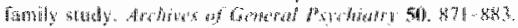

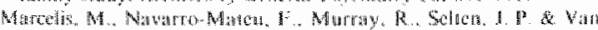

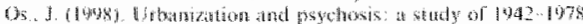

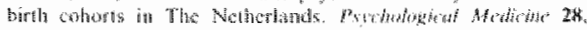
sing

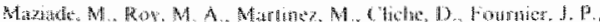

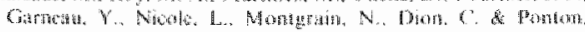

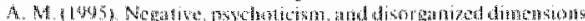

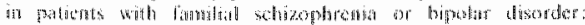

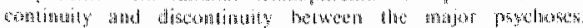

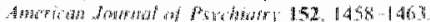

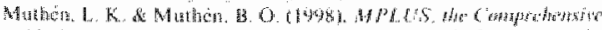

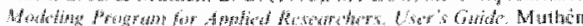

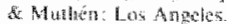

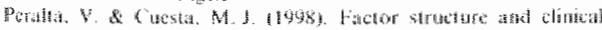

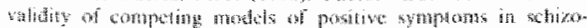
Filrewia, How

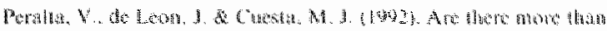

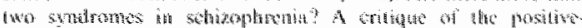

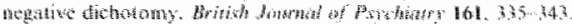

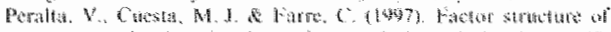

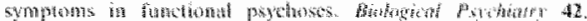
$\$ 00,465$

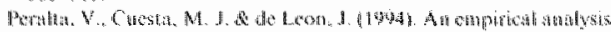

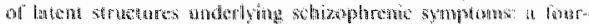

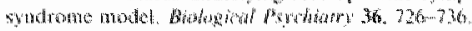

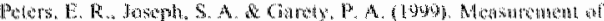

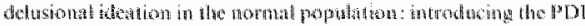

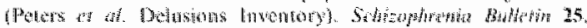
$\$ 3,3,5 \%$.

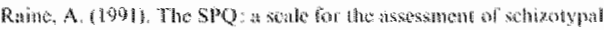

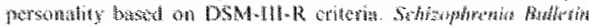
17. 585 .

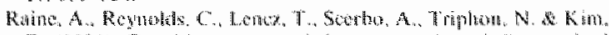

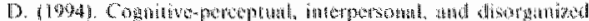

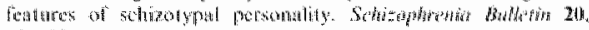
(2) $1-20 \%$,

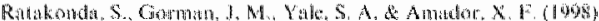

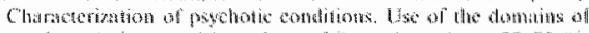

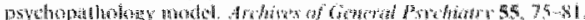

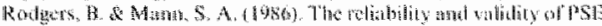

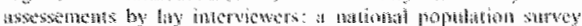

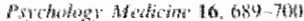

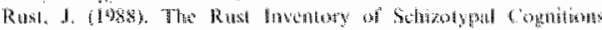

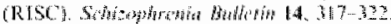

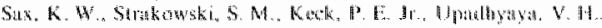

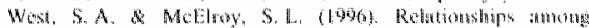
neted

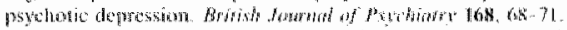

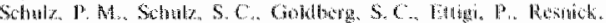

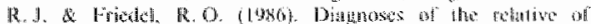

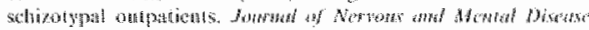
174. $457-467$

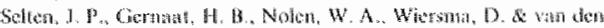

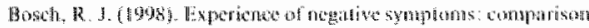

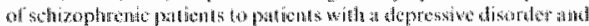

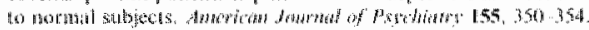

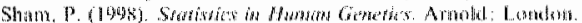

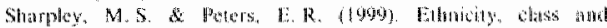

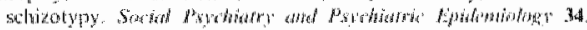
$50 \div-51 ?$

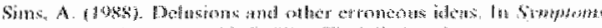

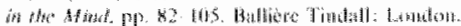

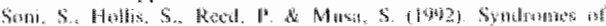

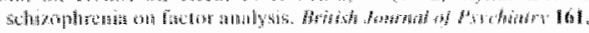
Bai $4(4)$

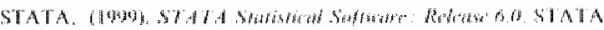

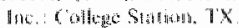

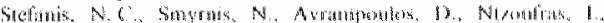

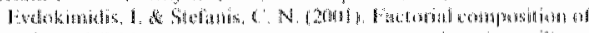

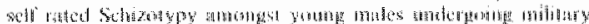

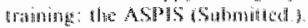

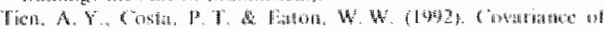

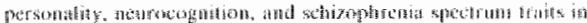

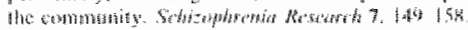

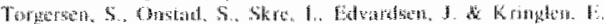

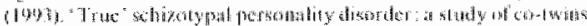

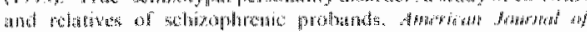

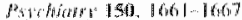

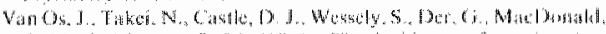

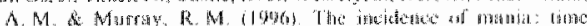

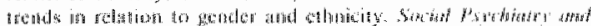

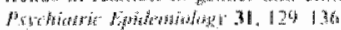

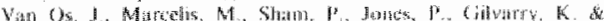

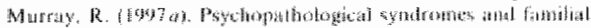

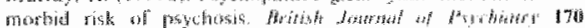
$24 \cdot 240$ 


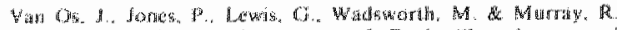

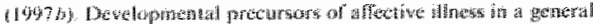

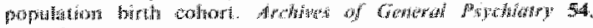
$6256 \%$

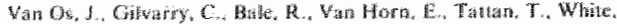

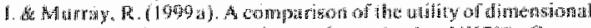

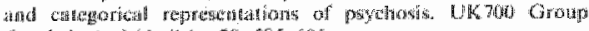

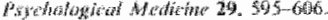

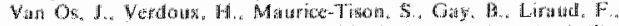

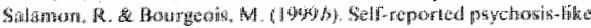

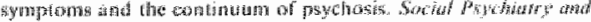

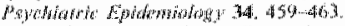

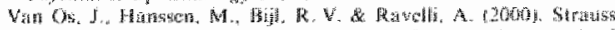

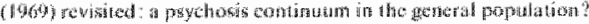

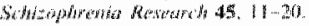

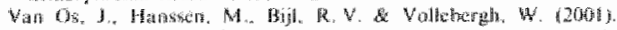

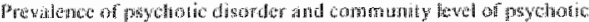

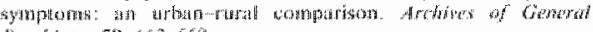

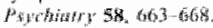

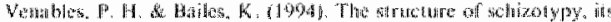

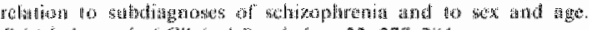

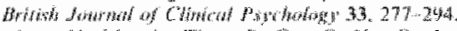

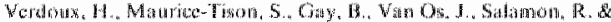

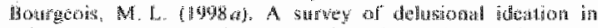

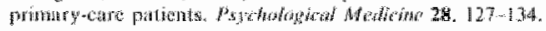

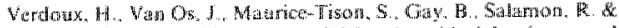

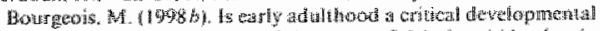

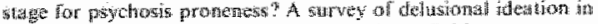

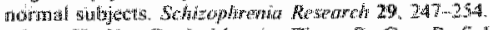

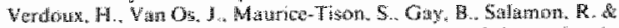
Bowrycos. M. L. (1999). Inereased oceurrenat of depression in paychors

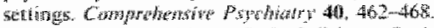

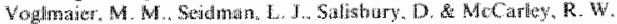

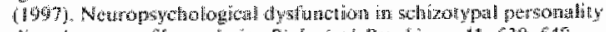

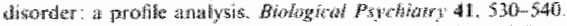

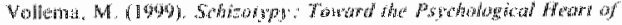

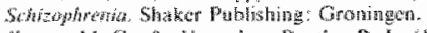

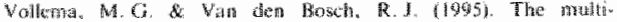

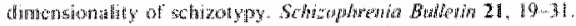

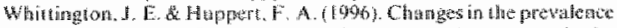

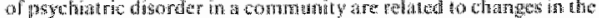

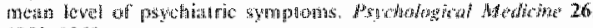
$125,-1250$

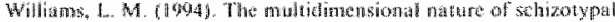

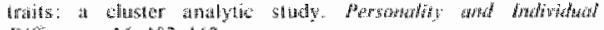
Differestes $16.603-112$

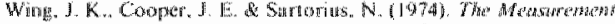

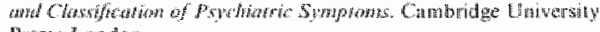
Pass: Loman. 


\section{CHAPTER 4}

\section{How psychotic are individuals with non-psychotic disorders?}
M. Hanssen"
Fi. Peeters
L. Krabbendam
S. Radstake
H. Verdoux ${ }^{2}$
J. $\mathrm{Van}_{\mathrm{Os}}^{\mathrm{ln}}$

"Department of Psychiatry and Neuropsychology, South Limburg Mental Health Research and Teaching Network, EURON, Maastricht University, Maastricht, The Netherlands

2 Department of Psychiatry, University Victor Segalen and Hôpital Charles Perrens, Bordeaux, France

${ }^{3}$ Division of Psychological Medicine, Institute of Psychiatry, London, United Kingdom 
58 CHAPTER 
M. Hanssen - F. Peeters - L. Krabbendam - S. Radstake - H. Verdoux * I. van Os How psychotic are individuals
with non-psychotic disorders?

Accepied: 31 Ockober 2002

\begin{abstract}
Background The objective of this study was to compare, using a self-report questionnaire, the dimensions of psychosis across different patient groups in a community mental healith service (CMHS) and in nonpatients in the generall population. Methods The Community Assessment of Psychic Experiences (CAPE) is a 40-item self-report instrument with positive, negative and depressive symptom dimensions. Seven hundred and sixiy-two patients and 647 subjects in the general population filled in the CAPE. In 555 of the 762 patients $_{\text {p }}$ a DSM-IV diagnosis was made. The following DSM-IV categories were used in the analyses: 1 . Schizophrenia and Other Psychotic Disorders $(n=72), 2$. Mood Disarders $(\mathrm{n}=214), 3$. Anxiety Disorders $(\mathrm{n}=129)$. The patient and non-patient groups were compared on the three dimensions of the CAPE using multivariate regression analysis. Results The patient groups scored significantly higher on the positive, negative and depres. sire dimensions than the non-patients. Patients with psychotic disorders had the greatest difference in positive psychosis itenns compared to non-patients $(\beta=0.94$, $95 \% \mathrm{Cl}: 0.7-1.18$ ), whereas patients with mood and anxiely disorders had the highest depressive symptom
\end{abstract}

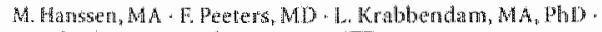

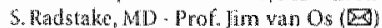

Deparatment of pspchiatry and we a ropsychology

Mastrithe Universing

POBOX 616 (DRT

$6200 \mathrm{MD}$ Midstsidyt, The Netherlands

Tet.:-31/43-3875-443

Fix: $+31149-3875+$ a 43

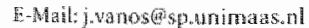

H. Yerdoux, ML, PhD

Departme of Pswethatry

Unaversily victor Segalen Bordeatur 2

and Hopital charles perrens

Bordeaux, France

J. Fen O5, MD PhD, MRCP Pwh

Davision of Psychological Medicine

Instinute of prychialiry

De Crespigny Park

Dernmark Hill, London SE 5 A E UK scores, and positive symptom scores that were internediate to that of non-patients and patients with psychotic disorders (mood disorders: $\beta=0.53,95 \% \mathrm{Cl}: 0.39-0.68$; anxiety disorders: $\beta=0.22,95 \% \mathrm{Cl}: 0.04-0.39$ ). The CAPE distress score adjusted for the corresponding frem quency score was not significantly different between the patient groups, but compared to the general population. patient status did contribute significantly to the level of distress. Discussion Patients with anxiety and mood disorders had elevated scores on positive psychosis items, indicating that expression of psychosis in non-psychotic disorders is common. The finding of elevatted scores of the patient groups on all three dimensions compared to non-patients suggests that the psychopathology associated with psychotic disorders varies quantitatively across DSM-IV categories.

Key words psychosis - mood disorder - anxiety disorder - continuum - symptoms

\section{Introduction}

The operational definition of psychosis plays a major role in guiding research questions, Over the last decades, the dichotomous definition of psychosis has been contested and evidence forwouring a continum view has accumulated (Strauss 1969; Claridge 1997; Peters ef al. 1999; Stefaris et al, 2002; Verdoux and van Ois 2002). The continum of psychosis is defined as a distribution on which non-psychotic affective disorders and affectuve psychosis constitute an intermediate point that connect normal psychological experiencess and psychotic disor* ders (Crow 1998; Van Os ell al. 2000; Van Os et al. 2001). In the dimensional approach, the question becomes not whether an individual has a particular psychotic disorder, but instead to what degree the person has the experience, measured on several dimensions. Studies with the purpose of identifying the symptom dimensions of psychosis, either in individuals with schizophrenia or with schizotypal traits, have typically yielded three-fac. 
tor solutionis, namely: 1) posituve symptoms, 2) negative symptoms, and 3) conceptual disorganisation or social impairmen: (Liddle 1987; Venables and Rector 2000; Vollema and Holigin $2000 \mathrm{~s}$.

Affective symptoms thave been relatively neglected in these studies in spite of these symptoms being wery prevalent in schizophrenia (Hirsch 1991; Taylor 1992: Van Os et all, 1999a). There may even be some degree of aetiological continuity between affective disorder and schizophrenia, as indicators of risk tend to overlap benwen both disorders with quantitative rather than qualitative differences in effect sizes (Van Os et al. 1999a). In aceordance with this, evidence was presented that indion viduals with elevated levels of anxiety and depression report positive psychotic sympton scores that are intermediate to those of non-patients and psychosis cases (Van Os et al. 1999b). Similarly in a recent study among primary cane patients, patients who experienced psychotic symptoms were far more likely to have non-psychotic affective disorders than patients without psychotic symploms (Olfon et al. 2002).

The an of the present paper was to stady the continum of psychosis in patiants with anxuly disorder, mood disorder" and psychotic disorder on the one hand, and in nom-patients from the gereral population on the other. To this end, a recently developed instrument was used the Conmumity Assessment of Psychic Experiences (CAPE) (Stefunis et al. 2002; http:/ www.cape42, homestead coml). This questionnaire was developed in order to measure attenuated psychotic experiences in the affective and nomaffective domains. The CAPL measures frequency of as well as distress associated with these experiences. Previous research with the CAPE has shown a three-factor sitructure of positive, negative and depressive factors in a large and representative sample of young men (Stefanis et al. 2002). The present study was carried out iru the gemeral population and a community mental health centre. dit wis thypothestsed that the three dimengions of psychosis would vary quantitatively across diagnostic groups, Specifically, for the negative and positive dimensions, we expected in creasing severty from nomality through anxiety and depression to clinical pychosis, whereas for the depres sive dimension it was hypothesised that the highest scores would be found in the mood disorders grotsp, with intermediate scores in both other patient groups. In additom, we carried out withingroup comparisons in order to assess to what degree the three groups had different levels of symptom contrasts. For example, we hypotthesised that the psychotic disonder group the scores on the positive dimension would be significantly higher than the score of the depressive dimension, whereas the reverse was hypothesised to hold for the depression group.

\section{Subjects and methods}

\section{Procedire amd Sample}

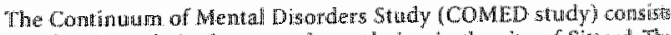

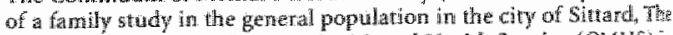
Wetherlands, and an a Communin Weatal Healh Service (CMHS)

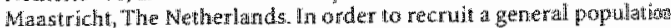

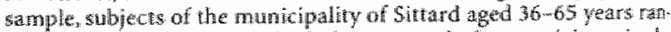

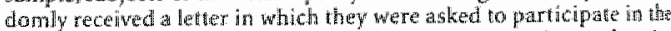

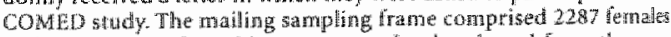

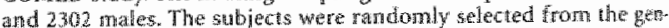

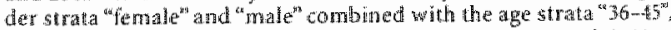

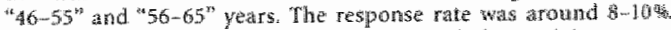
Therl, anowhall sampling procecture was used: the participand were

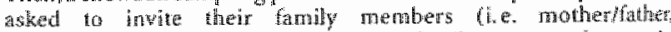

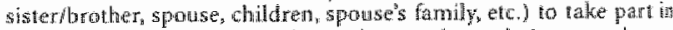
the study. The auge ramge of the total general popalation sanple was 18-70 years. The sampling procedure in the CMHS thas carried on sending lefers to all patients of the deparment for the treatrent 5ewere mental illints and the department for the treationt of da

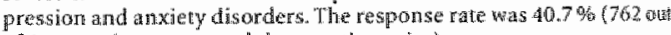

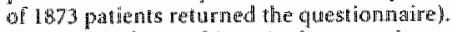

A total of 647 subjects in the gerner popwation and 762 pativuth

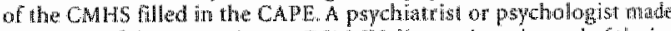
an 555 out af the 762 parients DSM-IV diagnosis at the end of the an-

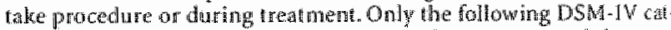
egories were wsed in the andyses, fbecouse they represented then most

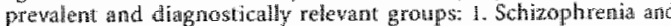
Other Psychotic Disorders $(1=72), 2$. Wood Disorders $(\mathrm{m}=214), 3$.

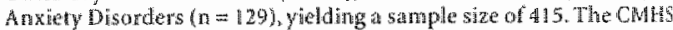

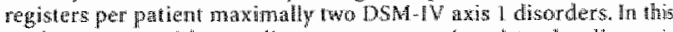
stidy, persons with two diagnoses were assigned to the diagnesis

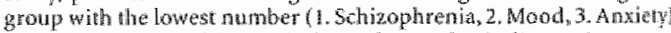
to skew assignation hierarchically to the mschos diagrosis group

\section{Instrument}

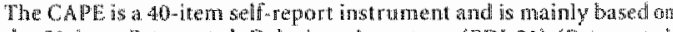
the 21 .them Pekers et al Delusions lnventory (PDI-21) (peters at a

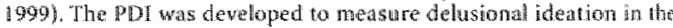
general population on a dimentional scale. The plol is derived from the Present State Examinaton (PSE 9 thedition; Winget al 19\%4). Pe ters and comorkers (1999) boned down the PSE itemus by adding "st

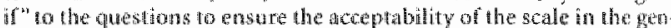

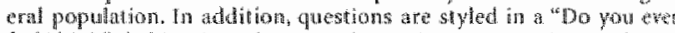

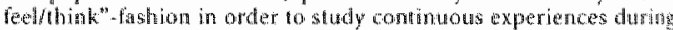
lifetime. The PDi enquires firstly about the presence of atdistond ideation; meastred with dichoomused answaw cateronies: "ves" of

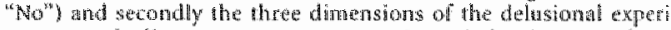

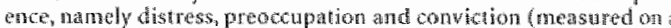

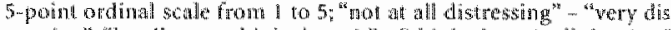

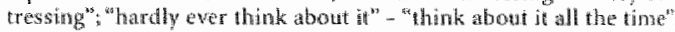

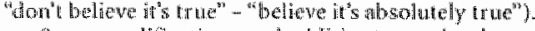

Sother modifications and additions were implementad to the ro

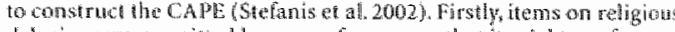

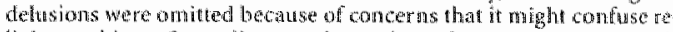

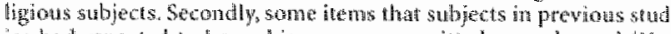
tes had reponted bo be ambiguous we omilted or rephrased Ver

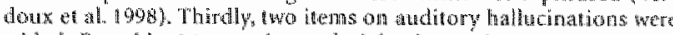

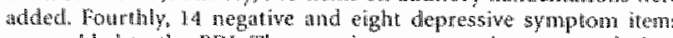

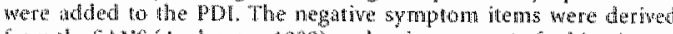

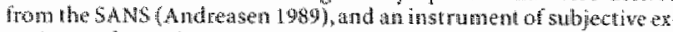

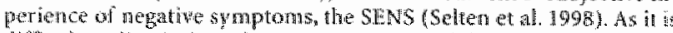
diffictl to discrimale betwean regative and depresine symptoms iterus of depressine symploms that are most specife for depressiont

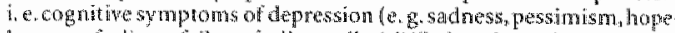

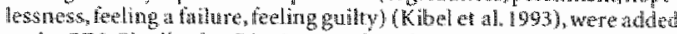
to the PDi Findy, the CAPH: was retuced to two dimensional scales The firs scale scores the frocuency of the experiene ineasured of 


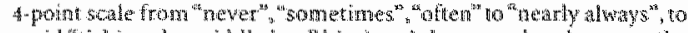

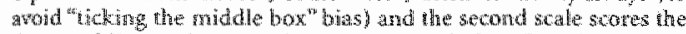

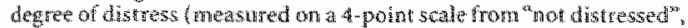

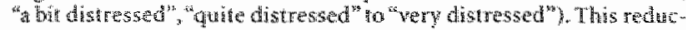
thom in dimensions of the psychotic experience was introdnced as pre. wions research with the PDI - 21 in a farge general population sat mple

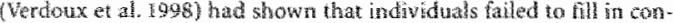
sistenty atl the dimensional scales of each symptom.

The CAPE prowides an overall score and a colal score per dimemsion by adding up the number of positive answers to the froquenty guesion, and it provides a distress score by adding up the soores of the distress questions.

\section{A Analyses}

All analyses were carried on with 5 atal wersion 7 (StataCorp 2001 . In order to acom for partial non-response, scotres were wejghted for the rumber of valid answers per dimencion, and in order to remove scale difference, CAPS positiwe, negative and depression scores were expressed as units standard deviation (gtandardised scores).

Assowations between the three dintaensions were assessed by performing corratiotion analyses for ant combinations of the the dimensions of the CAPE.

in order wo test for associations betwen dinnensions of the CAPE and diagnostic group, muli gariate multiple regression analysis wh

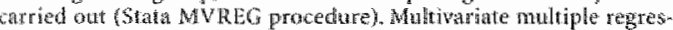
sion differs from ordinary muliple regression in that several depentdent variables (in this case CA $\mathrm{CH}$. positive, negative and depressive dir mension scoses) are joindy regressed on the same independent

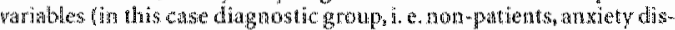
order mood disorder, and psychos is). The advantage of usirg molt wariate multiple regression andysis is that the between-equation $60-$ wariances are estimated, so that coefficients across equations can be fested with the Wald test. For axaraple, multivariate multiple regression anatysis atllowed ans to diredty fest the null hypothesis that the co. effich of the regression of the CAPE negative dimersion on mond Alisorder did not differ from the coefficient of the regression of the CAtE negaltixe dimension on psychotic disorders, in order to assess

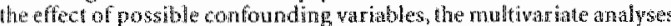
were adjusted tor the following a priorichosen covariates: gender, sin gle marital status (defined as single, divored or widow/widwwer), educational lewel (9 levels) and ange (in yeatrs). All conditions for apgly. mo mullwariate multiple regression andyses were met.

In addition we carred out within-group comparisons in order lo

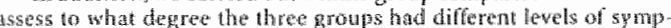
tom contrasts. For example, we tested in the psychotic disorder group whther the scores on the posinge dimension were significantly lugher thar the score on the depressibe donension.

The associalions betwen degrege of thistress and dagnosic group were analysed for each of the three CAM distress sures separately. These analyes sere adyusted for the corresponding frequency som. Agath, contrasts between diagnostic groups were assessed with the Wiald inst

\section{Results}

\section{Demographic variables}

A total of 415 patients with a known DSM-IV diagnosis and total of 647 subjects from the general population (hereafter" non-patients) were included in the analyses. In the patient groups $36.8 \%$ were male, whereas in the non-patients this proportion was $38.4 \%\left(\chi^{2}=0.3, d f=1\right.$, $p=0.6$ ). The mean age of the patients was 40.5 years $(\mathrm{SD}=1.2 .3)$ and the mean age of the non patients was 46.5 years $(S D=12.1)(t=7.6, d f=1011, p=0.00)$. The non-patients had a significantly higher educational level than the patients $(t=8.3, \mathrm{df}=1046, \mathrm{p}=0.00)$. Of the nonpatients, $21.5 \%$ were single, conpared to $49 \%$ of the patients $\left(\chi^{2}=84.4, d f=1, p=0.00\right)$.

\section{Between-group comparisons}

The negative and depressive dimensions were highly correlated $(\mathrm{r}=0.81)$. The positive dinnension correlated moderately high with the negative and depressive symp. tom dimension: 0.63 and 0.63 , respectively.

The three patient groups scored significantly higher than the non-patient group on all three dimensions of the CAPE (Table 1). On the positive dimension, the score of the anxiety disorder and mood disorder groups wats intermediate to the score of the psychotic disorder and the non-patient groups. The mood disorder group displayed a significantly higher positive dimension score than the anxiety disorder group (Wald test: $F(1,971)=9.7 ; p=0.002)$.

On the negative dimension, the mood disorder group had the highest score and this score differed signifcantly from the score in the psychotic discrder group (Wald test: $\mathbb{P}(1,971)=9,0, p=0,003$ ) and in the anxiety disorder group (Wald test: $P(1,971)=9.7 ; p=0.002)$. The psychotic disorder and the anxicty disorder groups did not differ with regard to the negative dimension (Wald test: $\mathrm{F}(1,97 \mathrm{I})=0.24 ; \mathrm{p}=0.63)$.

Compared to the psychotic disorder group, the levet of depressive symptons was higher in the mood disorder group (Wald test: $F(1,971)=19.7 ; p=0.00$ ) and in the anxiety disorder group (Wald test: $F(1,971)=9.04$ * $\mathrm{p}=0.003$ ). No significant difference was found between.

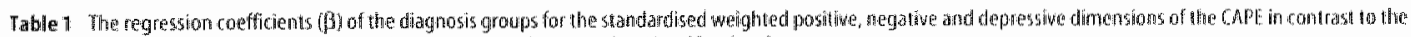

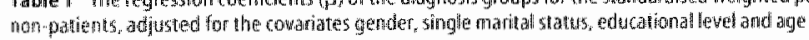

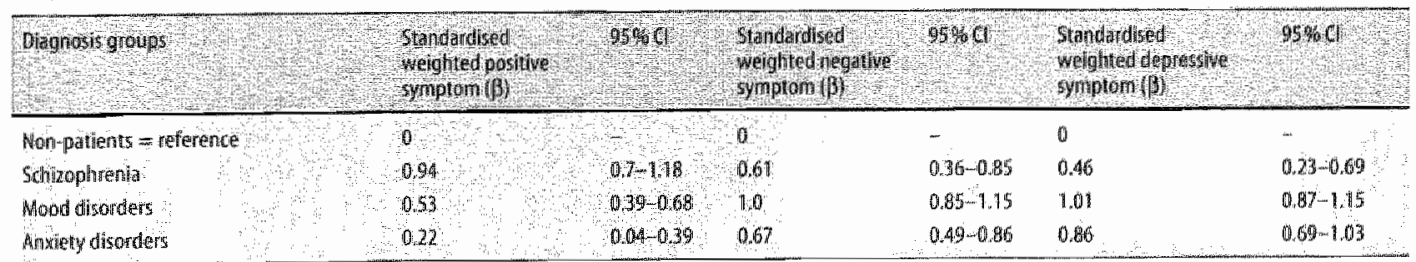


the mood disorder group and the anxiety disorder group (Wald test: $\mathrm{F}(1,971)=2.3 ; \mathrm{p}=0.13)$.

\section{Within-group comparisons}

In the psychotic disorder group, the score on the negative dimension was significantly higher than the score on the depressive dimension (Table 2 ). In the anxiety disorder group, the reverse was true. Only the mood disorder group displayed no difference between the negative and depressive dimensions.

The psychotic disorders patients displayed significantly more positive than depressive symptoms. Both the depressive and anxiety disorder group showed significantly more depressive than positive symptoms (Table 2).

In the depressive and anxiety groups, negative symp loms were robustly more present than positive symptoms, contrary to the schizophrenia group that showed more positive than negative symptoms (Table 2).

\section{Distress and frequency}

The positiwe, negative and depressive dimensions correlated highly with the corresponding distress scores $(r=0.82,0.88$ and 0.90 , respectiwely). The relationship was positive and linear and suggested a dose response pattern. After adjustment for the corresponding frequency score, there was a significant association between each diagnostic group and level of distress for all three CAPE dimensions. However, no differences in level of distress were found between patient groups for any of the dimensions (Table 3).

\section{Discussion}

Patients with clinically assessed DSM-IV anxiety and mood disorders had elevated scores on the positive di. mension, suggesting that these non-psychotic disorders have intermediate values for the continuous psychosis phenotype. This indicates that there are quantitative differences between psychotic and non-psychotic affective disorder, consistent with previous findings on the relationship between affective and psychotic disorder (Crow 1990; Peters at al. 1999; Verdoux et al. 1999).

In addition, the findings suggest that the psychosis phenotype may not only include variation in positive and negative symptomatology, but also in the affective domain. The patients with psychotic disorders had an intermediate score on the depressive dimension compared to non-patients and the anxiety and depression group. Evidence from other studies suggests that affective disorder may not only be phenotypically but also aetiologically related to psychotic disorder. Thus, developmental, perinatal, neuroradiological, familial and social risk factors also show quantitative, in addition to qualitative, variation between affective and psychotic disorders (Bebbington et al. 1993; Elkis et al. 1995; Van Os et al. 1998). It follows from this aetiological overlap that individuals who have a tendency to develop affective symptoms may also be more prone to develop psychotic symptoms. In clinical practice, this within-person continuity can be taken to indicate that the target for treatment should be symptom dimensions instead of diagnostic categories.

In general, the within-group analyses corroborated the hypothesis that patients had the highest score on the dimension of the CAPE that was most characteristic of

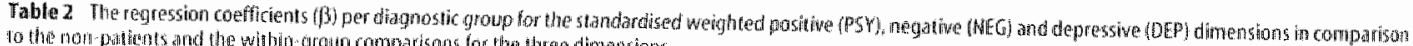

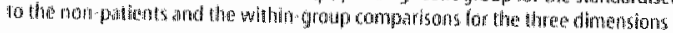

\begin{tabular}{|c|c|c|c|c|c|c|c|c|c|c|}
\hline Direituots Goups & 4 & $10+4019$ & HIEOSI & 85131 & Woldres DIV v NOC & 1 & Walduest 0 eros nor & 0 & WhidagtweG WS PSY & P. \\
\hline Songophrena & & 0.50 & 0.74 & 1.22 & $(1,1055)=4$ & 004 & $(1,1055)=43 s$ & 0,00 & $(1,1055)=230$ & 0,00 \\
\hline Mogod disorders & & 1.17 & 110 & 0.69 & $4(1,1055)=25$ & 0.12 & $(1,1053)-65.4$ & 0,00 & $(101055)=432$ & 0000 \\
\hline Andey disondens & & 1,04 & 0,09 & 0.49 & $P(1,1055)=65$ & 0.01 & $A(1,1055)=530$ & 100 & $1(1055)=257$ & 0.00 \\
\hline
\end{tabular}

Table 3 The assodalions (b) between degrea of distress and diagnosic group in comparison to the nori-padents, adjusted for the cornesponding standardised weighted
Frequency score

\begin{tabular}{|c|c|c|c|c|c|c|c|}
\hline 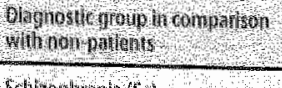 & 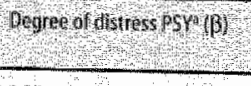 & 1) & Gegres oldintrest & NEGO 101 & p. & Oegree of $01 \mathrm{sin} s \mathrm{~s}$ & 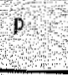 \\
\hline 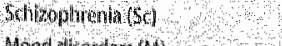 & 0.37 & 0,00 & 0,14 & & 0.02 & 011 & 0446 \\
\hline Mood disorder (M) & 031 & 900 & 0.24 & & 000 & 018 & 000 \\
\hline Mrrien of sordars (N) & 029 & 000 & 026 & & 800 & 916 & 000 \\
\hline Firedunc y come & 079 & 000 & 082 & 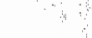 & 0.00 & 0,88 & 000 \\
\hline Wald test Sons M & $F(1,105 s-10$ & 0,40 & $-11,0521=23$ & & 013 & $(1,1045)-12$ & 027 \\
\hline Whld tors oc w A & $F(1,055)=0,0$ & 036 & $4(1052)=29$ & & 0.09 & $11,1045)=0.4$ & 051 \\
\hline Waldest wh $A$ & flOOS $=000$ & 0.86 & $(0,1052)=0$ & . & 071 & $\mathrm{~F}(1,04 \mathrm{~s})=03$ & 062 \\
\hline
\end{tabular}

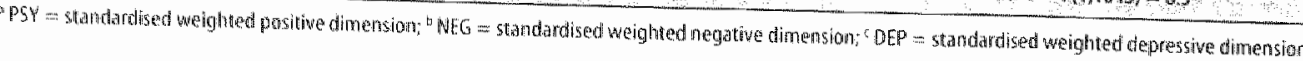


their DSM-IV diagnosis. For example, the psychotic disorder group showed significantly more negative than depressive symptoms, and more positive than depressive and negative symptoms. This prowides further support for wour previous findings that the dimensions of the CAPE have sufficient discriminant validity (Stefanis et all 2002). Contrary to our expectation, however, the results indicated that in the mood disorder group the level of negative symptoms matched the level of depressive symptoms, in contrast to the significant difference between both dimensions that were found in the other patient groups. This raises the question whether the CAPE provides sufficient discriminatory power between negatiwe and depressive dimensions in patients who suffer from depression. In the study by Stefanis et al. (2002), a three-factor model with separate depressive and negative dimensions provided a better fit to the data than a rwo-factor model, in which the depressive symptoms were not distinct from the negative symptoms. In mood disorder, however, the negatiwe and depressive dimensions, as measured with the CAPE, may show substantial overlap.

In line with the findings of Stefanis et al. (2002), the distress can depressive symptoms is largely mediated by the frequency of the symptoms and independent of being assigned to a specific diagnostic group. Yet, compared to the general population, patient status did contribute sig. nificantly to the level of distress, independent of symptom frequency. This finding is in accordance with current hypotheses that the distress associated with the experience of symptoms is a major determinant of the development of clinical disorder and need for care (Freeman and Garety 1999; Garety et al. 2001).

\section{Limitations}

The results should be viewed in the light of several limitations. Firstly, the mood disorder group in this study may have included a small (psychotic depression is rare and often treated in hospital) proportion of patients with affective psychosis, for example depressive disorder with psychotic symptoms. This may have led to increased levels of positive psychotic symptoms in this group. However, this does not discard our interpretation of the findings, as we hypothesised that the psychosis continuum varies from normality through non-psychotic affective disorder and affective psychosis to nonaffective psychosis.

Secondly, comorbidity in patient groups was not accounted for in this study. It is well known that patients with psychotic disorders may have a (post-psychotic) depressive episode and patients with anxiety disorders often have a dual diagnosis of mood disorder (Birchwood et al. 2000; Zimmerman et al. 2000; Nemeroff 2002 ). In this study, patients with a dual diagnosis were assigned to the diagnosis group that constituted the most severe disorder. Thus, mood and anxiety disorders in patients with a psychotic disorder would have been assigned to the psychosis diagnosis group and the anxiety disorder patient with mood disorder was assigned to the mood diagnosis group. This reduction of the data to discrete diagnostic categories was necessary to study the difference between different diagnostic groups, but it is clear that this is not the actual phenotypic manifestation of psychiatric disorders. The issue of comorbidity in fact highlights the need to describe psychopsthology along several dimensions simultaneously.

"Thirdly, the current data are based on an outpatient sample. Therefore, the results cannot be generalised to inpatients whose disorders presumably constitute the most severe end of the psychosis continuum. Future studies using the CAPE in residential patients are necessary.

Fourthly, the findings are based on self-report. This may result in less reliable data $a_{x}$ especially in the case of psychotic symptoms. Therefore, replication with interview data is necessary.

Fifthly, trained clinicians at the CMHS made in $73 \%$ of the patients a DSM-IV diagnosis. The diagnoses were, however, not based on standard structured psychiatric interviews, like the SCID or the OPCRIT Still, these diagnoses are valid because they represent daily practice at most outpatient services and should provide ample contrast between the broad diagnostic categories used in this study.

Finally, the response rate of the patients was around $40 \%$. Unfortunately, no information is available concerning the non-responders, but the observed frequency distribution of diagnoses was anticipated, indicating that selection bias according to diagnostic group may be small. Even if selection bias had operated, however, this is unlikely to have affected the validity of our findings.

\section{References}

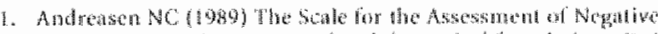

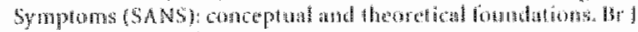

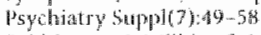

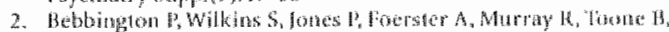

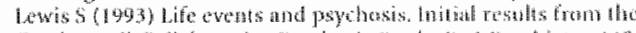

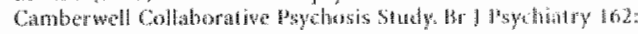
$72-7 \overline{1}$

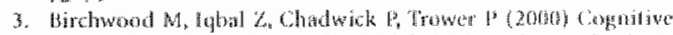

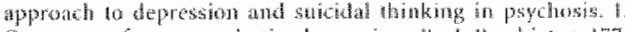

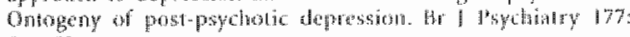
$56-521$

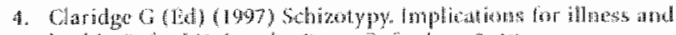

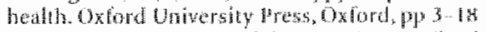

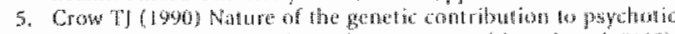

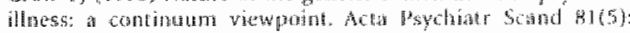
$401 \cdots 408$

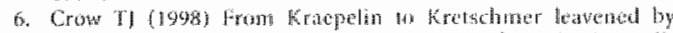

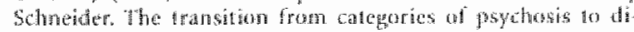

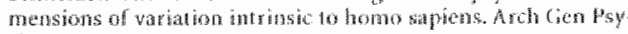
ahiat 1 y' $55,502-504$

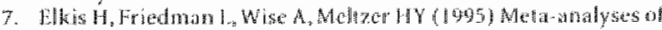

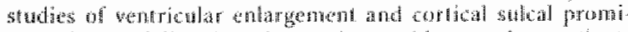

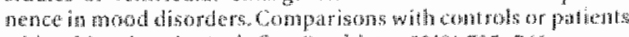

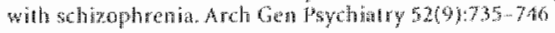




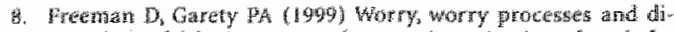

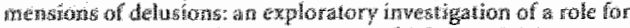

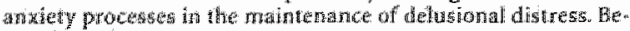
hav Cogn $\mathrm{H}^{3}$ sichowherapy $2747-62$

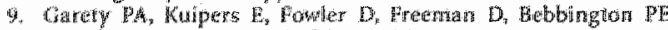
(2001) A congritue model of the posintwe symptome of prychosis.

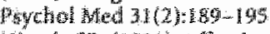

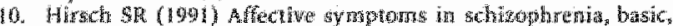

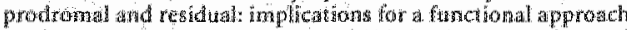

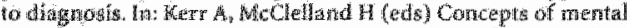

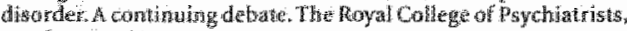
Londour, $19,66-73$

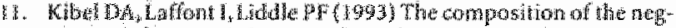

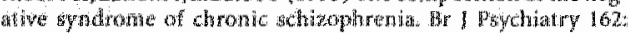
$744-756$

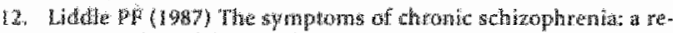

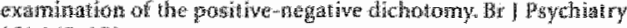
$|5|: \mid 45-351$

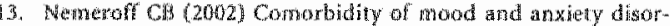

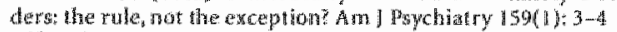

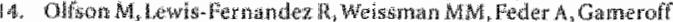

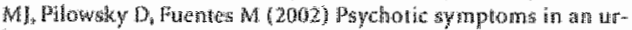
ban gereral medicine practice. An I Pswchiatry 159(8): $1412-1419$

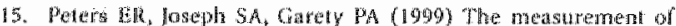

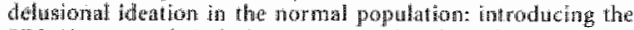
PDI (Peters et at. Delusions Inventory). Suhizophr Bull 25(3): $553-576$

16. Selten ID, Germat Hot Noten WA, Whersma D, wan den Bosch $R$ ] (1998) Exper itence of negatime symptoms: comparison of schizom phertic patients to parients wh a depressive disorder and to normal subiectis. An I Psychiat ry $155(3): 350-354$

17. StataCorp 12001) Stata Satistical Softwafe: Reledse 7.0. Stata Corporation, College Stution, TX

18. Stefaris NC, Hassen $M$, Smirnis NK, Avamopoulos DA, Ewdokimidis $1 K$, Stefanis CN, Vendoux H, Van Os I (2002) Fotdence that the dimensions of pspehosis have a distribution in the general population. Insphol Med 32(2),3,47-358

19. Stratis IS (1969) Hallicinations and delusions as points on con-

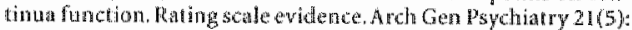
$581-586$

20. Tabylor MA (1992) Ars schizophrenia and affective disorder te. lated? A selective literature review. Am I Psychatry 149(1):22-32

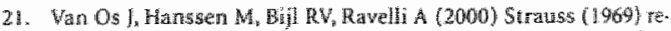

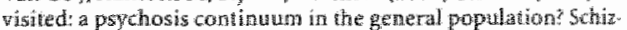

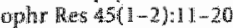

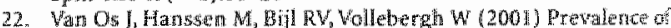
psychotic disorder and community lewe of psychotic symatoms:

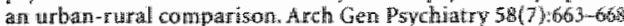

23. Van Os l, Jones Ps Sham Py

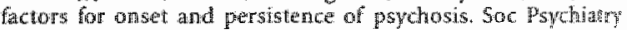
Ifschiatr Epidemiol 33(12):596-605

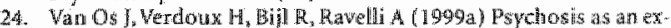
treme of continuots wariation in dimens ons of psychopathol ogy. In: Gattaz W, Hafner H (eds) Search for the causes of sthit. aphrenial. IV Dietrich Steinkopff Verlag, Darmstadl, Germany, pog $59-80$

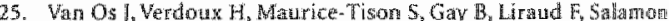

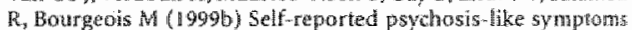
and the continum of psychosis Soc Psychattry Prychiatr Epi. demiol $34: 459-463$

26. Venables PH, Retior $N A$ (2000) The content and structure of schicotypy: a study wing confinutory factor analysis schizoptiv Bull $26(3): 587-602$

27. Werdoux $\mathrm{H}$, wan Os (2002) psychotic symptoms in non-citinical poputations and the contintum of psochosis. Sctuzophre Res $54(1-2) 1,59-65$

28. Verdoux $H$, wan Os I, Mantice-Tison $S$, Gay B, Salanton $R$, Bourgeolis M (1998) Is early wathood a critical developmental stage for psychosis proneness? A survey of delusional ideation in nor. mal subjects. Schizophr Res 29(3):247-254

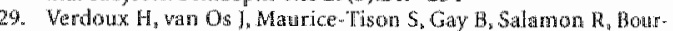
geasis ML (1999) Increased occurrence of depression in psychosis-prone subjects: a follow-up study in primary care set things. Compr Psychiatry $40(6) 462-468$

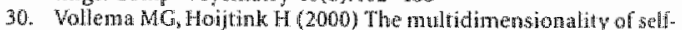
report shizotypy in a psychiatric population: an analysis using muluidinensional Rasch models. Shizosht Bull 26(3),565 -575

31. Wing IK, Cooper $₫ \mathrm{E}$, Sartoris $\mathrm{N}$ (1974) Meastrement and chas sificat ion of psychiatric symproms. Cambridge University Press, Cambridge

32. Zimmernan M, MCDernat $W$, Martia If (2000) Frequency of anxiety disorders in psychiatric ontpatients with major depressive disorder. Am J flsychatry 157(8):1337 1340 


\title{
CHAPTER 5
}

\section{Evidence for family-specific variation of subclinical psychosis dimensions in the general population}

\author{
M. Hanssen ${ }^{1}$ \\ L. Krabbendam" \\ M. Vollema ${ }^{2}$ \\ P. Delespaul ${ }^{\prime}$ \\ I. $\operatorname{van} \mathrm{Os}^{1,3}$
}

1 Department of Psychiatry and Neuropsychology, South Limburg Mental Health Research and Teaching Network, EURON, Mastricht University, Maastricht, The Netherllands

${ }^{2}$ Meerkanten GGZ Flevo-Veluwe, Veldwijk Psychiatric Hospital/Diepartment of Psychological Assessment, Emelo, The Netherlands

"Division of Psychological Medicine, Institute of Psychiatry, London, United Kingdom 


\begin{abstract}
Background. Prevtous work has shown that dimensions of subclinical psychotic experiences vary in the general population, but it is not known whether this variation is family-specific. In addition, self-report measures of such experiences may be less robust in detecting familial clustering than interview measures.

Methods. A longitudinal family study in the general population involving 768 subjects aged 17-77 years from 116 families was conducted. Subjects with a mean or a high score on the self-report Community Assessment of Psychic Experiences (CAPE) positive psychosis dimension at $T_{1}$ were interviewed at $T_{2}, 7-8$ months later, by trained psychologists who administered the Structured Interview for Schizotypy-Revised (SIS$R$; $n=496)$. At $T_{2}$, subjects also completed the CAPE again $(n=507)$. Multilevel regression analyses were used to examine family-specific variation in the subclinical psychosis phenotype as assessed by CAPE and SIS-R.

Results. The $T_{2}$ correlation between the positive and the negative dimensions of the SIS-R with their corresponding dimensions on the CAPE were $0.63(p=0.00)$ and 0.48 $(p=0.00)$, respectively. Both positive and negative dimensions of the SIS-R showed significant family-specific variation. For data collected with the CAPE, family-specific variation was apparent only for the positive dimension.
\end{abstract}

Conclusions. The present findings provide evidence for familial clustering of dimensions of the subclinical psychosis phenotype in the general population, suggesting a broad distribution of familial factors that drive variation in psychosis. 


\section{Introduction}

The psychosis phenotype is thought to be expressed also at levels well below its clinical manifestation, commonly referred to as psychosis proneness, psychotic experiences, schizotypy or at-risk mental states Meehl 1962; Chapman, Chapman et al. 1994; Kwapil 1998; Verdoux, Maurice-Tison et al. 1998; van Os, Hanssen et al. 2000; Stefanis, Hanssen et al. 2002; Vollema, Sitskoorn et al. 2002; Yung, Phillips et al. 2003). It has been noted that the dimensions of this variously labelled subclinical psychosis phenotype closely resemble those that have been identified in schizophrenia, suggesting continuity between the clinical and non-clinicall phenorypes (Vollema and van dem Bosch 1995; Gruzelier 1996; Vollema and Hoijtink 2000; Mata, Gilvarry et al. 2003). The existence of a positive and a negative dimension of the clinical and the subclinical phenotype has been by fat the most consistently walidated, whereas the evidence for a third, disorganisation dimension is less compelling in both the clinical and the subclinical domains (van $\mathrm{Os}$ and Verdoux 2003). As affective symptoms tended to be excluded from the first generation symptom-analytic studies even though they form an integral part of schizophrenia and ther psychotic syndromes (Soni, Hollis et al. 1992; Sax, Strakowski et al. 1996), more recent endeavours that were less biased by Kraepelinian concerns of dichotomising affective and non-affective syndromes, included depressive and manic symptoms. These investigations yielded additional dimensions of depressive and manic/excitement symptoms but less consistent evidence of a conceptual disorganisation factor (Kitamura, Okazaki et all. 1995; Lindenmayer, Bernstein Hyman et al. 1995; Lindenmayer, Grochowski et al. 1995; McGorry, Bell et al. 1998; van Os, Gilvarry et al. 1999; Stefanis, Hanssen et al. 2002; Krabbendam, Myin-Germeys et al. in press).

Given the substantial level of familial elustering of psychotic disorders (Kety, Rosenthal et al. 1971; Kendler and Gardner 1997), researchers have investigated to what degree the dimensions of the subclinical psychosis phenotype are also transmitted independently. For example, Wickham et al. (2001) found evidence for familial clustering of psychomotor poverty, manic symptom dimensions and, to a lesser extent, disorganisation in families multiply affected with schizophrenia (Wickham, Walsh et al. 2001). Vollema et al. (2002) reported that the score on the positive dimension of a schizotypy questionnaire administered to relatives of patients with psychotic disorders corresponded to their genetic risk of psychosis. Fanous and colleagues (2001) demonstrated that interview-based positive and negative symptoms in schizophrenia predicted their equivalent non-clinical symptom dimensions in nonpsychotic relatives, implying an aetiological continum between the subclinical and the clinical psychosis phenotypes (Fanous, Gardner et al. 2001). 
The issue of familial clustering of the multidimensional, subclinical manifestation of psychosis has been much less extensively studied in family samples from the general population. compared to general population twin samples. Kendler and Hewitt (1992) studied twins from the general population and concluded that the variance in most selfrepott schizotypy scales, except for perceptual aberration, involved substantial genetic contributions (Kendler and Hewitt 1992). In addition, Meyer and Hautzinger (2001) reported familial aggregation of the hypomanic personality scale (a vulnerability marker for affective disorders), as well as the social anhedonia and impulsive nonconformity scales, in families from the general population (Meyer and Hautzinger 2001). MacDonald and colleagues (2001) found in their general population-based twin study only one common schizotypy factor, mainly explained by perceptual aberration, magical ideation, schizotypal cognitions and to a lesser extent social anhedonia. The common schizotypy factor was influenced by shared environmental, nonshared environmental, and possibly genetic effects (MacDonald, Pogue-Geile et al. 2001). Recently, a general population female twin study by Linney and colleagues (2003) showed that additive genetic and unique environmental effects influenced self-reported psychotic experiences. The multivariate structural equation model generated two independent latent factors, namely a positive (i.e. cognitive disorganisation, unusual experiences and delusional ideation) and a negative dimension (i.e. cognitive disorganisation and introvertive anhedonia), suggesting different aetiological mechanisms for the various scales of the subclinical psychosis phenotype (Linney, Murray et al. 2003).

Although many of the above studies used self-report instruments, it has been suggested that the comparative ability of self-report instruments versus the clinical interview method to detect familial clustering of subclinical psychotic experiences is not the same. Kendler et al. (1996) found that only self-reported social anhedonia differed significantly between relatives of patients with schizophrenia and control subjects. However, contrary to the findings with the self-report scales, results from the interview assessments in the same sample yielded evidence for higher levels of negative schizotypy, social dysfunction and odd behaviour in the relatives (Kendler, Thacker et al. 1996). Catts and colleagues (2000) concluded that the Eysenck Psychoticism Scale and the Chapman Perceptual Aberration and Physical Anhedonia Scales were not specific familial markers for schizophrenia, comparing parents-pairs of nonaffected subjects with parents-pairs of patients with schizophrenia or nonpsychotic psychiatric disorder. The authors, in accordance with Kendler et al. (1996), suggested that their inconclusive results could be explained by the use of self-report scales rather than direct interview measures (Catts, Fox et al. 2000).

Taken together, the emerging evidence regarding familial aggregation of dimensions of the subclinical psychosis phenotype in the general population is not entirely consistent, but existing studies suggest a degree of familial clustering. However, 
studies in families randomly selected from the general population are scarce and the choice of instrument may play a pivotal role in the validity of the dimensions studied. In particular, results have suggested that self-report measures of psychotic experiences may be less robust in detecting familial clustering than interview measures.

In a previous study in a large general population sample, we showed independent variation of positive and negative dimensions of the subclinical psychosis phenotype in the general population (Stefanis, Hanssen et al. 2002). Taking these findings further, we wished to examine, in the current study, to what degree such dimensions were subject to family-specific variation as an indicator of independent transmission within families. The ain of the present study, therefore, was twofold:

1. to assess familial clustering of dimensions of the subclinical psychosis phenotype, in particular in the positive and the negative domain, in a large sample of related. individuals in the generall population, and

2. to compare the ability of the self-report instrument CAPE versus the Structured Interview for Schizotypy-Revised (SIS-R) in assessing familial clustering of these dimensions in a general population sample.

\section{Method}

\section{Procedure and Sample}

The Continum of Mental Disorders Study (COMED study) is a longitudinal family study in the general population in the city of Sittard, The Netherlands. In order to recruit a general population sample, subjects of the municipality of Sittand aged 36-65 years were randomly selected and sent a letter in which they were asked to participate. The mailing frame comprised 2287 females and 2302 males. The subjects were randomly selected from the gender strata 'female' and 'male" combined with the age strata ' 36 45 ', '46-55' and '56-65' years of age. The response rate was $8-10 \%$ in the different strata. In the next sampling phase, a snowball sampling procedure was used: the participants (i.e. index subjects who had responded to the mail survey) wert asked to invite their family members (i.e. mother/father, sister/brother, spouse, children, spouse's family, etc.) to take part in the study. The total general population sample thus comprised 768 subjects aged $17-77$ years, pertaining to 116 families.

\section{Longitudinal design}

The COMED study included wo measurement points: $T_{\|}$and $T_{2}$. At $T_{1}$, all participants filled in several self-report questionnaires, including the Community Assessment of Psychic Experiences (CAPE; see Jnstruments section) and a demographic questionnaire (see Instruments section). The subjects with a mean (i.e. between $40^{\text {th }}$ and $60^{\text {th }}$ 
percentile) or a high (i.e. above $75^{\text {th }}$ percentile) score on the CAPE positive psychosis dimension and their relatives were asked to participate in the second measurement. This strategy was aimed at oversampling of individuals with higher levels of psychosis, thus increasing statistical power, while at the same time ensuring that the sample included sufficient individuals with "average" levels of the subclinical psychosis phenotype so as to have sufficient variation along a hypothesised contimum of psychosis. At $T_{2}$, trained psychologists administered a two-hour interview at the home of the subject, including the Structured Interview for Schizotypy-Revised (SIS-R; see Instruments section), the CAPE and the Brief Psychiatric Rating Scale (BPRS; see Instruments section). The mean period between $T_{1}$ and $T_{2}$ was 7.7 months (SD 4.8 months; range $1-26$ months).

This study used CAPE $\mathrm{T}_{2}$ and SIS-R $\mathrm{T}_{2}$ measurements to examine the familiality of dimensions of the subclinical psychosis phenotype in the general population. A total of 765 subjects filled in the CAPE at $T_{1}$. At $T_{2}, 507$ subjects completed the CAPE and 496 subjects were interviewed with the SIS-R.

Relatives participating in the COMED study were asked not to speak to each other about the instruments to prevent bias in answering. It was not possible to control for this, but all subjects consented with the request of the interviewer.

\section{Instruments}

The Community Assessment of Psychic Experiences (CAPE) ((Stefanis, Hanssen et al. 2002); htp:/www.cape42.homestead.com), a self-report instrument, and the Structured Interview for Schizotypy-Revised (SIS-R) (Kendller, Lieberman et al. 1989; Vollema and Otmel 2000) were used to study familiality of dimensions of the subclinical psychosis phenotype in the general population. The demographic questionnaire yielded information regarding gender, age, educational level, marital status, lifetime psychological complaints (subjects could answer positively or negatively to the question whether they had had lifetime psychological complaints and if the answer was "yes" subjects completed the question "Which lifetime psychological complaints did you have and which diagnoses were made?"), help-seeking behaviour (subjects could tick the relevant category indicating whether they had sought help for their psychological complaints, for example the general practitioner, a mental health outpatient facility, psychiatric hospital etc.) and presence of relatives with psychological complaints (subjects answered the question whether they had family nembers with psychological complaints and in the case of an affimative answer, subjects completed the question "Could you please describe which diagnoses your family member or family nembers had?"). The Brief Psychiatric Rating Scale (BPRS) is a structured interview to measure psychopathology (Lukoff, Nuechterlein et al. 1986) as a function of frequency and functional impaitment, and includes ratings at the level of subclinical experiences. 
The CAPE was developed in order to rate self-reports of attenuated psychotic experiences in the affective and non-affective domains. The CAPE measures, on a dimensional scale, frequency of as well as distress associated with these experiences. The frequency score is measured on a 4-point scale from "never (1)", "sometimes (2)', 'often (3)' to "nearly always (4)'. The degree of distress associated with the experience is also measured on a 4-point scale with labels ranging from 'not distressed (1)', 'a bit distressed (2)', 'quite distressed (3)' to 'very distressed (4)'. The CAPE includes dimensions of positive psychotic experiences, negative psychotic experiences and depressive experiences. The depressive dimension was added so as to allow variation of the negative dimension independent of affective symptoms, and because variation in the affective domain can be considered itself as an independent dimension of psychosis (see (Stefanis, Hanssen et al. 2002)). Measures of hypomania and disorganisation were not included in the CAPE, given the fact that these may not be reliably measured by selfreport in the general population.

Previous research with the CAPE has shown i) a three-factor structure of positive, negative and depressive dimensions in a large and representative sample of young men (Stefanis, Hanssen et al. 2002) and in a large sample of undergraduate female students (Verdoux, Sorbara et al. 2002), and ii) discriminative validity across groups of individuals with schizophrenia, affective and anxiety disorders and individuals from the general population (Hanssen, Peeters et al. 2003). The 40-item instrument is mainly based on the 21-item Peters et al. Delusions Inventory (PDI-21) (Peters, Joseph et al. 1999). Furthermore, two items on auditory hallucinations, 14 negative and eight depressive symptom items were added. For a detailed description of the development of the CAPE, we refer to previous work (Stefanis, Hanssen et al. 2002; Verdoux, Sorbara et al. 2002; Hanssen, Peeters et al. 2003). The CAPE positive, negative and depressive dimensions encompass 18,14 and 8 items, respectively.

The CAPE provides a total score per dimension by adding up the scores on the frequency question. In order to account for partial non-response, CAPE scores werte weighted for the number of valid answers per dimension (weighted scores).

The Structured Interview for Schizotypy (SIS) was originally developed by Kendler (Kendler, Lieberman et al. 1989). Vollema and Ormel (2000) translated the SIS into Dutch and revised the SIS by improving and standardising the rating procedures (Vollema and Ormel 2000), thus creating the SIS-Revised (SIS-R). The instrument is designed to measure the symptoms and signs comprising the three dimensions of the subclinical psychosis phenotype. Items can be scored on a four point scale from absent (score 0 ) to severe (score 3). Positive schizotypy (PS) covers the symptoms referential thinking, magical ideation, illusions and suspiciousness (in total 6 items). Negative schizotypy (NS) contains the symptoms social isolation, social anxiety, introversion, restricted affect, referential thinking and suspiciousness (in total 8 items). 
Disorganisation schizotypy (DS) encompasses the signs goal-directness of thinking, loosening of associations and oddness (in total 3 items).

The BPRS (Lukoff, Nuechterlein et al. 1986) was used to also allow a comparison with a clinical, symptom-based measure that allowed examination of the possibility of selection bias (see below). The BPRS time frame used in the COMED study was the past four weeks. BPRS ratings of 2-3 indicate non-pathological experiences and ratings of 4-7 parallel pathological experiences (Lukoff, Nuechterlein et al. 1986). The BPRS positive score was composed of the following four items: suspiciousness, unusual thought content, delusions and hallucinations (score range 4-28). The BPRS negative score comprised the items flattened affect and self-neglect (score range 2-14). Finally, the BPRS disorganisation score consisted of the items conceptual disorganisation and bizarre behaviour (score range 2-14).

\section{Analyses}

All analyses were carried out with STATA version 8 (StataCorp 2001). Families consisting of subjects with $0 \%$ shared genes only, i.e. partners or spouses $(n=32)$, or consisting of only one subject ( $n=145)$, were excluded from the analyses.

First, correlations between the CAPE positive and negative dimensions, and the SIS-R positive and negative dimensions were calculated. Second, the degree of familial clustering of CAPE and SIS-R dimensions was tested with a maximum-likelihood random-effects model, i.e. a multilevel random regression analysis. For this purpose, the weighted CAPE scores were expressed as units standard deviation (standardised scores). Data of related individuals have a hierarchical structure, with level-1 units (individuals), clustered within level-2 units (families). Level-1 variation thus concerns variation between individuals. However, the focus of our hypothesis was on level-2 variation: is therc ramily-specific variation or, in other words, do families differ significantly in their level of variation in positive or negative sub-clinical psychotic experiences? The maxinum-likelihood random-effects model was used to estimate whether level-2 variation was equal to zero, using the intra-family correlation (rho) as effect size. The intra-family correlation is the level-2 variance expressed as a proportion of the total variance: the higher this proportion, the more it reflects the fact that individuals in the same family are more alike than individuals in different families. The multilevel model that was tested comprised the random effect of families and the fixed effects of age, gender, educational level and the two CAPE or SIS-R psychosis dimensions that were not entered as the dependent variable in the model. The inclusion of the other two dimensions allowed for an assessment of the degree of familial clustering for a given dimension that was independent of the others. The other fixed effects were added to the model in order to control for possible confounding by familial differences in education, age or sex composition. Residuals were inspected to check for violation of assumptions 
of normality and linearity. As the SIS-R disorganisation dimension was severely skewed $(6.0 \%$ scored at least one item) analyses for this dimension were repeated with the dichotomised outcome ( 0 versus other) as independent variable. Results were the same.

\section{Results}

\section{Sample characteristics at $T_{2}$}

The sample of 505 individuals with complete data comprised more women than men: $59.4 \%$ and $40.6 \%$, respectively (Table 1). The mean age was 47.3 years (SD 12.0) ranging from 18 to 77 . Most subjects $(71.3 \%$ ) were married. In total $43.7 \%$ of the sample reported lifetime experience of any psychological complaints. Depressed mood, nervous exhaustion and anxiety were the most commonly reported psychological complaints. The prevalence of self-reported schizophrenia or other psychotic disorders was $1.4 \%$ (7/501). In total $87.8 \%$ of subjects with psychological complaints had sought professional and/or informal help. Hundred-and-fifty subjects $(78.1 \%$ of people with complaints) had sought help with their general practitioner, 55 subjects $(28.7 \%)$ had visited a mental health out-patient facility, 38 subjects (19.8\%) had been in contact with social services, 18 subjects $(9.4 \%)$ had been referred to a psychiatric ward of a general hospital and 13 subjects $(6.8 \%)$ had been referred to a psychiatric hospital. Seventy-five subjects ( $40.3 \%$ of people with complaints) had had recourse to informal help by, for example, family and friends, and alternative medicine. Around $48 \%$ of the participants had a relative who had had a lifetime experience of psychological complaints. Again depressed mood, nervous exhaustion, and anxiety were most commonly reported. In total 19 subjects $(1.0 \%)$ indicated they had a relative diagnosed with schizophrenia or another psychotic disorder.

The mean of the weighted positive (PSY), negative (NEG) and depressiwe (DEP) dimensions of the CAPE were 1.16, 1.57 and 1.61 , respectively. The negative and depressive dimensions of the CAPE showed a more or less normal distribution in contrast to the more skewed positive dimension of the CAPE. Subjects scored a mean of respectively 2.15 (score range of $0-18$ for six items), 2.86 (score range of 0-24 for eight items) and 0.11 (score range of $0-9$ for three items) on the Positive (PS), Negative (NS) and Disorganisation (DS) dimension of the SIS-R measure of the subclinical psychosis phenotype. The three SIS-R dimensions showed a moderately skewed distribution. Only 30 out of $497(6.0 \%)$ subjects scored on the Disorganisation items of the SIS-R. The sample mean score of the positive (i.e., 4.4 for four positive dimension items), negative (i.e., 2.09 for two negative dimension items) and disorganisation (i.e., 2.03 for two disorganisation items) dimensions of the BPRS did not reach pathology level (see method section). 
Table 1 Characteristacs of subjects participating alt $T_{2}$

\begin{tabular}{|c|c|}
\hline \multirow[t]{2}{*}{ Gender $(n=505)$} & Frequency $(\%)$ Male \\
\hline & $205(40.59)$ \\
\hline \multirow[t]{2}{*}{ Age in years $(n=490)$} & Mean (SD) \\
\hline & $47.27(12.02)$ \\
\hline Ed ucational level $(n=502)$ & Frequency $(\%)$ \\
\hline Primary aducation & $25(5.0)$ \\
\hline Lower tcehnical a vocational education & $52(19.4)$ \\
\hline Midile secondary education & $51(10.16)$ \\
\hline Middle technicaf vocational education & $103(20.5)$ \\
\hline Higher secondary education & $57(11.4)$ \\
\hline Higher wocal horat training & $153(30.5)$ \\
\hline Higher general training & $61(12.2)$ \\
\hline Maritall staturs $(n=494)$ & Frequency $(\%)$ \\
\hline Married & $352(71.26)$ \\
\hline C.iving together & $30(6.07)$ \\
\hline Diwored & $34(6.88)$ \\
\hline Widow/widower & $8(1.62)$ \\
\hline Singles & $70(14.17)$ \\
\hline \multirow[t]{2}{*}{ Lifetime psychologicall complaints $(n=501)$} & Present $(\%)$ \\
\hline & $219(43.71)$ \\
\hline \multirow[t]{2}{*}{ Help-seeking behaviour $(n=221)$} & Present $(1 / 6)$ \\
\hline & $194(87.78)$ \\
\hline \multirow[t]{2}{*}{ Relatives with psychological complaints $(n=494)$} & $\operatorname{Yes}(\%)$ \\
\hline & $238(48.18)$ \\
\hline CAPE $_{2}(n=505)$ & Mean $(\mathrm{SD})$ \\
\hline$\overline{P S Y^{*}}$ & $1.16(0.18)$ \\
\hline $\mathbb{N E G}$ & $1.57(0.34)$ \\
\hline DEP & $1.61(0.35)$ \\
\hline SIS-R T $T_{2}(n=496)$ & Mean (SD) \\
\hline $\mathrm{PS}^{n}$ & $2.15(2.21)$ \\
\hline$N S^{i n}$ & $2.86(2.77)$ \\
\hline $\mathrm{DS}^{\text {istilit }}$ & $0.11(0.52)$ \\
\hline BPRS T $_{2}(n=495)$ & Mean (SD) \\
\hline $120 \mathrm{~s}^{12}$ & $4.40(1.13)$ \\
\hline MLOS & $2.09(0.40)$ \\
\hline DIS & $2.03(0.30)$ \\
\hline
\end{tabular}

- Woighteal positive dimension (scote range: $1-4$ ):

"Weightol negative dithersion (score range: $\{$ w)

"We Wighted depressive dimersion (score range: 1 -4)

"Positive sehwolypy (10tal score of 6 items: 3core ronge: 0-18)

"Nagative schizolypy (total score of 8 itens; score range: 0-24)

"Disonganisation sehizolypy (total score of 3 items; score range: $0-9$ )

"BPRS positive dimension (lotal score of 4 items; score range: 4-28)

2:it BPRS negative dimension (toul score of 2 iterns, score range: $2-14$ )

* B BPIS disorganisation dimension (total score of 2 items; score range: 2-14) 


\section{Correlation analysis of self-report and interview}

The positive dimension of the SIS-R and the positive dimension of the CAPE were moderately high correlated $(r=0.63, p=0.00, n=492)$. The correlation between the negative dimension of the SIS-R and the negative dimension of the CAPE was somewhat lower $(r=0.48, \mathrm{p}=0.00, \mathrm{n}=492)$.

\section{Familial clustering of the subclinical psychosis phenotype: self-report versus interview}

After excluding study participants without relatives and accounting for missing values, multilevel regression analysis examined the interfamilial variance of $\mathrm{CAPE}(n=283 ; x$ families $=97$ ) and SIS- $R(n=286 ; x$ families $=97$ ) dimensions of the subclinical psychosis phenotype. The family random effect was significant for the positive dimension of the CAPE (Table 2), as well as for the positive and negative dimensions measured with the SIS-R (Table 3). The rho's were significant, suggesting familial clustering, with familyspecific variance accounting for $10-20$ percent of the total variance. Importantly, the CAPE positive dimension showed familial clustering independently of the CAPE negative and depressive dimensions, as the analysis of variance was adjusted for the two CAPE dimensions that were not entered as the dependent variable in the model. The same held for the positive and negative dimensions of the SIS-R.

Table 2 Maximum likelihood random-effects model of CAPH psychosis dimensions: lesting for betweenfan ily nandom efrect

\begin{tabular}{|c|c|c|c|c|c|}
\hline $\mathrm{CAPET}_{2}$ & $\begin{array}{c}\text { Variance } \\
\text { between fanily }\end{array}$ & $\begin{array}{c}\text { Likelihood-ratio } \\
\text { test }\end{array}$ & $p$ & the & $95 \% 0 \mathrm{Cl}$ \\
\hline Positive dimension" & 0.34 & 4.64 & 0.02 & 0.21 & $0.07-0.44$ \\
\hline Negative dimension & -- & $-\cdots$ & n.s. & -- & - \\
\hline Dapressive dimension" & $\ldots$ & $-\infty$ & n.s. & 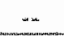 & $=$ \\
\hline
\end{tabular}

:Analysis of variance is adjusted for age, gender, edectional level, and the other two psycthosis dimensions of the CAPL

4. The weighted CAPle scores were expressed as wnits standard daviation (standardisco scorw)

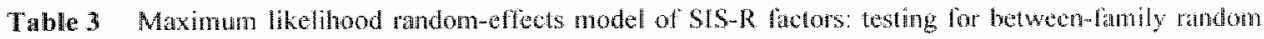
effect

\begin{tabular}{|c|c|c|c|c|c|}
\hline SIS-R & $\begin{array}{c}\text { Varlance } \\
\text { belween fanily }\end{array}$ & $\begin{array}{c}\text { Like hihood-ratio } \\
\text { test }\end{array}$ & $p$ & $r+170$ & $95 \% \mathrm{Cl}$ \\
\hline Positive schizotypy & 0.56 & 4.96 & 0.01 & 0.13 & $0.04 \times 0.31$ \\
\hline Negative schizotypy & 0.69 & 4.02 & 0.02 & 0.13 & $0.03-0.34$ \\
\hline Disorganisation schizotypy & - & $\therefore$ & n.s. & $=$ & - \\
\hline
\end{tabular}

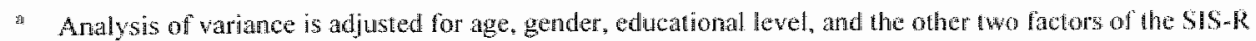




\section{Discussion}

\section{Is there familial clustering of the subclinical psychosis phenotype in the general population?}

In previous studies using the CAPE, evidence was found for widespread variation of different dimensions of the subelinical psychosis phenotype in the general population (Stefanis, Hanssen et al. 2002; Verdoux, Sorbara et al. 2002; Hanssen, Peeters et al. 2003). In the current general population study, evidence for family-specific variation and therefore familial clustering of the CAPE positive dimension and the SIS-R positive and negative dimensions was additionally found. Thus, attenuated expressions with a continuous distribution reflecting the subclinical psychosis phenotype aggregated within families sampled from the general population. Furthermore, dimensions of the subclinical psychosis phenotype aggregated in families independently of each other. These findings parallel the family and adoption studies in schizophrenia (Kety, Rosenthal et al. 1971; Kendler and Gardner 1997), which demonstrated that relatives of patients with psychotic disorders display a higher prevalence of schizophrenia-spectrum disorders than controls. Moreover, the present study is contiguous with studies using schizotypy scales in the relatives of patients with schizophrenia, showing increased levels of the subclinical psychosis phenotype in relatives (Wickham, Walsh et al. 2001), and twin general population studies demonstrating sibling resemblance on positive and negative dimensions of the subclinical psychosis phenotype, part of which was explained by additive genetic factors (Linney, Murray et al. 2003). These converging findings suggest that there is aetiological continuity between the subclinical and the clinical psychosis phenotype in the general population.

\section{Criterion validity of the CAPE}

The CAPE positive dimension and the SIS-R positive dimension displayed a moderately high and significant correlation. This suggests that the positive psychosis dimension of the CAPE has good criterion validity. The correlation of the negative dimension between the CAPE and the SIS-R was lower, but still indicative of criterion validity for the negative dimension of the CAPE. One possible explanation for the lower correlation of the negative dimension is that attenuated negative symptoms are somewhat more difficult to capture with self-report and are more validly assessed by clinical observers. Although the content of the SIS-R negative dimension and the CAPE negative dimension items overlap considerably regarding social isolation, social anxiety and restricted affect, the interview and self-report measure also differ, in that the SIS-R negative dimension incorporates items regarding referential thinking and paranoid ideation (which in the CAPE are included in the positive rather than the negative dimension), whereas the CAPE includes questions regarding avolition. 
Faniliality of the subclinical psychosis phenotype: Structured interview ws. self-report The ability to discern familial clustering of the positive dimension was equally good for both the CAPE and the SIS-R. As the application of self-report measures is costeffective, this research method, at least when using the CAPE and only for the dimension of positive psychotic experiences, may be more economical for the purpose of conducting research in the general population. However, the ability of the CAPE to detect familial clustering of the negative dimension of the subclinical psychosis phenotype was inferior to the interview-based negative dimension. This was partially reflected in the lower correlation between the interview-based and self-report based negative psychosis dimension.

The present findings are a mixture of both affirmative and disconfirmative evidence regarding the superiority of interview-based measures of the subclinical psychosis phenotype in familial research. The inability of our self-report measure to detect familiality of a negative psychosis dimension is in agreement with the findings reported by Kendler et al. (1996) and Catts et al. (2000). The findings of Vollema and Ormel (1999) suggesting equal ability of self-report and interview to measure positive and negative schizotypy (Voliema 1999) contrast with the results of the current study and those reported by Kendler et al. (1996) and Catts et al. (2000). One reason for this discrepancy may be related to the difference in item content and factor solution between the CAPE and the Schizotypal Personality Questionnaire (SPQ), the self-report instrument employed in the study of Vollema and Ormel (1999). In the study by Kendler et al. (1996), the self-report scales used were shortened versions of the original scales and in this way could have lost some of their sensitivity in measuring positive dimensions of psychotic experiences reflecting genetic liability for schizophrenia. The contrasting studies of Catts and colleagues (2000), and Vollema and Ormel (1999) had very small sample sizes that may have contributed to a type II error.

\section{Methodological considerations and liwitations}

Arguably, a disadvantage of the CAPE is the fact that it does not, for psychometric reasons, attempt to measure a disorganisation dimension. Therefore, the self-report and interview measure in the present study could not be compared regarding disorganisation.

The results showed a level of self-reported lifetime psychological complaints in the general population sample (44\%, see Results section) that corresponded with other large scale general population studies in the Netherlands such as the NEMESIS survey, which reported a $41.2 \%$ lifetime prevalence of at least one DSM-III-R disorder (Bijl, Ravelli et al. 1998). In this and previous general population studies, depressed mood, nervous exhaustion and anxiety were the most prewalent problems. The prevalence of selfreported psychotic disorder (1.4\%) was also in accordance with comparable general 
population studies in the Netherlands (1.5\% combined affective and non-affective disorder in NEMESIS (van Os, Hanssen et al. 2001)). Moreover, the mean of the BPRS positive dimension in our general population sample (total score of 4.4 for four positive dimension items) does not fall into the pathological range of the psychiatric rating scale. Therefore, the $44 \%$ prevalence of self-reported lifetime psychological complaints argues against a defensive response style of the subjects and this may be extended to the measures regarding subclimical psychotic experiences. Also, the prevalence of selfreported psychological complaints and the presence of subclinical positive psychotic experiences measured with a psychiatric rating scale argues against the presence of a major selection bias in the present sample.

The findings of the present study showed significant familial clustering of dimensions of the subclinical psychosis phenotype in the general population. Familial clustering does not necessarily imply that the observed phenotype is genetically transmitted (Faraone and Tsuang 1995). It is possible that the observed phenotype aggregates in families due to non-genetic causes or to gene-environment interactions. "Familial" may indicate transmission of environmental risk factors within families that, in combination with predisposing genes, may push an individual over the threshold of disorder (van Os and Marcelis 1998). Nevertheless, familial clustering of psychosis is thought to predominantly represent the influence of shared genes rather than shared environment (Kety, Wender et al. 1994; Cardno, Rijsdijk et al. 2002).

\section{Theoretical implications}

The finding of familial aggregation of dimensions of the subclinical psychosis phenotype in the general population lends credence to the suggestion of a continum of psychosis at both the phenotypic and the aetiological level.

According to the multi-factorial polygenic (MFP) model, quantitative trait loci display small additive effects that in interaction with environmental risk factors may result in the expression of the quantitative psychosis phenotype (Tsuang, Stone et al. 1999). For example, Murray and Fearon (1999) suggest that susceptibility genes in interaction with early intra-uterine or post-partum environmental factors lead to structural abnormalities in the brain or contribute to abnormal cognitive schemata during development (Garety, Kuipers et al. 2001). These in tum may lead to childhood motor and cognitive problems, and tendency to express psychosis-like experiences which in turn may induce a pattern of social relationships in which behaviour is not corrected, an increased risk exists for drug abuse, and difficulties arise in completing education. All these factors may interact and mutually reinforce the risk for clinical psychosis. 


\section{References}

Bijl, R. V., Ravelli, A. and wan Zessen, G. (1998). Prevalence of psychiatric disorder in the general population: results of The Netherlands Mental Healfh Survey and Incidence Study (NEMESIS). Social Psychiatry cand Pspchiatric Epidemiology 33(12):587-595.

Cardno, A. G., Rijsdijk, F. V., Sham, P. C. Muray, R. M. and McGulin, P. (2002). A twin study of genedic relationships between psychotic symptoms. American Journal of Psychiotrm 159(4):539-545.

Catts, S. V., Fox, A. M., Ward, P. B. and McConaghy, N. (2000). Schizotypy: phenotypic marker as risk factor. Australian and New Zealand Jownal of Pspchiaty Sipplemen 34: S101-S107.

Chapman, L. J., Chapman, J. P., Kwapil, T. R., Eckblad, M. and Zinser, M. C. (1994). Putatively psychosisprone subjects 10 years later. Journal of Abrormal fosychology 103(2): $171-183$.

Fanous, A. Gardner, C., Walsh, D. and Kender, K. S. (2001). Relationship between posible and negutive symptoms of schizophremia and schizotypal symptoms in nonpsychotic relatives. Archives of General Pswchiatry 58:669-673.

Faraone, S. V. and Tsuang, M. T. (1995). Methods in psychiatric genetics. In: Textbook in Psychichic: Epidemiolog: M. T. Tsuang, M. Tohen and G. E. P. Zahner (Eds.). New York, Wiley-Liss Inc.: 81-134.

Garety. P. A., Kuipers, E., Fowler, D., Freeman, D and Bebbington, P. E. (2001). A cognitive model of the positive symptoms of psychosis. Psychological Medicime 3/(2): 189-195.

Gruzelier, J. H. (1996). The factorial structure of schizotypy: Part I. Affinities with syndromes of schizophrenis. Schizophrenia Bulletin 22(4): 611-620.

Hanssen, M., Peeters, F., Krabbendam, L. Radstake, S., Verdoux, H. and van Os, J. (2003). How psychotic are individuals with non-psychotic disorders? Social Psychiaty and Powchiotric Epidemiology 38(3): 149-154.

Kendler, K. S. and Gardner, C. O. (1997). The risk for psychiaric disorders in telatives of schizophrenic and control probands: a comparison of three independent studies. Psychological Medicine 27(2): 411-419.

Kendler, K. S. and Hewitt, J. (1992). The structure of self-report schizotypy in twins, Jowrwal of Persomality Disorders o(1): 1-117.

Kendler, K. S., Lieberman, J. A. and Walsh, D. (1989). The Structured Interview for Schizotypy (SIS): a preliminary report. Schizophenia Bulletist $15(4): 559-571$.

Kendler, K. S. Thacker, L. and Walsh, D. (1906). Self-teport measures of sehrotypy as indices of himilial vulnerability to schizophrenia. Schizophenio Bulletin $22(3): 511-520$.

Kety, S. S., Rosenthat, D., Wender, P. H. and Schulsinger, F. (1971). Mental illiness in the biological and adoptise families of adopted schizophrenics. American Jownal of Psychiatry 128(3):82-86.

Kety, S. S., Wender, P. H., Jacobson, B., Ingratham, L, J. Jansson, L.. Faber, B. ef al (1994). Mental illacss in the biological and adoptive rellatives of schizophrenic adoptes. Replication of the Copentangen Situdy in the rest of Denmark. Archives of Genewal Paychatry $5:(6): 442-455$.

Kitamura, T., Okazaki, Y.. Fujinawa, A., Yoshino, M. and Kasahara, Y. (1995). Symptoms of psychoses. A factor-analylic study. Brisish Joumal of Psychiary 166:236-240.

Krabbendam, L... Myin-Germeys, 1., de Graf, R. Vollebergh, W., Nolen, W. A. and van Os, J. (in press). Dimensions of depression, mania, and psychosis in the general population. Pspchollogrided Medicine.

Kuapil, T. R. (1998). Social anhedonia as a predictor of the development of schizophremia-spectrum disorders, Journal of Abroumal Psychology 107(4): 558-565.

Lindemayer, J. P., Bernstein Hyman, R., Grochowski, S. and Bark, N. (1995), Psychopalhology of schizophrenia: initial validation of a 5 -lactor model. Psychopathology $28: 22-31$. 
Lindenmayer, I, P., Grochowski, S. and Hyman, R. B. (1995). Five factor model of schizophrenia: replication across samples, Schizophewa Research /4:229-234.

Linney, Y. M., Murray, R. M., Peters, E. R., MacDonald, A. M., Rijsdijk, F, and Sham, P. C. (2003). A quanitative gentic analysis of schizotypal personality traits. Psychological Medicine 33: 803-816.

Lukoff, D. Nuechterlein, K. H. and Venura, J. (1986). Manual for Expanded Brief Psychiatric Rating Scalle. Schizaphenia Bullein 12(4):594-602.

MacDonatd. A. W., Pogue-Geile, M. F., Debski, T. T. and Manuck, S. (2001). Genetic and environmentat innluerices on schizotypy: A community-based win study. Schizophremia Buhlerin $27(1): 47-58$.

Mata, L., Gilwarry, C. M., Jones, P. B., Lewis, S. W., Murnay, R. M. and Sham, P. C. (2003). Schizotypal perronality trats in nonpsychotic relatives are associated with positive symptoms in psychotic probands. Schizophrevia Bulletim $29(2): 273-283$.

McGory, P. D. Bell, R, C., Dudgeon, P. L. and Jackson, H. J. (1998). The dimensional structure of first episodite psychosis: an exploratory factor analysis. Psychological Medicime 28: 935-947.

Mechl. P. E. (1962). Schizotaxia, schizotypy, schizophrenia. The Anterican Psychologist 17: 827-838.

Meyer, T. D. and Hautzinger, M. (2001). Hypomanic personality, social anhedonia and impulsive nonconlormity: evidence for familial aggregation? Joumal of Personality Disarders 15(4): 281-299.

Peters, E. R2.. Joseph, S. A. and Garety. P. A. (1999). Measurement of delusional ideation in the normal popidation: Introducing the PDI (Peters ef al. Delusions Jnventory). Schizaphenia Bultetin 2.5(3): 553576.

Sax, K. W., Strakowski, S. M., Keek, P. E. J., Upadhyaya, V. H., West, S. A. and McEElroy, S. L. (1996). Relationships among negative, positive, and depressive symptoms in sehizophrenia and psychotic depression. British Joumat of Psychiary 168: 68-71.

Soni, S., Hollis, S., Reed, P. and Musa, S. (1992). Syndromes of schizophrenia on factor analysis. British Jow of Psychiatry 161: 860-861.

StalaCorp (2001). Stata Statistical Sofhware: Release 7.0. Texas, College Station.

Stefanis, N. C., Hanssen, M., Smirn is, N. K., Avramopotilos, D. A., Evdokimidis, 1. K., Stefanis, C. N., et al. (2002). Evidence that three dimensions of psychosis have a distribution in the generall population. Psycholongical Medicine 32(2): 347-358.

Tsuang, M. T. Stone, W. S. and Faraone, S. V. (1999). Schizophrenia: A review of genetic studies. Harword Revien of Psychialy 7: 185-2017.

van Os, J. Gilvarry, C., Bale, R, wan Horn, E. Tattan, T., White, 1., et a. (1999). A comparison of the utillty of dimensional and categorical representations of psychosis. UK 700 Group. Psychological Medicine $29(3): 595 \cdot 606$.

van Os, J. Hanssen, M., Bijl, R. V. and Ravelli. A. (2000). Strauss (1969) revisited: a psychosis continum in the gencral population? Schizophrenia Rexearch $45(1-2): 11-20$.

var Os, J. Hansen. M., Bijl, R. V. and Vollebergh, W. (2001). Prevalence of psychotic disorder and eommunity tewel of psychotic symptoms: an urban-iural comparison. Archives of General Psychiatry $58(7): 663-668$.

vam Os, J. and Marcelis. M. (1998). The coogenetics of schizophrenia: a review. Schizophwenia Restarch $32(2): 127-135$.

van Os, I. and Verdoux, 11. (2003). Diagnosis and classification of schizophrenia: categories versus dimensions, distributions versus disease. In: The Ephemiology of Schizophrenia. R. M. Murtay, P. B. Jones, I: Susser, 1. wan Os and M. Cannon (Eds.). Cambridge. Cambridge University Press: 364-410.

Verdoux, H., Maurice-Tison, S., Gay, B., Van Os, J., Salamon, R. and Bourgeois, M. L. (1998), A survey of delusional ideation in prinary-eare patients. Psychological Medicine 28(1): $12 \%-134$. 
Verdoux, H., Sorbara, F, Gindre, C., Swendsen, I. D. and van OS, J. (2002). Cambabis ase and dinensions of psychosis in a nonclinical population of female subjects. Schizophyen he Reranch $59: 77-84$.

Vollema, M. G. (1999). Schizorppy: Toward the Psychological Hear of Schizophrenta. Oroningen. Groningen University.

Vollema, M. G. and Hoijtink, H. (2000). The multidimensionality of self-report schizotypy in a psychiatric population: an analysis using multidimensional Rasch models. Schizophrento Bullarin 26(3): 565-575.

Vollema, M. G. and Ormel, 3. (2000). The reliability of the structured interview for schizotypy-revised. Schizophrenia Bulletin 26(3): 619-629.

Vollema, M. G., Sitskoorn, M. M. Appels, M. C. and Kalnn, R. S. (2002). Does the Schizotypal Personality Questionnaire reflect the biological-genetic vulnerability to sehizophrenia? Schizophrenia Rexearch $54(1-2): 39-45$.

Vollema, M. G. and wan den Bosch, R. J. (1995). The multidimensionality of schizotypy. Schizophrenia Bulletin $2 /(1): 19-31$.

Wickham, H., Walsh, C., Asherson, P., Taylor, C., Sigmundson, T., Gill, M., et al. (2001). Finniliality of symptom dimensions in schizophrenia. Schzophrenia Research 47(2-3): 223-232.

Yung, A. R., Plvillips, L. J., Yuen, H. P., Francey, S. M., McFarlane, C. A., Hallgren, M., et all. (2003). Psychosis prediction: 12-month follow up of a high-risk ("prodromal") group. Schizophenta Research 60: $21-32$. 



\title{
CHAPTER 6
}

\section{Self-reported psychotic experiences in the general population: a valid screening tool for DSM-III-R psychotic disorders?}

\author{
M. S. S. Hanssen \\ R. V.Bigl ${ }^{2}$ \\ W. Vollebergh ${ }^{3}$ \\ I. van $\mathrm{Os}^{1.4}$
}

1 Department of Psychiatry and Neuropsychology, South Limburg Mental Health Research and Teaching Network, EURON, Maastricht University, Maastricht, The Netherlands

2 Research and Documentation Centre (WODC), Ministry of Justice, Den Haag, The Netherlands

3 The Netherlands Institute of Mental Health and Addiction (Trimbos Institute), Utrecht, The Netherlands

* Division of Psychological Medicine, Institute of Psychiatry, London, United Kingdom 
84. CHATER 6 


\section{Self-reported psychotic experiences in the general population: a valid screening tool for DSM-III-R psychotic disorders?}

\begin{abstract}
Hanssen MSS, Bijl RV, Vollebergh W, van OS J. Self-reported psychotic experiences in the general population: a valid screening tool for DSM. III-R psychotic disorders?

Acta Psychiatr Scand 2003: 107: 369-377. B Back well Munksgand 2003.

Objective: To examine the diagnostic value of self-reported psychoticlike experiences for DSM-III-R psychotic disorders.

Method: A general population sample of 7076 subjects aged 18-64 years was interviewed with the Composite International Diagnostic Interview (CIDI) and, if there was evidence of psychotic experiences, the Structured Clinical Interview for DSM-III-R.

Results: The probability of having a psychotic disorder increased in a dose-response fashion with the level of self-reported psychotic experiences, but individual CIDI psychotic experience ratings had relatively low post-test probabilities (PPs) (range: $5.1-26.5 \%$ ). However, limiting the sample to individuals who had been in contact with mental health services substantially improved PPs (range: 1.3.3$43.1 \%)$

Conclusion: Screening for psychosis in the population carries all high risk of stigmatization in false-positive cases and violation of the right 'not to know' in true-positive cases. However, in mental health care users, self-reported psychotic experiences may be at useful screening tool in individuals who have already developed help-seeking.
\end{abstract}

\section{S. S. Hanssen', R. V. Bijl', W. Volleberght ${ }^{3}$ J. van Os $^{1,4}$}

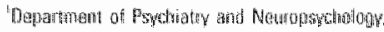

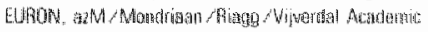

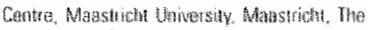

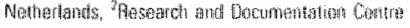

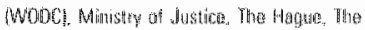

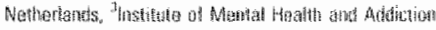

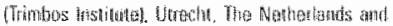

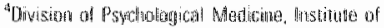

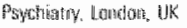

\section{Introduction}

Early detection and intervention of psychosis has become increasingly topical in mental health practice and research $(1,2)$, with interest extending well into the prodromal phases of psychosis $(3-5)$. One of the key variables used to identify possible cases of psychosis is the use of attenuated, brief, or imited psychotic experiences as well as schizotypa! signs and expertences (6-15). However. the prevallence of such often self-limiting or transient psychotic and psychotic-like experiences is many times higher than that of psychotic disorders fulfilling DSM or International Classification of Diseases criteria $(16-18)$. This opens the possibility of high rates of false-positive diagnoses $(7,19)$, with the exception of selected, special groups with a very high baseline prevalence of psychotic disorders $(20,21)$. As the movement of early recognition and intervention, including intervention in the prodromal phases, is rapidly progressing to the stage of ratudomized controlled urats, there is a growing need ror basic epidemiological work investigating the sensitivity, specificily and post-test probability (PP - the probability of having a disorder given the presence of an experience) of psychotic and psychotic-like experiences in generisl population samples.

A crucial distinction is at whe level along the different filters on the pathway to mental bealth care (22) early delection of early psychosis cases is actually intended to lake place. In the general population, psychotic disorders ane rare, and individuals may not have developed illnesssand/or help-seeking behaviour. At the level of mental health services (MHS) and above, the prevalience of psychosis is thigher and help-seeking bethunour is the rule. Thus, risk of stigmatization in false positives should be lowest at the level of MHS whereas at this level violation of the right "not to know" (that onc has an illness) in truc positives should be absent. 
The current study investigates crostsectionaly to what degret the presence of self-reported psychotic experionces in the general population may be used as an indicator of clinician-assessed psychotio disorders [i.c. not examination of predictive afficiency in a longiludinal study (23)]. The PPS of experiences were investigated in two groups. The first group comprised a random cross-section of the general population, and the second comprised a ratndom cross-section of individuals in the general population who had been in contact with MHS

\section{Aimps of the sidudy}

First. to investigate the accuracy of self-reported psychotic experiences as a screening tool in (i) at genetal population sample, and (ii) a MHS sample, by calculating false-positive rates and PP. Secondly, to examine the possible modification of the relationship between self-reported experiences and climician-assessed disonder by the variables age, sex, recency of experiences and disorder, presence of comorbid non-psychotic diagnosis and addilional obserwational psychosis ratings.

\section{Material and methods}

Sample and proredures

The Netherlands Mental Health Survey and Incidence Study (NEMESIS) is a longitudinal study of the prevalence, incidence, course and consequences of psychiatric problems in the general population. There were three measurement points in 1996, 1997 and $1999(24,25)$. The current atticle is based on crossmectional data from the first measurement. A multistage, stratified, random sampling procedune was used to identify a simple. First,90 municipalities were randomly selected, then at sample of private households (anddresses) was taken and eventwally a Duch-spesking individual with the most recent birthday aged 18-64 years from each householk was chosen. A total of 7076 subjects participated at baseline. The response rate was $69.7 \%$. No diflerence in psychiatric morbidity bused on the General Health Questionnaire, $(12$ iiens) (26) was found between responders and nonresponders [for details see $(24,25)]$.

\section{thistrument}

Subjects were interviewed at home. The Composite Internationa Diagnostic Interview (CIDI) version $1.1(27-29)$ was used, yielding DSM-III-R diagnoses: The CIDl was designed for trained interview ers who are not clincians and has been found to have high inter-rater reliability $(0,31)$, and high test-retest reliability $(32-34)$. Interviewers read out questions in at standardized way and record respondents" answers, making the CWDI essentially a self-report instrument (35). Ninety interwewers experienced in systematic data collection collected the data, having received a 3 -day training course in recruiting and interviewing, followed by at 4-day course at the WHO-CID training centre in Amsterdam. Extensive monitoring and quatity checks took place throughout the entire data collection period $(24,25)$.

\section{ClOi psychosis ntems}

The CIDI psychosis section (G-section) consists of 17 core psychosis items on delusions ( 13 iterns) and hallucinations (four items): items $G I-G|3, G| 5$, $\mathrm{G} 16, \mathrm{G} 20$ and $\mathrm{G} 21$. These psychosis items correspond to classic psychotic experiences like persecuwion, thought interference, auditory hallucinations and passivity phenomena. The CIDI has six categories to rate each psychosis item: "I" no experience; '2' experience present but Not Clinically Relevant (NCR) (not bothered by it and not seeking help for it): ' 3 ' and ' 4 ' experience is the result of drug, use or somatic disease; " 5 " true psychotic symptom: 6" experience is not a real symptom because there appears to be some plausible explanation for it with an actual basis in fact. The difference between an experience rating of ' 2 ' and ' 5 ', for example, would be the difference between a person with auditory hallucinations who is not bothered by his voices. or even finds them helpful, and does not seek help, and a person who is severely distressed by the hallucinations and has discussed this with his generat practitioner. A rating of " 6 ", for example, would apply to reports of persecution, which cotald have a basis in fact for example perceived persecution ant the work placel. Psychotic experiences in categories 1-6 will be indicated by the following labels: " 2 " NCR -experience; ' 3 ' and '4' Secondary symptom; " 5 ' Clintical symptom and '6" Possible symptom. Al the NEMESIS basidine measurement, lifetime presence of experiences was assessed, with additionall assess. ment of the recency of the experience and the resulting diagnosis (see below).

\section{Cinicail renuteniews}

According to WHO field research, the CIDI has a high inter-rater reliability $(30,34)$ and test-retest reliability for almost all DSM-III-R diagnoses (34). except for acute psychotic presentations. Acuts psychotic presentations are difficult to analyse in structured interviews $(36-38)$. Therefore, each lime 
when (possible) psychotic symptoms (CIDI rating of 5 " or "67) were detected in the NEMESIS study, a psychiatric clinician conducted clinical re-interviews over the telephone. The clinician used questions from the Structured Clinical Interview for DSM-III-R (SCID) (39) to validate the ratings of the persons who had at least one lifetime rating of 'clinical symptom' or 'possible sympton' on the G-section of the CIDI. If a clinician did not agree with the psychosis rating of the lay-interviewer, the psychosis rating was changed to the rating of the clinician. For all subjects, the CIDI software package accordingly generated DSM-III-R diagnoses based on the corrected CIDI psychosis ratings. The decision not to re-intervew the subjects with an NCR-rating at baseline was motivaled by the very large number of subjects with only an NCR-rating (10\% of the general population). It is highly unlikely that $10 \%(681$ of 7075$)$ of subjects in the general population are missed in diagnosing a psychotic disorder compared with the calculated prevalence of $1.5 \%$ DSM-III-R defined affective and non-atfective psychosis in this sample. However, at T2 it was decided to include the NCRrating in the selection criteria for the re-interview, as the incidence of these at $T 2$ was much lower than the prevalence at baseline.

Of a total of 479 individuals who were eligible for a clinical re-interview over the telephone, 226 $(47.2 \%)$ were actually interviewed (See Table 1). The 226 individuals who were re-interwiewed did not differ from the 253 who were not re-interviewed in the total number of CIDI psychosis items rated '2, ' 3 ', '4, '5' or ' 6 ' (Odds ratio over five-level sum score of number of experiences: $1.07,95 \% \mathrm{Cl}: 0.95,1.21)$. Out of possible 3842 $(226 \times 17) \mathrm{CIDI}$ ratings of psychotic experiences in the 226 individuals who were re-interviewed, changes after clinical re-interview were introduced in 266 ratings $(6.9 \%)$. Excluding CIDI ratings of " 1 " (no experience), this proportion was $35.0 \%$.

\section{Andivses}

As both non-affective and affective psychotic disorders are the object of early recognition and

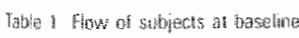

Inclugint

Number of 5 and

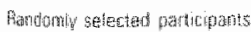

$71, \pi^{*}$

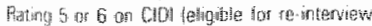

79

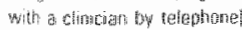

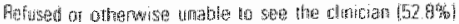

2531

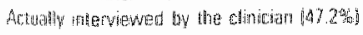

$22 \%$

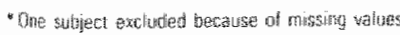

treatment, the current study uses a browd combined grouping of affective and non-affective psychosis, including schizophrenia. schizoplateniform disorder, schizonffective disorder, major depression single/recurrent severe with psychotic features, and bipolar disorder manc/depressed/ mixed severe with psychotic features as outcome variable. Ratings of lifetme presence of experiences and DSM-III-R psychotic disorders were used. with examination of the effect of recency (see bellowy

In total, 7075 subjects completed the whole CIDl-interview at baseline and one subject was excluded from the analyses because of missing values, so the risk for sequence and positioning effects deseribed by Wittchen (1994) (34) is the same for all subjects. In order to avoid the tautology that dinician-assessed experiences were used ans a lest for clinician-assessed psychosis, we used the original, whorrected lay inderviewer assessed CIDI self-report ratings as a sereening tool (i.e. diagnostic test) for elinician-assessed DSM-III-R psychotic disorder. Cross-tabulations of "diagnosis of psychotic disorder" and "the pres. ence of psychotic experiences' were generated by Statta 7.0 (40). Diftereni classes of psychotic experiences were formed, based on the type of CIDI rating.

Three types of analyses were conducted. In the first type of analysis, the diagnostic test was the dichotomous presence/absence of the CIDI psychotic experience ratings. The cross-tabulations of, for example "diagnosis of any psychosis" by "at least one "clinicall sympom" (i.e. score 5 on at least one tem of the G-section of the CIDID", were analysed using likelifiood ratios (LRs) and PPs (4I).

The LR, or how much more likely it is that a positive test result (a psychotic experience) is soen in those with as opposed to those without the disease (psycholic disorder) in question, is the traditional measure of diagnostic watue foulculated as the proportion of true positives (sensiliwity) divided by the proportion of filse posifives $(1$ - specificity)]:

\section{Likelihood ratio $=$ sensitivily/(1 - spectheily)}

A test with a LR of 10 (i.c. 10 times more likely to be a true rather than at latse positive) is generally considered useful (4l).

The PP is the likelihood of disterse (psycholic disorder) given a posilive test resuld (psychotic experience), calculated as the proportion of individuals with psychotic experiences who also have a psychotic disorder:

$$
\mathrm{PP}=\operatorname{pr}(\text { disease } \mid \text { positive test })
$$


As the PP is prevalence-dependent (42) and early recogrition has different implications at different levels of the pathways to care as discussed above, the analyses were re-iterated for the 1352 individuals in the sample of 7076 who had been in contact with MHS during their lifetimes (any contact with community mentent health centre psychiatric outpatient clinic, private psychiatrist, psychologist or psychotherapist, or any psychiatric admission or day treatmentl).

In the second lype of analysis, fogistic regression with the dichotomous experience ratings was used to assess which type of self-reported experience (NCR', "gecondary", "clinical", "possible') had the strongest independent effect on the diagnosis of psychotic disorcler.

In the third analysis, the diagnostic test used was a continuous experience rating the sum score of the number of experiences) of the experience with the strongest independent effect on presence of disorder (clinical symplom - see below). The use of a continuous rating aflowed testing for doseresponse rellationships in the association between psychotic experience loading and presence of psychosis. To this end, PPs were calculated for increasing values of the continuous scores.

Finally, we examined whether the PP of experiences in relation to disorder was nodified by (i) the reported recency of the experience and the disorder (present in the last year or longer than 1 year ago), (ii) age of the individual (aged 45 years or younger ws. older than 45 years (with the rationale that the great majority of schizophrenial onsets occurs before the age of 45), (iii) the presence of comorbid non-prychotic diagnoses (presence of at least one non-psychotic CIDI lifetime diagnosis), and (iv) the presence of one or more of the CIDI lay interviewer observational ratings of neologisms, thought disorder, that affect and thatheinatory behaviour.

\section{Results}

Sample and prevalences

The total general population sample at baseline consisted of 7075 subjects (men: $46.6 \%$, mean age: $41.1, \mathrm{SD}: 12.0$; women: $53.4 \%$, mean age: $41.2, \mathrm{SD}$ : 12.4). Ages were similar in the groups with and without a history of mental health contact (mean ages, respectively, 41.7 and 41.0 years), but the proportion women was, as expected, higher in the mental health contact group $(61.9 \%$ \%5. $53.4 \%$ ) The prevalence of at least one self-reported 'NCRexperience" was 13.0\% (916 of 7075), of "secondary symptom $0.5 \%$ (37 of 7075 ), of clinical symptom $5.6 \%$ (393 of 7075) and of "possible symptom" $4.2 \%$ (297 of 7075 ). The total prevalence of any type of self-reported psychotic experience was $18.1^{\%} \%(1278$ of 7075$)$, in contrast to the reponted $17.5 \%$ (1237 of 7075) of any type of corrected climician-rated psycholic experience in previous papers. The total prevalence of DSM-III-R nonaffective psychosis was $0.4 \%$ (26 of 7075 ) and the prevalence of DSM-IIL-R affective psychosis was $1.1 \%$ (8) of 7075$)$, yielding a total prevalence of psychotic disorder of $1.5 \%$ (107 of 7075 ). The prevalence of psychotic disorder in the group with the additional selection criterion "lifetine contact with MHS' lany psychosis mental health contact (MHC)] was much higher at $6.4 \%$ (86 of 1348 ).

\section{Likelilinod ratios}

The LR for a positive test result for psychotic disorder was high for the experience category "clinical symptom" (23.4) (Table 2). The false-positive rate in this category was low $(4.2 \%)$, and the true-positive rate (sensitivity) was high at $97.2 \%$. The prevalences of the CIDI psychosis items in Table 2 were generally oute high, except for the

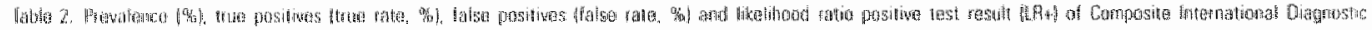

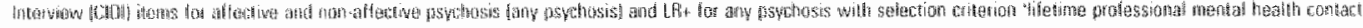
(I)

\begin{tabular}{|c|c|c|c|c|c|}
\hline \multirow[b]{2}{*}{ 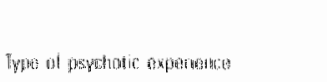 } & \multicolumn{4}{|c|}{ An pasplosis: } & \multirow[b]{2}{*}{ 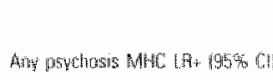 } \\
\hline & Proug & Thu fat & Walse inten & $19+x+40$ & \\
\hline 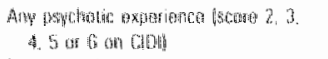 & 辟! & $|(10)| a$ & 16.8 & $6.0[5.7 \times 6.3\}$ & $37 \mathrm{~m}, 4.0$ \\
\hline 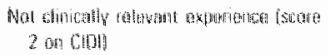 & 100 & 13.9 & 123 & $35[28-4$ & $23: 17-30$ \\
\hline 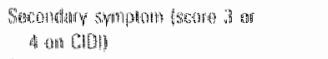 & a 5 & 75 & a.t & $380104-344$ & $79(3.4-394$ \\
\hline 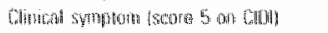 & $5 n$ & $9+2$ & 42 & $23.4120 .9-264$ & $11.19 .3-134)$ \\
\hline 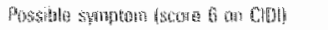 & 42 & 50 & 34 & $168(137-207)$ & $82152 \mathrm{~m}, \mathrm{~g}]$ \\
\hline
\end{tabular}

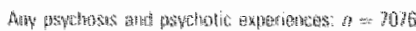

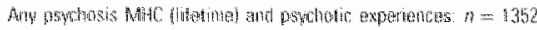




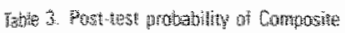

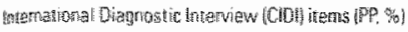

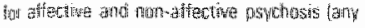

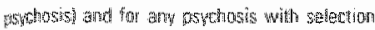

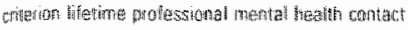

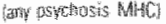

\begin{tabular}{|c|c|c|}
\hline \multirow[b]{2}{*}{ The al perchonic axperimea" } & \multicolumn{2}{|c|}{ 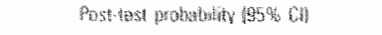 } \\
\hline & An mothosis & 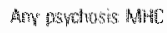 \\
\hline 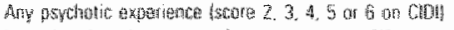 & 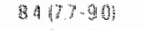 & $2010189-24)$ \\
\hline 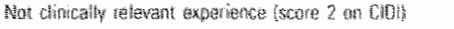 & $5114657)$ & $121415 \cdots 15$ \\
\hline 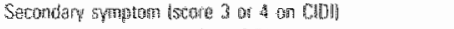 & $2 \mathrm{H} 6[207-226$ & $350125-35$ \\
\hline 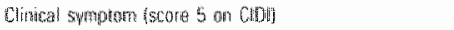 & $265,254-235$ & 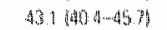 \\
\hline 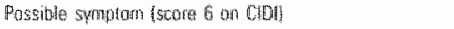 & 20.5019627 .5 & 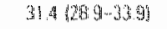 \\
\hline
\end{tabular}

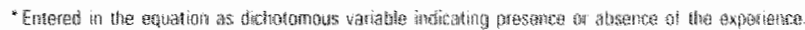

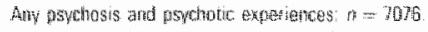

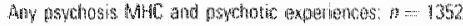

category "secondary symptom" $(0.5 \%)$. After selection of subjects who had a history of contact with MHS during their lifetimes, the LRs of all categories decreased (Table 2, sixth column), but was still thigher than 10 for the category clinical symptom".

\section{Past-test probabilites}

Table 3 lists the PPs of CIDI items for psychotic disorder (any psychosis) and for any psychosis with the additional selection criterion lifetime contact with MHS' (any psychosis MHC). The PP of the clinical symptom" was lighest $(26.5 \%)$. The other psychotic experience ratings had low PPs in the range of 5.1-21.6. After applying the selection criterion of lifetime contact with MHS, the PPS of all experience categories increased (Table 3, third column). The category "clinical sympton' still had the highest vallue $(43.1 \%)$ and the other categories had values in the range of $13.3-35.0 \%$.

\section{Srongest diagnostic test}

The 'NCR", "secondary", "clirical" and "possible" dichotomous experience ratings all were significantly associated wh any psychotic disorder in the logistic regression analysis where each rating was

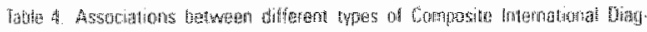

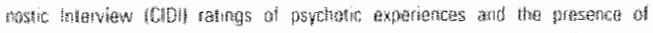

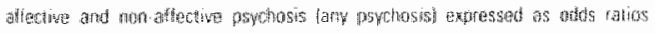
(4)

\begin{tabular}{|c|c|c|}
\hline 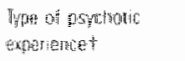 & 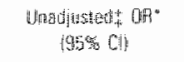 & 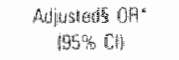 \\
\hline 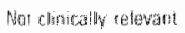 & 5503.919 & 1050.6 - \\
\hline Subntary & 19390.64 .4 & $5.3\{1,5-190\}$ \\
\hline 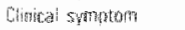 & 0012 4.252.-2539 & $46041 \mathrm{JB}: 5642$ \\
\hline Possible & 37805367 & $56\{34-90\}$ \\
\hline
\end{tabular}

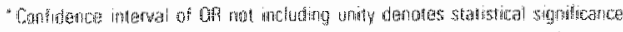

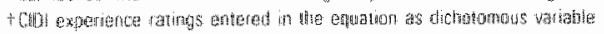

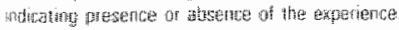

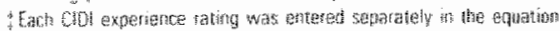

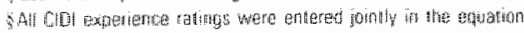

entered separately in the equation (Table 4). Entering the four ratings together in the equation revealed that the "clinical", "possible" and secondary" experience ratings continued to have independent effects on presence of psychotic disonder. The "clinical symptom" was by far the smongest independent diagnostic test.

\section{Continuty of prediction analysis}

In order to assess dose-response, the score indicating the number of 'clinical symptom' ratings for each person (range: 0-16), wats transformed into five categories: zero symptom, one symptom, two symptoms, three symptoms, four or nore symptoms. The more elinical symptoms' were present, the higher the PPs, with monotonic increases from one category to another (Tuble 5). Thas, the PP increased from 13.9 to $82.4 \%$ from the lowest to the highest 'clinical symptom' score category.

\section{Modilication by third variables}

PPs for "clinical psychotic erperience" were calculatied with stratification by age, recency of experience and presence of comorbid non-psychotic dangnosis. The PP was similar for individuats aged up to 45 years $(25,8,95 \%$ Cl: $24,5,27,1)$ and individuals aged $46-64$ years $(28.2,95 \% \mathrm{Cl}$ : 26.5. 29.9). The PP was only slighily higher for women $(27.7,95 \%, \mathrm{Cl}: 26.2,29.1)$ than for men $(24.7,95 \% \mathrm{Cl}: 23,2,26.2)$.

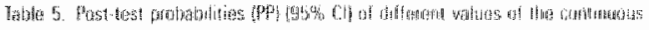

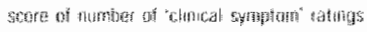

\begin{tabular}{|c|c|c|c|}
\hline 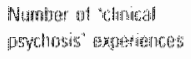 & 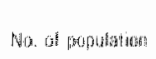 & Wo ar patments & 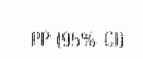 \\
\hline 0 & 664 & 3 & 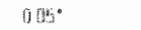 \\
\hline 4 & 224 & 3 & $150113 \% 14 \pi$ \\
\hline 2 & 3 & 50 & $455 \mid 4 \times 3+4(0)$ \\
\hline 3 & 10 & 9 & $3131322 \cdots 414$ \\
\hline और आMa: & 0 & 20 & 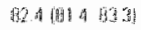 \\
\hline
\end{tabular}

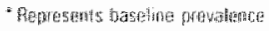


The Pp for 'ellnical symptom' was much higher if the experience was combined with absence of a fiferme non-psychotic DSM-III-R diagnosis $(P P=51.5,95 \% \mathrm{Cl}: 50.3,52.7)$, compared with the combination of the experience and presence of a. DSM $*$ III R non-psychotic disorder $(P P=35.3$, $95 \% \mathrm{Cl}: 34.1,364)$. Similarly, the diagnostic value was substantially increased if "clinical symptom" was combined with a CIDI lay interviewer observattional rating of neologism, thought disorder, flat affec or hallucinatory behaviour $(\mathrm{PP}=54.6,95 \%$ C1: $53.4,55.7)$. The sensitivity of the conbined criterion of "clinical symptom" and absence of comorbid non-psychotic diagnosis was high at $97.2 \%$, whereas the sensitivity of the combined criterion of "clinical symptom' and CIDI lay interviewer observational fating of neologism, thought disorder, flat affect or hallucinatory behaviour was only $5.6 \%$.

Alter exclusion of individuals who had had a 'clinical symptom' or a DSM-III-R psychotic disorder for the last time ionger than y year ago, the PP aropped to $15.2(95 \% \mathrm{Cl}: 14.4,16.1)$. This value was substantially lower than the PP for the entire sample reported in Table $3(26.5,95 \%$ Cl: $25.4,27.5)$.

\section{Discussion}

In a sample of 7076 individuals, only $1.5 \%$ had a DSM-III-R diagnosis of affective or non-affective psychosis, whereas $18.1 \%$ displayed any type of self-reported psychotic experience. A similar discrepancy was reported by Kendter et al. (43), who reported that in the National Comorbidity Study in the US $28.4 \%$ screened positive for any type of pisctwotic experience, whereats the prevalence of broadly defined psychosis was only $0.7 \%$. In the current sudy, some psychotic experiences had PPS in the order of $20^{\%} \%$ or higher with simillarly high L.Rs. The diagnostic value was better in individuals who had had previous mental health care and in individuats without a conorbid, non-psychotic DSM dicignosis. Poorer diagnostic value resulted if only ind viduats with recent psychotic experiences and disorders were included. The greater the number of experiences, the beter the diagnostic value - with no evidence of a threshold effect. These results are in line with the findings of Eaton a al. (1991) (16). These authors reported that in the general poputution. the prevalences of the psychotic expericme inems of the National Institute of Mental Heulh (NIMH)-Diagnostic Interwiew Schedule (DIS) varied between 1 and $12 \%$. The DIS is at precursor of the CIDI (34). Furthermore, when code 5 of the DIS - ie. a clinical symptom - was applicd. Eaton et al. (1991) observed an increase in the specificity of the psychotic experience itens of the DIS, but a decrease in sensitivity. The resuls of the present study show the same patiern of increase/decrease in, respectively, specificily and sensitivity of the CIDI psychosis items.

\section{Nerthdologlal issies}

The rationale for deciding only io re-interview the group with a score of ' 5 ' or 6 ' 6 ' on the CIDI psychosis items was that it was not possible to re-interview all subjects $(n=7076)$. Thus, some individuals with a CIDI NCR psychosis rating are likely to represent false positives or false negatives. It is unlikely that the very high proportion of subjects with only an NCR-rating $(10 \%$ represents a group of false negatives compared with the expected prevalence of psychosis of $1.5 \%$ in this sample.

In addition, the focus of this paper was on diagnostic value, contrasting lay-interviewer recorded self-repart (i.e. without reminterview by the clinician) and chinctan assessed disorder. We chose for this design because it is important to assess the value of self-reported experiences, as only these can arguably be used economically in the context of population screening. Population screening by clinicians using the SCID is not a sereening scenario. ats this amounts to a direct clinical diagnostic procedure rather than a screening procedure.

The age range examined (18-64 years) is arguably large. However, the outcome in this study wots all affective and non-affective psychosis, with a considerably larger age range of onset than just narrowly defined schizophrenia. The fact that there was no difference in diagnostic value as a function of age group jusifies the selection.

Because of the incomplete clinical re-interview rate of individuals with (possible) CIDI psychotic symptoms, 40 of the 107 individuals with at DSM-III-R psychotic disorder fulfilled the diagnostic criteria withou verification by cincian interview, In order to check whether this could have influenced the results, analyses were repeated. excluding the 253 indriduats with (possible) CIDI psychotic symptoms who were eligible for dinical re-interview but who were not interviewed. This yielded very similar results. For example, the PP" for "clinical symptom" was $27.1 \%(95 \%$ CI: 26.0. 28.1 , the PP for possible symptom $22.6 \%$ o $95 \%$ CI: $21.6,23.6)$ and the PP for NCR experience was $3.5 \%(95 \%, \mathrm{Cl}: 3.1,4.0)$

Intenpretation of tindings

Deteting a rane disease. Three problems arise in the seatch for markers of psychotic disorder in the 
aeneral population. Firsi, known risk indicators of psychotic disorder, for example, a family rnember disgnosed with schizophrenia, are more prevalent than psychotic disorder itself. Even psychotic experiences like delusions and hallucinations are more prevalent in the population than in psychotic disorder $(16,44)$. This means that the specificily of risk indicators is low, resulting in a low PP. Secondly, the sensitivity of risk indicators for psychotic disorder is low. For example, only around $20 \%$ of the individuals with a ditgnosis of psychotic disorder have a positive family history for psychotic disorder $(45,46)$. Most important. however, is that the prevalence of psychotic disorder is too low to guarantee a good PP of potential diagnostic tests (19).

Can experiences be used as a diagnostic best in the geweral poyulation? The current study examined the value of self reported psychotic experiences as a dagnostic test for clinical psychotic disorder in a cross-sectional setting. Only one category of the CIDI had a $P P$ higher than $25 \%$ : at least one 'clinical symptom' (26.5\%). A PP of $26.5 \%$ indicates that of 100 subjects with at least one clinical symptonn, one-quarter has a psychotic disorder and three-guarter does not have a psychotic disorder. In addition, the LRs of this category was higher than 10 , i.e. satisfactory, and the number of false positives was small. In spite of these values, however, this experience arguably does not constitute a good diagnostic rest, i.e. screening tool. Although it would be relatively easy to collect self-reports on psychotic experiences in the general population, around $75 \%$ of those who tested positive would be wrongly labelled with psychotic disorder. Although this might be acceptable in the case of a disease with a $100 \%$ mortality ralle that strikes young people and for which an acceptable and successful cure is avalable, it may not constitute good screening practice in the case of schizophrenia. Furthermore, the results show that further reductions in diagnostic efficiency cat be anticipated in the case of recent symptomatology (the most interesting from the point of wiew of screening). One explanation of this observed 'recency" effect is that subjects with recovered insight might be reporing more reliably on a past episode of psychosis than subjects reporting active psychotic experiences.

Solutums the "rare discase" problem. One practical solution for the problems inherent to screening for psychotic disorder is to increase artificially the prevalence of schizophrenia in the screening population. This is because the PP is prevalence-dependent and increases dramatically is the prevalence of the disease in question rises $(20$. 42). One way to increase the prevalence is to serially combine several risk factors together so that the test becomes much more stringent and the prevalenee of psychosis in this group much higher. Yung and McGorry (1997) advocated the use of a clase in" strategy by adding several risk factors to identify at very high-risk group. However this approach would not be suitable in the general population. as each time a (rare) risk factor is added, the sensitivity drops so that finally only at fruction of the target group could screen positive and most would be missed by the test. For example, combining the "clinical symptom" rating with CIDI lay interviewer observational ratings greatly increased the PP. but had a sensitivity of only $5.6 \%$. The same reasoning holds for the dose-response analysis presented in Table 5. The PP in the highest experience score category was more than $80 \%$, but only around $25 \%$ of the patients had four or more clinical symptoms. For some criteria, thowever, a "close in" strategy may work if the criterion is very prevalent. For example. the sensitivity of the combination "slinical psychosis experience' rating with absence of conorbid DSMIII-R non-psychotic diagnosis had a sensitivity of $97.2 \%$

A better solution to the problem may be to "astise" the prevalence of psychosis by only using the diagnostic test in individuals who have alreacy been in contact with MHS. Goldberg and Huxley's filter model predicts that the prevalence of schizophrena will increase whenever one passes a filier to another level of MHS (22). Levels 1-5 comprise the levels of the general population, primary care (physician), mental disorder recognized by the physician, out-patient mental heallh care and in-patient care. Because of the low prevalence of psychotic disorter and the resulting lack of specil icity and sensitivity of diagnostic markers, screening cannot be implemented effectively at the lower levels, as suggested by our results. We therefore selected from our sumple the subjects who had aready entered the fourth or fith level of Goldberg and Huxley's mould, ice the individuals who had sough help for mental heald problems. The prevalence of non-affective and affective psychosis in the sample of people who had entered the fouth or fifth level of Goldberg and Huxley's molel was $6.4 \%$, or more than four times higher than in the general population. Screening in this group hats several important advantages. First. as the prevat ance of psychotic disorder in this group wats much bigher than in the general popalation, the PP's also increased (although LRs may decrease becduse of diagnostic "admixture'). Sccondly, as 
these individuas have already developed helpseeking behaviour for a mental health problem $447,48)$, there is much less danger of stigmatization in the case of a false-positive test result, or of wiolating the right "not to know" in the case of a the-positive test resull.

Another way to reconsider the outcome under study is to conceive of the clDl psychotic ratings themselves as intermediary phenotypes that soneumes, after exposure to additional risk factors, may progress to psychosis (49). In this case, identification of the intermediary phenotype could be a goal in itself if there were ways to modify the rate of progression to the psychosis endpoint. However, this type of primary prevertion is not yet possible in psychosis. Nevertheless, further study of the nature of subclinical psychotic phenomena in the general population as possible "catual intermediates" for the psychosis endpoint (49) is clearly warranted.

Confinum of diagnostic funcolom. Although the CIDI rathgs used in this study were self-report in the absence of clinical re-interview, the CIDI has follow-up questions to separate organic from nonorganic psychotic experiences, and to separate 'possible' and 'non-patthological' experiences from clinical symptoms. Thus, the experience with the highest diagnostic value for psychotic disorder was the CIDI rating of 'clanical symptom", whereas the rating of "any experience" had a very low walue. In order to obtain comparable results for self-report ratings of psychotic experiences, inclusion of CIDIlike follow-up questions is therefore necessary. A recent investigation allso found that selfreported psychotic experiences in 11 -year-old children had very higl predictive values for clinical psychosis 15 years later (15). The finding of a dose response relationship in the association between a CIDI Clinical Isychosis malling on the one hand, and any psischotic disonder on the other in a general population sample suggests the absence of a "Threshold effect" in diagnostic function. Thus, the number of experiences can be interpreted as a continuots diagnostic function in clinical practice.

\section{References.}

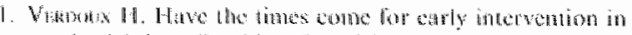

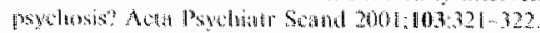

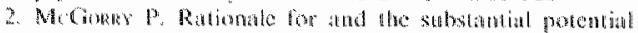

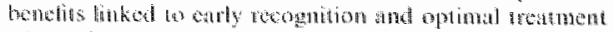

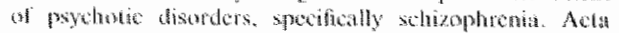

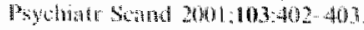

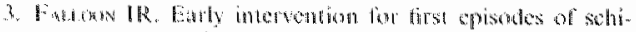

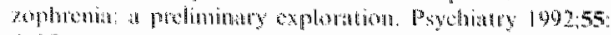
$+45$

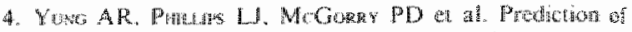

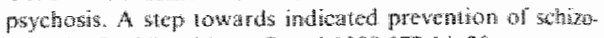
pharenia. Br I Psychiatry Supp! $1098: 172: 1420$

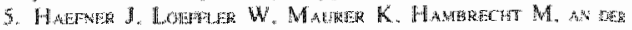

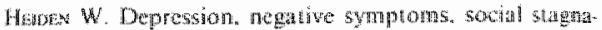

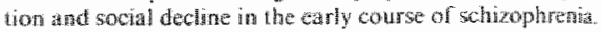

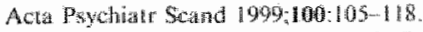

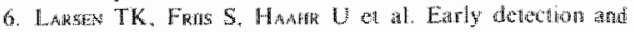

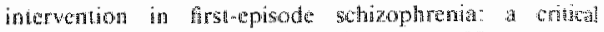
review. Acta Psychial Scand 2001:103.323-334.

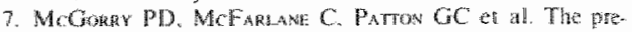

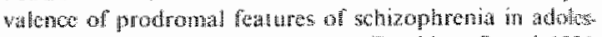

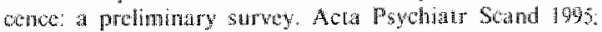
$92: 24: 1-249$

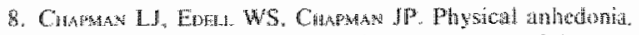

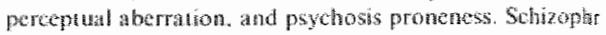
Bull 1980:663965\%.

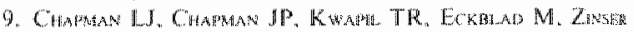
MC. Patadely poychosis-prone subjeds 10 years ande.

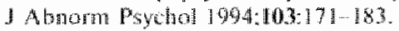

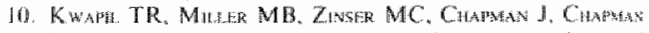
11. Magicat idention and sorial anfwedonia as predichors ol paychosis: proneraess: a partidal replication. I Abnorm Psychol 1997;106:491-4955

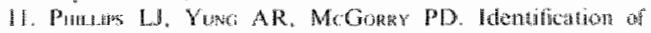
young people at risk of psychosis vallidaton of Persond Assessment and Crisis Evaluation Clinic wake crisernot.

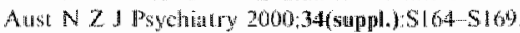

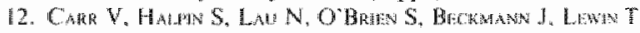
A risk lactor screening and assessment protocol for sch.

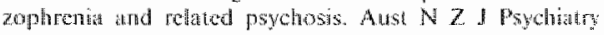
$2000 ; 34($ sappl.) $5170 \% 5180$.

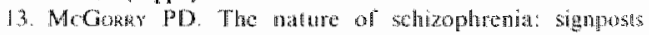

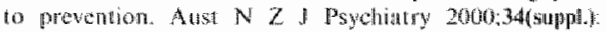
$514-521$

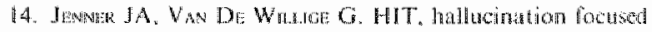

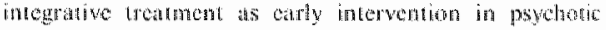

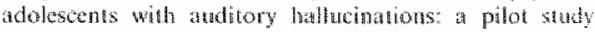
Acta Psychiati Soand 2001:103:1483:152.

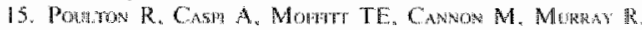

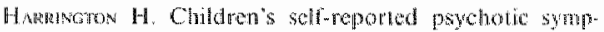
toms and adul sethizophendorm disorder: it 15 year

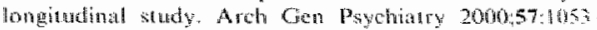
$\$ 0.58$

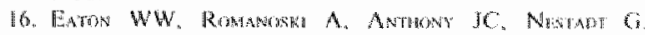

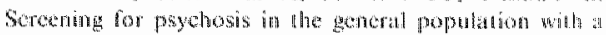

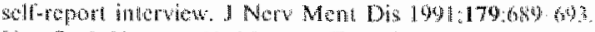

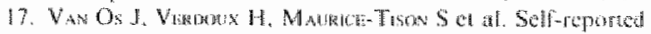

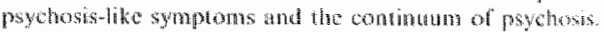

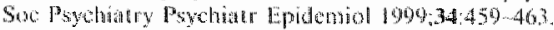

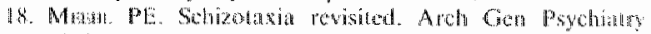
$1980.460 .35-9,44$

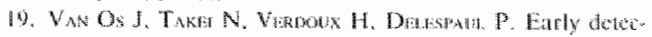

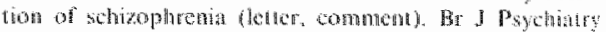
$1997: 170: 5 \%$.

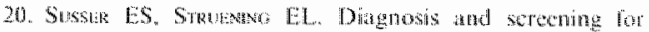
prychotic disordes in a study of the homeles Schizoph Bull 199016:13\%145.

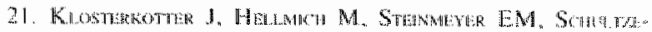

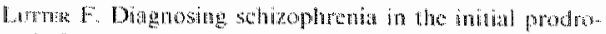
mat phase. Arch Gen Psychiat ry 2004:58:158-164.

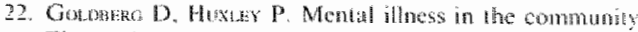

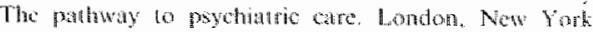

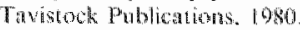

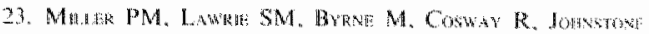

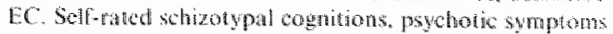




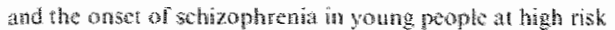
of schizopingena Acta Pyehier Seand $2002105341-345$

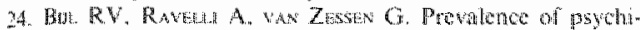

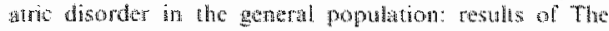
Nebertands Mental Heath Surey and Inchdence Study (NEMESH). So Psychatry Psychiat Epidomol togs $33.387-395$

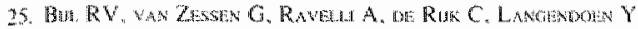
The Netherlands Mental Health Survey and Incidenes

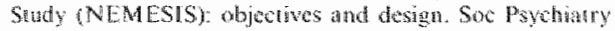
Psychint Epidemiol $199833.581-586$.

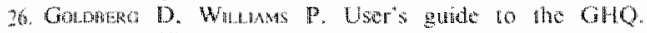
Windsor: MEER-Melson, 198s

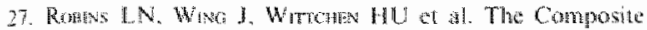
International Diaznostic Interwew, An eprdemologto insurument suitable for use in conjunction wibl difterent diagnoste systems and in difleren cullures. Aroh Gen Psychiat $1988: 45: 1069$ 1077?

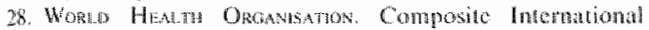

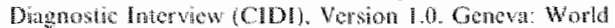
Heath Onganisation, 1900 .

29. Shatrs RMW. Dingamans PMAJ, Composite Internathomal Diagnostic Interview (CIDI). Versie 1.1. Amsterdanz Geneve: Word Healh Oramisanon. 1998

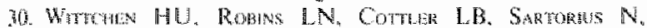

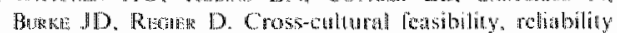
and soutecs of varianoe of the Composite Untoratarional Diagnostic Interew WHOMADAMHA Field Trakls (Published cranum in Br

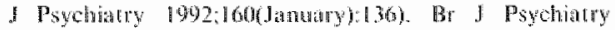
$1901159 \cdot 645-637$

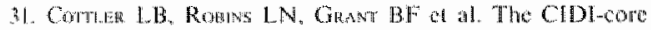
substance ibuse and dependence questions: cross-culutal

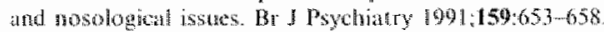

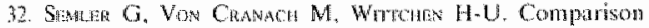
berwen the Conmposite International Diagnostic Interview and the Prescrat State Examination. Repont to the WHO/ADAMHA lask fore on instrumen development. Geneva: World Healh Oreanisation. 1987.

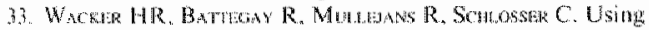
the ClDH in the general popution. In: Srepand CN, RAb-

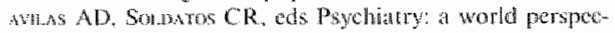

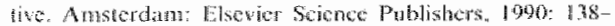
143

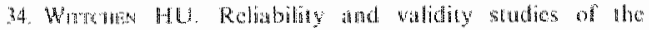

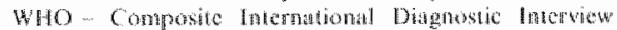

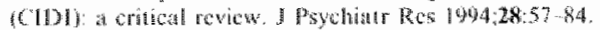

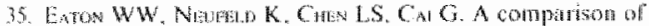

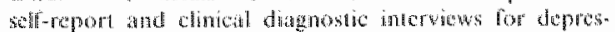
sion, diagrostic inferves scheduly and setnedules for clin-

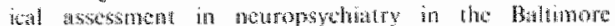

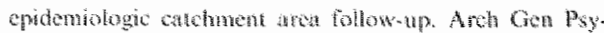
dhentry $2040.57+277-222$.

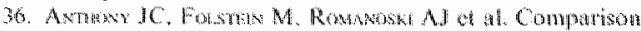

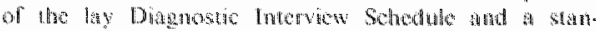

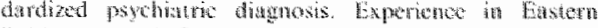

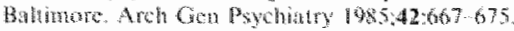

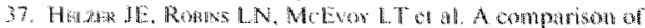

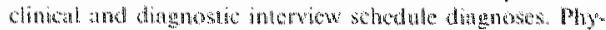

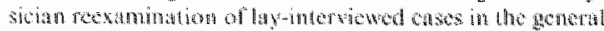

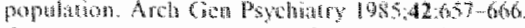

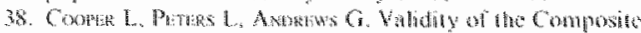

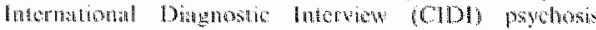

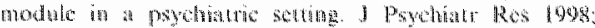
$32.361 \cdots 368$

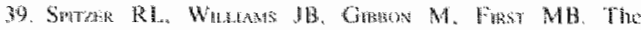

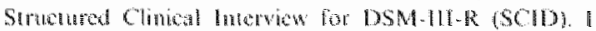

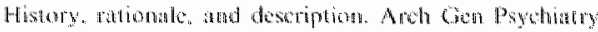
$1902.49: 624029$

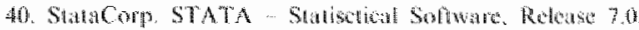
College Sulam. TX: Siatacarp. 2001.

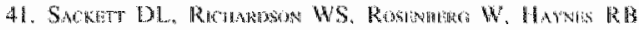

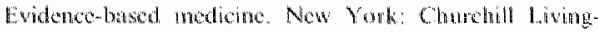
scone, 1997 .

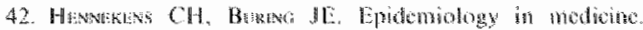

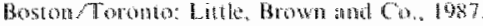

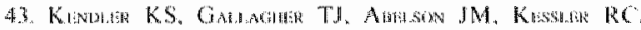

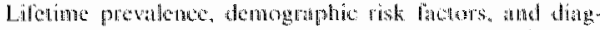

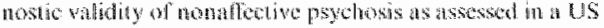
community sinmple. The Nintional Combromblity Survay. Arch Gen Psychiat 1996,53:1022 1001

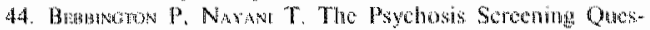

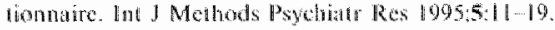

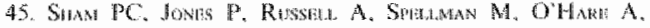

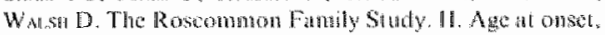
$\mathrm{sex}$. and fomilat psychistro notbidy in schizophronia. Camberwell Collatbontive Pychosis study. Be I Psychinatry $1994: 165: 466-473$

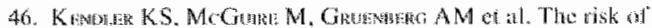

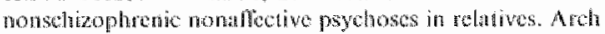
Gen Psychichtin 1993:50:645-652.

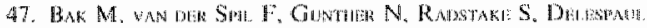
P. Van OS $J$. Matatridu Assessment of Coping Sirategics (MACS-1): brief instrenent 10 assess coming wibn psy-

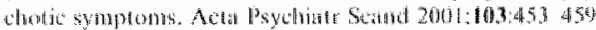

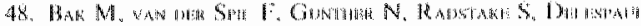

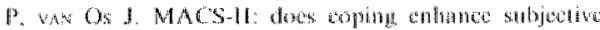

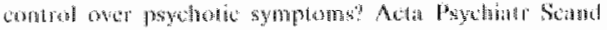
$2001: 103: 460.464$

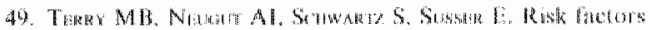

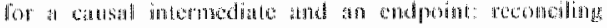

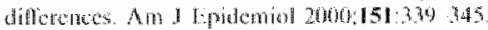





\section{CHAPTER 7}

\section{Outcome of self-reported psychotic experiences in the general population: a prospective study}

M. Hanssen"

M. Bak

R. Bijl $\left.\right|^{2,3}$

W. Vollebergh ${ }^{3}$

J. $\operatorname{van} \mathrm{Os}^{1.4}$

1 Department of Psychiatry and Neuropsychology, South Limburg Mental Health Research and Teaching Network, EURON, Mastricht University, Maastricht, The Netherlands

2 Research and Documentation Centre (WODC), Ministry of Justice, Den Haag, The Netherlands

3 The Netherlands Institute of Mental Health and Addiction (Trimbos Institute), Utrecht, The Netherlands

4 Division of Psychological Medicine, Institute of Psychiatry, London, United Kingdom 


\begin{abstract}
Objectives. To examine the 2-year outcome of incident psychotic experiences in terms of stability, umpaiment and need for care.

Design. The Netherlands Mental Health Survey and Incidence Study (NEMESIS), a longitudinal general population study.

Methods. A representative population sample of 7076 subjects was interviewed with the Composite International Diagnostic Interview at baseline, one year later at $T_{1}$ and again two years later at $T_{2}$. A sample of individuals was selected who had onset of a new, broadly defined, self-reported psychotic experience between baseline and $T_{1}$ $(n=83)$. In this sample, stability outcome of positive psychotic experiences at $T_{2}$ was assessed by clinician-corrected CIDI lay interview (CIDI outcome, $n=58$ ) and by clinical interview both in terms of presence of any psychotic experiences measured by the BPRS (BPRS outcome, $n=47$ ), and in terms of clinical relevance using criteria of functional impairment and need for care (clinical outcome, $n=11$ ).

Results. The great majority of individuals with incident psychotic experiences at $T_{1}$ had no detectable psychotic experience at $T_{2}$. The 2 -year predictive values of incident psychotic experiences at $T_{1}$ were $18.1 \%$ (16.9-19.3) for the CIDI outcome, $16.5 \%(15.3$ - 17.6) for the BPRS outcome and 7.6\% (6.8 - 8.4) for the clinical outcome. Presence of distress connected with the $T_{1}$ psychotic experience was associated with poorer outcome in terms of functional impairment and need for care.
\end{abstract}

Conclusions. The great majority of incident positive psychotic experiences remits spontaneously, but a small proportion becomes clinically relevant, depending on type and emotional appraisal of the psychotic experience. 


\section{Introduction}

Key variables used to identify possible cases of psychosis in the early stages are attenuated, brief, or limited psychotic experiences as well as schizotypal signs and symptoms (Chapman, Edell et al. 1980; Chapman, Chapman et al. 1994; Kwapil, Miller et al. 1997; Carr, Halpin et al. 2000; McGorry 2000; Phillips, Yung et al. 2000; Poulton. Caspi et al. 2000; Jenner and van de Willige 2001). However, such experiences are very prevalent (van Os, Hanssen et al. 2000; Johns, Nazroo et al. 2002) and little is known about their outcome with the exception of selected, special groups (Susser and Struening 1990; Klosterkötter, Hellmich et al. 2001), or groups that were followed over much longer periods of time than are practical for the purpose of clinical evaluation (Chapman, Chapman et al. 1994; Kwapil, Miller et al. 1997; Poulton, Caspi et al. 2000).

This study is a follow-up of individuals with recent onset of self-reported psychotic and/or psychosis-like experiences in the general population, examining their outcome in terms of stability of the psychotic experience, as well as functional impairment and need for care. In view of the literature suggesting that outcome of psychotic experiences is in part dependent on the severity and emotional appraisal of the experience (Garety and Freeman 1999; Birchwood, Meaden et al. 2000; Poulton, Caspi et al. 2000; Krabbendam, Janssen et al. 2002), the prognostic value of these was additionally examined.

\section{Method}

\section{Participants}

The present article describes a longitudinal study of the outcome of incident psychotic experiences in the general population. This study is a part of the Netherlands Mental Health Survey and Incidence Study (NEMESIS), a longitudinal study of the prevalence, incidence, and course and consequences of psychiatric disorders in the Dutch general population. Subjects were contacted at three points in time, namely 1996 (baseline), $1997\left(\mathrm{~T}_{1}\right)$ and $1999\left(\mathrm{~T}_{2}\right)$ (Bijl, Ravelli et al. 1998; Bijl, van Zessen et al. 1998). The sampling procedure and response rate is described in detail in previous work (van Os, Hanssen et al. 2000; van Os, Hanssen et al. 2001). A total of 7076 subjects between 1864 years were enlisted at baseline. At T, 5618 subjects participated for the second time; at $T_{2}, 4848$ subjects participated. 


\section{Measures}

\section{CID psychosis ratings}

The sample was interviewed at home with the Composite International Diagnostic Interview (CIDI) version 1.1 (Smeets and Dingemans 1993) at all three measurements. The CIDI generates DSM-III-R diagnoses and is designed for trained interviewers who are not clinicians. Interviewers read out questions in a standardised way and record respondents" answers, making the CIDI essentially a self-report instrument (Eaton, Neufeld et al. 2000). Ninety interviewers experienced in systematic data collection collected the data for the NEMESIS, having received a 3-day training course in recruiting and interviewing, followed by a 4-day course at the WHO-CIDI training centre in Amsterdam. Extensive monitoring and quality checks took place throughout the entire data collection period (Bijl, Ravelli et al. 1998; Bijl, van Zessen et al. 1998).

The CIDI psychosis section (G-section) consists of 17 core psychosis items on delusions ( 13 items) and hallucinations ( 4 items): items G1-G13, G15, G16, G20 and G21. These psychosis items correspond to classic psychotic symptoms like persecution, thought interference, auditory hallucinations and passivity phenomena. The CIDI has six possible ratings for each psychosis item: i) no psychotic experience; ii) not clinically relevant psychotic experience (the subject is not experiencing distress and is not seeking help); iii) and iv) experience is the result of drug use or somatic disease; v) true psychiatric symptom (subject experiences distress and/or seeks help); vi) what appears to be a psychotic symptom with distress/help-seeking may not be a real symptom because there appears to be some plausible explanation for it. The difference between a symptom rating of ' 2 ' and ' 5 ' for example, would be the difference between a person with auditory hallucinations who is not bothered by his voices, or even finds them helpful, and does not seek help, and a person who is severely distressed by the hatlucinations and/or has discussed this with his general practitioner. A rating of ' 6 ', for example, would apply to reports of persecution, which could have a basis in fact (for example perceived persecution at the work place). Psychotic experiences in categories 1-6 will be indicated by the following labels: i) No Experience; ii) Without Distress; iii) and iv) Secondary Experience; v) With Distress; vi) Possible Experience. Validation of these symptom contrasts was presented previously (van Os, Hanssen et al. 2001).

\section{$T_{1}$ incident psychotic experiences}

In order to define a sample with incident psychotic experiences that could be followed over time, individuals who had a diagnosis of any affective or non-affective psychotic disorder according to the DSM-III-R at baseline and at $T_{1}$ were excluded from the analyses. In addition, individuals who had had any rating of CIDI psychotic experiences in the 12 months before baseline and/or at baseline were also excluded from the 
analyses. This ensured that the sample was skewed towards those who had onset of at least one new self-reported psychotic experience between baseline and $T_{\text {: }}$

\section{$T_{2}$ psychosis ourcome}

At $\mathrm{T}_{2}$, clinical re-interviews were conducted over the telephone by an experienced clinician (psychiatrist, senior psychiatric trainee or psychologist) for all indiwiduals who had a rating of ' 2 ', ' 5 ' or ' 6 ' on any CIDI psychosis item. The proportion of eligible individuals that was successfully re-interviewed by the clinician was $74.4 \%$ (see below). The two items of the Brief Psychiatric Rating Scale (BPRS) (Overall \& Gorham, 1962) of 'unusual thought content' and 'hallucinations' were additionally scored by the clinician (range: 1, 'absent' to 7, "very severe"). These BPRS items were chosen as they represent the positive psychosis items. If clinicians rated a CIDI symptom differently than the lay-interviewers, the rating of the lay-interviewer was changed to the clinician's rating as it represents the 'golden' standard. DSM-III-R diagnoses were based on these corrected CIDI ratings.

Three $\mathrm{T}_{2}$ psychosis outcomes were defined and used to examine the degree of stability from $T_{1}$ to $T_{2}$. The three outcomes reflected differences in severity and differences in the way psychosis was assessed.

The first was the CIDI outcome, defined as the presence of 'Any psychotic experience' measured by the CIDI at $T_{2}$ given the presence of one or any of the various CIDI psychosis ratings of ' 2 ', ' 5 ' or ' 6 ' at $T_{1}$. The second outcome was evidence of any psychotic experience at any level on either of the two BPRS items (score > 1; hereafter: BPRS outcome). The third outcome was defined in terms of severity and functional impaiment on the one hand, and in terms of clinical judgement of need for care on the other (hereafter: clinical outcome). This outcome was based on presence of two criteria: i) a BPRS score on either of the two psychosis items that was greater than pathology level in terms of severity and functional impairment (i.e. BPRS score $>3$, see (Lukoff, Nuechterlein et al. 1986) and ii) presence of clinical judgement of need for care, as recommended for case identification in the general population (Spitzer 1998). Clinical judgment of need for care was determined during a consensus meeting after the telephone-interviews at $T_{2}$, attended by two psychologists and two psychiatrists. During the consensus meeting, all material was presented for each case. The clinicians then discussed whether there was a need for mental health care, using information gathered on the 22 areas of need as defined in the Camberwell Assessment of Need (CAN) (Slade, Phelan et al. 1996), in particular in relation to psychotic symptoms and psychological distress. Need for care was rated as follows: i) no need for care ii) probable or definite need for care. 


\section{Diagnostic walidarion}

In order to validate the clinical outcome rating, associations with a priori selected third variables were examined in a comparison with the rest of the individuals who were interviewed at $T_{2}$ and who did not have a previous diagnosis of psychotic disorder at baseline or $T_{1}$. All these validating variables had been collected during the CIDI interview by the trained non-clinicians, independent of the re-interview by the clinicians, who had been blind to this information from the CIDI interview. For example, one of the selected third variables is item 10 of the Short Form Health Survey, i.e. SF-36 (van der Zee, Sanderman et al. 1993; Ware, Gandek et al. 1994). The SF-36 measures the health-related quality of life and item 10 of the SF-36 inquires about the interference of physical and emotional problems with nomal social activities in the past four weeks.

\section{Analyses}

In order to test whether psychotic experiences associated with distress had a worse oulcome, different classes of self-reported psychotic experiences at $T_{1}$ were formed, based on the type of CIDI rating. These $T_{1}$ CIDI ratings were analysed in relation to the three psychosis outcomes at $T_{2}$, calculating i) post-test probabilities (PPs) with the DIAGTEST procedure in the STATA statistical program, version 7 (StataCorp 2001), and ii) odds ratios (ORs) using the LOGISTIC procedure in STATA. The PP is the likelihood of disease (psychotic disorder) given a positive test result (psychotic experience), calculated as the proportion of individuals with psychotic experiences who had developed a psychotic disorder two years later (Sackett, Richardson et al. 1997).

\section{Sensitivity analyses}

As we did not re-interview all of the eligible subjects at $T_{2}$ who had displayed evidence of psychosis (the clinical re-interview rate was $74.4 \%$ as described above), we conducted sensitivity analyses to examine whether differential attrition could have biased any findings. This was done by substituting missing data in the subjects who had missed clinical re-interview in such a way that the extremes of any bias could be quantified. In the first sensitivity analyses, all missing subjects were allocated to the category of clinical outcome (i.e. a person with BPRS pathology-level of psychotic symptoms and a need for care) and in the second type of analyses, all missing subjects were allocated to the category of non-clinical outcome. 


\section{Results}

A total of 4067 individuals who had i) no DSM-III-R affective or non-affective psychotic disorder at baseline and $T_{1}$ and ii) no CIDI psychotic experiences in the 12 months before baseline, and iii) valid baseline, $T_{1}$ and $T_{2}$ interviews were available for analysis. Of these, the number of subjects with incident psychotic experiences at $\mathrm{T}$, was 83. At $\mathrm{T}_{2}$, the number of individuals with clinical outcome was 11 (probable: 8 , definite: 3), with BPRS outcome 47 and with CIDI outcome 58.

In terns of relative risk, effect sizes of psychotic experiences at $T_{\text {, for the clinical }}$ outcome at $\mathbb{T}_{2}$ was very high with odds ratio"s varying from 46.5 to 94.2 (Table 1). However, the odds ratios for the BPRS and CIDI outcome were more moderate, albeit still rather high (BPRS outcome: OR 14.8-24.9; CIDI outcome: OR 12.8-26.6). In terms of post-test probabilities, the effect sizes for the clinical outcome were modest, with PPS ranging from 0.00 to $15.8 \%$ (Table 1). Similar results were apparent for the BPRS and CIDI outcome.

\section{Diagnostic validation}

The clinical outcome was strongly associated with a family history of delusions and/or hallucinations as reported by the subject ( $\mathrm{OR}=5.3,95 \% \mathrm{CI}, 2.0,14.6)$, lifetime history of use of mental health services $(\mathrm{OR}=5.2,95 \% \mathrm{Cl}: 2.3,11.8)$, reported interference of physical and emotional problems with normal social activities (item 10 of the SF-36 (van der Zee, Sanderman et al. 1993; Ware, Gandek et al. 1994); OR over 5 levels: 1.5, $95 \% \mathrm{Cl}: 1.1,2.0)$, and lay-interviewer CIDI rating of observed emotional blunting $(\mathrm{OR}=31.1,95 \% \mathrm{Cl}: 6.6,145.5)$. Also, the clinical outcome was strongly associated with the demographic variables: being unemployed $(\mathrm{OR}=5.6,95 \% \mathrm{CI}: 2.2,14.2)$ and being single or divorced $(\mathrm{OR}=3.0,95 \% \mathrm{CI}: 1.3,6.6)$.

\section{Prediction as a function of quality of psychotic experiences}

For the clinical outcome, With Distress psychotic experiences and Possible Experiences had significantly higher PPs than Without Distress experiences, as indicated by nonoverlapping confidence intervals (Table 1). For the BPRS and CIDI oulcome. differences between the different CIDI psychosis ratings were less marked. PPS for Secondary Experiences could not be estimated due to the small number of these at $T_{1}$.

The sensitivity analyses showed that the results were largely robust io possible diagnostic differential attrition (shown for clinical outcome in Table 2 ). 


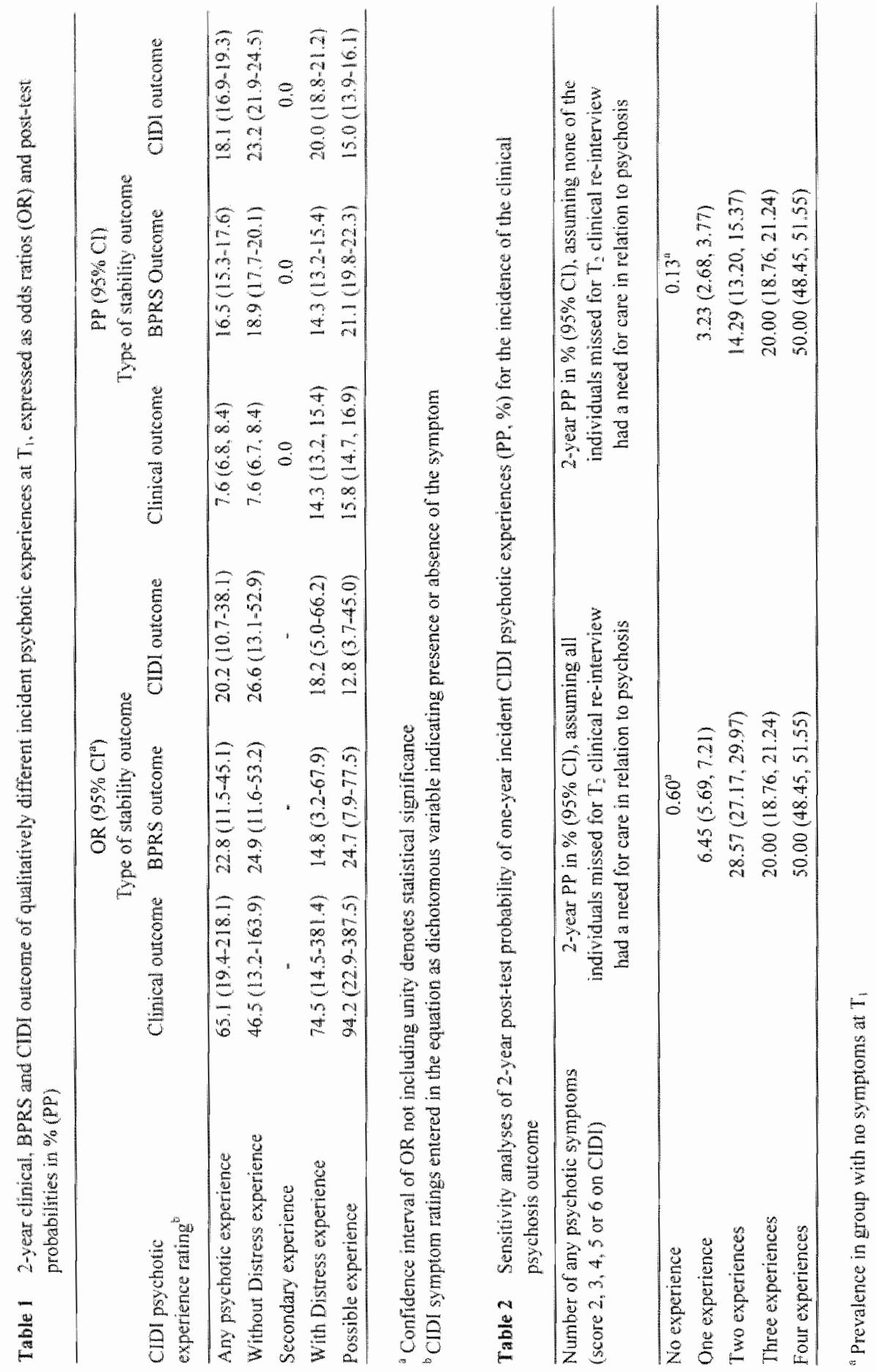




\section{Discussion}

Around 5-15\% of individuals with incident self-reported psychotic experiences had developed an outcome defined in terms of functional impairment and need for care 2 years later. The quality of psychotic experiences shaped the magnitude of the predictive value. Psychotic experiences with distress/help-seeking behaviour, even if the interviewer doubted that they might have a basis in fact, had better predictive value for future functional impairment and clinical need than psychotic experiences without distress and help-seeking behaviour. This distinction in predictive value was specific for prediction of clinical need and was not apparent for prediction of presence of psychotic experiences at any level per se. In other words, the results show that psychotic experiences without distress have a better outcome whereas experiences accompanied by distress are associated with a more malignant course.

\section{Quality of psychotic experience and outcome}

The CIDI psychosis ratings were qualitatively different in their ability to predict future functional impairment and need for care but not future psychotic symptoms per se. Those experiences associated with distress/help-seeking behaviour were better predictors of clinical need than experiences without distress/help-seeking behaviour, even if the interviewer doubted whether the apparent psychotic experiences might have a basis in fact. It has been suggested that psychotic experiences per se may not be pathological, but rather that aspects of the interaction between the person and the psychotic experience may determine whether somebody becomes a 'case' for treatment (Claridge 1990; Johns and van Os 2001). Thus, some individuals, faced with psychotic experiences, may develop distress and help-seeking behaviour through dysfunctional attributions or coping styles, whereas others may not (Birchwood, Meaden et al. 2000; Garety, Kuipers et al. 2001 ).

\section{Previous work}

The modest predictive values found in this study are in stark contrast with the sometimes very thigh PP's reported in the literature. Thus, recent work reports PP"s of $40-70 \%$ on the basis of a variety of prodromal, developmental or symptomatic measures (Davidson, Reichenberg et al. 1999; Phillips, Yung et al. 2000; Klosterkötter, Hellmich et al. 2001). However, all these studies have in common that they apply a series of selection processes that result in selected samples with a very high baseline prevalence of schizophrenia (and therefore a very high baseline PP). These selection procedures may involve the analytical technique used in processing the data (Jones and van Os 2000), or, more commonly, the use of a series of referral filters by which the selected population is increasingly "dense" with schizophrenia risk and therefore schizophrenia 
prevalence. For example, Klosterkotter and colleagues described a series of filters hnvolwing German University Departments selecting individuals at risk for schizophrenia (Klosterkotter, Hellmich et al. 2001), resulting in a sample that had a 50\% prevalence rate of schizophrenia over an approximately 10-year period. Thus, by chance alone any young adult in this sample would have had a PP of $50 \%$ for any predictor used. In our study, no selection filters were used, and the reported PP's are comparable with other unselected studies showing high relative risks, but much lower PP's in the general population (Tien and Eaton 1992; Chapman, Chapman et al. 1994; Kwapil, Miller et al. 1997; Poulton, Caspi et al. 2000).

\section{From screening to primary intervention?}

Critical factors for effective primary intervention of psychosis are the economical cost of the intervention, avalability of adequate interventions for a disease, risk of stigmatisation and inconvenience associated with the diagnosis and treatment (McGorry, Yung et al. 2001). McGorry and colleagues (2002) were the first group to present data pertaining to a Randomised Controlled Trial (RCT) in subjects who were at high risk for psychosis transition. High-risk subjects were randomised to a treatment with a low dose of risperidone and Cognitive Behavioural Therapy (CBT) or a control condition of needs-based intervention. The transition rate for the control group was 10 out of 28 subjects $(36 \%)$ and for the treatment group 3 out of 31 subjects $(10 \%)$ (McGorry, Yung et al. 2002). Taking into consideration the low discriminating power of the CIDI regarding early psychosis, prediction and treatment on the basis of psychotic and psychosis-like symptoms may not be very rewarding at the level of the general population. Applying the figures from the above RCT to our findings would mean that, given a PP of $14 \%$ for With Distress symptoms, and assuming a maximum $26 \%$ rate of preventing psychosis transition with treatment as in the RCT, one would need to treat 28 individuals with With Distress symptoms in the general population in order to prevent one psychosis transition (calculated as $100 / 14 \times 100 / 26$ ).

\section{Linnifations}

These results should be interpreted in the light of several methodological limitations. First, the clinical re-interview rate at $\mathbb{T}_{2}$ was incomplete. The sensitivity analyses, however, showed that the results are unlikely to be biased by missed interviews at the $T_{2}$ interview. Second, one of our outcomes was based on a clinical judgement of functional impairment and need for treatment as assessed by our panel, rather than by conventional diagnostic criteria. However, we think that this may represent an advantage rather than a disadvantage, as need for care is not synonymous with traditional diagnosis (Spitzer 1998) and, in the context of early intervention, need for care is a more relevant parameter than diagnosis per se. Third, we have no data to examine the possibility that 
some individuals developed functional impaiment and a need for care between $T_{1}$ and $T_{2}$, but were recovered again by the time of the $T_{2}$ interview. Similarly, we have no data to establish how many individuals in the high-risk group developed functional impairment and need for care after the $\mathrm{T}_{2}$ assessment. Long-term studies, however, do not suggest that every person with psychotic experiences will develop need for care psychosis remains a rare outcome no matter how long the follow-up. Furthermore, follow-up longer than two years in clinical practice cannot be justified. Fourth, the number of incident cases of any psychotic state in need for care over the 2-year period was around 3 to 4 times (11 persons over $2 \times 4067=9134$ person years or 120 per 100,000 person-years) higher than reported service-based incidence rates for any affective and non-affective psychotic disorder. This is a well-known phenomenon in population based studies (Tien and Eaton 1992; Poulton "Caspi et al. 2000) and may point to the fact that, as in depression, many milder cases of psychosis do not come to the attention of psychiatric services. In addition, a number of individuals with very severe psychosis may also remain out of treatment. Fifth, for the clinical outcome a broad definition of psychosis was used, in that we did not make a difference between non-affective and affective psychosis. However, as both are suitable targets for early detection, this distinction is less relevant in the context of this paper. Finally, our $T_{1}$ predictor was based on self-reported psychotic experiences, rather than on interview assessed symptoms. This however, is the only realistic scenario for the general population, where large-scale and/or routine assessment by clinicians is not feasible, and psychosis first becomes evident on the basis of self-reports. In addition, it has been shown that even those self-reported psychotic experiences that are rejected by the clinician during clinical interview, still have predictive value for onset of psychotic disorder (Bak, Delespaul et al. 2003). These, and other findings on the predictive value of self-reported psychotic experiences (Poulton, Caspi et al. 2000), suggest that selfreported psychotic experiences form a valid base from which to conduct a follow-up study. 


\section{References}

Bak, M., Delespatul, P. Hansser, M. de Grad, R., Vollebergh, W, and van Os, J (2003). How false are "false" positive psychotic symptoms? Schizophrenia Research 62)(1-2\%: 187-189.

Bijl, R. Y. Ravelli. A. and wan Zessen, G. (1998). Prevalence of psychiatric disorder in the general population: results of The Netherlands Mental Health Survey and Incidence Study (NEMESIS). Social Psychicatry and Psychatric Epidemiology 33(12): 587-595.

Bijl, R. V, wan Zgessen, G., Ravelli, A. de Rijk, C, and Langendoen, Y. (1998). The Netherlands Mental Health Survey and thcidenee Study (WEMESIS): objectives and design. Social Psychiary and Psychiatic Epldemiology $33(12) ; 581-586$.

Birchwood, M., Meaden, A., Trower, P., Gilbert, P. and Plaistow, J. (2000). The power and onmipotence of woices: subordination and entrapment by voices and significant others. Psychological Medicine $30(2)$ : $337-344$.

Carr, V. Halpin. S. Lau, N. O'Brien, S., Beckmann, J. and Lewin, T. (2000). A risk factor screening and assessment protoeol for schizophrenia and retated psychosis. Ausrowian and New Zealand Journal of Psychary Suppotement 34:S170 I80.

Chapman, I., J., Chapman, J. P, Kwapil, T. R., Eckblad, M. and Zinser, M. C. (1994). Putatively psychosisprone subjects 10 years later. Jow of a Abnomal Psychology 103(2): 171-183.

Chapman, 1. J., Edell, W. S. and Chapman, J. P. (1980). Physical awhedonia, perceptual aberration, and psychosis proneness. So hizophrenia Bulletin 6(4): $639-653$.

Claridge, G. S. (1990). Carn a disease model of schizophnenia survive? In: Reconsincting Schizophrenia. R. P. Bentall (Ed.). London, Routledge: 87-103.

Davidson. M., Reichenberg, A, Rabinowitz, J., Weiser, M., Kaplan, Z. and Mark, M. (1999). Behavioral and intellectual markers for schizophrenia in apparently healthy male adolescents. Amertcar foumat of Psychiatey 156: 1328-1335.

Eaton, W. W.. Neufeld, K., Chen, L. S. and Cai, G. (2000). A comparison of self-report and clinical diagnostic interviews for depression: diagnostic interwiew schedule and schedules for clinical assessment in neuropsychiatry in the Baltimore epidemiologic catchment area follow-up. Archives of General Psiychiatry 57(3): $217-222$.

Garety, P. A and Freenan, D. (1999). Cognitive approaches to dolusions: a critical review of theories and

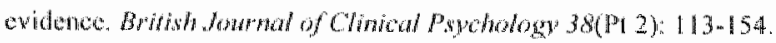

Garely, P. A. Kuipers, l:, Fowler, D., Fueman, D. and Bebhington, P. E. (2001). A cognitive model of the positive symploms of psychosis. Psychological Medicine $31(2): 189-195$.

Jenner, I. A. and van de Willige, $G$. (2001). HT, hallucination focused intcgrative treatment as carly intervention in psychotic adolescents with auditory hallucinations: a pilot study. Acta Psychiatrica Scandinatiag toj(2): 148-152.

Johns, 1. C., Nazroo, I. X., Bebbington, P. and Kuipers, E. (2002). Occurtence of hallucinatory experiences in

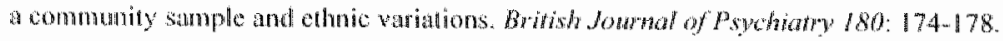

Jothis, L. C. and van Os, I. (2001). The continuity of psychotic experiences in the general population. Climical Psphology Rever $21(8): 1125-1141$.

Jones, P. B. and van Os, J. (2000). Commentary: Behavioural and intellectual functioning in Israel adolescent boys predted psychatric hospital admission for schizophrenia. Evidence Based Mental Health 3: 89.

K. losterkötter, I.. Hellmich, M., Steinmeyer. F. M. and Schultze-Lutter, F. (2001). Diagnosing schizophrenia in the inilial prodromal phase. Archines of General Psychiary 58: 158-164.

Krabbendam. L., Janssen, 1. Bak, M., Bijl. R. V., de Graaf, R. and van Os, J. (2002). Neuroticism and low self-esteem as risk hactors for psychosis. Social Psychiatry and Psychiarric Epidemiology $37(1)$ : 1-6. 
Kwapil, T. R., Miller, M. B., Zinser, M. C. Chapman, J. and Chapman, L. J. (1997). Magical ideation and social anhedonia as predictors of psychosis proneness: a partial replication. Jenarmat of abnormal Psychology 106(3): 491-495.

Lutorf, D., Nuechterlein, K. H. and Ventura, J. (1986). Manual for Expanded Brite Psychiatric Rating Scale. Schizophrenia Bulletin 22(4): 594-602.

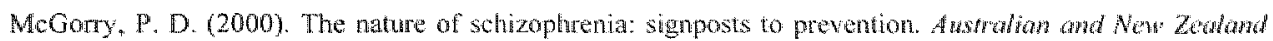
Journat of Psychiatry Supplement 34: \$14-21.

McGorry. P. D., Yung, A. and Phillips, L. (2001). Ethics and carly intervention in psychosis: kecping up the pace and staying in step. Schizophrenia Research $5 /(1): 17-29$

McGorry, P. D., Yung, A. R., Phillips, L. J. Yuen, H. P., Francey, S., Cosgrave, [. M.. et al. (2002). Randomized controlled trial of intervertions designed to reduce the risk of progression to firstepisode psychosis in a clinical sanple with subtheshold symptoms. Anchives of Gexeral Psychiatry $59(10): 921$ 928.

Phillips, L. A. Yung, A. R. and MeGionry, P. D. (2000). Ldentification of young people at risk of psychosis: validation of Personal Assessment and Crisis Evaluation Clinic intake criteria. Aratralian and New Zealand Joumal of Psychiatry Stupplement 34: \$164-169.

Poulton, R. Caspi, A., Moffitt, T. Ex, Cannon, M., Muray, R. and Harringion, H. (2000). Children's selfreported psychotic symptoms and adult schizophrenitorm disorder: a $1.5 \mathrm{y}$ ear longitudinal study. Archives of General Psychiarty 57(11): 1053-1058.

Sacket, D. L. Richardson, W. S., Rosenberg. W. and Haynes, R. B. (1997). Evidence-based Medicine. New York, Churchill Livingstone.

Slade, M., Phelan, M., Thomicrolt, G. and Parkman, S. (1996). The Camberwell Assessment of Need (CAN): comparison of assessments by staff and patients of the needs of the severely mentally ill. Social Psychiatry and Psychiatric Epidemiology 3/(3-4): 109.113.

Sineets, R. M. W. and Dingemans, P. M. A. J. (1993). Composite International Diagnostic Anterview (CIDI), Fersion 1.l. Amsterdam/Geneva, World Healih Organisation.

Spitzer, R. L. (1998). Diagnosis and need for treatment are not the sarne. Archives of Genenal Psychiaty $55(2): 120$.

StataCorp (2001). Stata Statistical Sofrware: Release 7,0. Texas, College Station.

Susser, E. S. and Struening. E. L. (1990). Diagnosis and screening for psychotic disorders in as study of the homeless. Schizophremia Bullefin 16(1): 133-145.

Tien, A. Y. and Eaton, W. W. (1992). Psychopathologic precursors and sociodemographic risk factors for the schizophrenia syndrome. Archwes of General Psychialy 4l: $37-46$.

van der Zee. K. Sanderman, R. and Heyink, J. (1993). De psychometrische kwaliteilen van de MOS 36-ilem Short Form Health Survey (SF-36) in en Nederlandse populatics. Tijalschwift woon Sociale, Gezondheidszorg 7l: 183-191.

van Os, J., Hanssen, M. Bijl, R. V. and Rávelli, A. (2000). Strauss (1969) revisited: a psychosis continum in the general population? Schrophimenia Resedrch 45(1-2): 11-20.

wan Os. J., Hanssen, M. Bijl. R. V. and Vollebergh, W. 2001). Prevalence of psychotic disorder and community level of psychotic symptoms: an urban-rural comparison. Archives of Getracrat Pasharary $58(7): 663-668$.

Ware. J. E, Gandek, B. and Group, 1. P. (1994). The SF-36 Health Survey: Development and use in mental health research and the IQOLA project. Interhational Journat of Mental Heathr 23:49-73. 



\title{
CHAPTER 8
}

\section{The role of distress in delusion formation}

\author{
M. Hanssen \\ L. Krabbendam ${ }^{1}$ \\ R. de Graaf ${ }^{2}$ \\ W. Vollebergh ${ }^{2}$ \\ J. $\operatorname{wan} \mathrm{Os}^{1,3}$
}

1 Department of Psychiatry and Neuropsychology, South Limburg Mental Health Research and Teaching Network, EURON, Maastricht University, Maastricht, The Netherlands

2 The Netherlands Institute of Mental Health and Addiction (Trimbos Institute), Utrecht, The Netherlands

3. Division of Psychological Medicine, Institute of Psychiatry. London, United. Kingdom 


\section{Abstract}

Background. Contemporary cognitive psychological theories suggest that distress plays a mediating role in delusion formation.

Aims. To study the amplifying role of distress from early perceptual intrusions to delusion formation.

Method. A general population sample of 7076 subjects was interviewed with the Composite International Diagnostic Interview (CIDI) in 1996 (baseline), $1997\left(\mathrm{~T}_{1}\right)$ and $1999\left(\mathrm{~T}_{2}\right)$. At $\mathrm{T}_{2}$, clinicians additionally scored the BPRS item "unusual thought content". Analyses compared hallucinatory experiences with and without subjective distress at baseline for risk of delusion formation at follow-up.

Results. Subjects with hallucinations experiencing distress, compared to those without, had a fourfold increased risk of subsequent delusion formation.

Conclusions. This finding corroborates the proposition that distress associated with early perceptual intrusions serves as a catalyst in the development of delusions.

Declaration of interest. Funded by the Dutch Department of Health. 


\section{Introduction}

Hallucinations and delusions tend to co-occur both in clinical and in non-clinical samples (Liddle and Barnes 1990; Johnstone and Frith 1996; van Os, Hanssen et al. 2000). One possible explanation for this association may be that the experience of hallucinations gives rise to secondary delusional interpretations (De Clérambault 1942; Maher 1988). Little is known, however, about the factors that mediate the transition from hallucinatory experience to delusional interpretation. Recent psychological hypotheses on delusion formation emphasize the role of attributional style, distress and worry in the aetiology and maintenance of delusions (Garety, Kuipers et al. 2001). Thus, the experience of voices or visions may lead to full-blown delusional ideation, when it is attributed to an external source or when it is given personal significance.

In an earlier study, for example, it was reported that delusion formation in adolescents hearing voices was mediated by, among other factors, attributions of externality, perceived power over the person, and emotional appraisals (Escher, Romme et al. 2002). We wished to extend these results to a large general population sample that had no previous evidence of delusional ideation. It was hypothesized that subjects experiencing hallucinations with distress at baseline, compared to those without, would show a greater risk of developing delusions over the follow-up period.

\section{Method}

\section{Procedure, instruments and sample}

The Netherlands Mental Health Survey and Incidence study (NEMESIS study) is a large general population study with three measurement points (hereafter: baseline, $T_{1}$ and $T_{2}$ ) in 1996, 1997 and 1999. At the three measurement points respectively 7076,5618 and 4848 subjects aged 18-64 years participated. Trained lay interviewers at all three measurements applied the Composite International Diagnostic Interview (CIDI) (Smeets and Dingemans 1993). The CIDI has 17 psychosis items (13 delusions, 4 hallucinations) with six possible ratings for each psychosis item: 1) no psychotic experience; 2) not clinically relevant psychotic experience; the subject is not experiencing distress and is not seeking help; 3) and 4) experience is the result of drug use or somatic disease; 5) true psychiatric symptom; subject experiences distress and/or seeks help; 6) what appears to be a true psychotic symptom may not be a real symptom because there appears to be some plausible explanation for it (i.e. it may be "real").

At baseline, the lay interviewers inquired about lifetime presence of symptoms and at the two follow-up measurements the period between the measurements was assessed. For the current analysis, ratings of 2 and 5 on the four hallucination items at baseline, 
both indicative of presence of psychotic experience in the absence of doubt or secondary cause but crucially different in terms of subjective distress and help-seeking behaviour, were included in the analyses. The distinction between the ratings of ' 2 ' and ' 5 ' was validated in a previous study (van Os, Hanssen et all. 2001). The four hallucination items encompassed all possible hallucinatory modalities.

At baseline and $T_{2}$, attempts were made to clinically validate the lay interviewer administered CIDI interview. Each time when at baseline (possible) psychotic symptoms (CIDI rating of ' 5 ' or ' 6 ') were detected in the NEMESIS study, a psychiatric clinician conducted clinical re-interviews over the telephone by using the Structured Clinical Interview for DSM-III-R (SCID) (Spitzer, Williams et al. 1992). If a clinician did not agree with the psychosis rating of the trained lay interviewer, the psychosis rating was changed to the rating of the clinician. All DSM-III-R diagnoses in the NEMESIS study are based on these corrected ratings. At baseline, $47.2 \%$ of the eligible individuals were actually interviewed. The probability of a selection bias was studied in a previous study and deemed unlikely (Hanssen, Bijl et al. 2003). At $T_{2}$, all inclividuals with a rating of ' 2 ', ' 5 ' or ' 6 ' on any CIDI psychosis item were administered a clinical re-interview over the telephone by an experienced clinician. The proportion of eligible individuals that was successfully re-interviewed was $74.4 \%$. At $T_{2}$, the clinician also scored the 'unusual thought content' item of the Brief Psychiatric Rating Scale (BPRS) (Lukoff, Nuechterlein et al. 1986). The BPRS symptom-items are rated on a 7point scale on the basis of frequency of the symptom and functional impairment. Ratings 2-3 represent a nonpathological form of the symptoms and ratings 4-7 represent a pathological form (Lukoff, Nuechterlein et al. 1986). For a more detailed description of the NEMESIS study we refer to Bijl et al. (1998) and van Os et al. (2001) (Bijl, van Zessen et al. 1998; van Os, Hanssen et al. 2001).

\section{Analyses: The development of delusions}

The study sample at $T_{2}$ was restricted to subjects who did not report delusions at baseline and again at ' $T_{1}$ (i.e. had no ratings of ' 2 ' ' ' 5 ' on any' of the CIDI delusion items at baseline and $T_{1}$ ) in order to skew the sample towards individuals with truly incident delusions at $T_{2}$ (original sample at $T_{2}: n=4848$; sample restricted to those without delusions at baseline and $T_{1}$, and non-missing data on the delusion variable at $\mathbb{T}_{2}$, hereafter referred to as 'risk set': $n=4236$; risk set and non-missing covariates: $n=4181$ ).

All analyses were carried out with Stata version 7 Special Edition (StataCorp 2001). Logistic regression analysis was performed with the BPRS "unusual thought content" item measured at $T_{2}$ as dependent variable (score 1 rated absent and score $>1$ rated present) and the baseline CIDI ratings on hallucinations with and without distress (entered as two dummy variables) as independent variables. To account for possible 
confounding variables, we controlled for the following a priori chosen covariates, guided by previous findings in this sample (van Os, Hanssen et all. 2000; van Os, Hanssen et al. 2001; Krabbendam, Janssen et al. 2002; van Os, Hanssen et al. 2002; Janssen, Hanssen et al. 2003): age (five categories), gender, urbanicity (three levels), ethnic group (0: subject and both parents born in the Netherlands, and 1: other), neuroticism (Ormel 1980), experience of discrimination (a six-item questionnaire measuring experience of discrimination regarding the colour of skin or ethnicity, sex. age, appearance, handicap and sexual orientation), experience of abuse before the age of 16 years (a four-item questionnaire), educational level (four levels), unemployment and single marital status. The effect sizes of baseline hallucinations with and without distress on risk for delusion formation at $T_{2}$ were compared by Wald test. In order to exclude misclassification at the lower end of the BPRS scoring range of the unusual thought content item, analyses were repeated with a more stringent definition of the BPRS 'unusual thought content' item as dependent variable, i.e. a score greater than 2. Finally, in an attempt to clinically validate any findings, analyses were repeated using the clinical definition of delusions, namely a score greater than 3 on the item of BPRS unusual thought content, which is indicative of pathology level in terms of functional impairment (Lukoff, Nuechterlein et al. 1986).

\section{Sensitivity analyses}

Sensitivity analyses were conducted to examine whether differential atrition in the sample as a whole ( 7076 at baseline, 4848 at $\mathbb{T}_{2}$ ) could have biased the findings. This was done by multiple imputation of missing values of delusional ideation at $T_{2}(n=1962$ missing, 31.4\%) using the HOTDECK command in STATA. The HOTDECK procedure is used several times within a multiple imputation sequence since missing data are imputed stochastically rather than deterministically. One thousand imputation sequences were run, ylelding 1000 data sets in which the regression coefficients werc estimated within the HOTDECK procedure. Imputation of missing values was stratified by known risk factors of psychosis (van Os, Hanssen at al. 2000; van Os, Hanssen et al. 2001; Krabbendam, Janssen et al. 2002; van Os, Hanssen el al. 2002; Janssen, Hanssen et al. 2003), namely age, gendet, urbanicity, ethnic group, neuroticism, experience of discrimination, experience of abuse before the age of 16 years, educational level, unemployment and single marital status. The HOTDECK procedure replaces missing values in the relevant variables by values randomly sampled from complete lines in the same stratum. Individuals who had delusions at baseline and at $T$, were again excluded from these analyses $(n=831)$. 


\section{Results}

\section{Dexcriprives}

At baseline and limited to the risk set $(n=4236), 161$ subjects (males: $34.8 \%)$ reported lifetime occurrence of hallucinations without distress, whilst 32 subjects (males: $21.9 \% \%$ ) reported hallucinations with distress. Five subjects reported both types of hallucinations.

In the risk set $(\mathrm{n}=4236)$, visual, auditory, olfactory and tactile hallucinations without distress were reported by $79(1.9 \%), 26(0.6 \%), 34(0.8 \%)$ and $60(1.4 \%)$ subjects, respectively. Visual, auditory, olfactory and tactile hallucinations accompanied with distress were present in respectively $19(0.5 \%), 8(0.2 \%), 5(0.1 \%)$ and $8(0.2 \%)$. In the group of 161 individuals who reported hallucinatory experiences without distress, the proportions of visual, auditory, olfactory and tactile hallucinations were respectively $49.1 \%(79 / 161), 16.2 \%(26 / 161), 21.1 \%(34 / 161), 37.3 \%(60 / 161)$. In the distress group $(n=32)$ these proportions were $59.4 \%(19 / 32), 25.0 \%(8 / 32), 15.6 \%(5 / 32), 25.0 \%$ $(8 / 32)$.

Thirty-seven subjects in the risk set (males: $35 \%$ ) had developed delusions (BPRS $>1$ ) at $\mathrm{T}_{2}, 16$ out of these thirty-seven persons (males: $56 \%$ ) had developed delusions with a BPRS score greater than 2, and 7 (males: $71 \%$ ) out of these 16 persons had developed clinical delusions according to the BPRS definition (BPRS $>3$ ).

\section{Distress and delusion formation}

The risk for delusion formation at $T_{2}$ was 5 times greater in the individuals who at baseline were distressed by their hallucinations $(6$ out of 32 subjects reporting hallucinations with distress developed delusions $\mathrm{BPRS}>1$; $\mathrm{OR}=25.0,95 \% \mathrm{CI}$ 9.3-67.8) than in the individuals who reported hallucinations without distress ( 7 out of 161 subjects reporting hallucinations without distress developed delusions BPRS $>1$; $O R=$ $4.9,95 \% \mathrm{Cl} 2.0-11.9$ ) (Table 1). This difference was statistically significant $\left(\chi^{2}=5.2\right.$, $d f=1, p=0.02)$. After adjustment for the covariates, the difference remained robust $\left(\chi^{2}=3.8, \mathrm{df}=1, \mathrm{p}=0.05\right)$ (Table 1).

Results were similar using the more stringent definition of delusions (BPRS $>2$ ), with again a highly significant difference in effect size $\left(\chi^{2}=8.7, \mathrm{df}=1, \mathrm{p}=0.003\right.$ ) (Table 1), also after adjustment of covariates. Similar results were apparent for the clinicall definition of delusions: no individuals with hallucinations without distress developed clinically relevant delusional ideation, whereas the risk was very high in those whose hallucinatory experiences were accompanied by distress (Table 1). 
Trable 1 Comparison between hallucinations accompanied with and without distress regatding the formation of delusions thee years later

\begin{tabular}{|c|c|c|c|c|c|c|}
\hline & & $\begin{array}{l}\text { BASELINE: } \\
\text { Hallucination } \\
\text { with distress } \\
\text { OR (95\% } \mathrm{Cl}) \\
\text { frequency }\end{array}$ & $\begin{array}{l}\text { BASELUNE: } \\
\text { Hallucination } \\
\text { wifhouf distress } \\
\text { OR (95\% CO) } \\
\text { frequency }\end{array}$ & $x^{3}$ & df & $p$ \\
\hline \multirow[t]{3}{*}{ Unadjusted } & $\begin{array}{l}\mathrm{T}_{\mathrm{y}} \text { : BPRS } \\
\text { delusion }>1\end{array}$ & $\begin{array}{c}25.0(9.3-67.8) \\
6 / 32\end{array}$ & $\begin{array}{c}4.9(2.0-11.9) \\
7161\end{array}$ & 5.2 & 1 & 0.02 \\
\hline & $\begin{array}{l}T_{3}: \text { BPRS } \\
\text { delusion }>2\end{array}$ & $\begin{array}{c}50.4(14.9-169.9) \\
4 / 32\end{array}$ & $\begin{array}{c}0.9(0.1 .7 .8) \\
1161 \\
\end{array}$ & 87 & 1 & 0,0003 \\
\hline & $\begin{array}{l}T_{1}: \text { BPRS } \\
\text { dellusion }>3\end{array}$ & $\begin{array}{c}126.4(26.8-595.3) \\
3 / 32\end{array}$ & 0.161 & $\ldots$ & $\cdots$ & $\cdots \cdots-$ \\
\hline \multirow[t]{3}{*}{ Adjusted } & $\begin{array}{l}T_{2}: \text { BPRS } \\
\text { delusion }>1+ \\
\text { covariates }\end{array}$ & $13.7(4.4-42.4)$ & $3.2(1.2-8.4)$ & 3.8 & 1 & 0.05 \\
\hline & $\begin{array}{l}\mathrm{T}_{2}: \text { BPRS } \\
\text { delusion }>2+ \\
\text { covariates }\end{array}$ & $25.1(4.8-131.3)$ & $0.5(0.04-4.9)$ & 8.5 & 1 & 0.004 \\
\hline & $\begin{array}{l}\mathrm{T}_{2}: \text { BPRS } \\
\text { delusion }>3+ \\
\text { covsriates }\end{array}$ & $136.2(13.1-1414.3)$ & $\ldots$ & 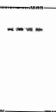 & $\ldots$ & $-m+\infty$ \\
\hline
\end{tabular}

* Frequency means the number of subjecis with delusion formation given the number of subjects with lifetime hallucinations with or without distress

* Predicts failure perfectly

\section{Sensitivity analyses}

Using 1000 imputation sequences in which missing values of the outcome of delusions at $T_{2}$ were imputed stochastically, the estimated effect size for baseline hallucinations with distress was $\mathrm{OR}=18.3(95 \% \mathrm{CI} 5.6-60.2)$ and for baseline hallucinations without distress $\mathrm{OR}=5.4(95 \% \mathrm{CI} 2.1-14.3)$, indicating a similar pattern of results.

\section{Discussion}

The results show that subjects who experience negative emotional states associated will anomalous perceptual intrusions have a much greater risk of developing delusional ideation, including experiences of clinical relevance, than individuals who report similar experiences without distress.

Subjects reporting distress associated with their hallucinations did show a much greater risk for developing clinical delusions than subjects reporting hallucinations without distress. Our findings support the amplifying role of distress in current cognitive models of delusion formation (Freeman and Garety 1999; Birchwood, Meaden et al. 2000; Morrison and Baker 2000; Garety, Kuipers et al. 2001). According to these models, feelings of uncontrollability and hopelessness associated with negative 
emotional states may contribute to onset of delusional interpretations. Emotions may also make hallucinatory experiences personally significant or more intrusive, which in furn may trigger the individual to search for explanations of the experiences. The distress caused by hallucinatory experiences may in turn be related to the interpretation of the experience (Morrison and Baker 2000). The mechanism of delusion formation may depend on the mitial interpretation subjects give to their unusual perceptual intrusioris. If this initial interpretation leads to distress, the subject may be more prone to selective attentional processes and safety behaviours diminishing the opportunity to test the accuracy of the psychotic experience (Garety, Kuipers et al. 2001), resulting in increased levels of delusional ideation.

The role of distress associated with unusual experiences may also be crucial to understand further transitions over the psychosis continuum. Peters and colleagues (1999) measured delusional ideation in the general population as well as in deluded patients using the Peters et al. Delusions Inventory (PDI). The PDI scores of the general population and the deluded patients showed a large degree of overlap and nearly 10 percent of the general population scored above the mean of the group with delusions. However, compared to patients, non-patients displayed significantly less distress, preoccupation and conviction regarding their unusual perceptual experiences and ideas.

The present study is limited to psychological factors, but biological factors may also be relevant in this regard. Hemsley's cognitive model hypothesizes that the problem in schizophrenia encompasses the inability to integrate the moment-by-moment sensory input with stored memory (Hemsley 1993; Hemsley 1994). A neuronal circuit, including the limbic system, is proposed to be involved in this integration process. Distress can lead to an increased dopamine release that in turn may influence the lunctioning of these brain structures (Robinson and Becker 1986). Thus, a stressinduced dopaminergic response in humans could result in a heightened risk for positive psychotic symptoms in vulnerable persons, with possible subsequent sensitization of dopaminergic response and persistence of delusional ideation (Laruelle 2000).

\section{Clinical implications}

The present findings have implications for early intervention in psychosis or psychosislike experiences, and underline the significance of Cognitive Behavioural Therapy (CBT) in treating psychotic disorders (Kingdon and Turkington 1994; Turkington and Kingdon 2000), If distress associated with hallucinations is involved in the development of delusions, ameliorating the distress may prevent the formation of delusions in some subjects. Cognitive behavioural, anxiety reducing and re-appraisal techniques could be instrumental in preventing the development of delusions in subjects with anomalous experiences (McGorry, Yung et al. 2002; Morrison, Bentall et al. 2002). 


\section{Limmations}

This work should be interpreted in the light of several potential limitations. Firstly, distress was operationalised as feeling bothered by the hallucinations and/or displaying help-seeking behaviour. Thus, the mediating role of distress in the development of delusions is a general one, as we did not have any information linking distress to content of or beliefs about hallucinations and/or delusions. Secondly, differential attrition in this longitudinal design could have biased the results. However, sensitivity analyses generated essentially similar results. Thirdly, the present study monitored only one of the many proposed mediating and maintaining factors by Garety and colleagues (2001). However, it was not possible to examine the role of many other important variables in the formation of delusions, for example extemalising attributional biases, problems with self-monitoring, dysfunctional schema's etc., as we did not gathered this information. Finally, the outcome 'incident unusual thought content' was very rare, affecting the precision with which we could estimate effect sizes. 


\section{References}

Bijl, R. V., van Zessen, G., Ravelli, A., de Rijk, C. and Langendoen, Y. (1998). The Netherlands Mental Health Survey and Incidence Study (NEMESIS): objectives and design. Social Psychatry and Prychiatic Epidemiology $33(12): 581-586$.

Birchwood, M., Meaden, A., Trower, P., Gibert, P. and Plaistow, J. (2000). The power and onnipotence of volces: subordination and entrapment by voices and significant others. Psychological Mediche $30(2)$ : $337-344$.

De Clérambault, O. G. (1942). Oempe Psychiatrique, PUF.

Escher, S. Rommen, M., Buiks, A., Delespaul, P. and Van Os, J. (2002). Formation of delusional ideation in adolescents hearing voices: A prospective study. American Jownd of Medical Genetics $1 / 4(8)$ : $913-$ 920.

Freeman, D. and Garety. P. A. (1999). Worry, worry processes and dimensions of delusions: an exploratory investigation of a role for anxiety processes in the maintenance of delusional distress. Behorvioural and Cogntive Psychorhenapy $27,47-62$

Garey, P. A. Kuipers, E., Fowler, D. Freeman, D. and Bebbington, P. E. (2001). A cognitive model of the positive symptoms of psychosis. Psychological Medicine 3/(2): 1894195.

Hanssen, M., Bjil, R. V., Vollebergh, W. and van Os, J. (2003). Self-reported psychotic experiences in the general poputation: a valid sereening tool for DSM-IIL-R psychotic disorders? Acta Psychiatrica Scandinavica 107(5): $369-377$.

Hensley, D. R. (1993). A simple (or simplistic?) cognitive model for schizoplarenia. Bethaviour Research Theropy 3/(7): 633-645.

Hensley. D. R. (1994) A cognilive model for schizophrenia and its possible neural basis. Acta Psychiarrica Scandinavica Supplement 384: 80-86.

Janssen, I., Hanssen, M., Bak, M., Bijl. R. V., de Grad, R.., Vollebergh, W., et al. (2003). Discrimination and delusional ideation. British Joumal of Psychiatry 182: $71-76$.

Johnstone, E. C. and Frith. C. D. (1996). Validation of thee dimensions of schizophrenic symptons in a large unselected sample of patients. Psycholegrical Medicine 26(4): 669-679.

Kingdon, D. and Turkington, D. (1994). Cognative-Behavoral Therapy of Sehzophrenia Hove (UK) Hillside

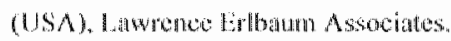

Krabhendam, L., Janssen. 1., Bak, M., Bij, R. V., de Grad, R. and wan Os, J, (2002). Neuroticism and low self-estem as risk factors for psychosis. Sociol Psychiary and Paychatric Epidemiology 37(1): 1-6.

Latuclle. M. (2000). The role of endogenous sensitization in the pathophysiology of schizophenia: implications from recent brain innang sudies. Brain Research Reviews $3 /(2-3)$ : 371-384.

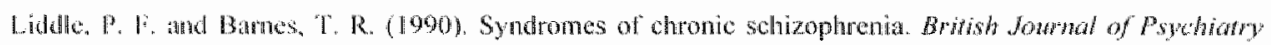
$157: 558-561$.

Lukoli, D.. Nuecherlein, K.H. and Ventura. J. (1986). Mantal for Expanded Brief Psychiatric Rating Scale.

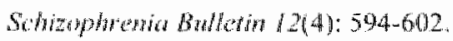

Mahtu, B. A. (1988). Anowalous experience and delusional thinking: the logic of explanations. In: Delusional Bediefs. T. F. Olunams and B. A. Maher (Eds.). New York, Wiley: 15-33.

McGorry, P. D., Yung, A. R., Phiflips, L. J., Yuen, H. P.. Francey, S., Cosgrave, E. M., et al. (2002). Randomized controlled trial of interventions designed to aeduce the risk of progression to first-episode

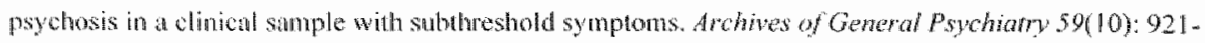
928

Morrison, A. P. and Baker. C. A. (2000). Intrusive thoughts and auditory hallucinations: a comparative study of indrusions in psychosis, Behowiour Research and Therapy 38(11): 1097-1106. 
Mortison, A. P., Bental, R. P., Freneh, P, Walford, L, Kilcommons, A., Knigh, A, et al. 2002). Randomised controlled frial of early detection and cognitive therapy for preventing tramsition to psychosis in high-risk indwhuals. Study design and interime analysis of transition ate and psyohological

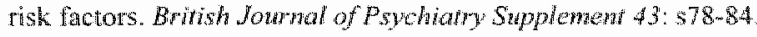

Omel. J. (1980). Moeite met Leven ol een moeilik leven? Groningen, University of Gromingen.

Robinson, T. E. and Becker, J. B. (1986). Endurng changes in bran and behavior produced by ahnonic amphetamine administration a rewiew and avaluation of animal models of anphetamine psychosis. Broin Research $396(2): 15 T-198$.

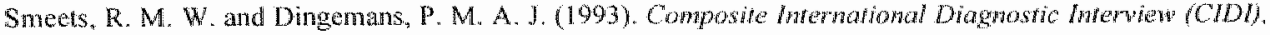
Fersion 1. 1. Amsterdan/Genev: Wonld Healh Organisation.

Spitzer, R. L., Willians, J, B., Gibbon, M. and Fist, M. B. (1992). The Structured Clinical Unterview for

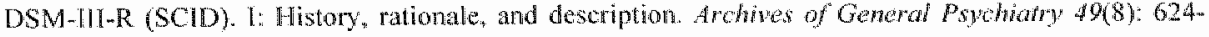
629 .

StataCorp (2001). Stala Sfarishical Sofnume: Release 7.0. Texas, College Station.

Turkington, D. and Kingdon, D. (2000). Cognive-betewiounal techniques for general psychiatrists in the management of patients with psychoses. Britris Jownal of Psychasy $17 \%$ : $101-106$.

wan Os, I. Manssen, M. Bijl, R. V. and Ravelli. A. (2000). Surass (1 969) revisited: a psychosis continum in the general population? Schizophrenia Research 45(1-2): 11-20.

wan Os, J., Hanssen, M. Bijl, R. V. and Vollebergh, W. (2001). Prevalence of psyohotic disorder and

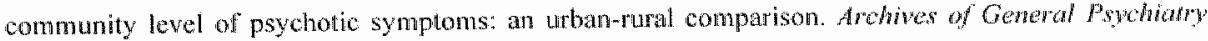
$58(7): 663 \times 668$.

wan Os, J., Hanssen, M., de Grat, R. and Vollebergh, W. (2002). Does the urban enwironinent independently

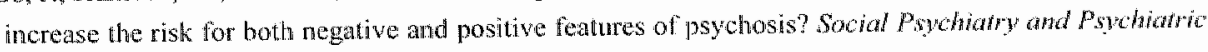
Eprdemiology $37(10): 460-464$. 

CHAPTER 9

Epilogue 
$122 \mid$ CHAPTER 9 
This thesis has covered the phenomenology of psychosis, the family-specific variation of subclinical psychosis dimensions in the general population and the feasibility of early prediction of psychosis. First, it touched on the issue of heterogeneity of the psychosis phenotype. One approach to this problem was the description of a continuous psychosis phenotype. The first three studies discussed in the thesis explored the psychosis dimensions in three different general population samples. Inherent to the psychosis contimuum approach, the concept of schizotypy combines the observable traits of schizotypy with the assumption of an underlying genetic constellation that may predispose to clinical disorder. Following studies of familiality in climical psychosis, we examined the familial aggregation of subchinical psychosis dimensions and schizotypy in the general population. We have also compared the ability of self-report and interview measures to detect familial clustering of psychosis dimensions. Given the presence of a psychosis continuum, persons experiencing attenuated psychotic symptoms may make a transition along the continum to florid psychosis. The last decade has seen considerable growth in the research devoted to early prediction and prevention of psychosis. Until now, however, research designs regarding early prediction have been predominantly limited to bigh-risk groups with a high baseline prevalence of psychosis. Therefore, two of the studies described in this thesis addressed the feasibility of early prediction of psychosis in the general population, with implications for the early prevention of psychosis. Since psychosis is regarded as a multi-factorial polygenic disease, many risk and protective factors interact before a person with psychosis-like symptoms crosses the threshold to full-blown psychosis. This thesis has focused on an important psychological factor in this transition process: the cognitive appraisal of unusual experiences. The significance of this factor lies in the fact that it is modifiable to become either a risk or a protective factor, since cognitive behavioural techniques may change the cognitive appraisal mechanisms in subjects. We studied the mechanism of distress that accompanies unusual experiences and influences the progression to clinical psychosis.

The main findings of the studies are summarised and discussed below, together with their theoretical and clinical implications.

\section{Main findings and implications}

Evidence for a psychosis continutum in the general population

The first study was based on the baseline measurement of the Netherlands Mental Health Survey and Incidence Study (NEMESIS). The Composite International Diagnostic Interview (CIDI) was administered, yielding DSM-III-R diagnoses. The CIDI psychosis items can be rated in six ways: "1" no symptom present; "2" NCR (Not 
Clinically Relevant) symptom (i.e., symptom present but not clinically relewant); " 3 " and "4. Secondary symptom (i.e., symptom is the result of drugs use or somatic disease)" " 5 " Clinical synptom (i.e., true psychotic symptom); "6" Plausible or Possible symptom (i.e., experience is not a real symptom, because there appears to be some plausible explanation for it).

This cross-sectional study showed that in a large representative general population sample, psychotic symptoms were much more prevalent than the diagnosis of nonaffective psychosis. Individuals with a CIDI psychiatric diagnosis (i.e., cases) had a higher rate of positive psychotic symptoms than individuals without a diagnosis (i.e., non-cases). The numbers of NCR symptoms, Secondary symptoms and Plausible symotoms were positively associated with the number of Clinical symptoms. In terms of these associations, there was no difference between cases and non-cases, except for the association between NCR symptoms and Clinical symptoms. This association was stronger in non-cases than in cases. Female sex, younger age, higher level of urbanicity, lower income, lower level of education, unemployment and single marital status were, with some exceptions, associated with NCR symptoms, Secondary symptoms, Plausible symptoms and Clinical symptoms. For all symptom ratings, there was a strong association with lower quality of life. The psychotic symptom ratings were also associated with flat affect and depressed mood. The presence of any rating of hallucinations was strongly associated with any type of delusion in individuals with and without any CIDI lifetime diagnosis. All psychosis ratings were strongly related to a CIDI psychiatric diagnosis, except non-affective psychosis. Non-affective psychosis was strongly associated only with Clinical symptoms and to a lesser extent with Plausible symptoms.

Given that all psychotic symptom ratings (i) were much mone common than clinical disorder and (ii) were related to risk factors common in clinical disorder, the findings suggest that the psychosis continum reported by Strauss (1969) should be extended to less severe psychotic-like experiences in the general population (Strauss 1969). It apparently implies the presence of phenomenological and aetiological continuity from psychosis dimensions to clinical psychosis. The risk factors for the disorder, for example a higher level of urbanicity, could point to possible aetiological mechanisms in the development to psychosis (Johns and van 0 s 2001). The findings are in accordance with several general population studies reporting a high prevalence of psychotic experiences compared to the rare clinical diagnosis (Eaton, Romanoski et al. 1991; Kendler, Gallagher ell al. 1996). It should be noted, however, that the prevalent psychotic symptoms without clinical psychosis did result in some dysfunction, because the psychotic symptoms were also associated with lower quality of life and unemployment. 
The results led to three implications for further research that were addressed in the present thesis. Firstly, the strong associations between positive symptoms and the affective and negative symptoms may imply that the psychosis continum includes affective and negative symptomatology. It was suggested that further research in general population samples should use measures incorporating negative and affective symptoms (chapter 2). The Community Assessment of Psychic Experiences (CAPE), a self-report questionnaire, was developed to meet this objective. The Athens Study of Psychosis Proneness and Ineidence of Schizophrenia (ASPIS) and the Continum of Mental Disorders Study (COMED Study) used the CAPE in a large sample of young men and a large general population and patients sample, respectively (chapters 3 and 4). Secondly, an important finding of the NEMESIS study that deserved to be studied more closely was that positive psychotic symptom dimensions were associated not only with nonaffective psychosis but also with other psychiatric diagnoses (chapter 2). Therefore, the study reported on in chapter 4 studied the psychosis continum across and within patient groups of psychotic, mood or anxiety disorders. Thirdly, the finding that the presence of hallucinations was associated with the presence of delusions (chapter 2) is compatible with the cognitive model of psychosis (Garety, Kuipers et al. 2001; Maher 2003). Since this cross-sectional finding was not able to elucidate the causal relationship between hallucinations and delusions, the mechanism of delusion formation was studied prospectively in chapter 8 , using the longitudinal design of the NEMESIS study.

The correlated, yet separately varying positive, negative and depressive dimensions have a distribution in the general population

The ASPIS study used the CAPE in a large population sample of young men. The threefactor model of positive, negative and depressive dimensions showed a better fit that a two-factor or unidimensional model. There was co-variation between the three dimensions, with comelations around 0.7 . It could be suggested that the co-variation between depressive experiences and positive and negative experiences is mainly due to the distress generated by the positive and negative experiences. However, partial correlations in which the distress accompanying positive or negative experiences was kept constant showed that the correlations of both positive and negative experiences with depressive experiences were still significant. Furthermore, the relationship between the frequency of experiences and distress could be described as a linear doseresponse pattem expressed by correlations of the order of 0.7 . In spite of the moderate correlation between the three CAPE dimensions, these scales showed good discriminant validity with commonly used scales. To sum up, these findings indicate that the correlated, yet independent CAPE dimensions have a distribution in the general population. In addition, depression may be an inherent part of the psychosis phenotype, as has been suggested by many previous authors (Taylor 1992; Crow 1998; Peralta and Cuesta 
2001: Cardno, Rijsdijk al. 2002), in contrast to the Kraepelinian dual view of schizophrenia and affective disorder. The more frequently individuals experienced attenuated psychotic experiences, the more distressed they were. It was speculated that the distress experienced by an individual is a moderator variable in the process of developing help-seeking behaviour (Johns and van Os 2001). Chapter 4 examines the association between distress and being a patient, while controlling for the frequency of symptoms.

Non-psychotic disorders have intermediate values for the continuous" psychosis phenotype

The NEMESIS study provided evidence for a psychosis continuum in the general population (chapter 2). Using a large sample of young men, the ASPIS study corroborated the finding of a quantitative psychosis continuum in the general population (chapter 3). Furthermore, it was shown that the CAPE is a valid self-report instrument in distinguishing between three correlated yet separately varying psychosis dimensions (i.e., positive, negative and depressive dimension). Since the findings of the ASPIS study were replicated by Verdoux and colleagues in a large sample of undergraduate female studients (Verdoux, Sorbara et al. 2002), the three dimensions of the CAPE can be extrapolated to both young women and men.

In order to study the continuum hypothesis across and within patient groups as well as the general population aged 18-70 years, the Continuum of Mental Disorders Study (COMED study) included both an ambulant patient sample and a general population sample. The diagnostic groups, including psychotic, mood and anxiety disorders, and the general population sample were compared on the dimensional factors of the CAPE. In addition, within-group comparisons were carried out to study symptom contrast within diagnostic groups. The results showed that patients diagnosed with psychotic disorders sconed significantly higher on the positive dimension than the patient groups with mood and anxiety disorder and the general population. Strikingly, the mood and anxiety disorder groups had an intermediate score on the positive dimension. The patients had the highest score on the positive, negative or depressive dimension of the CAPE that was most characteristic of their diagnosis. Frequency of experiences and the accompanying distress displayed a positive and linear relationship. Nonetheless, distress added to the development of clinical disorder irrespective of the frequency of experiences, as the level of distress was significantly higher in the patient groups than in the general population sample. These findings (chapter 4) are in line with the hypothesised continum view, which states that the psychosis continuum runs from normal variations in experiences or personality traits, via affective and schizo-affective disorders, to the clinical diagnosis of schizophrenia (Claridge and Beech 1995; Johns 
and van Os 2001). Moreover, the presence of increased distress determined patient status.

Thus, these results show that psychotic experiences that were thought to be mainly pathognomonic for psychotic disorders are also obserwable in less serious variants in other diagnostic groups and the general population. The tentative validation of the psychosis contimum has several important implications for aetiological hypotheses and the treatment of psychosis. Based on phenotypic (Taylot 1992 ; Peralta and Cuesta 2001) as well as aetiological evidence (van Os, Marcelis et al. 1997; Cardno, Sham et al. 2001; Cardno, Rijsdijk et al. 2002), the assessment of the quantitative psychosis phenotype should also include affective symptomatology. The within-person continuity of psychotic and affective features observed in chapter 4 argues for a treatment targeting symptom dimensions instead of diagnostic categories.

Subclinical psychosis dimenswons aggregate within families from the general population The COMED study used multilevel regression analysis to examine the family random effect for self-report psychosis dimensions versus interview-based schizotypy in a large sample of related individuals from the general population. The variation at family level was significant for the CAPE positive psychosis dimension, as well as for the Structured Interview for Schizotypy-Revised (SIS-R) positive and negative schizotypy domains. Moreover, the CAPE positive dimension clustered independently from the CAPE negative and depressive dimensions in families. Both positive and negative schizotypy allso showed inclependent familial clustering. The correlation between the positive factors of the CAPE and the SIS-R was moderately high and significant. In contrast, the correlation between the negative factors of the self-report and interview measures was modest, albeit also significant. In conclusion, the interview measure is suitable for disceming familial clustering of both positive and negative schizotypy in the general population, whereas the self-report measure is only able to detect familial aggregation of subclinical positive psychotic experiences. This finding may imply that individuals from the general population are less able to report and reflect on their own attenuated negative symptoms, while clinical observers can more validly observe and record these subclinical symptoms. The family-specific variation of dimensional psychotic experiences in the general population does not warrant a fully genetic explanation of the finding. Besides genes, environmental risk factors may also be transmitted within families.

Twin and adoption studies are the only designs fit to discover the relative contributions of genes and envirommental risk factors to a disorder or attenuated experiences (Faraone and Tsuang 1995), although these studies often do not collect enough information to examine gene-environment interactions and gene-environment correlations. It is crucial to differentiate the 'modes of reciprocity' between genotype 
and environment. Genotype-enwironment correlation has three types: passive, evocative and active. Passure correlation means that someone"s genotype is correlated with their family environment. Evocative correlation is the reaction individuals evoke with their genetically determined behaviour. Finally, active correlation involves individuals choosing environments that correspond with their genetic liabillity. It is important to acknowledge the influence of genes on the chosen environment, particularly if an environmental risk factor is assumed to play a role in an observed trait. Additionally, genotype-environment interaction involves genetically based vulnerability to the environment, resulting in the expression of a genetic trait (Plomin, DeFries et al. 2001). According to van $O$ s and Marcelis (1998), there is evidence in schizophrenia research for both genotype-environment correlation and interaction (van Os and Marcelis 1998).

The findings of chapter 5 support a phenomenological and aetiological continum approach to the psychosis phenotype. The observed clustering of both positive and negative schizotypy and positive psychotic experiences in certain families from the general population is most probably caused by shared genes and their interactions with environmental factors (Kety, Wender et al. 1994; van Os and Marcelis 1998; Cardno, Rijsdijk et al. 2002; van Os and Sham 2003). According to contemporary psychosis research, most evidence points to a multi-factorial polygenic model involving both genetic and environmental factors acting on the expression of the continuous psychosis phenotype (Tsuang, Stone et al. 1999; Linney, Murray et al. 2003). Similarly, the stresswulnerability model by Zubin states that, besides the diathesis, additional factors, like stressors and coping mechanisms, come into play in the pathway to psychosis (Zubin and Spring 1977). Assuming psychosis to be a multi-factorial polygenic disease opens the way for multiple explanatory factors. However, psychosis research is still in the Dark Ages" regarding the combinations of factors that act as sufficient causes resulting in an wltimate 'hit' that in turn causes the climical expression of the psychosis phenotype.

Self reported pwychotic experiences are mot a valid screening tool for psychosis in the general population, but may well be walld for mental health care users displaying helpseeking behaviou"

Compared to the rare DSM-HI-R diagnosis of affective or non-affective psychosis, the prevalence of self-reported psychotic experiences in the NEMESIS study is high: $1.5 \%$ versus $18.1 \%$. The same pattern of results has been observed by several other researchers (Eaton, Romanoski et al. 1991; Kendler, Gallagher ef al. 1996) and corresponds to the fully-dimensional continuum model of psychosis (Claridge 1997). The best diagnostic value of self-reported psychotic experiences was observed for the 'clinical symptom' category, i.e. a psychotic experience accompanied by distress, with a post-test probability of $26.5 \%$. This means that if the criterion of displaying at least one 
clinical psychotic symptom is used in the general population as a screening instrument for the presence of psychotic disorder, only 25 out of every 100 persons with at least one clinical psychotic symptom will indeed have a clinical psychotic disorder, whereas 75 out of every 100 persons with a clinical psychotic symptom in the general population would be labelled false-positives. Besides, the diagnostic value of self-reported psychotic experiences was higher in persons without comorbidity of a non-psychotic DSM diagnosis. The larger the number of psychotic experiences were present, the more likely an individual was to be diagnosed with a psychotic disorder. Nonetheless, combining psychotic-like symptoms was at the expense of the sensitivity of the diagnostic indicator. In the early prediction research, combining risk factors is a common procedure, used to allow adequate prediction of psychosis (Yung, MoGorry et al. 1996; van Os, Takei et al. 1997; Yung, Phillips et al. 1998). This 'close in' strategy is the only feasible strategy in trying to screen for psychotic disorders at the level of ambulant mental health services where people seek help. Other strategies would yield unacceptable rates of false-positives, and the ethics regarding unnecessary diagnostic labelling would become a major concern.

The diagnostic value of the 'clinical symptom' category was considerably lower in subjects with recent psychotic symptoms than in the complete sample. This finding is important, as early prediction in psychosis operates in a narrow time window after the onset of psychotic symptoms (McGlashan and Johannessen 1996). Chapter 6 raised the possibility that persons with recent-onset psychotic experiences might be less accurate in reporting the active psychotic experiences than persons with recovered insight after remission of their symptoms. It should also be noted that in contemporary early prevention clinics, all individuals are seen by a clinician, so that reliable and valid reports of recent-onset psychotic-like experiences can be obtained (Yung, Phillips et al. 1998; Comblatt 2002; McGorry, Yung et al. 2002; Morrison, Bentall et al. 2002; Rosen, Woods et al. 2002). Finally, when the sample was restricted to mental health care users, the diagnostic values increased due to the obvious increase in the baseline prevalence of psychosis. This is in accordance with common practice at early prevention clinics, as prodromal symptoms can currently only serve as valid criteria for screening in selected groups with a high baseline prevalence of psychosis, that is, in subjects who have sought help for their problems, as is the case in the PACE clinic in Melbourne (Yung, McGorry et al. 1996; Yung, Phillips et al. 1998; McGorry, Yung et al. 2002).

A minority of incident self-reported psychoric experiences become clinically relevant. depending on the type and emotional appraisal of the psychotic experience

We wished to extend our knowledge of the diagnostic value of psychotic experiences in the general population to the predictive value of such experiences. To this end, the 2 year outcome of incident psychotic experiences was studied in the NEMESIS sample. 
Similar to the findings of the cross-sectional study, the experience of distress related to the psychotic experience increased the risk of the presence of a clinical psychotic disorder. However, only a small percentage of subjects with incident psychotic experiences, at most $15 \%$, developed a psychotic disorder that needed treatment within two years. An interesting finding was that psychotic experiences without distress predicted a better outcome than experiences accompanied by distress. Again, these results can be interpreted in the light of phenomenological continuity, meaning that less severe variants of psychotic symptoms are present in the general population (Eaton, Romanoski et al. 1991; Bebbington and Nayani 1995). The findings also shed light on the longitudinal continuity of psychotic experiences in a large general population sample, in that only a minority of self-reported psychotic experiences in the general population predict the transition to psychotic disorder with a need for care. Besides the mere presence of psychotic experiences, additional psychological and sociological factors interact with the person before he or she ultimately develops a psychotic disorder that requires treatment. Examples include the coping mechanisms implemented by an individual (Bak, van der Spil et al. 2001; Bak, van der Spil et al. 2001), the level of neuroticism (Krabbendam, Janssen et al. 2002), the emotional and cognitive appraisal of the unustal experiences (Garety, Kuipers et al. 2001), discrimination and childhood abuse (Janssen, Hanssen et al. 2003; Janssen, Krabbendam et al. 2004) and urbanicity (van Os, Hanssen et al. 2001; van Os, Hanssen et al. 2003).

These findings (chapter 7) coincide with the contemporary state of knowledge in early prediction research. Early prediction of psychosis without a high rate of falsepositives is to the present day only possible in selected samples based on a combination of selection processes and close-in risk factor-based strategies (Yung, Phillips et al. 1998).

\section{Distress induces delusion formation in indwiduals with hallucinatory experiences}

In the NEMESIS study, individuals with baseline hallucinatory experiences were followed over a period of three years. The group was divided into individuals who were distressed by these perceptual abnormalities and those who were not distressed. At follow-up, the distressed group had an increased risk of delusion formation, up to a clinical level. These results are in agreement with the cognitive model of psychosis, which states that a delusional interpretation may develop in response to an emotionally salient unusual experience (Maher 1974; Maher 1988; Maher 2003). Factors that may influence the development of delusions are an externalising explanatory style (Bentall, Corcoran et al. 2001), a jumping-to-conclusions style of thinking (Dudley, John et al. 1997), the lack of a "theory of mind" (i.e., insight into the mental states of other people, which is necessary for adequate social interaction) (Corcoran, Mercer et al. 1995), a selective information processing bias focused on threat-related information (Bentall, 
Corcoran et al. 2001 ) and difficulties in recognising the source of self-generated thoughts and actions (Frith and Done 1989).

The role of cognitive factors in psychosis development should be assessed in interaction with biological factors. The review by Walker and Diforio (1997) combines the psychosocial and biological knowledge on stress responsivity in schizophrenia. According to these authors, the liability to distress in schizophrenia is reflected in hippocampal damage and hyperactivity of dopamine neurotransmission. During stress, the hypothalamic-pituitary-adrenal axis (HPA axis) is activated and the elevated cortisol levels activate dopamine neurotransmission through dopamine synthesis and dopamine receptors. A high level of glucocorticoid receptors, including those for cortisol, has been found in the hippocampus and acts as a negative feedback loop to dampen the HPA axis. Chronic stress and cortisol release leads to damage to the hippocampus, decreasing its ability to mitigate the activity of the HPA axis and thus further increasing stress sensitivity. Dopamine neurotransmission and HPA axis stimulate each other, and this biological mechanism explains the observation that stress aggravates psychotic symptoms. In other words, these authors claim that the vulnerability to schizophrenia that may be reflected by hippocampal damage and hyperactive dopamine neurotransmission parallels a hypersensitivity to stressors. Not only dopamine, but also other neurotransmitter systems, like glutamate, have been suggested to be involved in the pathophysiology of schizophrenia (Walker and Diforio 1997).

Walker and Diforio's neural diathesis-stress model (Walker and Diforio 1997) is compatible to Laruelle's 'two-hit' model, which integrates the neurodevelopmental and neurotoxic hypotheses on the pathophysiology of schizoplirenia (Laruelle 2000 ). Laruelle states that the liability to schizophrenia is based on a neurodevelopmental deficit and that persistent stress leads to an endogenous hypersensitivity of $\mathrm{D}_{2}$ receptors. This endogenous sensitisation is only found during the active phases of psychosis. The interaction between liability and a heightened dopamine response to stress is positively associated with positive psychotic symptoms (Laruelle 2000). Our epidemiological finding that distress associated with hallucinatory experiences serves as a catalyst in the development of delusions (chapter 8 ) is compatible with Walker and Diforio "s neural diathesis-stress model and Laruelle"s two-hit model, and may imply aetiological continuity between psychosis-like symptoms and clinical psychosis. A recently postulated framework linking the psychological and biological aspects of psychosis (Kapur 2003) suggested that a dysregulated, hyperdopaminergic state may lead to stimulus-independent release of dopamine, which may take over the normal process of contextually driven salience attribution and lead to aberant assignment of salience to extemal objects and internal representations. Hallucinations and delusions may consequently arise from cognitive explanations for these altered experiences. This theory is entirely compatible with relatively high, though not necessarily clinically 
relevant, rates of psychosis in the population, depending on the extent of variation of dysregulated dopaminergic states.

\section{Clinical implications}

The present findings have several clinical implications. The overlap in psychosis dimensions across diagnostic groups suggests that it may be more useful to treat symptom dimensions than diagnostic categories, as was indeed originally proposed by the Northwick Park Group (Johnstone, Crow al. 1988) and validated in subsequent studies (wan Os, Gilvarry et al. 1999). This could become centrall to the general treatment protocols and in particular the prescribing protocols for psychotropic medications established by national advisory boards. Due to the overlap, it is sometimes very difficult to assign diagnoses based on the qualitative distinctions made in DSM-IV. These patients would benefit from treatment selected on the basis of symptomatology instead of the assigned DSM-IV category.

The implementation of Cognitive Behavioural Therapy (CBT) techniques (Kingdon and Turkington 1994) has been recommended to ameliorate the distress associated with attenuated psychotic experiences in order to prevent transition to psychosis. Several authors even suggested that early intervention strategies should include antipsychotic medication, as $\mathrm{D}_{2}$ receptor blockade is seen as a possible remedy to prevent sensitisation of the dopamine receptor and further activation of the HPA axis (Walker and Diforio 1997; Laruelle 2000). Walker and Diforio (1997) stated that the administration of antipsychotics should be implemented soon after the onset of psychosis. In contrast, Gottesman and Erlenmeyer-Kimling (2001) underlined that dopaminergic exposure could be detrimental to the developing neocortex (Gottesman and Erlenmeyer-Kimling $2001)$.

The results of the research reported on in the present thesis underline the importance for primary and secondary care clinicians to apply a low threshold to inquiring about the presence of psychotic symptoms, given their high prevalence, and to relate any psychotic phenomena to a possible need for care, given the fact that the majority of these phemomena are not associated with clinical disorder.

Finally, the results suggest that subjects can shift along the continuum from affective to psychotic disorder, although a prospective design would be needed to address this question in a valid manner. The self-reported psychotic experiences in affective disorders may be predictors of a more severe psychotic disorder, since Haefner and colleagues (1999) showed that the first signs of prodromal psychosis are not only positive symptoms, but also depressive and negative symptoms (Haefner, Loeftler et al. 1999). 


\section{Directions for future research}

Some conceptual and methodological issues have been touched on. which need to be addressed in future psychosis research.

This thesis has shown the importance of distress in the pathopsychology of psychosis. Psychotic experiences accompanied by distress were found to have higher diagnostic as well as predictive values for the presence of clinical disorder than those without distress (chapters 6 and 7). Moreover, distress accompanying hallucinatory experiences was found to have a catalysing role in delusion formation (chapter 8) and distress was associated with being a patient (chapter 4 ). Future research should ellucidate the mechanism of distress in the development towards psychosis. It could be argued that this is a tautologic argument, since it is inevitable that patients experience distress because they have to experience more symptoms in order to meet the criteria for clinical psychotic disorder. Distress was indeed positively associated with an increase in symptoms, but was related to patient status irrespective of symptom frequency. Still, the causal relationship between distress and disorder needs to be investigated further. The NEMESIS and COMED studies only used general measures of distress, and more precise instruments examining distress should also be administered. Apart from psychological research tools, researchers should include in the same research design biological markers of distress, like diurnal cortisol level (Walker and Diforio 1997), the occupancy of $\mathrm{D}_{2}$ receptors (Laruelle 2000 ), candidate genetic polymorphisms (Caspi, Sugden et al. 2003) and central noradrenergic and dopaminergic stress responses (Matcelis, Cavalier et al. in press).

We would like to underline the significance of continuing research into the psychosis phenotype in the general population, because non-clinical populations are not subject to the disadvantages or confounding effects encountered in research among clinical populations. Non-clinical populations are medication-free and do not have a Distory of institutionalisation (Chapman, Edell et al. 1980; Raine and Lencz 1995; Loughland and Wilhams 1997). Furthemore, it is not more difficult to recruil large general population samples with schizotypy or psychotic-like experiences than to recruit clinical samples diagnosed with psychotic disorders - it may even be easier. At the same time, research using the CAPE in psychatric patients is also necessary to study the relative influences that drive variation at different points on the continum. The factors that drive variation at the lower end may have a diferent effect size at higher values in the distribution. A specific interpretation problen of results may thus be encountered in epidemiology. This thesis has provided evidence for a psychosis phenotype that is expressed in different variations on a continum including affective symptomatology. Attenuated psychotic experiences can be seen as causal intermediates to the endpoint of psychotic disorder. According to Terry and colleagues (2000), in is 
important to consider the number of causal pathways that lead to the endpoint, and whether the risk factor under study influences the intermediate phenotype but not the development of the disease itself (Terry. Neugut et al. 2000). In early prediction research, the objectwe is io find the optimal predictor of impending psychosis. In longitudinal designs, high-risk subjects are followed to assess their symptoms and to see whether they develop a full-blown psychotic disorder. It is important for future research to address the difference between risk factors for the attenuated psychotic experiences, that is, the intermediate point, and risk factors for the endpoint of clinical psychosis.

Finally, most of the studies described in this thesis employed self-report instruments or an interview implemented by lay interviewers to measure attenuated psychotic experiences, except for the COMED study, which used a clinician-assessed interview for schizotypy (chapter 5). The findings in chapter 5 suggest that more research into the psychosis phenotype using clinician-assessed interviews is warranted to validate and consolidate self-report findings.

\section{Conclusions}

The title of this thesis, $A$ contimuous psychosis phenotype: from description to prediction, not only serves to indicate its subject to the prospective reader. It also represents an alternative to the well-trodden paths in psychosis phenomenology and early prediction research of using only chinical and high-risk samples, respectively. The research reported on in this thesis included general population samples in the search for a valid psychosis phenotype and its effective markers. Results from the NEMESIS, ASPIS and COMED studies show that the continuous psychosis phenotype, ranging from psychotic experiences, via affective disorders, to psychotic disorder, seems to be a valid description. The COMED study has provided evidence for familial clustering of positive psychotic experiences and both positive and negative schizotypy in the general population, although it is unclear to what degree such aggregation of subclinical psychosis dimensions is due to genetic liability. In the NEMESIS study, psychotic experiences accompanied by distress were found to be a better predictor of the concurrent and future presence of a clinical psychotic disorder than psychotic experiences without distress. Subjects who become distressed by their unusual experiences are more likely to subsequenty develop delusions than subjects who are not distressed by their unusual experiences. The COMED study showed that distress contributes to patient status, irrespective of symptom frequency. According to the cognitive model of psychosis, these findings provide clear opportunities to use CBT to intervene in the pre-psychotic phase. Nevertheless, scteening the general population using the criterion of any psychotic experience is not safe, as was evidenced by the large 
proportion of false-positives found in the NEMESIS study. However, screening highrisk subjects may be feasible.

In conclusion, this thesis provides strong evidence for a phenomenological continuity, and to a lesser extent for a longitudinal and aetiological continuity, of psychotic experiences in the general population. The idea of a psychosis continuum is destigmatising and may thus be useful in early prediction and prevention services for psychosis (Yung and McGorry 1997). Since diagnostic categories and pre-clinical states are not mutually exclusive but may overlap, therapeutic strategies should no longer be indicated on the basis of a diagnosis but on the basis of overlapping symptom dimensions. Future biological, psychological and sociological researchers should join forces in searching for the multi-factorial aetiological explanatory model of the continuous psychosis phenotype. 


\section{References}

Bak, M., van der Spil, F., Gunther, N, Radstake, S., Delespaul, P. and van Os, J. (2001). Maastricht Assessment of Coping Strategies (MACS-1): a brief instrument to assess coping with psychotic symptoms. Acta Psychiatrica Scandincivica 103(6): 453-459.

Bak, M., van der Spil, F., Gunther, N. Radstake, S., Delespatu, P. and wan Os, I. (2001). MACS-11: does coping enbance subjective control over psychotic symptoms? Acta Psychiantica Scandinavica 10 (6): $460-464$.

Bebbington, P. and Nayani, T. (1995). The Psychosis Screcning Questionaire. Haternationat Jownal of Methods in Psychiatric Researeh $5: 11-19$

Bentall, R. P., Corcoran, R., Howard, R., Blackwood, N. and Kinderman, P. (2001). Persecutory delusions: a review and theoretical integration. Chincal Psychology Revtew 2/(8): 1143-1192.

Cardno, A. G., Rijsdijk, F. V., Sham, P. C., Murray, R. M. and McGuffin, P. (2002). A twin study of genetic retationships between psychotic symptoms. Anerican Jondud of Psychatry 159(4): $539-545$.

Cardno, A. G. Sham, P. C. Murray, R. M. and McGuffin, P. (2001). Twin study of sympiom dimensions in psychoses. British Xowwat of Psychiatry 179: 39-45.

Caspi, A. Sugden, K., Moffint, T. E., Taylor, A., Craig, I. W., Harrington, H., et al. (2003). Influence of life stress on depression: moderation by a polymorphism in the 5-HTT gene. Scrence 301: 386-389.

Chapman, L. J., Edell, W. S. and Chapman, J. P. (1980). Physical anhedonia, pereeptual aberration, and psychosis proneness. Schizophrenia Bulletin 6(4): 639-653.

Claudge, G. (1997). Schizotypy. Implications for Illness and Heath Ox ford, Oxford University Press.

Claridge, G. and Beech. T. (1995). Fully and quasi-dimensional constructions of schizotypy. In: Schizonyal Personatity. A. Raine. 'T. Lencz and S. A. Mednick (Eds.). New York, Cambridge University Press.

Corcoran, R., Mereer, G. and Frith, C. D. (1995). Schizophrenia, symptomatology and social inference: Investigating "theory of mind" in people with schizophrenia. Schizophrenta Resedrch 17: 5-13.

Comblatt, B. A. (2002). The New York high risk project to the Hillside recognition and prevention (RAP) program. Amorican Journal of Medical Genetics 1/4(8): 956-966.

Crow, T. J. (1998). From Kraepellin to Kretschmer leavened by Schneider. The transition from categories of psychosis to dimensions of variation intrinsic to Homo sapiens. Archives of General Psychatry 55 : 502 504.

Dudley, R. E. J., Jolm, C. Ill, Young. A. W. and Over, D. E. (1997). Normal and abnomal rasoning in

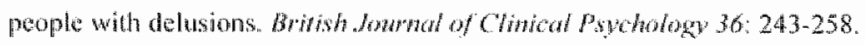

Eaton, W. W... Romanoski, A., Anthony. 1, C. and Nestad, G. (1991). Screening for psychosis in the general population with a selfatepon interview. The dournal of Nervons and Mertal Discase 179(11): 689-693.

Furanc, S. V. and Tsuang, M. T. (1995). Methods in psyclatric genetics. In: Textbook in Psychowric

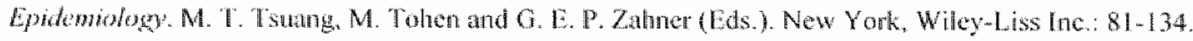

Frith, C. D. and Done. D. 1. (1989). Experiences of atien control in schizophrenia reflect a disorder in the central monitoring of action. Pspchological Medicine $19(2): 359-363$.

Garety, P. A., Kuipers. E. Fowler, D. Freeman. D. and Bebbington, P. E. (2001). A cognitive model of the positive symptoms of pychosis. Psycholagical Medicine 3/(2): 189-195.

Gottesman, 1, and Erlenmeyer-Kimling. L. (2001). Family and wh stategies as a thead stat in detining prodromes and endophenotypes for hypothetical early-interventions in schizophrenia. Schizophrenia Resedrch 5/(1): 93-102.

Haether, I., Locher. W. Maurer. K.. Hambrech, M. and an der Heiden, W. (1999). Depression. negative symploms, social statgation and social decline in the early course of schizophrenta Acta Psychiotrica Seandhavica $100(2): 105-118$. 
Janssen, 1., Hanssean, M., Bak, M., Bill, R. V., de Graat, R., Vollehergh, W., et al. (2003), Discrimination and delusional ideation. British Sowrnat of Pspehatm 182: 71-76.

Janssen, I., Krabbendan, L., Bak, M., Hanssen, M., Vollebergh, W., de Oraf, R. el al. (2004). Childhow

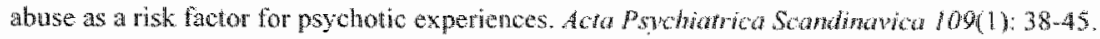

Johns, L. C. and van Os, J. (2001). The continuty of psychonic experiences in the general population. Chatical Psychology: Review 2/(8): 1125\%1141.

Johnstone, E. C., Crow, T. J., Frith, C. D. and Owens, D. G. (1988). The Northwick Park Functionat" Psychosis Study: diagnosis and treatment response. Lanced 2: 119-125.

Kapur, S. (2003). Psychosis as a state of aberrant salience a framework linking biology phenomenology, and pharmacology in schizophrenta. Americon Joursal of Pspdiatry $160(1): 13-23$.

Kendler, K. S., Gallagher, T. J. Abelson, J. M. and Kessler, R. C. (1996). Lifet ime prevalence, denographic risklk factors, and diagnostic validity of nonaffective psychosis as assessed in a US communty sample. The National Comorbidity Survey. Archies of General Prychiaty $53(11): 1022-1031$.

Kety, S. S., Wender, P. H. Jacobson, B., Ingraham, L. J.. dansson, L. Fouber. B., a al. (1994). Mental illness in the biological and adoptive relatives of schizophrenic adoptees. Replication of the Copenhagen Study in the rest of Denmark. Archives of General Psychary 5/(6): 442-455.

Kingdon, D. and Turkington, D. (1994). Cogmiwe-Behawional Therapy of Schizophrema. Hove (UK) Hillside (USA), Lawrence Erlbaum Associates.

Krabbendam, L., Janssen, I., Bak, M., Bij1, R. V., de Graaf, R. and van Os, J. (2002). Neuroticiam and low self-esteen as risk factors for psychosis. Social Psychiaty and Pswchiatric Epickntology 37(1): 1-6.

Laruelle, M. (2000). The role of endogenous sensitization in the pathophysiology of schizepphrenta: implications from recent brain imaging studies. Bram Rexearch Rewewr 3/(2-3); $371-384$.

Limney, Y, M., Murray, R. M., Peters, E. R., MacDonald, A. M., Rijsdijk, F, and Sham, P. C. (2603). A quantitative genetic anslysis of schizotypal personalify trats. Psyctofogical Medicke. 33: 803-816.

Loughland, C. M, and Willams, L. M. (1997). A cluster analytic study of schizotypal trail dimerwions. Personality and Individuat Differences 23(5): $877-883$.

Matyer, B. A. (1974). Delusional thinking and perceptual disorder. Journal of mdividual Psychology 30 ; 98 113.

Maher, B. A. (1988). Anomalous experience and delusional thinking: the logic of explanations. In: Delusionat Beliefs. T. F. Olmanns and B. A. Maher (Eds.). New York. Wiley: 15-33.

Maher. B. A. (2003). Psychopathology and delusions: rellections on methods and models. In: Princiglex af Experimenol Psychopathology. M. F. Lenzenweger and 1 . M. Hoolcy (lids.). Washington, DC, American Psychological Association: $9-28$.

Marcelis, M. Cavalier, E., Gielen, J., Delespanl. P. and wan Os, J. (in press). Abnormal reciponse to motabolic

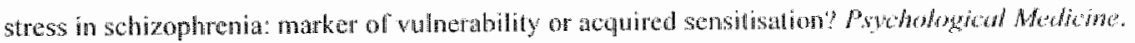

MeGiashan, T. H. and Johannessen, J. O. (1996). Early detection and intervention with schizophrenia: rationale. Schizophrenia Bulletin 22(2): $201-222$.

McGorry, P. D., Yung, A. R., Phillips, L. J. Yuen, H. P.. Francey, S., Cosgrave, E. M. at al. (2002). Randonized controlled trial of interventions designed to reduce the risk of progression to lirst-episude psychosis in a clinical sample with subthreshold symptoms. Archwes of Gencral Psychiory $50(10)$ : 921 928.

Morrison, A. P., Bentall, R. P., French, P., Walford, L... Kilcommons. A., Knight, A., et al. (2002). Randomised controlled trial of early detection and cognitive therapy lior preventing transition to psychosis in high-risk individuals. Study design and interim analysis of transition rate and psychological risk factors. Brifish Jownol of Psychicary Stupplement 43: 578-84 
Peralta, V. and Cuesia, M. J. (2001). How many and which are the psychopathological dimencions in schizophronia? Issues influencing their ascentanment. Schizophrenia Researeh $49(3): 269-285$.

Plomin, R. Defries, J. C. McClearn. G. E. and MoGution, P. (2001). Behoworal Genetics. New York, Worth Publishliers.

Raine, A and Lencz. T. (1995). Conceptual and theoretical issues in schizotypal personality research. In: Schizotypal Persondity. A. Raine, T. Lencz and \$. A. Mednick (Eds). Cambridge, Cambridge Universily mess: $3-15$.

Rosen, 1. L.. Woods. S. W.. Millier, T. J. and MoGtashan, T. H. 2002). Prospective observations of emerging psychosis. The Jous arat of Nervous and Memal Disease 190: 133-141.

Strass, J. S. (1) 69 ). Hallucimations and delusions as points on continua function. Rating scale evidence. Atchives of Gevesial Psychialy 2/(5):581-586.

Taylor. M. A. (1992). Are schizophrenia and affective disorder related? A selective literature review.

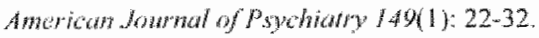

Terry. M. B. Neugut, A. I., Schwartz, S. and Susser, E. (2000). Risk factors for a causal intermediate and an endpoint: reconciling differences. American Jounal of Epidewiology 15/(4):339.345.

Tstang, M. T., Stone, W. S and Faraone, S. V. (1999). Schizophrenia: A review of genetic studies. Harvard Revicu of Psychothy 7: 185-207.

van Os, J, Gilvarry, C., Bale, R., van Horn, E., Tattan, T., White, I, et al. (1999). A comparison of the utility of dimensional and categorical representations of psychosis. UK700 Group. Psychological Medicine $29(3): 595-606$.

wan Os, J., Hanssen, M., Bak, M., Bijl, R. and Vollebergh, W. (2003). Do urbanicily and familial liability coparticipate in causing psychosis? Anerican Joumal of Psychiary /60(3): 477-482.

wan Os, J., Hanssen, M., Bijl, R. V. and Vollebergh. W. (2001). Prevalence of psychotic disorder and community level of psychotic symptoms: an urban-itural comparison. Archives of General Psychiatry $58(7): 663-668$

van Os, J. and Marcelis, M. (1998). The ecogenetics of schizophrenia: a review. Schizophemia Research $32(2): 127-135$.

wan Os, J., Marcelis, M., Sham, P.. Jones, P., Gilvarry, K. and Murray, R. (1997). Psychopathological syndromes and tamilial morbid risk of psychosis. British Jounat of Psychiany 170: 241-246.

van $O_{3}$. 1. and Sham, P. (2003). Gencenvironment corretation and interaction in schizophrenial. In: The

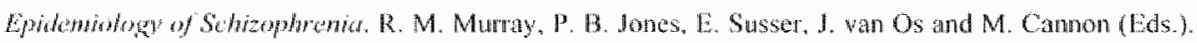
Cambridge, Combridge Universiry Press: $235-254$.

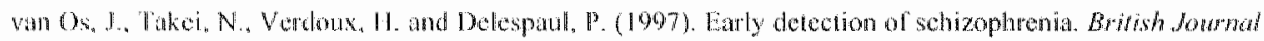
of forchiary 170:57\%.

Verdoux, II., Sorbara, I. Gindre, C. Swendsen, J. D. and wan Os, J. (2002). Cannabis use and dimensions of

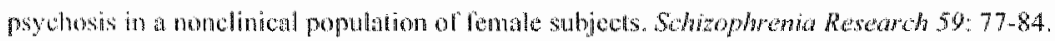

Walker. I. F. and Diforin, D. (1997), Sehizophrenia: a neural dathesis-stress model. Pspchological Review $104(4): 667-685$.

Yung. A. R. and McGory. P. D. (1997). Is prepsychotic intervention realistic in schizophrenia and related

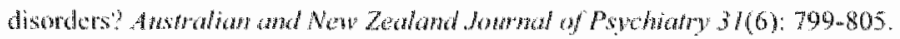

Yung, A. R. McGorry, P. D., Mclfarlane. C. A. Jackson, H. J., Pation, G. C. and Raklkar, A. (1996). Monitoring and care of young people at incipient risk of psychosis. Schizophrenia Bulletin 22(2y: 283. 303.

Yung, A. R., Phillips, L. 1. MeGorry. P. D., MeFarlane, C. A. Francey, S., Harrigan, S., et al. (1998). Prediction of psychosils. A step towards indicated prevention of schizophrenia. British Jonenal of Prochiom Supplement 172(33): 14-20.

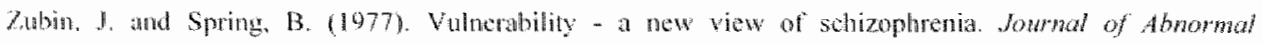

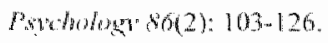




\section{Summary}

The title of this thesis, $A$ continuous psychosis phenotype: from description to prediction reflects its theme and represents an altemative view to the psychosis phenomenology and early prediction research using only clinical and high-risk samples, respectively. The research on which this thesis is based included general population samples in the search for a valid psychosis phenotype.

Chapter 1 provides an overview of the phenomenology research and early prediction research into psychosis. A continuous psychosis phenotype is introduced as an approach to the heterogeneity issue in psychosis phenomenology research. Two continutum views of psychosis currently prevail: the quasi-dimensional model states that schizophreniaspectrum disorders lie on a continum of increasing severity, while the fully-dimensional model states that the psychosis continuum extends from normal variations in symptoms, or personality to clinical psychotic disorders. According to the fully-dimensional model, the psychosis continumm is often defined using psychotic-like experiences, schizotypy, psychosis proneness and psychoticism. Evidence is provided for phenomenological, longitudinal and aetiological continuity between clinical psychosis and schizotypy or attenuated psychotic symptoms. Accordingly, early prediction studies are searching for specific and sensitive predictors of the transition along the continum to full-blown psychosis. The feasibility of early prediction and prevention of psychosis is discussed on the basis of relevant studies. A mediating factor in the transition along the continum to clinical disorder is cognitive appraisal of unusual experiences. From the cognitive explanatory model of psychosis arises the incentive to apply cognitive behavioural techniques to psychosis and the pre-psychotic phases. Guided by the literature on phenomenology and early prediction, this thesis has three objectives: (i) to examine and validate the notion of a continum of psychosis in the general population and in patients receiving outpatient care, (ii) to study familial clustering of subclinical psychosis dimensions in families sampled from the general population, and (iii) to study the predictive validity of psychotic-like experiences in terms of their ability to predict clinical need and to formulate the clinical implications of the findings.

Chapter 2 hypothesises that the psychosis continumm extends into the general population and that psychotic-like experiences show the same associations with risk factors as clinical symptoms. This study was based on the baseline measurement of the Netherlands Mental Health Survey and Incidence Study (NEMESIS).

NEMESIS is a prospective study of the prevalence, incidence, course and consequences of psychiatric problems in the general population, inwolving three 
measurement points over a period of 3 years. A total of 7076 subjects aged 18 -64 years participated at baseline. The Composite Intemational Diagnostic Interview (CIDI) was administered by trained lay interviewers, yielding DSM-III-R diagnoses. The CIDI psychosis items can be rated in six ways: " 1 " no symptom present; "2' NCR (Not Clinically Relevant) symptom (i.e., symptom present but not clinically relevant); ' 3 " and '4' Secondary symptom (i.e.s symptom is the result of drugs use or somatic disease); " 5 " Clinical symptom (i.e., true psychotic symptom); '6' Plausible or Possible symptom (i.e., experience is not a real symptom, because there appears to be some plausible explanation for it). At baseline, a senior registrar in psychiatry conducted clinical reinterviews over the telephone with all subjects with at least one clinical or plausible symptom, using questions from the Structured Clinical Interview for DSM-III-R (SCID). The CIDI psychosis ratings of clinical or plausible symptoms were corrected if necessary on the basis of the clinical interviews. Accordingly, the DSM-III-R diagnoses were based on the corrected CIDI psychosis ratings.

The results indicated that psychotic symptoms were much more prevalent than the diagnosis of non-affective psychosis and were related to risk factors common in clinical disorder. These findings suggest that the psychosis continuum should be extended to less severe psychotic-like experiences in the general population. The psychotic symptom ratings were associated with flat affect and depressive mood, implying that the psychosis continuum includes negative and affective symptomatology. Furthermore, positive psychotic symptom dimensions were associated not only with non-affective psychosis but also with other psychiatric diagnoses. The finding that the presence of hallucinations was strongly associated with any type of delusion is compatible with the cognitive model of psychosis.

Chopter 3 examines whether correlated, yet independently varying psychosis dimensions have a distribution in the general population. The Athens Study of Psychosis Proneness and Incidence of Schizophrenia (ASPIS) examined schizotypy and psychosis dimensions among conscripts in Greece, using the Community Assessment of Psychic Experiences (CAPE), a self-report instrument, in a representative population sample of 932 young men. The CAPE was developed to measure attenuated psychotic experiences in the affective and non-affective domains. The three-factor model of positive, negative and depressive psychosis dimensions showed a better fit than a twofactor or unidimensional model. All three psychosis dimensions showed co-variation, with correlations around 0.7 . It could be suggested that the co-variation beween depressive symptoms and positive and negative symptoms is mainly due to the distress generated by the positive and negative symptoms. However, partial correlations in which the distress accompanying positive or negative symptoms was kept constant showed that the correlations of either positive or negative symptoms with depressive 
symptoms remained significant. The relationship between frequency of symptoms and distress could be described as a linear dose-response pattern expressed by correlations of the order of 0.7 . In spite of the moderate correlation between the three CAPE psychosis dimensions, these scales showed good discriminant walidity with commonly used scales. Taken together, these findings indicate that the correlated, yet independently varying CAPE psychosis dimensions have a distribution in the general population and that depression may be an inherent part of the psychosis phenotype.

Chapter 4 presents the findings of the baseline measurement of the Continum of Mental Disorders Study (COMED study). The objective of this study is to compare the CAPE psychosis dimensions across and within patient groups from a Community Mental Health Service (CMLS) and non-patients from the general population. The COMED study involves a longitudinal family study among the general population in the town of Sirtard (the Netherlands), and a cross-sectional study at a CMHS in the town of Maastricht (the Netherlands). In order to recruit a general population sample, residents of Sittard aged 36-65 years were selected at random to receive a letter in which they and their relatives were asked to participate in the COMED study. The age range of the total general population sample was $18-70$ years. The sampling procedure at the CMHS involved sending letters to all patients of the depariment for the treatment of severe mental illness and the department for the treatment of depression and anxiety disorders. A total of 647 subjects in the general population and 762 CMHS patients completed the CAPE. A DSM-IV diagnosis was made in 555 of the 762 patients. The following DSMIV categories were used in the analyses: (1) Schizophrenia and Other Psychotic Disorders ( $n=72$ ), (2) Mood Disorders ( $n=214$ ), (3) Anxiety Disorders ( $n=129)$. The results showed that patients diagnosed with psychotic disorders scored significantly higher on the CAPE positive dimension than the patient groups of mood and anxiety disorder, and the general population. Strikingly, the mood and anxiety disorder groups had an intermediate score on the CAPE positive dimension. The patienis had their highest score on the positive, negative or depressive psychosis dimension of the CAPE that was most characteristic of their diagnosis, implying that the CAPE dimensions have sufficient discriminant validity. Frequency of symptoms and the accompanying distress displayed a positive and linear relationship. Nonetheless, distress added to the development of clinical disorder irrespective of symptom frequency, as the level of distress was significantly higher in the patient groups than in the general population sample. The findings suggest that non-psychotic disorders yield intermediate values for the continuous psychosis phenotype and that the psychopathology associated with psychotic disorders varies quantitatively across DSM-IV categories. This means that measurements of the quantitative psychosis phenotype should also include affective symptomatology. Furthermore, the results show that psychotic experiences that were 
thought to be mainly pathognomonic for psychotic disorders are also observable in less serious variants in other diagnostic groups and the general population. The observed within-person continuity of psychotic and affective features argues for a reament targeting symptom dimensions instead of diagnostic categories.

Chapter 5 describes the assessment of family-specific variation of subclinical psychosis dimensions among relatives from the general population, while also comparing the ability of the CAPE self-report instrument to detect familial clustering of psychosis dimensions with that of the Structured Interview for Schizotypy-Revised (SIS-R). This stutly comprised the second measurement of the COMED study, a longitudinal family study in the general population. A total of 768 subjects aged $17-77$ years from 116 families participated at $T_{1}$. Subjects with a mean or high score on the CAPE positive psychosis dimension at $T_{1}$ were interviewed at $T_{2}$, i.e., 7-8 months later, by trained psychologists who administered the SIS-R $(n=496)$. At $T_{2}$, subjects also completed the CAPE again $(n=507)$. Multilevel regression analyses were used to examine familyspecific variation in CAPE psychosis dimensions and SIS-R schizotypy. The $T_{2}$ correlations between the positive and the negative dimensions of the SIS-R and their corresponding dimensions on the CAPE were $0.63 \quad(p=0.00)$ and $0.48 \quad(p=0.00)$, respectively. Both positive and negative dimensions of the SIS-R showed significant family-specific variation. In the CAPE findings, family-specific variation was apparent only for the positive dimension. A possible explanation is that attenuated negative symptoms are somewhat more difficult to capture with self-report and are more validly assessed by clinical observers. The present findings provide evidence for familial clustering of dimensions of psychotic experiences in the general population, suggesting a broad distribution of familial factors that drive the variation in psychosis.

Chopra 6 examines the research question whether self-reported psychotic experiences in the general population are a valid screening tool for DSM-III-R psychotic disorders. Until now, research on early prediction of psychosis has been limited to high-risk groups with a high baseline prevalence of psychosis. Therefore, the studies described in chapters 6 and 7 addressed the feasibility of early prediction in the general population. The former chaptel is based on cross-sectional data from the first measurement of the NEMESIS study. The angmal, uncorrected CIDI self-report psychosis ratings as assessed by the lay interviewers were used as a diagnostic test for the clinician-assessed DSM-III-R psychotic disorder that was based on the corrected CIDI psychosis ratings after re-interview. The best diagnostic value of self-reported psychotic experiences was observed for the 'clinical symptom' category, that is, a psychotic experience accompanied by distress, with a post-test probability of $26.5 \%$. In subjects with recent psychotic symptoms, the diagnostic value of the 'clinical symptom' category was 
considerably lower than in the complete sample. The greater the number of self-reported psychotic experiences that were present, the more likely individuals were to be diagnosed with a clinical psychotic disorder. However, combining psychotic-like symptoms was at the expense of the sensitivity of the diagnostic indicator. The diagnostic value of self-reported psychotic experiences was greater in persons without co-morbidity of a non-psychotic DSM diagnosis. Moreover, the diagnostic value was greater for individuals who had previous received mental health care. In conclusion, screening the general population for psychosis carries a high risk of stigmatisation in. false-positive cases and violations of the 'right not to know' in true positive cases. However, among mental health care users, self-reported psychotic experiences may be a useful screening tool for individuals who have already developed help-seeking behaviour, due to the artificial increase in the baseline prevalence of psychosis. This is in accordance with the common practice of early prevention clinics, as prodromal symptoms are currently only valid predictors in selected groups with a high baseline prevalence of psychosis, that is, in subjects who have sought help for their problems.

Chapter 7 addresses the 2-year outcome of incident self-reported psychotic experiences in the general population in terms of stability, impaiment and need for care. The study described here used the longitudinal design of the NEMESIS study. At T2, clinical reinterviews were conducted over the telephone by an experienced clinician for all individuals who had had a clinical, plausible or not clinically relevant rating on any CIDI psychosis item. A sample of individuals was selected who had experienced an onset of a self-reported psychotic experience between baseline and $T_{1}(n=83)$. In this sample, the stability autcome of positive psychotic experiences at $\mathrm{T}_{2}$ was assessed by cliniciancorrected CIDI lay interview ratings (CIDI outcome, $n=58$ ) and by clinical interview, both in terms of the presence of any psychotic experience measured by the Brict Psychiatric Rating Scale (BPRS outcome, n=47), and in terms of clinical relevance, using criteria of functional impaiment and need for care (clinical outcome, n=11). The 2-year predictive values of incident psychotic experiences at $\mathrm{T}_{1}$ for all thee outcome measures at $\mathbb{T}_{2}$ were small to modest. Similar to what was found in the cross-sectional study reported in chapter 6 , the experience of distress related to the psychotic experience increased the risk of the presence of clinical psychotic disorder. However, only a small proportion of subjects with incident psychotic experiences, with a maximum of $15 \%$, developed a psychotic disorder with need for treatment over a two-year period. To sum up, a minority of incident self-reported psychotic experiences become clinically relevant, depending on the type and emotional appraisal of the psychotic experience. These findings coincide with the current state of knowledge in early prediction research. Early prediction of psychosis without a high rate of false-positives is still only possible in selected samples, based on a combination of risk factors. 
Chapter 8 examines the amplifying role of distress resulting from unusual perceptual experiences in delusion formation. In the NEMESIS study, individuals with baseline hallucinatory experiences were followed for three years. At $T_{2}$, clinicians additionally scored the BPRS item 'unusual thought content'. Analyses compared baseline hallucinatory experiences, whether or not accompanied by subjective distress, for the risk of delusion formation at follow-up. The distressed subjects had an increased risk of delusion formation, up to a clinical level. This finding corroborates the proposition that distress associated with early perceptual intrusions serves as a catalyst in the development of delusions. Thus, it is not only the presence of an unusual perceptual experience in itself, but also the emotional appraisal by the subject which constitutes an important risk factor for subsequent delusion formation. A clinical implication is that Cognitive Behavioural Therapy (CBT) in the context of early hallucinatory experiences may be more efficient when specifically targeting the distress generated by the experience.

Chapter 9 summarises and discusses the main findings of the studies reported on in this thesis, resulting in both theoretical and clinical implications and providing suggestions for future research. Findings indicate that the continuous psychosis phenotype, varying from psychotic experiences, via affective disorders, to psychotic disorders, seems to be a valid description. It is shown that diagnostic categories and pre-clinical states are not mutually exclusive but may overlap. This implies that therapeutic strategies should no longer be indicated on the basis of a diagnosis but on the basis of overlapping symptom dimensions. The thesis provides evidence for familial clustering of subclinical psychosis dimensions in the general population, although it is unclear to what degree such aggregation of subclinical psychosis dimensions is due to genetic liability. The cognitive appraisal of unusual experiences plays a major role in the transition process to clinical psychotic disorder. Based on the cognitive model of psychosis, these findings provide clear opportunities to intervane with $C B T^{\prime}$ in the pre-psychotic phase. In future research, interactions with biological markers should be considered as a risk factor on the pathway to clinical psychosis. Screening the general population using the criterion of any psychotic experience is not safe, as evidenced by the large proportion of falsempositives found in the NEMESIS study. However, sereening high-risk subjects may be feasible.

In conclusion, this thesis provides strong evidence for phenomenological continuity and, to a lesser extent, for longitudinal and aetiological continuity of psychotic experiences in the general population. Future biological, psychological and sociological researchers should join forces in searching for the multi-factorial aetiological explanatory model of the continuous psychosis phenotype. 


\section{Samenvatting}

De titel van dit proefschrift Een continu psychose fenotype: van beschrijwing naar predictie geeft de rode draad van het proefschrift weer. Het onderzoek naar de fenomenologie van psychose en het vroege predictie-onderzock maken gebruik wan respectievelijk klinische en hoge-risico steekproeven. Dit proefschrift vertegenwoordigt een alternatieve kijk op beide onderzoeksvelden. De studies waarop het onderhavige proefschrift is gebaseerd betrekken ook steekproeven uit de algemene bevolking bij de zoektocht naar een valide psychose fenotype.

Hoofdstuk I is een overzicht van het onderzoek naar de fenomenologie en het vroege predictie-onderzoek van psychose. Er wordt gesteld dat een continu psychose fenotype cen oplossing is voor het heterogeniteitsprobleem bij het onderzoek naar de fenomenologie van psychose. Op dit moment zijn twee theorieën omtrent het psychosecontinuum gangbaar. De eerste is het quasi-dimensioneel model, dat beweert dat schizofrenie-spectrumstoornissen op een continuum van toenemende ernst gelegen zijn. Volgens de tweede theorie, het fully-dimensioneel model, loopt het psychosecontinuum van normale variaties in symptomen en persoonlijkheid tot klinisch psychotische stoormissen. De termen psychose-achtige ervaringen, schizotypie, psychosis-proneness en psychoticisme worden in het fully-dimensioneel model vaak toegepast om het psychosecontinuum te definiëren. In dit hoofdstuk worden bewijzen aangedragen die fenomenologische, longitudinale en etiologische continuйteit tussen klinische psychose en schizotypie of licht psychotische symptomen ondersteunen. De vroege predictiestudies zijn derhalve op zoek naar specifieke en sensitieve voorspellers voor de transitie op het continuum naar floride psychose. De haalbaarheid van vroege predictie en preventie van psychose wordt besproken aan de hand van relevante studies. Een essentiële factor bij de transitie op het continum naar een klinische stoornis is de cognitieve evaluatie van ongewone ervaringen. Het cognitieve verklaringsmodel voor psychose stimuleen de toepassing van cognitief-gedragstherapeutische lechnieken bij psychose en de pre-psychotische fasen. De fenomenologie en vroege predictie literatuur dient als leidraad voor de drie doelstellingen van dit proefschrift: Ten eerste, het bestuderen en valideren van het begrip psychosecontinum in de algemene bevolking en in ambulante patiënten. Ten tweede, het bestuderen van familiale clustering van subklinische psychosedimensies in steekproeven van families uit de algemene bevolking, en ten derde het bestuderen van de predictieve validiteit van licht psychotische ervaringen en wel wat betreft het vermogen om de klinische zorgbehoefte te voorspellen en de klinische implicaties te formuleren. 
Hoofdswk 2 veronderstelt dat het psychosecontinuum zich uitstrekt tot de algemene bevolking en dat licht psychotische ervaringen dezelfde associaties vertonen met risicofactoren als klinische symptomen. Deze studie is gebaseerd op de baselinemeting van de Netherlands Mental Health Survey and Incidence Study (NEMESIS).

De NEMESIS-studie is een prospectieve studie naar de prevalentie, de incidentie, het beloop en de consequenties van psychiatrische problemen in de algemene bevolking. Er vonden drie metingen plaats ower een periode van drie jaar. In totaal 7076 personen in de leeftijd van 18-64 jaar namen deel aan de baselinemeting. Getrainde lekeninterviewers namen de Composite International Diagnostic Interview (CIDI) af. De CIDI genereert DSM-III-R-diagnoses. De CIDI psychose-items kunnen op zes manieren beoordeeld worden: "I" geen symptoom aanwezig; "2" NCR (Niet Klinisch Relevant)symptoom (i.e. symptoom is aanwezig, maar niet klinisch relevant); "3" en "4" Secundair symptoom (i.e. symptoom is het gevolg van drugsgebruik of een somatische zickte); "5" Klinisch symptoom (i.e. een klinisch psychotisch symptoom); "6" Plausibel symptoom (i.e. de ervaring is niet een klinisch symptoom, omdat er enige plausibele verklaring voor schijnt te zijn). Bij de baselinemeting voerde een psychiater via de telefoon klinische herinterviews uit bij alle personen met ten minste én klinisch of plausibel symptoom. De psychiater maakte hierbij gebruik van vragen uit de Structured Interview for DSM-III-R (SCID). De CIDI-beoordelingen van klinisch of plausibel psychotische symptomen zijn gecorrigeerd op basis van de klinische interviews. De DSM-III-R-diagnoses zijn aldus gebaseerd op de gecorrigeerde CIDIpsychosebeoordelingen.

De resultaten tonen aan dat psychotische symptomen een hogere prevalentie hebben dan non-affectieve psychose en dat ze gerelateerd zijn aan risicofactoren die algemeen voorkomen bij de klinische stoornis. Deze bevindingen suggereren dat het psychosecontinum ook licht psychotische ervaringen in de algemene bevolking dient te omvatten. De CIDI-psychotische symptomen zijn geassocieerd met vlak affect en depressieve stemming. Dit impliceert dat het psychosecontinum ook negatieve en affectieve symptomatologie onvat. Bovendien zijn de positieve psychotische syumptoomdimensies niet alleen geassocieerd met non-affectieve psychose, maar ook met andere psychiatrische diagnoses. De bevinding dat de aanwezigheid van hallucinaties sterk geassocieerd is met de aanwezigheid van wanen - ongeacht de inhoud van de wanen - sluit aan bij het cognitieve model van psychose.

Hoofdstwk 3 bestudeert of gecorreleerde, doch onafhankelijk variërende psychosedimensies een verdeling in de algemene bevolking hebben. The Athens Study of Psychosis Proneness and Incidence of Schizophrenia (ASPIS) is een studie betreffende schizotypie en psychosedimensies in dienstplichtigen in Griekenland. In een representatieve steekproef van 932 jonge mannen uit de algemene bevolking werd de 
Community Assessment of Psychic Experiences (CAPE), een zelfrapportageinstrument, gebruikt. De CAPE is ontwikkeld om licht psychotische ervaringen zowel in het affectieve als het niet-affectieve domein te meten. Het drie-factorenmodel van positieve, negatieve and depressieve psychosedimensies past beter bij de data dan een twee-factorenmodel of een unidimensioneel model. De drie psychosedimensies covariëren met correlaties van rond de 0.7 . Het is mogelijk dat de covariatie tussen depressieve symptomen aan de ene kant en positieve en negatieve symptomen aan de andere kant, grotendeels veroorzaakt wordt door de lijdensdruk ten gevolge van de positieve en negatieve symptomen. Partiële correlaties warbij de lijdensdruk, veroorzaakt door positieve of negatieve symptomen, constant werd gehouden, laten echter zien dat de correlaties van positieve of negatieve symptomen met depressieve symptomen nog steeds significant zijn. Het verband tussen frequentie van symptomen en de mate van lijdensdruk kan beschreven worden als een lineaire dosis-effect-relatie, uitgedrukt in correlaties van rond de 0.7 . Ondanks de redelijk hoge correlatie tussen de drie CAPE- dimensies laten de schalen een goede discriminante validiteit met bekende schalen zien. Samengevat tonen deze bevindingen aan dat de gecorreleerde, doch onafhankelijk variërende CAPE-psychosedimensies een verdeling in de algemene bevolking hebben en dat depressie een inherent deel van het psychose venotype vormt.

In hoofdstuk 4 worden de bevindingen van de baselinemeting van de Continuum of Mental Disorders Study (COMED-studie) beschreven. Het doel van deze studie is om de CAPE- psychosedimensies te vergelijken tussen en binnen patiëntengroepen van een regionale instelling voor ambulante geestelijke gezondheidszorg (RIAGG) en controlepersonen uit de algemene bevolking. De COMED-studie is een longitudinale familiestudie in de algemene bevolking uit de gemeente Sittard (Nederland) en een cross-sectionele studie in de RIAGG te Maastricht (Nederland). Willekeurige personen uit de gemeente Sittard in de leeftijd 36-65 jaar ontvingen een brief warrin hen en hun familieleden werd gevraagd om deel te nemen aan de COMED-studie. De lexftijdsrange van de totale steekproef uit de algemene bevolking was 18-70 jaar. De steekproefprocedure bij de RIAGG bestond uit het toesturen van brieven aan alle patiënten van de chronisch psychiatrische afdeling en de afdeling voor behandeling van depressie of angststoomissen. In total 647 personen uit de algemene bevolking en 762 patiënten van de RIAGG vulden de CAPE in. Bij 555 van de 762 patiẻnten werd een DSM-IV-diagnose gesteld. De volgende DSM-IV-categorieën werden gebruikt in de analyses: 1. Schizofrenie en andere psychotische stoomissen $(n=72), 2$. Stemmingsstoornissen $(n=214), 3$. Angststoomissen $(n=129)$. De resultaten tonen aan dat patiënten met psychotische stoomissen significant hoger scoren op de CAPE positieve dimensie dan de patiëntengroepen met stemmings- en angststoornissen, en dan de algemene bevolking. Het is opvallend dat de stemmings- en angststoornissengroepen 
een tussenliggende score heef op de CAPE positieve dimensie. De patienten hebben de hoogste score op de positieve, negatieve of depressieve psychosedimensie van de CAPE die het meest karakteristiek is voor hun dagnose. Deze bevinding impliceert dat de discriminante validiteit van de CAPE dimensies voldoende is. De frequentie van symptomen en de mate van lijdensdruk vormen een positief lineair verband. Desalniettemin speelt de mate van lijdensdruk een rol in de ontwikkeling van een klinische stoomis onathankelijk van symptoomfrequentie, aangezien de mate vau lijdensdruk met correctie voor de bijbehorende frequentiescore significant hoger is in patiëntengroepen dan in de algemene bevolking. De bevindingen suggereren dat nietpsychotische stoornissen tussenliggende waarden van het continu psychose fenotype weergeven en dat de psychopathologie geassocieerd met psychotische stoornissen kwantitatief varieert over DSM-IV-categorieenn. Dit betekent dat bij het meten van het kwantitatieve psychose fenotype ook affectieve symptomatologie betrokken moet worden. Bovendien tonen de resultaten aan dat psychotische ervaringen, waarvan gedacht wordt dat ze grotendeels karakteristiek zijn voor psychotische stoornissen, ook in minder ernstige varianten waargenomen kunnen worden bij andere diagnostische categorieën en bij de allgemene bevolking. De geobserveerde intra-persooncontinuilteit van psychotische en affectieve kenmerken pleit voor een behandeling gericht op symptoomdimensies in plaats van diagnostische categorieën.

Hoofdstuk 5 beschrijf het beoordelen van familie-specifieke variatie van subklinische psychosedimensies in familieleden afkomstig uit de algemene bevolking. Tevens wordt het vermogen van het zelfrapportage-instrument CAPE om familiale clustering van subklinische psychosedimensies te ontdekken, vergeleken met het Structured Interview for Schizotypy-Revised (SIS-R). De onderhavige studie bestaat uit de tweede meting van de COMED-studie, een longitudinale familiestudie in de algemene bevolking. In total 768 personen in de leeftijd van 17-77 jaar, afkomstig van 116 families, namen deel op $T_{1}$. Personen met een gemiddelde en een hoge score op de CAPE positieve psychosedimensie op $T_{1}$ werden $7-8$ maanden later op $T_{2}$ mer de SIS-R geïnterviewd door getrainde psychologen $(n=496)$. Op $T_{2}$ vulden de personen de CAPE voor de weede mal in $(n=507)$. Multilevel regressie-analyses werden toegepast om de familiespecilieke variatie van de CAPE psychosedimensies en de SIS-R schizotypie te bestuderen. De $T_{2}$ correlatie tussen de positieve en negatieve dimensies van de SIS-R met de overeenkomstige dimensies van de CAPE luiden respectievelijk 0.63 $(\mathrm{p}=0.00)$ en 0.48 ( $p=0.00)$. Zowel de positieve als de negatieve dimensies van de SIS-R laten een significante familie-specifieke variatie zien. Wat betreft de CAPE is er alleen sprake van familie-specitieke variatie bij de positieve dimensie. Een mogelijke verklaring is dat de licht negatieve symptomen iets moeilijker te meten zijn door middel van zelfrapportage en meer valide kunnen worden beoordeeld door klinische beoordelaars. 
Deze bevindingen verschaffen bewijs voor familiale clustering van het subklinische psychose fenotype in de algemene bevolking. Dit suggereert een brede verdeling van familiale factoren, die de variatie in psychose beinwloeden.

Hoofdstuk 6 bestudeert de onderzoeksvraag of zelfgerapporteerde psychotische ervaringen uit de algemene bevolking een valide screeningsinstrument zijn voor psychotische stoornissen beschreven in de DSM-III-R. Tot nu toe werden onderzoeksdesigns betreffende het vroeg voorspellen van psychose beperkt tot hogerisicogroepen met een hoge prevalentie van psychose. Daarom behandelen de studies die worden beschreven in de hoofdstukken 6 en 7 de haabaarheid van het vroeg voorspellen van psychose in de algemene bevolking. Het eerstgenoemde hoofdstuk is gebaseerd op cross-sectionele data van de eerste meting van de NEMESIS-studie. De originele, ongecorrigeerde CIDI zelfrapportage psychosebeoordelingen, afgenomen door leken-interviewers, werden gebruikt als diagnostische test voor DSM-MI-R psychotische stoomis beoondeeld door clinici. Met andere woorden: de diagnose DSMIII-R psychotische stoomis is gebaseend op de gecorrigeerde CIDI psychosebeoordelingen na herinterview. De beste diagnostische warde van zelfgerapporteerde psychotische ervaringen wordt waargenomen voor de "klinisch symptoom"-categorie, i.e. een psychotische ervaring met lijdensdruk, met een post-rest probabiliteit van 26.5\%. Bij personen met recente psychotische symptomen is de cliagnostische waarde van de "klinisch symptoom"-categonie aanzienlijk lager vergeleken met de complete steekproef. Hoe meer zelfgerapporteerde psychotische ervaringen aanwezig zijn, hoe waarschijnlijker dat een individu word gediagnosticeerd met een klinisch psychotische stoomis. Desalniettemin gaat het combineren van psychose-achtige symptomen ten koste van de sensitiviteit van de diagnostische indicator. De diagnostische waarde van zelfgerapporteerde psychotische ervaringen is hoger bij personen zonder comorbiditeit wan een niet-psychotische DSM-diagnose. Bovendien is de diagnostische waarde beter bij individuen die vootheen hulp hebben gezocht bij de geestelijke gezondheidszorg (GGZ). Er kan geconcludeerd worden dal het screenen naar psychose in de bevolking een hoog risico met zich meebrengl ap stigmatisering van fout-positieve diagnoses en een schending van het recht om onwetend te blijven bij terecht-positieve diagnoses. Zelfgerapporteerde psychotische ervaringen zouden echter een bruikbat screeningsinstrument kumen zijn bij GOZgebruikers die reeds hulp gezocht hebben, vanwege de kunstmatige toenane in de prevalentie van psychose. Dit komt overeen met de algemene praktijk van de woege preventieklinieken, aangezien op dit moment prodromale symptomen slechis valide voorspellers zijn in geselecteerde groepen met een hoge prevalentie van psychose, i.e. bij personen die hulp hebben gezocht woor hun problemen. 
Hoofshk 7 behandelt de uitkomst van incidente zelfgerapporteerde psychotische ervaringen in de algemene bevolking na een periode van twee jaar in termen van stabiliteit, beperking en zorgbehoefte. Hiertoe wordt het longitudinale design van de NEMESIS-studie gebrukt. Op $T_{2}$ nam een ervaren clinicus via de telefoon klinische herinterviews af bij alle individuen die een klinische, plausibele of niet klinisch relevante beoordeling op een CIDI psychose-item hadden. Geselecteerd werden individuen met een recent ontstane, zelfgerapporteerde psychotische ervaring tussen de basismeting en $\mathrm{T}_{\mathbb{1}}(\mathrm{n}=83)$. In deze steekproef werd de stabiliteitsuitkomst van positieve psychotische ervaringen op $\mathrm{T}_{2}$ bepaald door clinici-gecorrigeerde CIDI lekeninterviewbeoordelingen (CIDI-uitkomst, n1 $=58$ ) én door een klinisch interview zowel in termen van de aanwezigheid van een psychotische ervaring, gemeten met de Brief Psychiatric Rating Scale (BPRS-uitkomst, $n=47$ ), als in termen van klinische relevantie gebruikmakend van criteria van functionele beperking en zorgbehoefte (klinische uitkonst, n=11). De 2-jaar predictieve waarden van incidente psychotische ervaringen op $T_{1}$, voor alledrie de uitkomstmaten op $T_{2}$, variëren van laag tot matig. Overeenkomstig met de bevindingen van de cross-sectionele studie in hoofdstuk 6 , vergroot lijdensdruk gerelateerd aan de psychotische ervaring het risico op de aanwezigheid van een klinisch psychotische stoornis. Slechts een klein aantal personen met incidente psychotische ervaringen, i.e. tot een maximum van $1.5 \%$, ontwikkelde echter een psychotische stoomis met zorgbehoefte over een periode van twee jaar. Samenvattend kan gesteld worden dat een minderheid van incidente zelfgerapporteerde psychotische ervaringen klinisch relevant worden, afhankelijk van type en emotionele evaluatie van de psychotische ervaring. Deze bevindingen komen overeen met de hedendaggse stand van zaken in het vroege predictic-onderzoek. Vroege predictie van psychose zonder een hoog cijfer van fout-positieven is tot op de dag van vandaag slechts mogelijk in geselecteerde steekproeven gebaseerd op een combinatie van risicotactorent.

Hoofdshk 8 bestudeert de versterkende rol van lijdensdruk ten gevolge van ongewone perceptuele erwaringen bij wanvorming. In de NEMESIS-studie werden individuen met hallucinatoire ervaringen op de baselinemeting opgewolgd gedurende drie jaar. Op $\mathrm{T}_{2}$ scoorden clinici bovendien het BPRS-item ongewone gedachteninhoud. Analyses vergeleken de hallucinatoire ervaringen met en zonder subjectieve lijdensdruk op de baselinemeting voor wat betreft het risico op waanvoming bij follow-up. De subjecten met lijdensdruk hebben een verhoogd risico op waanvorming, oplopend tot een klinisch niveau. Deze bevinding bevestigt de bewering dat lijdensdruk, geassocieend met vroeg perceptuele intrusies, dient als een katalysator voor de ontwikkeling van wanen. Dus niet alleen de aanwezigheid van een ongewone perceptuele ervaring op zichzelf, maar ook de emotionele evaluatie door een persoon is een belangrijke risicofactor voor 
waanvorming. Een klinische implicatie is dat Cognitieve Gedragstherapie (CGT) voor vroeg-hallucinatoire ervaringen efficiënter zou kumnen zijn als het specifiek gericht is op de lijdensdruk veroorzaakt door de ervaring.

In hoofdstuk 9 worden de hoofdbevindingen van de studies in dit proefschrift samengevat en bediscussieerd, uitmondend in zowel theoretische als klinische implicaties en suggesties voor toekomstig onderzoek. De bevindingen tonen aan dat het continu psychose fenotype, lopend van psychotische ervaringen, via affectieve stoornissen, naar psychotische stoornissen, een valide beschrijving lijkt te zijn. Er is aangetoond dat diagnostische categorieën en preklinische fasen niet onverenigbaar zijn, maar dat ze kunnen overlappen. Dit impliceert dat therapeutische strategieèn niet meer geïndiceerd moeten worden op basis van een diagnose, maar op basis van overlappende symptoomdimensies. Dit proefschrift verschaft bewijs voor familiale clustering van subklinische psychosedimensies in de algemene bevolking, hoewel het onduidelijk is in welke mate deze clustering van subklinische psychosedimensies is toe te schrijven aan genetische kwetsbaarheid. De cognitieve evaluatie van ongewone ervaringen speelt een belangrijke rol in het transitieproces naar klinisch psychotische stoomissen. Deze bevindingen geven volgens het cognitieve model van psychose duidelijk mogelijkheden om te interweniëren in de pre-psychotische fase met CGT. In toekomstig onderzoek moet men rekening houden met interacties van psychologische en biologische markers als risicofactor voor de ontwikkeling van klinische psychose. Bovendien is het screenen in de algemene bevolking, gebruikmakend wan het criterium "enige psychotische ervaring' niet veilig, getuige het hoge aantal fout-positieven, aangetoond met de NEMESIS-studie. Het screenen van personen met een hoog rísico zou halbaar kunnen zijn.

Tot besluit verschaft het onderhavige proefschrift sterk bewijs voor fenomenologische continuitteit en, in mindere mate, bewijs voor longitudinale en etiologische continuïteit van psychotische ervaringen in de algemene bevolking. Toekomstige biologische, psychologische en sociologische onderzoekers zouden hun krachten moeten bundelen in de zoektocht naar het multi-factorieel etiologisch verklaringsmodel van het continu psychose fenotype. 



\section{Dankwoord}

Volleyballen in je eentje is onmogelijk en dit geldt ook voor het doen van onderzoek. Binnen en buiten de sectie Sociale Psychiatrie en Psychiatrische Epidemiologie hebben veel mensen mij ondersteund en gesteund, en al deze mensen wil ik hiervoor bedanken.

$\mathrm{Tk}$ ben veel dank verschuldigd aan de families in Sittard en de cliënten van de RIAGG Maastricht die hebben meegedaan aan het onderzoek naar het continum van psychose. De COMED-studie heeft mede dankzij hen interessante gegevens opgeleverd.

Mijn promotor Jim van Os wil ik bedanken voor zijn onuitputelijke kennis en enthousiasme die hij op zijn onderzoekers in opleiding overbrengt. Jouw ideeën en wijze van onderzoek doen hebben op mij indruk gemakkt. Ik heb veel van je geleerd. Rob Bijl, voorheen verbonden aan de NEMESIS en thans werkzaam op het WODC van het Ministerie van Justitie, wil ik als copromotor bedanken voor zijn stimulerende commentaar op de artikelen van de NEMESIS. De keren dat we elkaar persoonlijk troffen leerde ik jouw interesse en enthousiasme voor onderzoek kennen. Philippe Delespaul, copromotor, ik wil je bedanken voor het meedenken bij de analyses en in het bijzonder voor het programmeren van de dataset met familierelaties. Zonder jou was het monnikenwerk geweest on deze dataset te creëren. Lydia Krabbendam voorziet sinds vorig jaar mijn eerste schrijfsels van commentaar. Ik heb veel van har geleerd en genoten van de prettige samenwerking.

Wilma Vollebergh en Ron de Graf van het Trimbos-instituut en verbonden aan de NEMESIS, hebben de artikelen over de NEMESIS van nuttig commentaar voorzien. Hartelijk dank hiervoor. Saskia van Dorsselaer van het Trimbos-instituut, bedankt voor je toelichting op de NEMESIS-datasets.

Ook aan mijn paranimfen Ilse Janssen en Maarten Bak ben ik yeel dank verschuldigd. Ilse heeft samen met mij de mensen in Sittard in het kader van de COMED-studie en Ilse's COPP-studie benaderd. We hebben samen heel wat brieven gevouwen en adresstickers geplakt, en elkaar ondenussen beter leren kemen. Ook de congresbezoeken moeten niet worden vergeten, samen met andere collega's werd heel wat afgelachen. Dank voor jouw samenwerking en steun. Maarten zat in dezelfde fase van het promotie-onderzoek als mij en het was altijd prettig om het wel en wee van onderzoek doen te bespreken. Dank voor je humor en directheid.

Met Lucia Valmaggia en Selma van der Schuur werd samengewerkt betreffende een onderzoek van onder andere de CAPE bij intramurale patiënten. Ik wil jullie hartelijk danken voor de prettige samenwerking. Meinte Vollema verzorgde de training in het gebruik van de SIS-R en ik heb veel van hem geleerd over schizotypie. Hartelijk dank hiervoor. Nick Stefanis and Hélène Verdoux are involved in the research concerning the CAPE, and are co-authors. Thank you for the pleasant collaboration. 
Truda Driesen is te beschrijwen als een vlijtige bij die zorgt dat al het onderzoek goed loopt. Dank voor jouw coördinatie van de onderzoeksassistenten van de COMEDstudic, het coderen van de vragenlijsten en het werwerken van de genogrammen. Heleen Boos, Lisbeth Evers, Solange Hardy, Tamara Smeets, Janneke Spauwen en Vivane Thewissen will ik bedanken voor het samen met mij uitwoeren van de interviews in de algemene bevolking. Dank voor jullie enthousiaste inzet en de leuke samenwerking. Dagmar Versmissen, dank voor het coderen van de vragenlijsten. Frieda van Goethem, bedankt voor het invoeren van de vele dozen met data. Farida van der Spil heeft samen met Maarten Bak en mij de herinterviews van de derde ronde van de NEMESIS gedaan. Hartelijk dank voor jouw bijdrage aan de NEMESIS. Frenk Peeters en Steven Radstake maakten het onderzoek van de CAPE binnen de RIAGG Maastricht mogelijk en Elly Mey verstuurde de vragenlijsten. Hartelijk dank. Charlie Kaplan en Patrick Domen, dank voor de Duitse vertaling van de CAPE en het opzetten van onderzoek van de CAPE in Duitsland. Nele Jacobs, jij hebt de CAPE gebruikt in jouw tweelingstudie. Dank hiervoor. Marjan Drukker, dank voor jouw bereidheid om samen te zoeken naar oplossingen bij analyseproblemen. Ik heb veel van jouw epidemiologische kennis geleerd. Trees Soute, bedankt voor het bijspringen bij de administratieve zaken rondon dit proefschrift.

De collega's van SP en diegenen die ik nog niet genoemd heb Anny, Cecile, Ger, Herman, Inez, Inge, Jean-Paul, Jikke, Josien, Karola, Machteld, Margo, Maria, Marieke, Marten, Nancy, Nicole, Thea en Ron wil ik bedanken voor de gezellige sfeer op de afdeling en de spamende verhalen tijdens de pauzes.

De medewerkers van de afdeling Sociaal Psychiatrische Dienst van de RIAGG Maastricht wil ik bedanken voor de mogelijkheid om clienten te begeleiden, en in het bijzonder Steven Radstake en Miranda Boon voor de begeleiding. Vervolgens maakte ik ueel un van r'sycope-team II. Dank aan alle leden van dit team.

Sinds vorig jaar mei heb ik een stel 'nieuwe' collega's erbij gekregen toen ik ging werken bij de afdeling Ouderenzorg van de RIAGG Maastricht. Ik wil alle collega's van de Ouderenzorg bedanken voor hun belangstelling en steun.

Ik wil mijn ouders en mijn zus Myron bedanken voor het stimuleren van mijn toekomstplamnen en hun steun, en dit beperkt zich niet tot de afgelopen vijf jaar. Mijn vrienden wil ik bedanken voor hun belangstelling, steun en het plezier dat we samen maken. In het bijzonder wil ik Lindy bedanken voor haar correcties op de Nederlandse teksten in het proefschrift en wil ik Ruth bedanken voor het ontwerpen van de omslag van het proefschrif. Mijn familie wil ik bedanken voor hun interesse en gezelligheid. Bij de volleybalclub kon ik zo nodig stress van me afspelen, bedankt voor jullie steun. Iohan. ik dank je voor je onvoorwaardelijke steun tot en met de laatste loodjes. Ik wardeer het dat je de layout van het proefschrift hebt verzorgd. Bedankt voor je vriendschap en relativerende blik op het leven. 


\section{Curriculum vitae}

Manon Hanssen werd op 1 juli 1975 geboren in Sittard. Na het afronden van het Gymnasium aan het College Sittard in 1993, ging ze Gezondheidswetenschappen met als afstudeerrichting Geestelijke Gezondheidkunde aan de Universiteit Maastricht (UM) studeren. Vervolgens startte ze ook met Psychologie met als afstudeerrichting Biologische Psychologie. In 1998 behaalde zij voor beide opleidingen hrar doctoraal diploma. Zij deed haar klinische en onderzoeksstage op de afdeling psychiatrische deeltijdbehandeling van het Maaslandziekenhuis te Sittard. Een tweede klinische stage voerde ze uit op de afdeling psychiatrie (geheugenpoli) van het Academisch Ziekenhuis Maastricht.

In mei 1999 startte zij als klinisch onderzoeker in opleiding met haar promotieonderzoek naar het continuum van psychose bij de capaciteitsgroep Psychiatrie en Neuropsychologie, sectie Sociale Psychiatrie en Psychiatrische Epidemiologie aan de UM. Daarnaast begeleidde ze cliënten op de Sociaal Psychiatrische Dienst van de RIAGG Maastricht. Sinds 1 mei 2003 is ze werkzaam als gedragswetenschapper op de afdeling Ouderenzorg van de RIAGG Maastricht en in september 2003 is ze gestart met de opleiding tot gezondheidszorgpsycholoog. 



\section{List of publications}

\section{Articles}

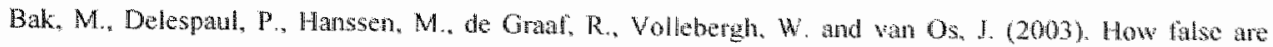
"false" positive psychotic symptoms? Schizopheria Rexezrch $62(1-2): 187.189$.

Bak, M., Myin-Germeys, I., Hanssen, M., Bijl, R., Volebegh, W. Delespaul. P., at al (2003). When does experience of pychosis result in a need for care? A prospective general population study Schirophrema Bulletin 29(2): 349-358.

Hanssen, M. Bak, M. Bijl, R. Vollebergh, W. and wan Os, 1. (sulmitted). Outcome of self-reported psychotic experiences in the general population: a prospective study.

Hanssen. M., Bijl. R. V., Vollebergh, W. and van Os, J. (2003\%. Sell-reported prychotic experiences in the general population: a valid sereening tool for DSM-l11-R psychotic disorders? Acta Psyctuafrica Scandinarica T07(5): $369-377$.

Hanssen, M., Krabbendam. L., de Grataf, R., Vollebergh, W. and van $O$ s, J. (in press). The role of distress in

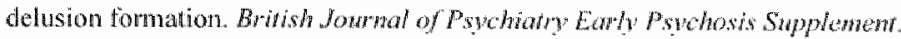

Hanssen, M. Krabbendam, L.., Vollema, M. Delespaul, P. and ran Os, J. (submitted). Evidence for lamilyspecific variation of subclinical psychosis dimensions in the general population.

Hanssen, M. Peeters, F., Krabbendan, L. Radstake, S. Verdoux, H. and Vin Os. 1. (2003). How psychotic

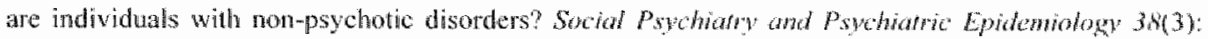
149. 154 .

Janssen, I., Hanssen, M., Bak, M., Bijl, R. V., de Grat, R., Volvebergh, W. et al. (200.3). Discrimination and defusional ideation. British Journal of Pswchiary 182:71-76.

Janssen, I., Krabbendam, L., Bak, M., Hanssen. M., Vollebergh, W., de Grat, R., et al. (2004). Childheod abuse as a risk factor for psychotic experiences. Acto Psychiarica Scandirawica 109(1): $38-45$.

Janssen, I., Krabbendam, L... Hanssen. M.. Bak, M., Vollebergh, W., de Graaf, R. at al. (submilled). Are apparent effects of parental rearing style on psychosis risk mediated by early tran ama?

Krabbendam. L., Myin-Germeys, I., Hanssen, M., Bijl, R. V., de Graat, R., Vallabergh, W.. et all, (in press). Hallucinatory experiences and onset of psychotic clisorder: Evidence that the risk is mediated by detusion formation. Acra Psuchantica Scandinavica.

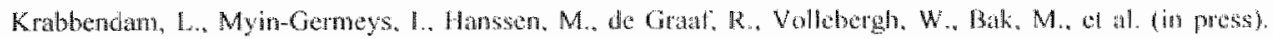
Development of depressed mood predicts onset of psychosis in individuals who report hatlutinatory

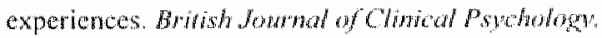

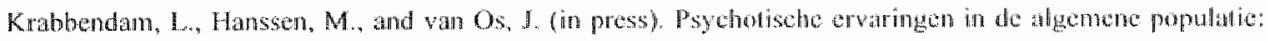
risicofactoren woor een psycholische stoorris? De Psych thong.

Stefanis, N. C. Hanssen, M. Smirnis, N. K., Avranopoulos, D. A. Cvdolkimidis, 1. K. Stedaris, C. N., ed al. (2002). Exidence that the dimensions of psychosis have a distribution in the gencal population. Prychological Mediche 32(2): 347-358.

van OS, J., Bak, M. Hanssen, M., Bijl. R. V., de Graal, R. and Verdoux. H, (2002). Canmabis use and

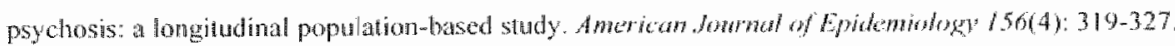

van. Os, J., Hanssen, M. Bak, M., Bijl, R. and Vollebergh. W. (2003). Do urbanicily and familial liability

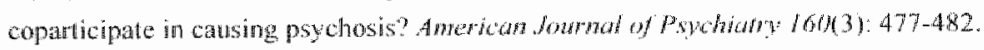

wan Os, J., Hanssen, M. Bij). K. V. and Ravelli, A. (2000). Strauss (1969) revisited a psychosis continum in the general population? Schizophrowio Research $45(1-2)$ : $11-20$. 
wan Os, J. Hamsen. M, Biil. R. V. and Vollebergh, W. (2001). Prevalence of psychotic disorder and communily level of psychotic synuptoms: an urban-rural comparison. Archives of General Psychatry 58(7): $663-668$.

van $O$, J., Hansesen, M., de Graal, R. and Vollebergh, W. (2002). Does the urban enwironment independently increase the risk for balli negative and positive features of psychosis? Social Psychatry and Psychatric Epidemislogy $37(10): 460-464$.

\section{Chapters}

Krabbendani, L., Hanssen, M., Bak, M. and van OS, J. (in press). Psychotic features in the general population. Risk factors for what? In: Search for the Causes of Schizophrenia. W. F. Gattaz and H. Hafner (Eds.). Damstadt, Germany, Dietrich Steinkophl Werlag.

van Os, J., Janssen, I., Hanssen, M. Bak, M., Myn-Gemeys, I., Marcelis, M. et al. (2002). Cognitive cpidemology: Psychological and social risk mechanisms for psychosis, In: Risk and Protective Factors in Schizophenia. Towards a Canceptual Model of the Disease Process. H. Hälner (Ed.). Darmstadt. Germany, Dietrich Stenkopff Verlag. 